\title{
Molecular biomarkers in skull base chordoma
}

\author{
Citation for published version (APA):
}

Yakkioui, Y. (2020). Molecular biomarkers in skull base chordoma. [Doctoral Thesis, Maastricht University]. ProefschriftMaken. https://doi.org/10.26481/dis.20200909yy

Document status and date:

Published: 01/01/2020

DOI:

10.26481/dis.20200909yy

Document Version:

Publisher's PDF, also known as Version of record

\section{Please check the document version of this publication:}

- A submitted manuscript is the version of the article upon submission and before peer-review. There can be important differences between the submitted version and the official published version of record.

People interested in the research are advised to contact the author for the final version of the publication, or visit the DOI to the publisher's website.

- The final author version and the galley proof are versions of the publication after peer review.

- The final published version features the final layout of the paper including the volume, issue and page numbers.

Link to publication

\footnotetext{
General rights rights.

- You may freely distribute the URL identifying the publication in the public portal. please follow below link for the End User Agreement:

www.umlib.nl/taverne-license

Take down policy

If you believe that this document breaches copyright please contact us at:

repository@maastrichtuniversity.nl

providing details and we will investigate your claim.
}

Copyright and moral rights for the publications made accessible in the public portal are retained by the authors and/or other copyright owners and it is a condition of accessing publications that users recognise and abide by the legal requirements associated with these

- Users may download and print one copy of any publication from the public portal for the purpose of private study or research.

- You may not further distribute the material or use it for any profit-making activity or commercial gain

If the publication is distributed under the terms of Article $25 \mathrm{fa}$ of the Dutch Copyright Act, indicated by the "Taverne" license above, 


\section{Molecular biomarkers in skull base chordoma}

$800 \%$

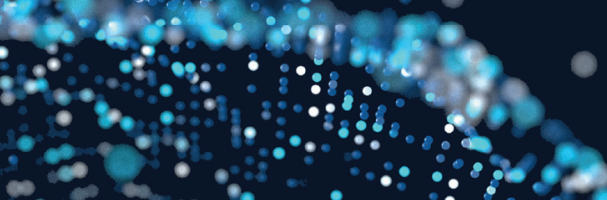

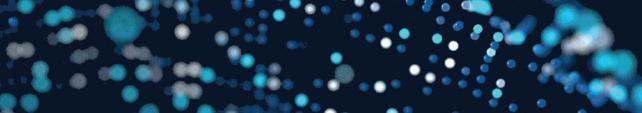

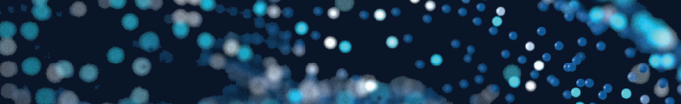

8

8

trotes

3

1.8. $\% 8$

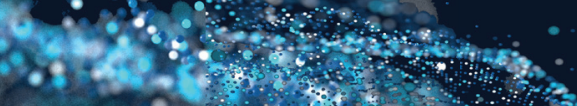

a das

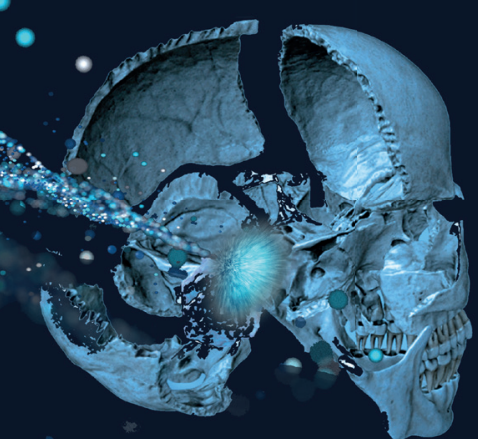

$\circ \bullet$

Y.Yakkioui 

Molecular biomarkers in skull base chordoma

Youssef Yakkioui 
Cover: Otman Yakkioui

Layout: $\quad$ Renate Siebes | Proefschrift.nu

Printed by: $\quad$ Proefschriftmaken.nl

ISBN: $\quad$ 978-94-6380-935-1

Copyright (c) Youssef Yakkioui, 2020.

All rights reserved. No part of this thesis may be reproduced, distributed, stored in a retrieval system of any nature or transmitted in any form of by any means, without the written consent of the author or, when appropriate, the publisher of the respective publications. 


\section{Maastricht University}

\section{Molecular biomarkers in skull base chordoma}

\section{ACADEMISCH PROEFSCHRIFT}

ter verkrijging van de graad van doctor aan de Universiteit Maastricht, op gezag van de Rector Magnificus, Prof.dr. Rianne M. Letschert volgens het besluit van het College van Decanen,

in het openbaar te verdedigen

op woensdag 9 september 2020 om 16.00 uur

door

\section{Youssef Yakkioui}




\section{Promotores:}

Prof. dr. Y. Temel

Prof. dr. M. van Engeland

\section{Beoordelingscommissie:}

Prof. dr. H. van Santbrink (voorzitter)

Dr. L. Ackermans

Prof. dr. S. Froehlich, University of Paris, France

Prof. dr. F. Ramaekers

Prof. dr. P. Vandetop, Amsterdam UMC 
Voor mama 



\section{Contents}

Chapter 1 General introduction and outline of the thesis 9

$\begin{array}{lll}\text { Chapter } 2 \text { Chordoma: the entity } & 15\end{array}$

Chapter $3 \quad$ Notochord isolation using laser capture microdissection 53

$\begin{array}{lll}\text { Chapter } 4 & \text { Integrated and quantitative proteomics of human tumors } & \mathbf{6 9}\end{array}$

$\begin{array}{lll}\text { Chapter } 5 & \text { Kinase activity in recurring primary skull base chordomas and } & \mathbf{8 7}\end{array}$ chondrosarcomas: identification of novel pathways of oncogenesis and potential drug targets

Chapter 6 A comparison of cell-cycle markers in skull base and sacral 101 chordomas

$\begin{array}{lll}\text { Chapter } 7 & \text { Oncogenic viruses in skull base chordomas } & 119\end{array}$

$\begin{array}{lll}\text { Chapter } 8 & \text { Discussion and concluding remarks } & 133\end{array}$

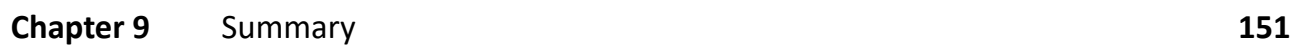

Valorisation 153

Curriculum vitae $\quad 159$

$\begin{array}{ll}\text { Published articles } & 160\end{array}$

Acknowledgement $\quad 162$ 

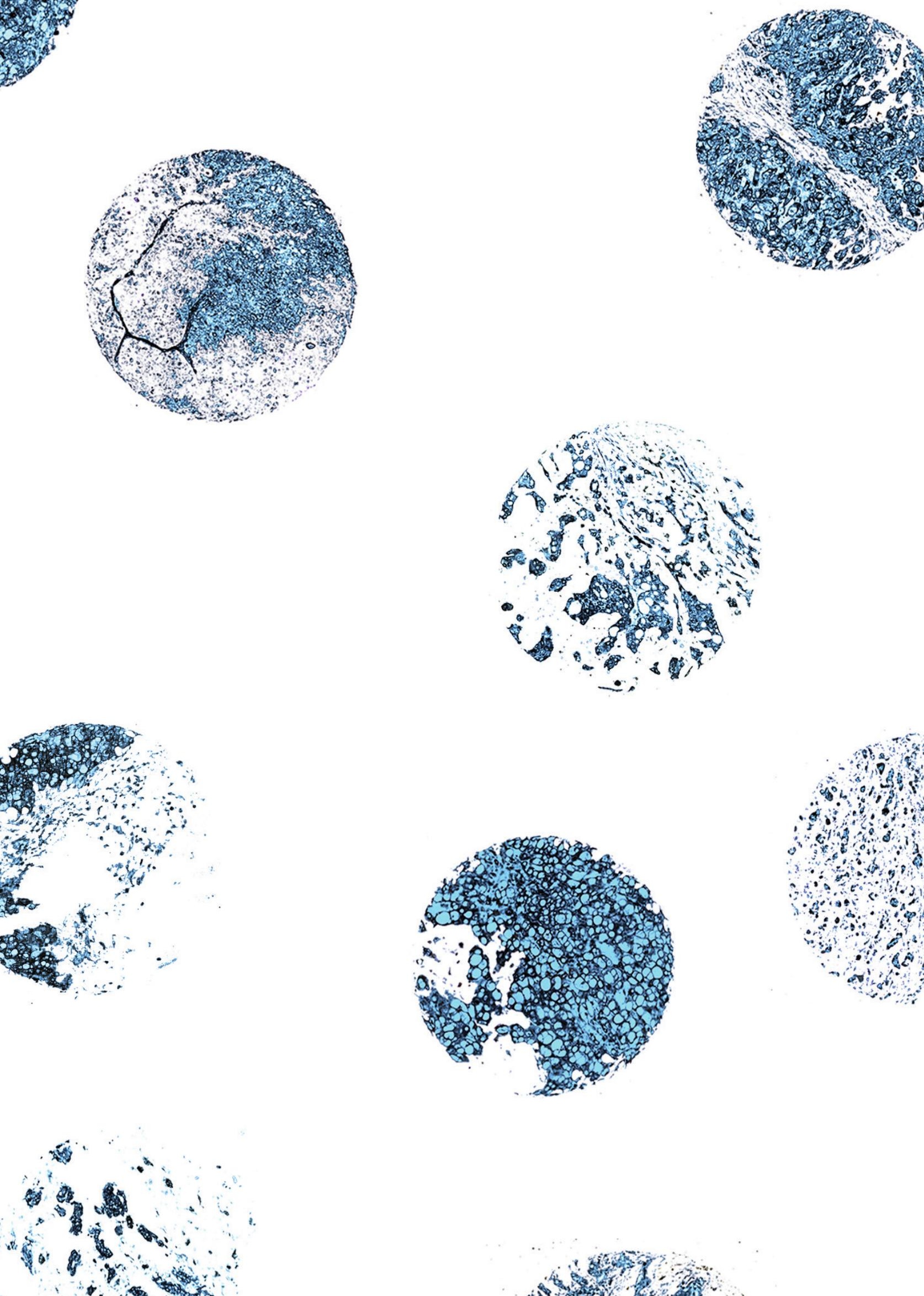

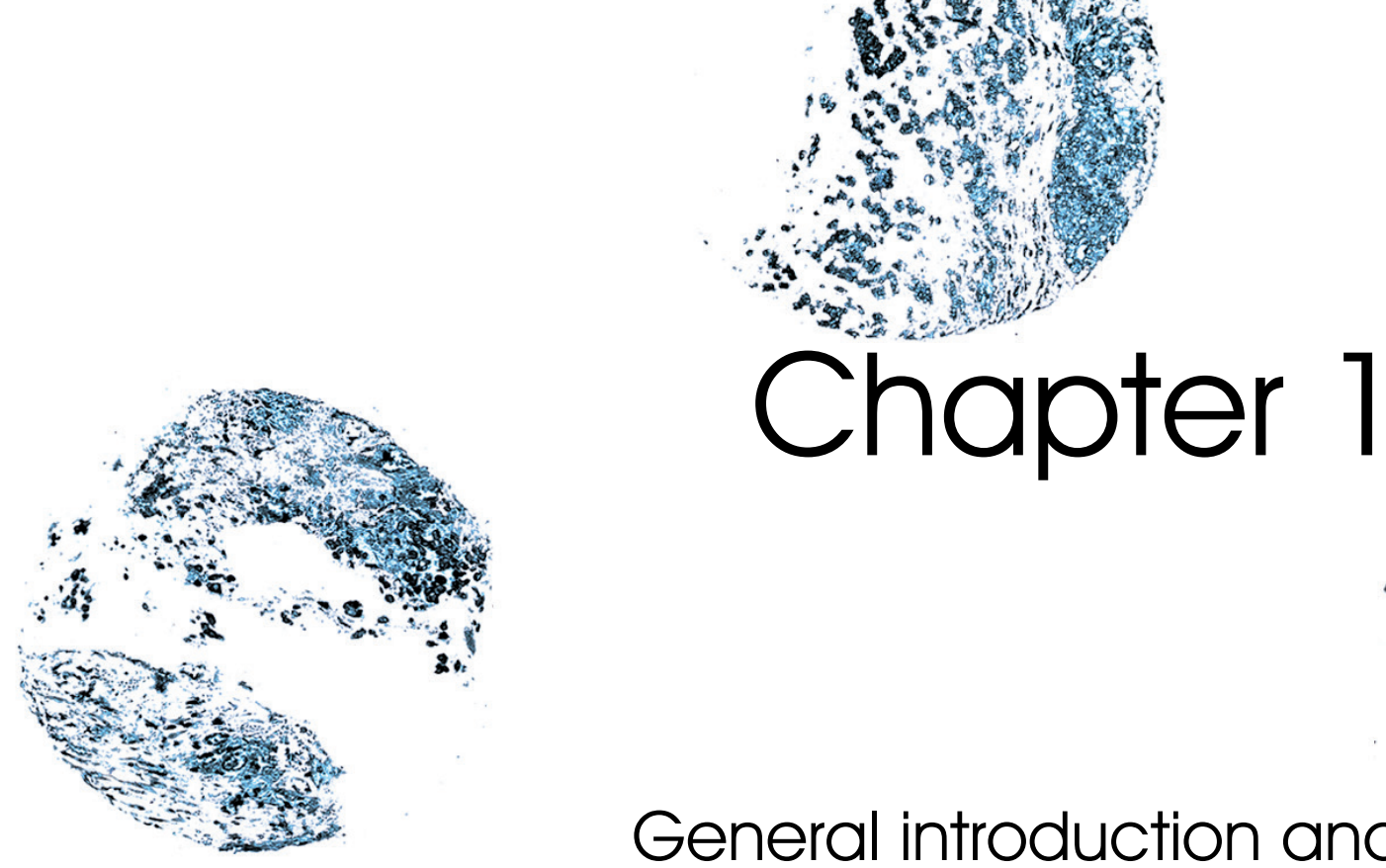

\section{General introduction and outline of the thesis}

Y Yakkioui
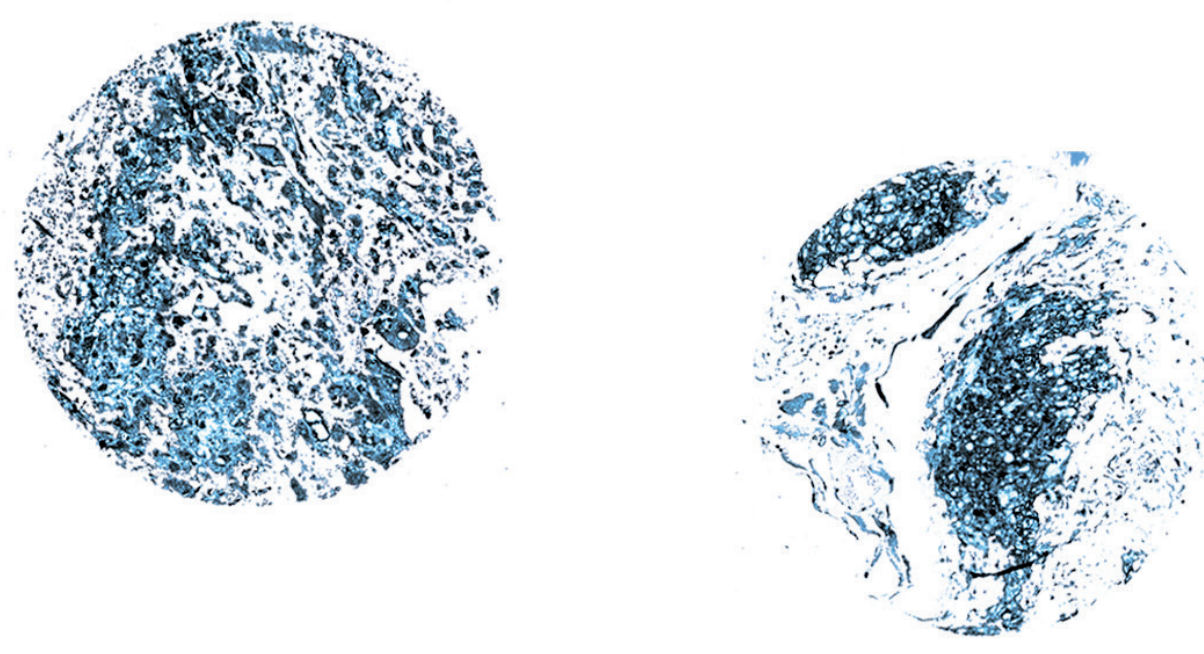

$4 y^{2}$ if Sto

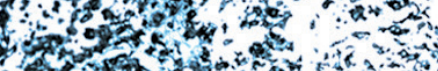
67 (1) 

Chordomas are relatively rare neoplastic tumors that are primarily situated along the axial spine with an occurrence of approximately one in one million. The most frequent tumour locations are the sacrum and the skull base. ${ }^{1}$ Patients with skull base chordomas present with neurological deficits as a result of tumoral compression on cranial nerves. Multimodal therapy with initial gross total resection combined with adjuvant radiotherapy with typically proton ions, are the mainstay of patients' clinical management today. Even as developments in this golden standard of therapy have improved patient outcome, approximately $50 \%$ of chordoma patients experience recurrence, or more appropriately, regrowth of the tumor within five years. ${ }^{2,3}$ As chordomas are considered to be resistant to conventional chemotherapy, patients are confronted with a poor prognosis. ${ }^{4,5}$ In order to improve outcome, scientists have focused on identifying molecular factors driving different clinical course of chordoma patients by comparing chordoma-tissue to a less malignant tumor called chondrosarcoma. ${ }^{6}$ Although chordomas and chondrosarcomas might both be present at the base of the skull and are often radiologically inseparable, it is the assumption that these tumors have a distinctive origin. Chordomas are thought to have a different cellular origin, firstly described in detail in 1857 by the famous pathologist Virchow as "a pea-sized, sparing, jelly-like tumor mass extending to the clivus": ${ }^{7}$

"...Brachte man ein Stück davon unter das Mikroskop, so sah man in einem ziemlich klaren, hyalinen, gans leicht streifigen Grundgewebe, eine grosse Menge blasiger, fast cystoider Gebilde, welche ihrerseits wieder neue Blasen einschlossen und zwischen denen nur hie und da einzelne deutlich zellige Gebilde erschienen."

Although Virchow mentioned a correlation with the chorda dorsalis (notochord), it was only decades later before the term "chordoma" was first phrased in $1894 .^{8}$ Long after this discovery, and only in the recent two decades, research on chordomas has increased exponentially. Besides the search for prognostic factors, one of the main reasons for researchers is the fascinating resemblance of these tumors to the embryonic notochord and the molecular mechanisms behind a "prechordoma-switch" that results in a malignant transformation of notochordal remnants, a phenomenon termed "chordomagenesis".

\section{Unmet needs and aim of the study}

After decades of molecular research in chordoma, our knowledge on the molecular foundation of the pathogenic process underlying the debilitating disease in chordoma patient has expanded significantly, however unfortunately, no molecular markers are currently being used in the clinic and no actionable therapeutic targets have been identified. The aim of this study is to gain further insight in the molecular pathophysiology of this disease in order to discover potential molecular markers and therapeutic targets to better manage this disease. As the bulk of scientific molecular knowledge on chordoma is fragmented in 
many articles, in Chapter 2, we provide an overview of the entity named chordoma. We discuss the presumed formation of chordomas and present an outline of the molecular studies performed by reviewing the most important developments in chordoma biology. Furthermore, we discuss a commonly accepted principle of chordomagenesis, which is the malignant transformation of notochordal remnants. This fundamental concept is also the motivation for using embryonic notochordal tissue and cells for further research in chordoma. In Chapter 3, we therefore have investigated the appropriate time-period and collecting method for notochordal tissue and cells from human specimens. The protocol that we developed will allow researchers to use a universal control tissue, which will improve our ability to compare and overlay datasets. While performing these experiments we have discovered that expression of Brachyury presents throughout the entire vertebral colomn in the developing embryo. This questions the involvement of the transcription factor in chordoma as a remnant of notochordal heritage or possibly a result tumor-environmental effect.

Another unexplored area in chordoma research is the spectrum of expression of tumor specific proteins. Using the isobaric tag for relative and absolute quantitation (iTRAQ) method, we have labeled peptides of chordoma tumor samples. Comparing this spectrum to the control embryonal intervertebral disk tissue containing the notochord and chondrosarcoma, we investigated the differential spectrum of proteins. The methodology applied in these studies is presented in Chapter 4. We further explored the differential expression of phosphorylated proteins in chordoma and chondrosarcomas in primary and recurrent tumors and present a group of biomarkers to identify skull base primary chordomas and chondrosarcomas with a propensity to recur in Chapter $\mathbf{5}$. In the same light in Chapter $\mathbf{6}$ we have investigated a cohort of twenty-five patients to explore if clinical parameters, (immuno)histological findings or the expression of cell cylcle factors have an influence on overall survival in chordoma. We present potential value of cyclin dependent kinase 4 in our cohort.

As growing number of publications are a valid depiction of the interest of gene- and protein expression in chordoma, no reports are focused on the effect of external effectors on chordoma. More specifically, no studies investigating the presence of viral gene expression in chordomas, even though viruses and other infectious agents cause nearly $20 \%$ of all human cancers worldwide. In order explore the role of external factors in chordomagenesis, we also studied the presence of viruses in Chapter 7.

Finally, Chapter 8 summarizes the most relevant concepts of the chapters in this thesis and an overall conclusion is made. 


\section{References}

1. Tenny, S. \& Dulebohn, S.C. Chordoma. in StatPearls (StatPearls Publishing StatPearls Publishing LLC., Treasure Island (FL), 2017).

2. Chambers, K.J., et al. Incidence and survival patterns of cranial chordoma in the United States. Laryngoscope 124, 1097-1102 (2014).

3. Heery, C.R. Chordoma: The Quest for Better Treatment Options. Oncology and therapy 4, 35-51 (2016).

4. Yakkioui, Y., van Overbeeke, J.J., Santegoeds, R., van Engeland, M. \& Temel, Y. Chordoma: the entity. Biochimica et biophysica acta 1846, 655-669 (2014).

5. Almefty, K., Pravdenkova, S., Colli, B.O., Al-Mefty, O. \& Gokden, M. Chordoma and chondrosarcoma: similar, but quite different, skull base tumors. Cancer 110, 2457-2467 (2007).

6. Bovee, J.V., Hogendoorn, P.C., Wunder, J.S. \& Alman, B.A. Cartilage tumours and bone development: molecular pathology and possible therapeutic targets. Nat Rev Cancer 10, 481-488 (2010).

7. Virchow, R. Untersuchungen uber die Entwickelung des Schadelgrundes im gesunden und krankhaften Zustande, und uber den Einfluss derselben auf Schadelform, Gesichtsbildung und Gehirnbau. G. Rimer, Berlin, p. 47 (1857).

8. Ribbert, H. Uber die Eccondrosis physaliphora spheno-occipitalis. Zertralbl. f. allg. Path. u. Path. Anat. 5457(1894). 

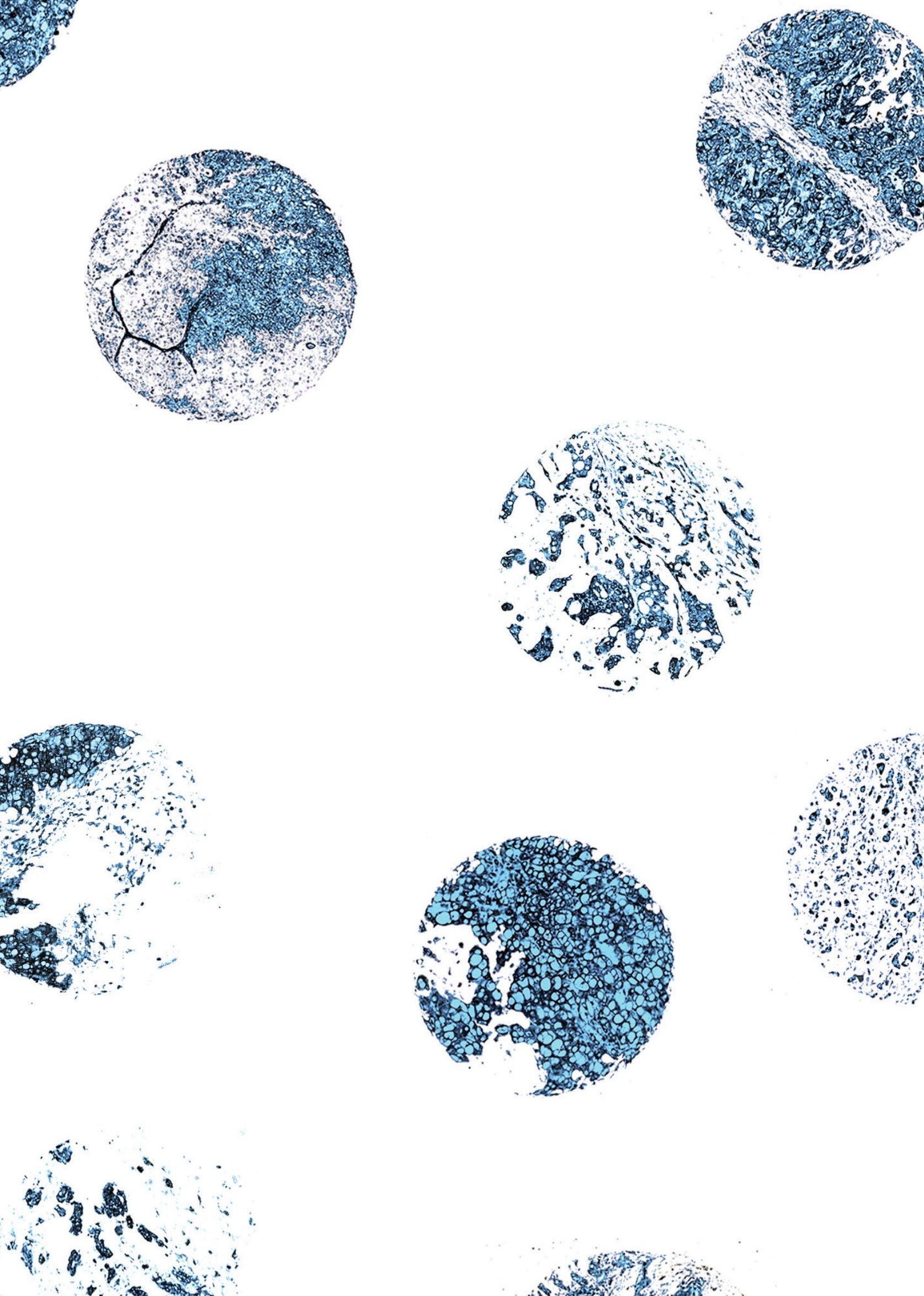

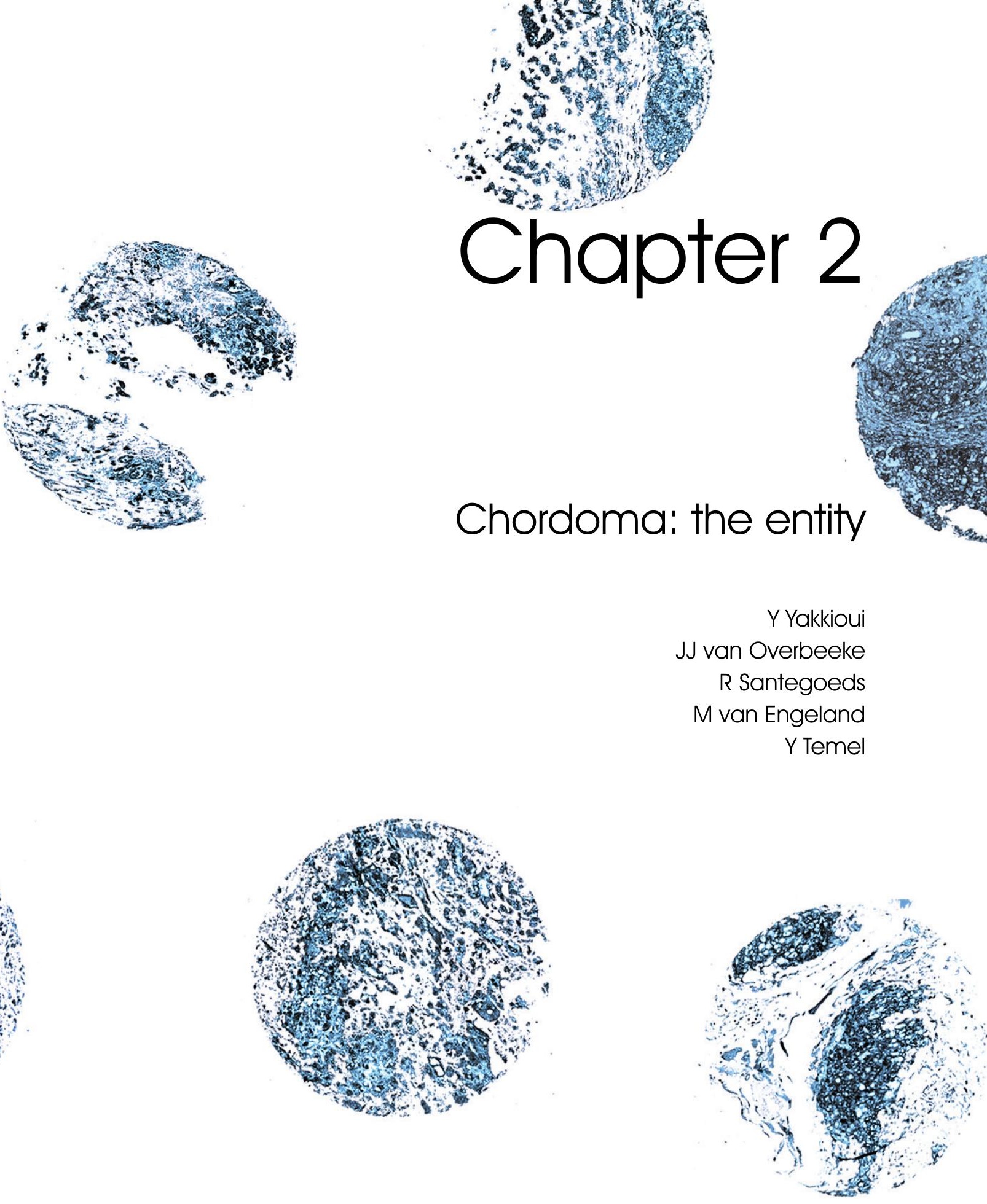

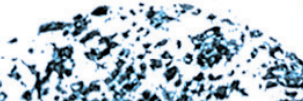

Biochim Biophys Acta. 2014 Dec; 1846(2):655-69 


\begin{abstract}
Chordomas are malignant tumors of the axial skeleton, characterized by their locally invasive and slow but aggressive growth. These neoplasms are presumed to be derived from notochordal remnants with a molecular alteration preceding their malignant transformation. As these tumors are most frequently observed on the skull base and sacrum, patients suffering from a chordoma present with debilitating neurological disease, and have an overall 5 -year survival rate of $65 \%$. Surgical resection with adjuvant radiotherapy is the first-choice treatment modality in these patients, since chordomas are resistant to conventional chemotherapy. Even so, management of chordomas can be challenging, as chordoma patients often present with recurrent disease. Recent advances in the understanding of the molecular events that contribute to the development of chordomas are promising; the most novel finding being the identification of brachyury in the disease process. Here we present an overview of the current paradigms and summarize relevant research findings.
\end{abstract}




\section{Introduction}

Chordomas are relatively rare neoplasms with an overall incidence of approximately one per million population. ${ }^{1}$ These tumors have a slowly aggressive and locally invasive character and predominantly arise at the cranial (clivus) and caudal (sacrum) ends of the axial skeleton. Due to the close relationship with vital structures, especially at the skull base, managing these tumors surgically has proven to be a challenge. ${ }^{2}$ Therefore, an increasing number of novel (radio)surgical and pharmacological strategies are currently being investigated. ${ }^{3,4}$ However, despite combining gross total resection with particle radiation therapy, frequent local recurrence remains a reality, and the 5 - and 10 year overall survival rates are circa $65 \%$ and $35 \%$, respectively..$^{5-7}$ Additional chemotherapy is not implemented in the standard treatment, as chordomas are known to be relatively resistant to conventional chemotherapies. ${ }^{8}$ With the aim of improving the management of these tumors, histopathological and molecular research on chordoma tissue and cell lines has been carried out to improve our understanding on the origin of chordoma. So far, most of the research has focused on well-known molecular markers found in other oncologic diseases. While these studies have contributed to our basic understanding of the pathophysiology of chordoma, recent experiments have reflected a paradigm shift away from focusing on important cell-cycle characters towards the investigation of more differentiating molecular markers that are primarily discovered by genome-wide experiments. Proteins involved in the cell-cycle regulation, including the p53 pathway and downstream messengers of the receptor tyrosine kinase pathway, have been mentioned in previous publications. However, the interpretation of more recent genome-wide projects together with associated smaller case-control studies is lacking. It is our understanding that a holistic approach will benefit research on chordomas and will result in an improved strategy for clinical management. In this article, we present an overview of the current paradigms and summarize relevant research findings.

\section{Embryology}

\subsection{Formation of the Notochord}

The current line of thinking is that chordoma cells originate from remnants of the embryonic notochord. ${ }^{9-11}$ For the purpose of clarifying the pathophysiology, we will discuss the function of the notochord and the formation of the vertebral axis. During embryogenesis, in the third week of human development, gastrulation takes place, in which the body axis and the three primary germ layers (ecto-, meso- and endoderm) are formed. One of the key events following this phenomenon is the formation of the notochord; an elongated rod of cells derived from the intraembryonic mesoderm initiated at the midpoint of the vertical axis (primitive node) with a caudo-cranial extension. ${ }^{12}$ 
In the developing embryo, the notochord plays a critical role by producing and secreting important signaling factors (e.g. sonic hedgehog $[\mathrm{shh}]^{13}$, bone morphogenetic protein $[\mathrm{bmp}]^{14}$ ) to the surrounding tissue in order to direct organogenesis by providing fate and positional guidance. ${ }^{15}$ The notochord also exhibits cartilage-like and epithelial properties ${ }^{16}$, with considerable significance as it not only functions as the embryonic backbone, but also orchestrates the formation of the axial skeleton. ${ }^{15}$ In this regard, several heterotopic grafting studies have illustrated a crucial role for chordal cells in the formation of somites. ${ }^{17-20}$ These paired rectangular shaped segments which bilaterally propagate alongside the notochord are derivatives of the para-axial mesoderm, and in later development (imposed by chordal cells) ${ }^{21}$ further evolve by an epithelial-to-mesenchymal transition to form the ventral sclerotomes. ${ }^{22}$ Soon after this transformation, the loosely arranged mesenchymal cells will coalesce around the notochord and neural tube (primordial spinal cord) to instigate the formation of the initially unsegmented perinotochordal or perichordal sheath. ${ }^{19,23-25}$ The subsequent events and ultimate fate of the chordal and mesenchymal cells are still not fully understood.

\subsection{Formation of the vertebral axis}

It has been proposed that mesenchymal cells of the perichordal sheath become cartilaginous (chondroblasts/chondrocytic cells) via a condensation process with a central role for the secreted factors Shh ${ }^{26}$, epimorphin ${ }^{27}$ and the production of collagens (type 1, 3 and 9) and type $2 \mathrm{~A}$ procollagen ${ }^{28}$ (all derived from the notochord). Subsequently, in the span of the perinotochordal sheath, condensation of mesenchymal cells is shown to occur in a metameric fashion, where less condensed areas containing the chondrocytic cells form a cartilage template (primordial vertebral body). Formation of this cartilage anlagen and its subsequent ossification ensues in a process called "endochondral ossification". ${ }^{29}$ During this process, the chondrocytic cells become hypertrophic and alter the matrix, enabling it to become mineralized (ossified) by calcium phosphate. ${ }^{30}$ Concurrently with the vertebral body morphogenesis, the confined notochordal cells probably undergo apoptosis as mechanical forces increase, or will be pressed out of the primordial bodies into the adjacent more condensed zones. ${ }^{24,31}$ In these more condensed areas, where mesenchymal cells still enclose an intact notochordal tube, both cells types will later be replaced by a mature intervertebral disc (IVD). The outermost portion of the IVD (the annulus fibrosus) is generally accepted to originate from the mesenchymal cells, whereas the source of the "chondrocyte-like" cells which are found primarily in the inner portion (nucleus pulposus) are shown to differ between chordates. ${ }^{28}$ In humans, the notochordal cells in the nucleus pulposus (NP) are hypothesized to either progressively degenerate after coordinating the formation of the NP, or differentiate into the chondrocyte-like cells. ${ }^{32}$ Either way, the ultimate fate of the notochordal tissue in the vertebral axis resides in the NP and is usually undetectable after the end of the first decade. ${ }^{33,34}$

Occasionally, notochordal cells remain in the IVD - noted as notochordal rests or vestiges, or can be witnessed in notochord-like tissue in the intravertebral region - in which case they 
are described as "benign notochordal cell tumors" (BNCT). ${ }^{35,36}$ These latter lesions also show morphologic characteristics that are different to typical notochordal rests or chordomas (discussed later). Furthermore, it is presumed that from these BNCT, which are found in approximately $20 \%$ of autopsies, the malignant variant chordoma arises. ${ }^{36}$ Evidence in favor of this concept is currently accumulating as Yamaguchi and colleagues described a classical chordoma to closely adjoin a benign notochordal cell tumor in a single section. ${ }^{37}$ Confirmation of this association was further provided by Nishigushi et al. ${ }^{35}$, who described a 59 -year old woman with similar findings in the lumbar vertebra.

Differentiating BNCTs from chordomas is crucial, as BNCTs tend to have a much better prognosis. These benign counterparts can be managed by a wait and scan policy, whereas patients with chordoma benefit from immediate gross surgical resection. ${ }^{38}$ In addition, (immuno)histological ${ }^{39}$ and anatomical differences have recently become more apparent (for review see Amer and Hameed ${ }^{38}$ ). Even so, differentiation between the two entities can still be challenging.

\subsection{Formation of the skull base}

In a similar fashion to the genesis of the vertebrae, the formation of the skull base is predominately preceded by a cartilage intermediate that becomes ossified by the same mechanism of endochondral ossification. This intermediate framework, termed the chondrocranium, forms by the fusion of several precursor cartilages. A set of three cartilage structures - the parachordal, hypophyseal and prechordal cartilages (trabeculae cranii) - together with the cartilage formed from the occipital sclerotomes, fuse to form a continuous platform that makes up the midline of the future skull base. The occipital sclerotomes are, as in case of the vertebrae, derived from somites, and the (subsequently formed) cartilage is combined with the parachordal cartilage to craft the cartilaginous continuum called the basioccipital cartilage (part of the future occipital bone). As the name already suggests, the parachordal cartilages lie alongside the notochord, which elongates and stretches cephalically to terminate at Rathke's pouch. Rathke's pouch, the primordial adenohypophysis positioned at the mid-sphenoid synchondrosis, demarks an important border, as the cartilage formed caudal to this structure is derived from mesodermal cells and is influenced mainly by molecular signaling of the notochord. Chondrocranial precursors rostral to this juncture (prechordal cartilages) are derived from neural crest tissue and require induction by signaling of the preoral gut endoderm. The hypophyseal cartilage, as an intermediary part between the perichordal and parachordal cartilages, develops around the pituitary, and is formed by differentiation of mesenchymal cells. By the end of the eighth week, the precursor cartilages have fused and the chondrocranium becomes apparent. ${ }^{40}$

At the same point in intrauterine life, numerous ossification centers arise and transform most of the chondrocranium into the four major bones that form the mature cranial base (the ethmoid, sphenoid, occipital and temporal bones), leaving only small segments of 
cartilage to function as growth plates in the spheno-occipital and spheno-petrous sutures. This cartilage at the spheno-occipital synchondrosis, which is responsible for much of the cranial lengthening, becomes ossified at pubertal onset. ${ }^{41}$ Even though only investigated in a mouse model, this growth and ossification appears to be regulated by the hedgehog signaling pathway which is induced by signaling originating from notochordal remnants. ${ }^{42}$

These notochordal remnants, which can persist throughout adult life, are also recognized in the region of the human skull base in $0.4-2 \%{ }^{43,44}$ of autopsies, and were first described by Lushka and Virchow in 1857.45,46 While Lushka and Virchow both describe the histological appearance of vacuolated cells ("physiliphoren") in the lesions, and their resemblance to the chorda dorsalis, Virchow appointed them as "Ecchondrosis Prolifera", suggesting a cartilaginous origin. Müller ${ }^{10}$ in 1858, discarded this description and proposed that the lesions have a notochordal source, renaming them as "Ecchordosis physaliphora Spheno-occipitalis" (EP). In $1894^{47}$ and $1895^{48}$ Ribbert first suggested the term "chordoma" to describe a resembling lesion that could be reproduced experimentally by puncturing the nucleus pulposus. It was not before the following century that Hortwitz associated chordal ectopia to the existence of chordoma. ${ }^{49}$ Before doing so, Stewart and Burrow ${ }^{43}$ had emphasized the clinical desire for differentiation between the two lesions. These authors proposed a nomenclature in which small extravertebral ectopic notochordal rests (jelly-like nodules) with very limited proliferative ability must be considered EP's, and the larger variant which causes symptoms and eventually death should be regarded as chordomas. In the last century, additional features have been proposed to help differentiate between these two lesions. EP patients are described to be usually younger, to have a better prognosis and their lesions are proposed to have a lower MIB-1 labeling index (MIB-1 LI) compared chordomas, and there is a reduced tendency for contrast enhancement and a frequent location intradurally at the prepontine cistern, typically connected to the clivus with a cartilage/osseous stalk. ${ }^{50,51}$ Even so, differentiation is still a challenge, as chordomas can sporadically occur in the intradural space, and these chordomas show a similar prognosis to EP tumors. ${ }^{52}$ Histological findings are almost identical as well, as both tumors show similar morphological and immunohistochemical patterns..$^{53,54}$ Thus, since differentiation is very difficult and both show similar biological behavior, the question remains whether such a differentiation should be made, or if we should consider these different entities on the same spectrum of pathology. ${ }^{52}$ On the contrary, a clear distinction in terms of survival can be made when both are compared to conventional extradural chordomas.

\section{Formation of chordoma}

Hitherto, a model has been described where chordomas arise via transformation of benign notochordal cells (Fig. 1). However, the question still remains as to what drives the notochordal cells to differentiate into the benign or malignant variant. The recent and popular cancer 
A

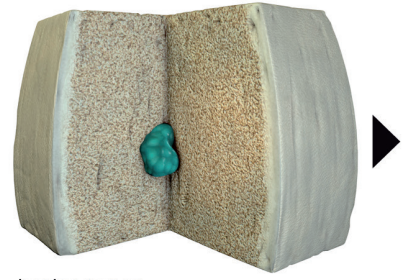

benign tumor

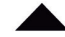

B

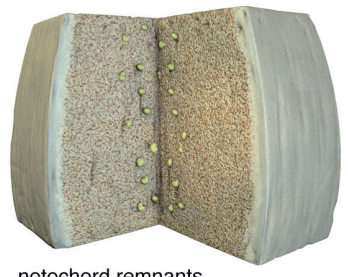

notochord remnants

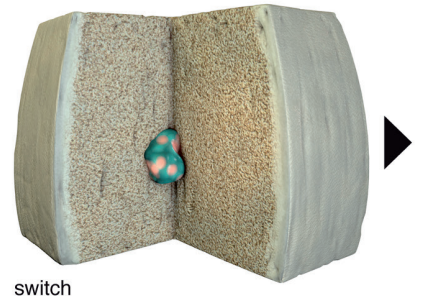

switch
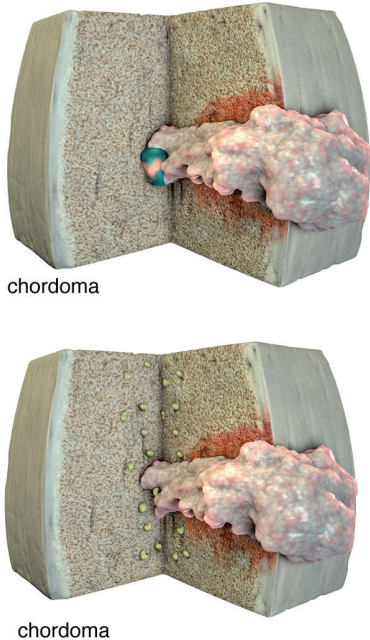

chordoma

C
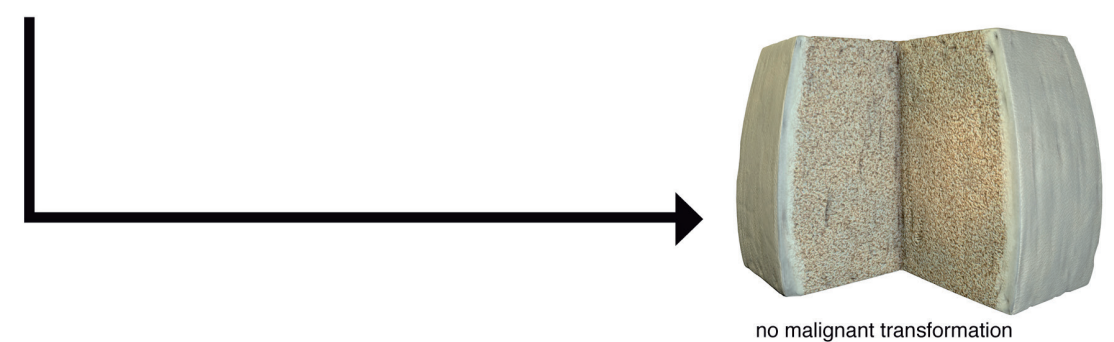

Fig. 1. A hypothesized model of chordomagenesis. Notochordal remnants are observed in $2 \%$ of autopsies. Although considered a separate entity, benign notochordal tumors show close resemblance to these lesions due to a common notochordal cell nature. A chordoma might be derived from these benign notochordal tumors, since chordomas have been located next to these lesions only separated by a fibrous septae. A certain malignant transformation in phenotype (switch) would in that case be responsible for the chordomagenesis (A). Chordomas might also be a result of direct malignant transformation of the notochordal remnant, without a benign notochordal tumor intermediary stage (B). However, as notochordal remnants are observed more frequently than chordomas, these cells in most cases do not result in a malignant phenotype or benign tumor and are expected to go in apoptosis or to advance in further differentiation (C). Lastly, chordomas might not be derived from notochordal cells, but might only mimic notochordal morphology due to altered genetic expression (not depicted).

stem cell (CSC) theory sheds more light on these transformations. This hypothesis states that a small subpopulation of tumor cells which exhibit stem cell characteristics (such as self-renewal, resistance to apoptosis, and the potential for multidirectional differentiation), are the driving force behind tumor growth and the presence of different neoplastic cells. ${ }^{55}$ Although debated ${ }^{56}$, such CSCs, can be observed as "spheres" by starvation of tumor cells, as this method selects for the most primitive cells by eliminating the differentiated cells that are unable to survive. Recently, in relation to chordoma, Hsu et al. ${ }^{57}$ illustrated the formation of sarcospheres in the human chordoma cell line $\mathrm{CHJ}-7$, and reported that these cells have a higher expression of the stem cell marker ALDH1 compared to typical chordoma cells. 
After injecting these sarcospheres into an athymic mouse, the authors revealed a transformation of these cells in the typical chordoma cells, suggesting a hierarchical model for the differentiation of typical chordoma cells. As this offers an interesting perspective, further investigations concerning the initiating factors for this differentiation step are crucial for our understanding of the development of chordoma.

\section{Molecular pathways in chordoma}

\subsection{Embryological pathways in chordoma}

Although a plethora of components involved in the control of embryological development have been investigated, only some of these developmental factors are thought to be crucial for notochordal development and maintenance. Since the notochord is hypothesized to be the predecessor of chordoma, proteins implicated in preservation of this vital structure have also been investigated in chordoma. These experiments have generated interesting results, with one of the most important and promising findings reported by Vujovic et al..$^{58}$ The authors compared thirty-five chordoma tissue samples with 33 normal and 323 other tumors, using a cDNA microarray technique, and reported the expression of the transcription factor Brachyury (Bra or T) to be very specific for the notochord and for notochordal derived tumors. This assumption has since been confirmed by the finding of a high protein expression level (90-100\%) in chordoma and none in genitourinary neoplasia, metastatic germ cell tumors and clear cell renal cell carcinoma. ${ }^{59,60}$ However, using RT-PCR amplification of cDNA samples derived from normal and tumoral tissues, Palena et al. ${ }^{61}$ indeed confirmed that there was no abnormal expression of brachyury in the normal tissue, but illustrated an overexpression in tumors of the small intestine, stomach, kidney, bladder, uterus, ovary, and testis. Even so, brachyury has not only been shown to help in the differential diagnosis of chordoma compared to other malignancies, but also to its assumed benign predecessor BNCT, makinpug it a crucial marker which might be implicated in events preceding chordoma formation. ${ }^{62-65}$

Following the article of Vujovic and coworkers, the same group ${ }^{66}$ reported their genetic analysis of brachyury in 181 tumor samples using fluorescent in situ hybridization (FISH) and real-time PCR ( $\mathrm{PPCR}$ ), and found a copy number gain of the brachyury gene in $54 \%$. Interestingly, regardless of the presence of amplification or any other type of chromosomal abnormality involving chormosome 6q27 (brachyury locus), all 23 investigated tumors showed high expression of brachyury mRNA on qPCR analysis. Furthermore, it was shown that RNA-interference mediated silencing of brachyury expression in the $\mathrm{U}-\mathrm{CH} 1$ cell line results in morphological changes of the tumor cells and in initiation of cell cycle arrest. With the use of a similar experimental design using a novel CHJ7-cell line, Hsu et al. ${ }^{67}$ recently confirmed this inhibiting effect. Consequently, as brachyury overexpression in chordoma seems to be a crucial marker for cell cycle progression, and this does not rely on alterations in the genetic 
material, understanding protein-protein interaction may improve our current insights. In line with this, Shalaby et al. ${ }^{68}$ attempted to evaluate the involvement of the potential upstream regulator fibroblastic growth factor receptors (FGFRs), their adaptor signaling protein fibroblast growth factor receptor substrate 2 alpha (FRS2 $\alpha$ ), and downstream mediators, such as ERK1/2. Although $94 \%$ of tumors were positive with immunohistochemical stainings for at least one of the four members of FGFRs, with phosphorylated FRS2 $\alpha$ present in a subset of these tumors, no directly mediated effect on ERK1/2 and other downstream moderators, including brachyury, was demonstrated. Moreover, screenings for mutations and amplifications showed no genetic alteration. It thus seems that alternative mechanisms are responsible for activation of brachyury expression, which remain to be unraveled.

In addition to brachyury, the expression of the cellular membrane protein galectin-3 has been implicated in the pathophysiology of chordomas. Galectin-3 expression was first described to be present in the human notochord in 1997 by Götz et al. ${ }^{69}$, and the expression was noted to increase as gestation proceeded beyond the $8^{\text {th }}$ week. In the same report, the authors illustrated positive galectin- 3 immunostainings in chordoma specimens, contributing to the notochordal origin of chordomas. Recently, this insight was confirmed as it was demonstrated that benign notochordal cell tumors showed almost no positive staining when compared to an aligning chordoma. ${ }^{39}$ However, while its expression has been characterized in chordoma, no reports have been made with regard to the functional aspect of this protein. Future studies might hold much progmise, as galectin-3 has been associated with more malignant behavior in other tumors. ${ }^{70,71}$

Besides Brachyury and Galectin-3, the canonical Wingless (Wnt) pathway is thought to maintain the notochord fate during development ${ }^{72}$ and has been associated with multiple neoplasms. ${ }^{73}$ Furthermore, Wnt proteins and the downstream effector molecule $\beta$-catenin regulate cranial base development, and $\beta$-catenin deficient mice are shown to lack typical growth plate zones at the synchondroses in addition to delayed endochondral ossification. ${ }^{74}$ Moreover, in Xenopus laevis, Wnt signaling is shown to be essential for the expression of brachyury. ${ }^{75,76}$ Notwithstanding the fact that Wnt regulate intracellular mechanisms in an intricate manner, several interactions of the canonical Wnt pathway have been identified. In these series of events, Wnt signaling is exerted by binding one of the large family of Wnts glycol-protein molecules to the cell-surface receptor Frizzled and co-receptor LRP5-LRP6. In the absence of this binding, the intracellular $\beta$-catenin is targeted for degradation by a cytoplasmic 'destruction complex' via phosphorylation by glycogen synthase kinase $3 \beta$ (GSK3 $\beta$ ) and casein kinase $1 \alpha$ (CK1 $\alpha) \cdot{ }^{77,78}$ Therefore, non-activated Wnt signaling results in low levels of cytoplasmic $\beta$-catenin. However, when activated, Frizzled receptor transfers the signal by inactivation of the destruction complex through recruitment of Dishevelled (Dvl1) to the receptor complex, which consequently results in cytoplasmic accumulation of $\beta$-catenin. ${ }^{77} \beta$-catenin is subsequently found to be localized in the nucleus, indicating a nuclear transposition, and finally serves as a transcription factor for multiple genes. ${ }^{78}$ 
Accumulation of $\beta$-catenin has been encountered in $56-78 \%$ of chordoma cases. However, there is a remarkable report by Cho et al. ${ }^{79}$ who, in 14 chordoma patients, found no positive staining, except for one weak staining. This controversial result might be due to the use of different primary antibodies compared to those used in the other studies. Aside from the amount of positive stainings, Horiguchi et al. ${ }^{80}$ and Triana et al. ${ }^{81}$ stated that their staining of $\beta$-catenin represented membranous immunoreactivity, reflecting a mechanism other than that suggested in the canonical pathway. One way to explain these findings is by the interaction of $\beta$-catenin with the cell adhesion molecules E-cadherin and $\mathrm{N}$-cadherin. In line with this, Hendriksen et al. ${ }^{82}$ showed that upon Wnt3a stimulation, dephosphorylated $\beta$-catenin is recruited to the plasma membrane. This migration occurred only in E-cadherin deficient cells, and not in E-cadherin expressing cells, suggesting a new step in the conveying of the Wnt signal. Furthermore, Wahl et al. ${ }^{83}$ showed that $\mathrm{N}$-cadherin-catenin complexes are formed prior to the transportation to the plasma membrane where linkage to the actin cytoskeleton can be established. Both of these findings become particularly interesting as analysis of multiple cell adhesion molecules in chordoma illustrate an overexpression of $\mathrm{N}$-cadherin and a downregulation of E-cadherin. Thus, protein-protein regulation is again likely to be responsible, as there have been no reports of frequent aberration on the coding sequences containing these adhesion molecules.

Chromosomal aberrations are observed for chromosome 3 and 1 p36 in many chordoma patients, with the latter also providing a connective link to familiar chordoma. These chromosomal changes might be accountable for the overexpression of $\beta$-catenin as chromosome 3 entails the GSK3 $\beta$ gene and locus 1 p36 comprises the adaptor molecule Dvl1. Although no sequence analysis has been performed on GSK-3 $\beta$, the gene transcript of Dvl1 has been noted by Riva et al. ${ }^{84}$ to encompass an abnormal $350 \mathrm{bp}$ spliced transcript fragment in $50 \%$ of the tumors, and a complete absence of the Dvl1 transcript in the remaining half. The effect of this loss of transcript on $\beta$-catenin's cellular action has yet to be analyzed in chordoma cell lines.

Thus, the Wnt pathway and the closely related cadherins appear to play a considerable role in the cellular process of chordoma. Further investigation should reveal the dimension of this impact, perhaps by suppressing their expression at the transcriptional level.

Finally, and conceivably the most well-known pathway central to the genesis of the human embryo, is the Hedgehog $(\mathrm{HH})$ signaling pathway. Although this pathway is observed to be altered in many tumors, there is a relative paucity of information in the literature regarding its involvement in chordoma. Shh, one of three family members of the hedgehog ligands, is the best studied molecule in the hedgehog family, and known to be involved in vertebrate development ${ }^{85}$. Upon binding to the transmembrane receptor Patched1 (PTCH1), Shh exerts its biological signal by inducing a conformational change of the PTCH1 receptor. Consequently, PTCH1 loses its ability to repress the constitutive signaling activity of Smoothened (SMO), an additional transmembrane receptor. Subsequent activation of downstream effector 
molecules Gli1, Gli2 and Gli3 mediated by SMO ensues via complex mechanisms which are not entirely understood. However, these transcription factors have been associated with multiple intracellular actions, including transcriptional activation of many genes involved in development and cross-talk with the Wnt and p53 pathway. ${ }^{86,87}$ Concerning $\mathrm{HH}$-signaling in chordoma, Cates ${ }^{88}$ and co-workers investigated the expression of $\mathrm{Shh}$. In their analysis of twenty-three chordomas, they found Shh to be overexpressed in twenty-two cases (96\%), and $89 \%$ of these cases also showed a positive staining for PTC1 receptor. However, this is not a chordoma specific marker, as anti-Shh antibodies also reacted in $50 \%$ of the notochordal cases, and in $81 \%$ of chondrosarcoma cases. Nevertheless, greater understanding of the involvement of this pathway in chordoma might unravel new therapeutic strategies.

\subsection{Other pathways in chordoma}

Numerous studies have been carried out in an attempt to describe the molecular-pathological pathways involved in the formation of chordoma. Even if no effective medical treatment is currently available for chordomas, novel molecular biomarkers are increasingly being identified for the development of targeted therapies. In the following sections, we will summarize the current knowledge on the pathophysiology of chordoma.

\subsubsection{Genome wide investigations}

The genetic profile of chordomas has been intensively investigated. Although varying data are published on this matter, some genetic aberrations have been consistently demonstrated. Most experiments concerning genetic integrity have focused on chromosomal segregation in cases of sporadic chordoma. Familial chordomas, however, rarely occur and have been linked to susceptibility of loci $1 p 36^{89}$ and $7 q 33^{90}$ (for an overview of families see Larizza et al. ${ }^{91}$ ). More recently, with the isolation of Brachyury as a characteristic feature of chordomas, Yang et al. ${ }^{92}$ linked the Brachyury coding sequence to affected individuals in four families with a frequent occurrence of chordoma.

Reports on sporadic cases of chordoma, however, reveal a considerable discrepancy regarding karyotype integrity. The incidence of aneuploidy in these cohorts ranges from $26 \%$ to $100 \%$ (mean $53 \%$ ) $^{93-100}$, with an average of 3.2 losses and 4.2 gains per tumor. ${ }^{97}$ Aneuploidy and chromosome instability are frequently attributed to gains or losses of either whole chromosomes or specific regions, which typically include losses of $1 p^{84,96,97,99,101-103}$ and $3 p^{93,96,97,99,101-103}$ and gains of chromosome 7 in most studies. ${ }^{97,99,101,102}$ The frequency of aneuploidy seems to be comparable for the classic and chondroid subgroup, but occurs more often in dedifferentiated chordomas. ${ }^{95,100}$

In the same vein, Almefty et $a l .{ }^{93}$, in an analysis of sixty-four patients, demonstrated a substantial increase in recurrence rate for patients with abnormal as compared to normal karyotypes. Detailed analysis revealed odds ratios (OR) for recurrence for patients with abnormality on chromosomes 3, 4, 12, 13 and 14, compared to cases with intact copies of 10, 7.5, 22, 
24 and 18, respectively. The overall OR for recurrence calculated for an abnormal karyotype was 12.45 . Besides recurrence rate, recurrence-free survival and overall survival was shown to be significantly impaired in patients with abnormal karyotypes, suggesting these findings may have a possible role in the prediction of prognosis, as previously suggested by Schoedel et al. ${ }^{104}$ in 1995.

Possible explanations for the origin of chromosomal instability include faulty cell-cycle regulation and telomerase activity. ${ }^{105,106}$ Increased telomerase activity and telomere shortening are observed in various tumors, and have been related to the stability of the genome and to a gradual increase in chromosomal aberrations over time. ${ }^{107-112}$ Thus far, five studies have been published on the subject of telomere length or telomerase activity in chordomas. Three of these originated from the group of Butler et al. ${ }^{113-115}$, who showed increased telomere length in a total of 10 chordomas (considering no double report of patients) and three patients of which one had increased telomerase activity. Expression of human telomerase reverse transcriptase (hTERT) messenger RNA was investigated by Pallini et al. ${ }^{116}$ in 26 chordoma cases in a study which yielded remarkable findings. Firstly, it was shown that despite the fact that only 14 out of 29 (48.3\%) classic chordoma specimens expressed hTERT, while none of the four chondroid and both of the two more malignant dedifferentiated variants did. Moreover, this seems to affect tumor behavior, as these authors reported patients with expression of hTERT to have shorter tumor doubling time, increased proliferation, an association with mutation of the p53 tumor suppressor gene, and a decrease in recurrence-free probability. In addition, in a different report from the same group, similar proportions (42\%) of hTERT expression were shown in a group of seven patients, and found exclusively in recurrent chordomas. ${ }^{117}$ However, although it seems that telomerase activity is present in a proportion of chordoma cases and has prognostic value, the basic mechanisms underlying hTERT and further downstream effects are still not well understood.

Besides the enhancement of chromosome aberration by hTERT expression, another phenomenon in tumor biology and chordomagenesis, called chromothripsis, was recently postulated by Stephens et al. ${ }^{118}$ This potential mechanism for genomic rearrangement refers to a single catastrophic event resulting in multiple genomic rearrangements, and appears to be more frequent in bone cancers. What defines this single event and its cause has yet to be clarified.

\subsubsection{Cell cycle regulation}

Denominated as the guardian of the genome, p53 exhibits multiple functions in the regulation of cellular processes in response to various forms of stress. Following DNA damage, p53 exerts its tumor suppressive function by inducing a reversible cell cycle arrest or apoptosis. ${ }^{119}$ Therefore, loss of p53 function is an important process in malignant progression, and may result from alteration in the gene encoding the protein, or from diminished activation due to protein-protein interactions. ${ }^{120}$ Mutations in the p53 gene, which is located on $17 \mathrm{p} 13.1$, 
occur in more than $50 \%$ of human cancers. ${ }^{121}$ In relation to chordoma, relatively few studies have focused on genetic mutations of the p53 gene, while many have focused on its protein expression. Naka et al. ${ }^{122}$ screened thirty-seven chordoma samples for mutations on specific exons 5,7 , and 8 , and found no changes. However, cytogenetic analysis using fluorescence in situ hybridization exposed the 17p13.1 locus to be deleted in $17.6 \%$ of cases with a higher occurrence in recurrent tumors. ${ }^{101}$ Loss of heterozygosity (LOH) on $17 \mathrm{p} 13$ was also reported for $52 \%$ of 23 cases, but this was not correlated to either overall survival or expression of the (impaired) p53 protein product. ${ }^{123}$ This might indicate that alterations on the gene level are located on different exons or $\mathrm{LOH}$ accounts for other closely located genes. DNA sequencing of the full p53 gene would clarify such ambiguity, but to date has not been reported.

However, data concerning p53 protein overexpression are available but varying expression has been reported between $0 \%$ and $53 \%{ }^{117,122-127}$ Even though all of the studies are based on immohistochemical techniques, the discrepancy in outcome might be explained by the use of semi-qualitative versus quantitative methods of analysis, and by differences in interpretations (cut-off points) of the data. In addition, positive staining for p53 should be interpreted carefully, as this does not necessarily indicate overexpression of a mutant protein, even though wild type p53 is usually not detected at high concentration because of its relatively short half-life of approximately 20 minutes. ${ }^{128}$ Other factors such as protein-protein interactions and a disruption of the degradation pathway should therefore also be considered.

Concerning both mechanisms, the mouse double murine 2 (MDM2) protein negatively regulates the function of $\mathrm{p} 53$ by binding at the $\mathrm{N}$-terminal end and, by means of ubiqitination, modifies it for subsequent degradation. Expression of MDM2 itself is also controlled by p53 transcription, making it a negative feedback regulatory system. ${ }^{129}$ In chordoma, MDM-2 gene amplification is noted in $15 \%$ of cases, however no sequence analysis has been reported to account for possible mutations. ${ }^{122}$ Moreover, a significant correlation has been reported for 553 protein expression and MDM2 overexpression and, when present, both separately show a higher MIB-1 LI. ${ }^{122}$ Considering their cellular behavior, one might not expect to find an overexpression of both in a dividing cell. A potential explanation for this phenomenon might be that the mutant p53-MDM2 complexes are responsible for a "gain of function" phenotype. ${ }^{130}$ Accumulation of p53 might also occur if the wild type protein is altered by an additional protein (e.g. HSP90) ${ }^{131}$, which opposes or counteracts the binding capability of MDM2. Furthermore, MDM2 might necessitate additional proteins for the ubiqitination of $\mathrm{p} 53$. In keeping with this notion, a crucial regulator has been shown for the retinoblastoma $(\mathrm{Rb})$ protein. ${ }^{132}$

Direct inactivation of the tumor suppressor $\mathrm{Rb} 1$ via mutation/deletion of the gene transcript (e.g. osteosarcoma) and functional inactivation due to (lack of) interaction with upstream regulators, including CDK4 (e.g. glioblastoma), cyclin D1 (lung carcinoma), and p16/INK4A (e.g. T cell lymphoma), are often described in many human neoplasms. ${ }^{133-136}$ 
Loss of heterozygosity for the $\mathrm{Rb}$ gene transcript in chordoma was described by Eisenberg et al. ${ }^{137}$ in 1996, who reported loss of heterozygosity in two introns (17 and 20) in 2 out of 7 cases. Furthermore, alterations of chromosome 13, where the Rb gene is located (13q14.2), are associated with frequent recurrence and a very short survival. ${ }^{93}$ Moreover, chromosomal loss on chromosome 13 occurs in $56 \%$ of the patients, with involvement of the specific13q14.2 locus in an additional $18 \% .{ }^{93}$ Similar proportions have been reported for $\mathrm{Rb}$ protein expression, which are absent in $52 \%$ of the chordoma tissues. ${ }^{122}$ Similar protein expression level were reported for cyclin D1, which was absent in $57 \%$ of the cases. Only one paper has been published regarding the genomic integrity of this enzyme's transcript, and reported a loss of heterozygosity in 2 out of the seven chordomas investigated..$^{137}$

Conversely, cytogenetic aberrations have been frequently reported for another associated upstream regulator, $\mathrm{p} 16^{\mathrm{INK} 4 \mathrm{~A}}$. Tumor suppressive function of this protein is mediated via an inhibitory effect on the phosphorylation process of the Rb protein, by preventing CDK4/ cyclin D1 complex formation, confining the cell to the G1 cell cycle arrest. ${ }^{138}$ The CDKN2A gene, which encodes the p16INK4A protein, is located on 9p21 and was shown by Hallor et al. ${ }^{139}$ to be homo- or heterozygously lost in 70\% of chordoma tumors. Immunocytochemistry has also revealed a $74 \%$ to $100 \%$ absence of p 16 protein expression in several cohorts. ${ }^{122,140,141}$ Analysis of the 9p21 region has also been shown to be of prognostic value, as deletion of this specific area will potentially show a more aggressive clinical course and shorter overall survival. ${ }^{123}$ It thus appears to be the case that activation of the $\mathrm{Rb}$ protein might have a significant impact on the clinical condition of patients with chordoma, and that this is most probably mediated by a frequent deletion of the CDKN2A gene. Further reports on the expression of CDK4 activation in chordoma might confirm this notion, and also offer a potential mechanism for chemotherapy, as CDK4 inhibitors are shown to have anti-tumoral activity. ${ }^{142}$

In addition to the production of $\mathrm{p} 16^{\mathrm{ink} 4 \mathrm{a}}$ and its effect on the Rb-pathway, another protein product of the CDNK2A gene is formed, called p14 arf. This protein has been reported to interfere with the function of MDM-2, and by blocking the MDM- 2 mediated ubiquitination, facilitates the action of $\mathrm{p} 53$.

Deregulation of the function or expression of cell cycle regulatory proteins is one of the hallmarks of cancer. P53 overexpression and loss of the intact CDKN2A gene are the main findings reported by studies on chordoma patients. As much as we know about the presence or absence of these factors, information about their functional effects is entirely absent. Moreover, aside from these two findings, information regarding other cell-cycle regulators is very limited.

\subsubsection{Receptor tyrosine kinase}

Receptor tyrosine kinases (RTK) are important mediators of extracellular induced intracellular signaling, and if constitutively activated are important for malignant transformation and tumor proliferation. As a large group of transmembrane proteins which include families such 
as the epidermal growth factor receptor (EGFR) family, the platelet-derived growth factor receptor (PDGFR) family, and the mesenchymal-epithelial transition factor receptor (c-MET), RTKs are generally composed of two domains, a ligand-binding extracellular domain, and a catalytic intracellular kinase domain. For many RTKs, binding of a ligand results in induced proximity and transautophosphorylation, processes, in which two receptor chains dimerize and, as both kinase domains interact, subsequent cross-phosphorylation on multiple tyrosines takes place. ${ }^{143}$ Besides phosphorylation of the kinase domains, adjacent tyrosines are also phosphorylated and serve as docking sites for specific intracellular proteins, with the best-characterized being the SH2-domain-containing proteins. These proteins often serve as transmitters of downstream signaling by activating second messenger modules that lack the SH2 domain. Ras, superfamily of monomeric GTPases, exemplifies one of the most important second messenger modules. Activation of Ras by promotion of its GTP-bound state occurs via RTK adaptor molecules grouped as guanine exchange factors (GEF, e.g. SOS and Grb2). Once activated, GTP-Ras instigates an intricate network of intracellular phosphorylation cascades, of which activation of the RAS/RAF/MEK/ERK pathway and the PI3K/RAS/ Akt/mTOR pathway are most frequently described. Even though several intracytoplasmic crosslink's with other pathways occur, both of these classical pathways have been extensively described as being responsible for transmission of proliferative signals from the RTK, and dysregulation of this pathway results in the uncontrolled proliferation and malignant transformation of naïve cells. ${ }^{144}$

Many molecular studies have focused on the expression of receptor tyrosine kinases and their related secondary messengers in chordoma (Table 1 and 2). Despite some varying results, these experiments have improved our understanding in regard to their involvement in the pathophysiology. While it has been shown that some RTKs are infrequently expressed, others are demonstrated to have repeated high expression levels and therefore seem to play a considerable role in chordoma's makeup. The platelet derived growth factor receptor (PDGFR), for instance, is observed consistently in the phosphorylated active form in almost all chordoma tissues. ${ }^{145-149}$ Real time RT-PCR analysis on the PDGFR alpha and beta comparing a group of 23 chordoma cases to a pool of normal mesenchymal tissues revealed a higher median expression of PDGFR beta $\left(2^{-\Delta \Delta C t}=2.34\right)$, but did not show an overall increased transcribed status for PDGFR alpha $\left(2^{-\Delta \Delta C t}=0.7\right) .{ }^{148}$ Considering that no activating mutations have been found, and the fact that FISH analysis on the associated chromosomes demonstrated diploidy in $79 \%$ of the cases, it seems likely that activation of the receptor is ligand mediated. Para- or autocrine activation might account for the activated state as mRNA encoding both PDGF $\alpha$ and $\beta$ ligands are present in nearly all of the tumors. ${ }^{148,149}$ However, quantification of the protein levels of these ligands compared to healthy tissue is required, since mRNA-expression microarray analysis carried out by Vujovic et al..$^{58}$ showed a conversely low expression mRNA expression of PDGF $\alpha$ in chordoma cells as compared to other tumors. Paracrine regulation by the surrounding tissues might also offer an alternative explanation for the phosphorylated form of the PDGFR. 
Table 1. Overview of melocular analysis performed on receptor tyrosine kinasis in chordoma

\begin{tabular}{|c|c|c|c|c|c|}
\hline Marker & IHC N. & WB/IP N. & WB/IP P. & mRNA overexp. (exon) & Sequence analysis (exon) \\
\hline PDGF $\alpha$ & & & & $100 \%(\text { n.s. })^{148}$ & \\
\hline PDGFR $\alpha$ & $100 \%^{146,148}$ & $100 \%^{148}$ & $100 \%^{148}$ & $17 \%(10,12,14,16,18)^{148}$ & $\begin{array}{l}20 \% \text { SM, 0\% AM }(10-22)^{1} \\
0 \%(12 \& 18)^{228}\end{array}$ \\
\hline PDGF $\beta$ & & & & $98 \%(10-20)^{148,149}$ & \\
\hline PDGFR $\beta$ & $100 \%^{146,148,149,229}$ & $98 \%^{148,149}$ & $100 \%^{148,149}$ & $25 \%(10-20)^{148}$ & $\begin{array}{l}45 \% \text { SM, 0\% AM }(10-20)^{1} \\
0 \%(12 \& 18)^{228}\end{array}$ \\
\hline EGF & & & & $100 \%(18-20)^{149}$ & \\
\hline EGFR & $62 \%^{145,149,151,154}$ & $77 \%^{149}$ & $88 \%^{149}$ & & $0 \%(18-21)^{149,154}$ \\
\hline$p$-EGFR & $50 \%^{145,154}$ & & & & \\
\hline HER2 & $18 \%^{145,151}$ & $43 \%{ }^{149}$ & & $0 \%$ (n.s.) $)^{149}$ & \\
\hline c-Met & $86 \%^{145,150,231}$ & & & & \\
\hline c-Kit & $49 \%{ }^{145,146,148}$ & $86 \%^{148}$ & $100 \%^{148}$ & $18 \%$ (n.s.) $)^{1} ; 0 \%(11)^{228}$ & $\begin{array}{l}20 \% \text { SM,100\% AS } 9 \text { \& 15, } \\
0 \% \text { AM }(8-21)^{148}\end{array}$ \\
\hline $\mathrm{pIGF1R/pIR}$ & $41 \%^{140}$ & & & & \\
\hline NGF & $96 \%^{232}$ & & & & \\
\hline TrkA & $93 \%{ }^{232}$ & & & & \\
\hline
\end{tabular}

$\mathrm{SM}=$ silent mutations; $\mathrm{AM}=$ activating mutations; $\mathrm{M} 541 \mathrm{~L}=$ exon 10 mutations; $\mathrm{AS} 9$ \& 15 = alternative splicing of exons 9 and 15; n.s. = not specified; IHC = immunohistochemistry; WB = western blotting; IP = immunoprecipitation; N. = non-phosphorylated; P. = phosphorylated.

Besides the PDGFR, the epidermal growth factor receptor (EGFR) has also received much attention in the literature. For this receptor, however, immunohistochemistry studies have shown varying degrees of positive signal in relation to chordoma, ranging from $32 \%$, described by Walter et al. ${ }^{150}$, to $92 \%$, reported by Weinberger et al. ${ }^{151}$ These different findings make the interpretation of the extent of involvement rather difficult. A promising link between the gene locus of the receptor, which is located on the frequently amplified chromosome 7, was negated as Walter et al. showed this to not be correlated to the protein expression seen on immunohistochemical stainings. ${ }^{150}$ However, the authors did illustrate a correlation between high expression of the mesenchymal-epithelial transition factor/ hepatocyte growth factor receptor (c-MET) and chromosome 7 amplification. On average, immunohistochemical reactivity of this receptor is found to be present in $86 \%$ of the patients, and high expression is significantly correlated to the expression of matrix metalloproteinases- 1 and -2 , suggesting an effect on local invasion and metastasis. In fact, in an experimental design using a human chordoma cell line (CCL-3), Ostroumov and Hunter ${ }^{152}$ illustrated the increased migratory capacity of chordoma cells following stimulation with its ligand HGF. Unfortunately, as these cells have been shown not to recapitulate chordoma cells, this concept has yet to be confirmed in an established chordoma cell line. 
Table 2a. Overview of downstream second messengers of RTK's signaling

\begin{tabular}{|c|c|c|c|c|}
\hline Marker & IHC normal & WB/IP normal & WB/IP phospho & Mutations (exons) \\
\hline ERK & & $100 \%^{149}$ & $100 \%^{149}$ & \\
\hline p-ERK & $88 \%^{140,145}$ & $100 \%^{149}$ & & \\
\hline p110 (PI3K) & & & & $0 \%(4,5,6,7 \& 20)^{141,149}$ \\
\hline p85 (PI3K) & & $95 \%^{149}$ & & \\
\hline PDK1 & & $100 \%^{158}$ & & \\
\hline p-PDK1 & & $100 \%^{158}$ & & \\
\hline PTEN & $80 \%^{141,163,154}$ & $95 \%^{149}$ & & $0 \%(5-9)^{149}$ \\
\hline Akt & & $93 \%{ }^{141,149}$ & $100 \%^{149}$ & \\
\hline p-Akt & $85 \%^{141,145}$ & & & \\
\hline TSC1 & $35 \%{ }^{141}$ & & & \\
\hline TSC2 & $100 \%^{141}$ & & & \\
\hline p-TSC2 & $96 \% 141$ & & & \\
\hline mTOR & $75 \%^{141}$ & $93 \%^{141,149}$ & $100 \%^{149}$ & \\
\hline $\mathrm{p}$-mTOR & $27 \%^{141}$ & $17 \%^{141}$ & & \\
\hline Src & & $100 \%^{166}$ & & \\
\hline pSrc & & $100 \%^{166}$ & & \\
\hline
\end{tabular}

Table 2b. Overview of downstream effector molecules of RTK's signaling

\begin{tabular}{llll}
\hline Marker & IHC normal & WB/IP normal & WB/IP phospho \\
\hline S6K & $100 \%^{141}$ & $100 \%^{141}$ & \\
pS6K & $62 \%^{141}$ & $100 \%^{141}$ & $100 \%^{141}$ \\
\hline S6 & & $17 \%^{141}$ & $65 \%^{149}$ \\
\hline p-S6 & $100 \%^{163}$ & $91 \%^{149}$ & \\
\hline 4EBP1 & & $83 \%^{141}$ \\
\hline p-4EBP1 & $97 \%^{141,163}$ & \\
\hline eiF-4E & $98 \%^{141}$ & $100 \%^{166}$ \\
\hline Stat3 & & $100 \%^{166}$ \\
\hline p-STAT3 & $92 \%^{145,165}$ & \\
\hline p-BAD (S75) & $32 \%^{140}$ & \\
\hline p-BAD (S99) & $77 \%^{140}$ & \\
\hline p-PRAS40 & $64 \%^{163}$ & \\
\hline
\end{tabular}

Concerning the downstream signaling following RTK's phosphorylation, a considerable number of second messengers is reported to be overexpressed, and these are cross-linked in a very complex manner ${ }^{153}$. 
As previously mentioned, downstream signaling subsequent to the transautophosphorylation process occurs via activation of adapter molecules to the phosphorylated non-kinase regions of the receptor. For the canonical MAPK pathway (RAS/RAF/MEK/ERK), subsequent activation of the RAS protein results in a cascade of phosphorylation signaling. This eventually leads to modification of proteins involved in cell cycle progression, transformation and cellular motility. In chordoma, some studies have focused on the genetic integrity of the family of RAS protein-sequences (KRAS, HRAS, NRAS and Rheb), but, using PCR and direct DNA sequencing, have found none to show alterations. ${ }^{68,141,149,154}$ However, to the authors' knowledge, no study has investigated the qualification or quantification of the (active) Ras protein, making its active condition generally presumed rather than scientifically proven. The same argument applies to the downstream activated BRAF protein. This serine/threonine kinase is commonly shown to be activated by somatic point mutation in human cancer. ${ }^{155}$ Mutated BRAF can exhibit constant activation and consequently results in high cellular activity of the extracellular signal-regulated kinase (ERK) mediated via the activation of MAPK/ERK kinase (MEK). ${ }^{156}$ However, although western blot analysis detected active phosphorylated ERK in nearly all chordoma tissue, denaturing high-performance liquid chromatography (DHPLC) for the BRAF gene did not show any genetic alterations on two frequently altered exons $(11 \& 15) .{ }^{68}$ This suggests that abnormal stimulation by auto- or paracrine growth factor is responsible for the constitutive RAS/RAF/MEK/ERK signaling, or that ERK activation might be subsequent to interaction with other proteins external to this classical pathway.

Besides signaling from the RAS/RAF/MEK/ERK pathway, the canonical signaling cascade of phosphoinositide-3-kinase ( $\mathrm{PI}$ KK) becomes activated either through direct interaction of its p85 subunit with the intracytoplasmic phosphotyrosine tail of the RTKs, or indirectly as intermediate activators, such as RAS, enhance its catalytic p110 domain. ${ }^{157}$ Once activated, the PI3K exerts its effect by converting the phosphatidylinositol $(4,5)$ bisphosphate (PIP2) to the active phosphatidylinositol $(3,4,5)$ triphosphate (PIP3), which recruits and activates phosphatidylinositol-dependent kinase 1 (PDK1). Schwab et al. ${ }^{158}$ detected the presence of this active phosphorylated protein in all of their investigated chordoma material on western blot. Furthermore, like others, they have also reported on the presence of its associated downstream messenger protein kinase $B$ (PKB/AKT), and noted it to be frequently phosphorylated, suggesting it has an active function in chordoma. This function becomes more apparent as known subsequent targets of AKT, including GSK3 $\beta$, mammalian target of rapamycin (mTOR), and the pro-apoptotic BCL2-associated agonist of cell death (BAD) ${ }^{159,160}$ are shown to be implicated in chordoma in several studies. Activated mTOR is also recognized to act as an upstream regulator of many important proteins. One of the proteins acknowledged to be regulated by mTOR is the S6 kinase (S6K). ${ }^{161}$ After phosphorylation by $\mathrm{mTOR}$, activated S6K is responsible for the activation of the ribosomal S6 protein and, via mechanisms which are still not completely understood, this pathway seems critical for several diverse and important cellular functions, including protein synthesis, metabolism 
and cell growth. ${ }^{161}$ Since chordoma patients frequently exhibit active forms of both proteins, this might explain the large cells observed in microscopic analysis. ${ }^{149,162,163}$ However, besides S6K, mTOR has been illustrated to elicit active forms of several other important proteins in cancer, of which the cytoplasmic transcription factor signal transducer and activator of transcription 3 (STAT3), and the eukaryotic translation initiation factor 4E (elF4E), are particularly interesting. ${ }^{164}$ Stat3, which can also bind directly to the EGFR, has been demonstrated to be highly expressed on immunohistochemical examination in half of the chordoma cases. It is also associated with aggressive tumor behavior and decreased overall survival in chordoma patients. ${ }^{165}$ Blockage of this signaling by inhibition of the phosphorylated Stat3 and the oncogenic upstream regulator Scr by 2-cyano-3,12-dioxooleana-1,9 (11)-dien-28-oic acid-methyl ester (CDDO-Me), resulted in chordoma cell growth inhibition. ${ }^{166}$ Even though no prognostic value has been proposed for elF4E, an important molecule involved in the regulation of RNA translation, this protein has been proposed as an interesting therapeutic target against cancer. ${ }^{167}$ In a normal functioning cell, elF4E is prevented from binding to mature mRNA, through binding of hypophosphorylated elF4E binding proteins (4EBPs), and so attenuates its mitogenic capacity. However, when 4EBP becomes phosphorylated, as it is the case in most chordoma patients, $4 \mathrm{EBP}$ loses its capacity to bind elF4E, and in this way facilitates mitogenesis. ${ }^{141,149,163}$

Since all these downstream molecules have been observed to be activated, an explanation has yet to be offered for the failed regulation by inhibitory phosphatases such as the tensin homology (PTEN), which is responsible for the regulation of both mTOR and STAT3. ${ }^{164}$ Some authors have suggested that more than half of chordoma cases lack the expression of PTEN. ${ }^{163}$ Other larger series have demonstrated absence in only $10-15 \% .{ }^{141,154}$ In their analysis of 22 chordoma patients, Tamborini et al. ${ }^{149}$ reported the expression of PTEN on immunoblot analysis in $95 \%$ of cases, and found no genetic mutation in any cases. Impaired function of this tumor suppressor might be induced by inactivation due to interactions with other proteins. One such protein might be a member of the Src family of protein-tyrosine kinases, which play an important role in signal integration and have been shown to alter the function of PTEN. ${ }^{168}$ As this protein has been shown to be overexpressed in a phosphorylated state in all chordoma cases, this hypothesis might clarify the increase in p53 observed in chordoma, as PTEN is also shown to regulate the transcriptional activity of p53 by antagonizing the Akt mediated activation of Mdm2. ${ }^{169,170}$

Two other tumor suppressor proteins - tuberous sclerosis protein (TSC) 1 and 2 - are also involved in regulation of the PI3K/AKT/mTOR pathway. In their normal cellular function, TSC1 and TSC2 form a complex that inhibits downstream signaling of mTOR and thereby prevents cellular growth and proliferation. Mutations on the encoding genes are associated with the tuberous sclerosis complex, a rare inherited autosomal disorder that is characterized by the presence of multiple hamartomas in possibly all organs. ${ }^{171}$ In the literature, some reports have been made about chordomagenesis in a subgroup of these TSC-patients, with an occur- 
rence almost exclusively in the pediatric population. ${ }^{172-178}$ As this on its own is a remarkable finding, it must be noted that such a tumor might easily be mistaken for chordoma, while it represents a giant notochordal hamartoma of intraosseous origin (also known as BNCT). ${ }^{179}$ Additional evidence in support of this notion comes from McMaster et al. ${ }^{180}$, who illustrate the substantial difference in survival in pediatric chordoma and TSC associated chordoma (favouring the last). However, in order to gain further insight and to improve discriminative capacity, further detailed investigation (e.g. immunohistochemical analysis) is required. ${ }^{39}$

Taken together, studies performed on RTKs and their downstream messengers illustrate active signaling via the canonical RAS/RAF/ERK and PI3K/PDK/AKT/mTOR pathways. Most of these second messengers are also shown to be present (in a large proportion of chordoma patients) in their active phosphorylated state, suggesting an important involvement in the disease process. Constraining signaling in this frequently activated pathway via pharmacological reagents has been proven to be effective in a number of case reports and small clinical trials. ${ }^{181}$ Recently, Stacchiotti et al. ${ }^{182}$ reported the results of their phase II clinical trial using imatinib mesylate, a kinase inhibitor primarily targeting PDGFR. The authors reported very promising findings, but also discussed the presence of PDGFR in patients with no response to the drug. This highlights the possible implication of other members of the RTK family of proteins in the (in)effect of this drug, as suggested by previous data. ${ }^{183,184}$ It might therefore be relevant to investigate the expression pattern of multiple RTKs in these patient cohorts.

\subsubsection{Cell adhesion molecules and matrix metalloproteinases}

Cell adhesion molecules (CAMs) encompass particular properties which are involved in cell-cell and cell-matrix interactions, and as a result participate in the induction and maintenance of cellular differentiation, proliferation, and migrations. ${ }^{185}$ The large number of CAMs is divided into four major families, of which the cadherins and the immunoglobulin superfamiliy are shown to be present in chordoma tissues. ${ }^{80,185}$

Cadherins are highly conserved $\mathrm{Ca}^{2+}$-dependent cell-surface receptors that are known for their involvement in crucial developmental steps in early embryonic morphogenesis and carcinogenesis. ${ }^{186}$ These proteins form trans-interactions on (mostly hemophilic) opposing cells by binding their extracellular domain, whereas the intracellular domain is responsible for modification of intracellular signaling by constituting a protein complex with members of the catenin family and the p120 protein. ${ }^{187,188}$ The classic E-, P- and N-cadherin were the first cadherins to be identified and have been extensively studied in the pathophysiology of multiple cancers. ${ }^{189,190}$ Several mechanisms have been proposed for their implication in neoplastic cell progression and metastasis, including cadherin switch and loss of contact inhibition.

Cadherin switch refers to a process by which cells alter their expression of cadherin isoforms. Although this represents a common phenomenon during development, in epithelial cancers a certain isoform-switch from $\mathrm{E}$ - to $\mathrm{N}$-cadherin is associated with an invasive and metasta- 
tic phenotype. ${ }^{191}$ In general, the "invasion-suppressor" E-cadherin initiates strong cell-cell bonds by clustering in complexes, whereas upregulation of $\mathrm{N}$-cadherin is shown to induce a scattered morphology, increased motility and invasive potential. ${ }^{192}$ Interestingly, this pro-invasive character seems to be independent of E-cadherin's existence in the cell, indicating a dominant role for $\mathrm{N}$-cadherin. ${ }^{192}$ This same principle of cadherin-switch has been demonstrated in chordoma. Triana et al. ${ }^{81}$ described a patient with recurrent chordoma who exhibited a high E-cadherin expression on primary resection and a twentyfold decrease in the recurrent tumor. The opposite was illustrated for $\mathrm{N}$-cadherin, in that a threefold upregulation was noticed in the recurrent tumors. As previously described, a relationship with survival has been proposed, although this appears to differ according to the investigative technique used. More investigation is needed in order to understand this switching.

In addition to cadherin switch, loss of contact inhibition probably indicates one of the most important mechanisms for an infiltrative and metastatic phenotype. This principle reflects an inhibition of cell growth by the binding of two or more cells to each other. E-cadherin seems to play a crucial role in the underlying mechanism, as loss of cell-cell adhesion of this transmembrane protein has been illustrated to induce early invasion and metastasis. ${ }^{193}$ Loss of functional E-cadherin might be due to several factors, including aberrations in the readings frame, transcriptional repression, or protein alteration by protein-protein interaction. Research concerning chordoma has mainly focused on the presence of the cadherin protein product, its relation to survival, and the distinctive character of chordoma in contrast to other diagnosis. ${ }^{79,80,194-196}$ In this regard, E-cadherin is variably detected in chordoma, but if present can differentiate between chondrosarcoma, where its expression is reported to be absent. ${ }^{194,195}$ Besides the variable expression, ranging from a positive intense expression in most cells reported by Naka et al. and Mori et al., to very low / no staining described by Horiguchi et al. and Laskin et al., E-cadherin expression seems to be a dynamic protein localized either on the bordering membranes of neighboring tumor cells or inside the cell's nucleus. ${ }^{80,194-196}$ In addition, Laskin and colleagues described this expression to be stronger in the physallyphorous cells and absent in the spindle cells, indicating a possible marker for chordoma cell differentiation.

However, besides protein expression, evidence for E-cadherin's function in chordoma is still lacking. In particular, analysis of the coding sequence integrity and its relation to intracellular signaling might shed more light on the pathological mechanisms of chordoma. In cancer, the regulation of cadherin in signaling has also not been fully elucidated, though it is believed to be mediated via clustering of its intracellular affixed catenin proteins, or by altering receptor responsiveness of RTKs. ${ }^{197}$ In regard to the latter, it has been shown that an intact ectodomain of the E-cadherin protein is required for regulation of RTK-mediated signaling and, as this domain is cleaved by matrix metalloproteinase 7 (MMP-7), this might be an interesting target to investigate, and could explain the high activity of c-Met and EGFR in chordoma. ${ }^{198,199}$ 
In addition to cadherins, most of the studies carried out on CAMs in chordoma also focus on the immunoglobulin superfamily of cell adhesion molecules (IgCAMs). This family consists of complex transmembrane proteins capable of multiple molecular interactions mediated by expression of repeated immunoglobulin-like domain at their extracellular $\mathrm{N}$-termini. ${ }^{200}$ Neural CAM1 (NCAM1), as a member of the IgCAMs that primarily mediate hemophilic interactions, is frequently expressed in chordoma where it can be witnessed on immunohistochemical analysis in 75-93\% of cases. ${ }^{79,80,195}$ Horiguchi et al. ${ }^{80}$ demonstrated, in addition to NCAM, the immunoreactivity of other members of IgCAMs: vascular CAM (VCAM) and intracellular CAM (ICAM), and showed a far less frequent involvement in $56 \%$ and $25 \%$ of the immunostained cases respectively. Moreover, the authors illustrate NCAM and not ICAM or VCAM to be present in the early notochord, suggesting a possible reactivation. However the underlying consequences in terms of morphology, cell growth or clinical parameters has not yet been investigated. Even so, considerable evidence in the literature implicates NCAM in the activation of FGFR, which is shown to be frequently expressed in chordoma. ${ }^{201-205}$ Furthermore, new insight has been gained into the potential crosstalk between NCAM and EGFR in mammals, which might also account for the overexpression of the latter in chordogenesis. ${ }^{206}$ Thus, experimental studies addressing these interactions in chordoma might offer interesting new perspectives.

The adhesion of cells to each other and to the extracellular matrix can be explained by the altered expression of other CAM subfamilies, including intergrins, selectins and cartilage-linked proteins. However, as yet there are no in depth studies concerning their function in chordoma, evidence for the involvement of some members (CD44 ${ }^{80}$, integrin $\beta 4^{207}$ and $\mathrm{CD} 24^{58,207}$ ) has been reported. In addition, and also in line with the altered expression of cell adhesion molecules, changed expression matrix metalloproteinases (MMPs) and other proteases in chordoma have sparked the interest of several investigators, as chordomas are known for their locally aggressive and invasive character, and even if infrequent, have a known metastatic potential. ${ }^{208}$ Generally, from the tumor cells' point of view, the ability to degrade and destroy extracellular matrix is very important because it provides a mechanism to divide while being embedded in a matrix. Additionally, it enables tumor cells to pass through this barrier. MMPs belonging to a family of highly conserved zinc atom-dependent endopeptidases are known to fulfill such roles. Currently, more than twenty family members have been identified, but the gelatinases MMP-2 and MMP-9 are particularly interesting for chordoma research. These members have been implicated in the tumor biology of several epithelial tumors, and have been shown to be of prognostic significance, signifying the potential presence in chordoma. ${ }^{209-216}$ Indeed, in chordoma, high levels of MMP-2 expression have been shown by Naka et al. to relate to a significant decrease in overall survival. ${ }^{217,218}$ In addition, this expression was shown to be more enhanced in primary lesions at sites where bone infiltration of the tumor was noticed. On the other hand, expression of the other gelatinase, MMP-9, has been described to be limited to only a few cells for a small number of cases. Although these cells were also observed by the authors near bone invasion fronts, 
the authors did not report on their possible prognostic significance. ${ }^{218}$ However, in a cohort of eleven patients, Rahmah et al. ${ }^{219}$ reported that ten (91\%) exhibited positive staining for MMP-9, and also showed high expression to be associated with recurrence within the first two years after the final treatment. No such relation was found for MMP-2, for which expression was noticed in six (55\%) of the cases. Other authors confirmed the prognostic significance of MMP-9, as patients harboring an immune-positive sacral chordoma revealed a significantly shorter continuous disease-free survival time. ${ }^{20,221}$ Besides these gelatinases, other proteinases of the MMP family (MMP-1) - cysteine proteinases (cathepsin B and K) and serine proteinases (urokinase plasminogen activator (UPA)) - appear to be implicated in chordoma, and all illustrate an increased expression at the bone invasive fronts, suggesting the involvement of multiple enzymes in the invasive character of chordomas. ${ }^{218,222}$ This is corroborated by the finding that high expression of both MMP-1 and UPA are related to a significantly worse prognosis for survival.

However, to date, an explanation for the overexpression of these proteinases is still lacking, as attempts to prove a significant downregulation of the tissue inhibitors of metalloproteinases (TIMP-1 and TIMP-2) and plasminogen activator inhibitor type 1 (PAI1) at the same areas of bone infiltration only demonstrate a non-significant trend. Regulatory intra- or extracellular factors responsible for the altered expression of proteinases and their inhibitors thus seem attractive investigative targets. Further investigation of the RTKs and their downstream pathway might offer new insights, since high expression of c-Met in chordoma significantly correlates with MMP-1 and $-2 .^{223}$

Altogether, it seems that increasing evidence points to an intricate but close relationship between cell adhesion molecules, proteinases, and RTKs. Inhibition of one might therefore also have an effect on the mode by which another exerts its cellular effect.

\subsection{Epigenetics and the formation of chordoma}

Epigenetics, a process by which gene expression is modified irrespectively of changes in the primary genomic sequence, has received increasing attention in many areas of research. This dynamic process entails a broad range of components, including DNA-methylation and non-coding RNA expression, which are recognized as important contributors in tumor formation. ${ }^{224}$ DNA-methylation, a biochemical alteration of distinct regions on the gene, so called CpG islands, is held responsible for phenotypic changes in the cell, such as morphologic conversions and increased proliferation rates. In relation to chordoma, Longoni et al., ${ }^{225}$ reported the methylation status of the TNFRSF8 gene in thirteen specimens, and found seven to have methylated DNA that correlated with transcriptional silencing of the gene. This association was not observed for the methylation status in the promotor region of the tumor suppressor proteins CDNK2A and PTEN. In the chordoma patients investigated by Le et al., ${ }^{226}$ the authors observed a methylated DNA sequence in two and four of the fifteen cases for CDNK2A and PTEN, respectively. However, the authors illustrate that loss of protein 
expression could be attributed to loss of chromosomal regions containing the gene transcript rather than the methylation status.

Next to DNA methylation, the well-established inhibitory process, known as RNA interference (RNAi), is based on the presence of endogenous non-coding micro-RNA (miRNA) fragments that bind and consequently impede target messenger RNA (mRNA) expression. Using miRNA microarray technology, Duan et al. ${ }^{227}$ analyzed differentially expressed miRNA's in chordoma specimens and cell lines and compared them to the expression in skeletal muscle. They found a different set of miRNA to be either up- or downregulated, with one of the most promising downregulated miRNA being miRNA-1. MiRNA-1 knockdown was then validated and subsequently demonstrated to have a significant effect on the cell growth of the UCH1 cells as transfection of miRNA-1 into these cells inhibited the growth rate substantially. In addition, the authors showed that downstream targets of miRNA-1, MET and HDAC4 were overexpressed and reacted in a dose-dependent manner. However, further studies are warranted to evaluate the potential of miRNA-1 as a therapeutic target.

\section{Discussion}

Research unraveling the mechanisms underlying the initiation and further progression of chordoma cells has gained substantial interest in the last decade. As time progresses, accumulating evidence supports the notion of a notochordal origin of chordoma. Even so, only limited progress has been achieved in discovering the presence and function of embryologically active proteins in chordoma. Research focusing on brachyury, one of the most promising and recently found markers in chordoma, has revealed this transcription factor to be a crucial aspect of chordoma, and highlights the impact of such embryological factors in the pathophysiology of chordoma. As we reviewed the importance of some other notochordal factors (SHH, Wnt, Galectin-3, NCAM) with regards to their effect in notochord formation and in chordoma, we would like to emphasize that more functional studies are required to gain a better understanding of their existence and interactive roles. Other, previously discovered molecular pathways involved in this tumor include the overexpression of cell cycle regulatory pathways and an activated receptor tyrosine kinase-pathway (Fig. 2). With regards to the former, expression of p53 and the loss of the CDKN2A gene have been related to a worse prognostic clinical course. However, no functional implication has been proposed for these aberrations in the tumorigenesis of chordoma and they may be a frequent result of tumor progression. More recent data have been collected on receptor tyrosine kinases and their downstream signaling pathway, which are shown to play a role in the pathophysiology of chordoma. Inhibition of the activity of these receptors via pharmacological interference (imatinib mesylate, erlotinib, cetuximab, gefitinib) has shown promising results in a small cohort of studies. However, as these receptor tyrosine kinase inhibitors are impeding the activity of multiple RTKs, it might be interesting to examine the phenotype of (non)respon- 


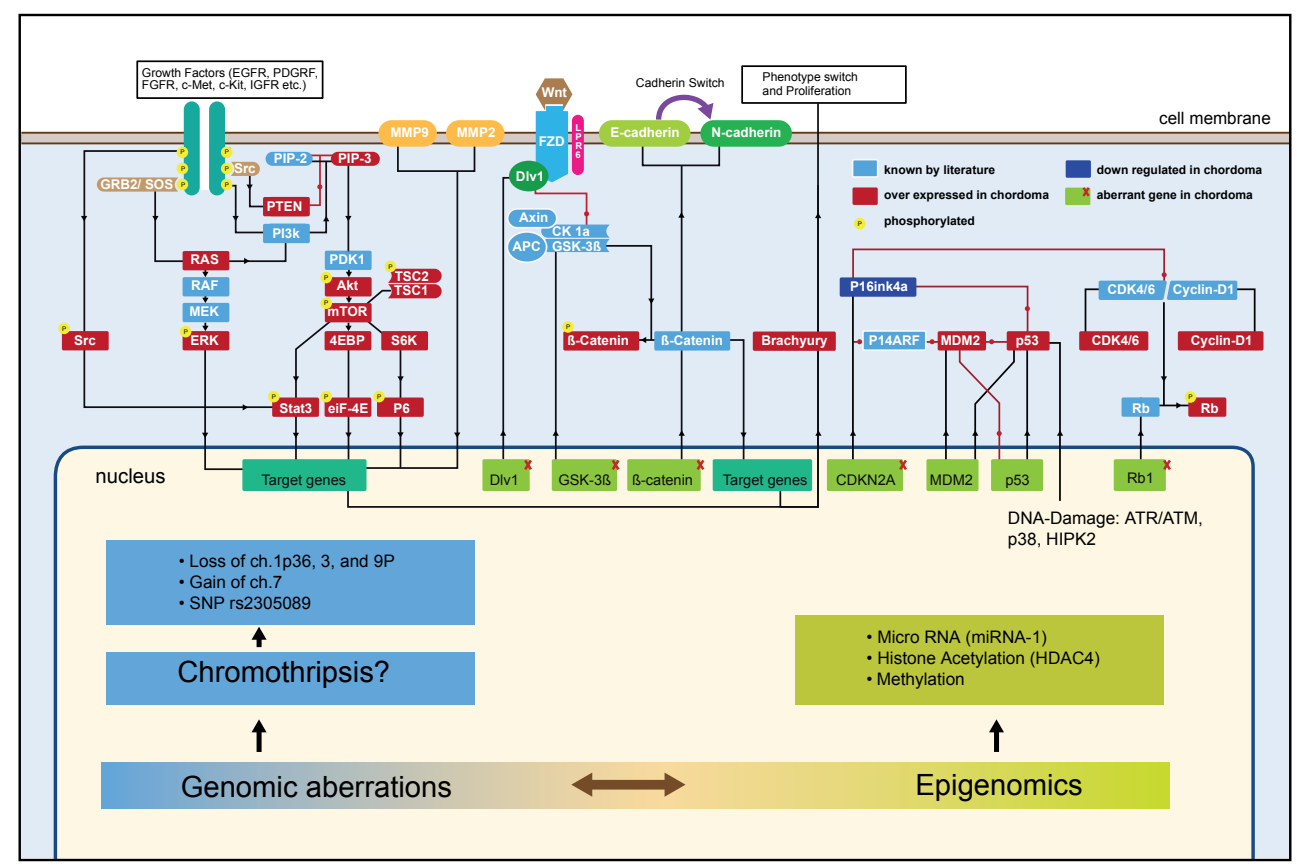

Fig. 2. A simplified overview of the molecular cell biology of a chordoma cell.

ding patients with respect to the expression of a particular member of this protein family. The use of patient selection with such an approach would improve clinical management significantly. In line with this patient-tailored management are the multiple genome-wide and karyotype integrity studies that are becoming more widespread. Here, the chordoma karyotype seems to be frequently altered in very heterogeneous manner, with amplifications of chromosome 7 and deletions of chromosome $1 p$ and $3 p$ as the most stable observations. These karyotype changes might be due to an overexpression of the hTERT protein or a recently suggested phenomenon called chromothripsis. However, as several studies report an overexpression on the RNA or protein level with an unaltered genetic sequence, evaluation of the epigenetic changes in chordoma are becoming increasingly attractive. Expression of miRNA-1 has shown to be a potent inhibitor of the proliferative capacity of chordoma cells. Additional experiments which are dedicated to other epigenetic regulations of transcription (acetylation, methylation etc) are required to fully comprehend the biology of this disease.

\section{Conclusion}

Chordomas are shown to be a management challenge, requiring multimodal therapy with a poor overall survival. The pathophysiology underlying this lethal disease is demonstrated to be complex. Molecular research has so far yielded significant findings, with the most 
prominent being the discovery of Brachyury's involvement in this disease. Future fundamental research would benefit from the discovery of other associated embryological markers, as more evidence is gathered supporting a notochordal origin for chordoma. In addition to brachyury, other promising targets have been identified to be crucial in chordomagenesis. However, as the genetic sequence is inconsistently altered, epigenetic changes are an exciting and relatively unexplored field of research in chordoma. 


\section{References}

1. Smoll, N.R., Gautschi, O.P., Radovanovic, I., Schaller, K. \& Weber, D.C. Incidence and relative survival of chordomas: the standardized mortality ratio and the impact of chordomas on a population. Cancer 119, 2029-2037 (2013).

2. Casali, P.G., Stacchiotti, S., Sangalli, C., Olmi, P. \& Gronchi, A. Chordoma. Curr Opin Oncol 19, 367-370 (2007).

3. Amichetti, M., Cianchetti, M., Amelio, D., Enrici, R.M. \& Minniti, G. Proton therapy in chordoma of the base of the skull: a systematic review. Neurosurg Rev 32, 403-416 (2009).

4. Staab, A., et al. Spot-Scanning-Based Proton Therapy for Extracranial Chordoma. Int J Radiat Oncol Biol Phys (2011).

5. Dorfman, H.D. \& Czerniak, B. Bone cancers. Cancer 75, 203-210 (1995).

6. McMaster, M.L., Goldstein, A.M., Bromley, C.M., Ishibe, N. \& Parry, D.M. Chordoma: incidence and survival patterns in the United States, 1973-1995. Cancer Causes Control 12, 1-11 (2001).

7. Mukherjee, D., et al. Survival of patients with malignant primary osseous spinal neoplasms: results from the Surveillance, Epidemiology, and End Results (SEER) database from 1973 to 2003. J Neurosurg Spine 14, 143-150 (2011).

8. Jacob, H.E. Chemotherapy for cranial base tumors. Journal of Neuro-Oncology 20, 327-335 (1994).

9. Luschka, H. Die Altersveränderungen der Zwischenwirbelknorpel. Virchows Arch A Pathol Anat Histol. 9, 311-327 (1856).

10. Muller, H. Uber das Vorkommen von Resten der Chorda dorsalis bei Menschen nach der Geburt und uber ihr Verhaltnis zu den Gallert-geschwulsten am Clivus. Ztschr f. rat. Med 2202(1858).

11. Kyriakos, M., Totty, W.G. \& Lenke, L.G. Giant vertebral notochordal rest: a lesion distinct from chordoma: discussion of an evolving concept. Am J Surg Pathol 27, 396-406 (2003).

12. Schoenwolf, G.C. \& Larsen, W.J. Third week: becomming trilaminar and establishing body axis. in Larsen's human embryology. (/Elsevier/Churchill Livingstone, Philadelphia, 2009).

13. Bumcrot, D.A. \& McMahon, A.P. Somite differentiation. Sonic signals somites. Curr Biol 5, 612614 (1995).

14. Liem, K.F., Jr., Jessell, T.M. \& Briscoe, J. Regulation of the neural patterning activity of sonic hedgehog by secreted BMP inhibitors expressed by notochord and somites. Development 127 , 4855-4866 (2000).

15. Stemple, D.L. Structure and function of the notochord: an essential organ for chordate development. Development 132, 2503-2512 (2005).

16. Salisbury, J.R. \& Isaacson, P.G. Demonstration of cytokeratins and an epithelial membrane antigen in chordomas and human fetal notochord. Am J Surg Pathol 9, 791-797 (1985).

17. Pourquie, O., Coltey, M., Teillet, M.A., Ordahl, C. \& Le Douarin, N.M. Control of dorsoventral patterning of somitic derivatives by notochord and floor plate. Proc Natl Acad Sci U S A 90, 5242 5246 (1993).

18. Claudio, D.S. Grafting of somites. Methods Mol Biol 461, 277-287 (2008).

19. Dietrich, S., Schubert, F.R. \& Gruss, P. Altered Pax gene expression in murine notochord mutants: the notochord is required to initiate and maintain ventral identity in the somite. Mech Dev 44, 189-207 (1993).

20. Alvares, L.E., Lours, C., El-Hanfy, A. \& Dietrich, S. Microsurgical manipulation of the notochord. Methods Mol Biol 461, 289-303 (2008).

21. Resende, T.P., et al. Sonic hedgehog in temporal control of somite formation. Proc Natl Acad Sci U S A 107, 12907-12912 (2010). 
22. Fleming, A., Keynes, R.J. \& Tannahill, D. The role of the notochord in vertebral column formation. J Anat 199, 177-180 (2001).

23. Moore, K.L., Persaud, T.V.N. \& Torchia, M.G. The developing human : clinically oriented embryology, (Saunders/Elsevier, Philadelphia, PA, 2008).

24. Bogduk, N. Embryology and development. in Clinical anatomy of the lumbar spine and sacrum p.149-163 (Elsevier/Churchill Livingstone, Edinburgh, 2005).

25. Christ, B., Huang, R. \& Scaal, M. Formation and differentiation of the avian sclerotome. Anat Embryol (Berl) 208, 333-350 (2004).

26. Rodrigo, I., Hill, R.E., Balling, R., Munsterberg, A. \& Imai, K. Pax1 and Pax9 activate Bapx1 to induce chondrogenic differentiation in the sclerotome. Development 130, 473-482 (2003).

27. Oka, Y., et al. Epimorphin acts extracellularly to promote cell sorting and aggregation during the condensation of vertebral cartilage. Dev Biol 291, 25-37 (2006).

28. Kim, K.W., et al. The origin of chondrocytes in the nucleus pulposus and histologic findings associated with the transition of a notochordal nucleus pulposus to a fibrocartilaginous nucleus pulposus in intact rabbit intervertebral discs. Spine (Phila Pa 1976) 28, 982-990 (2003).

29. Aszodi, A., Chan, D., Hunziker, E., Bateman, J.F. \& Fassler, R. Collagen II is essential for the removal of the notochord and the formation of intervertebral discs. J Cell Biol 143, 1399-1412 (1998).

30. Gilbert, S.F. DEVELOPMENTAL BIOLOGY, (SINAUER ASSOCIATES, Sunderland, 2010).

31. Guehring, T., Nerlich, A., Kroeber, M., Richter, W. \& Omlor, G.W. Sensitivity of notochordal disc cells to mechanical loading: an experimental animal study. Eur Spine J 19, 113-121 (2010).

32. Hunter, C.J., Matyas, J.R. \& Duncan, N.A. The notochordal cell in the nucleus pulposus: a review in the context of tissue engineering. Tissue Eng 9, 667-677 (2003).

33. Horwitz, T. The human notochord: A study of its development and regression, variations, and pathologic derivative, chordoma. (1977).

34. Peacock, A. Observations on the postnatal structure of the intervertebral disc in man. J Anat 86, 162-179 (1952).

35. Nishiguchi, T., Mochizuki, K., Tsujio, T., Nishita, T. \& Inoue, Y. Lumbar vertebral chordoma arising from an intraosseous benign notochordal cell tumour: radiological findings and histopathological description with a good clinical outcome. Br J Radiol 83, e49-53 (2010).

36. Yamaguchi, T., Suzuki, S., Ishiiwa, H. \& Ueda, Y. Intraosseous benign notochordal cell tumours: overlooked precursors of classic chordomas? Histopathology 44, 597-602 (2004).

37. Yamaguchi, T., Yamato, M. \& Saotome, K. First histologically confirmed case of a classic chordoma arising in a precursor benign notochordal lesion: differential diagnosis of benign and malignant notochordal lesions. Skeletal Radiol 31, 413-418 (2002).

38. Amer, H.Z. \& Hameed, M. Intraosseous benign notochordal cell tumor. Arch Pathol Lab Med 134, 283-288 (2010).

39. Shen, J., et al. Classic chordoma coexisting with benign notochordal cell rest demonstrating different immunohistological expression patterns of brachyury and galectin-3. J Clin Neurosci 18, 96-99 (2011).

40. Belden, C.J. The skull base and calvaria. Adult and pediatric. Neuroimaging Clin N Am 8, 1-20 (1998).

41. Scheuer, L. \& Black, S.M. Developmental juvenile osteology. p36-171 (Academic Press, San Diego, Calif. ; London, 2000).

42. Young, B., et al. Indian and sonic hedgehogs regulate synchondrosis growth plate and cranial base development and function. Dev Biol 299, 272-282 (2006).

43. Stewart, M.J. \& Burrow, J.L.F. ECCHORDOSIS PHYSALIPHORA SPHENO-OCCIPITALIS. The Journal of Neurology and Psychopathology s1-4, 218-220 (1923). 
44. Wyatt, R.B., Schochet, S.S., Jr. \& McCormick, W.F. Ecchordosis physaliphora. An electron microscopic study. J Neurosurg 34, 672-677 (1971).

45. Luschka, H. Ueber gallertartige Auswüchse am Clivus Blumenbachii. Archiv f. pathol. Anat. 11, 8-12 (1857).

46. Virchow, R. Untersuchungen uber die Entwickelung des Schadelgrundes im gesunden und krankhaften Zustande, und uber den Einfluss derselben auf Schadelform, Gesichtsbildung und Gehirnbau. . G. Rimer, Berlin, p. 47 (1857).

47. Ribbert, H. Uber die Eccondrosis physaliphora spheno-occipitalis. Zertralbl. f. allg. Path. u. Path. Anat. 5457(1894).

48. Ribbert, H. Uber die experimentalle Erzeugung einer Eccondrosis physaliphora. Verhandl. d. Kong. f. Inh. Med 13, 455 (1895).

49. Horwitz, T. Chordal ectopia and its possible relation to chordoma. Arch Pathol 31 354-356 (1941).

50. Mehnert, F., Beschorner, R., Kuker, W., Hahn, U. \& Nagele, T. Retroclival ecchordosis physaliphora: MR imaging and review of the literature. AJNR Am J Neuroradiol 25, 1851-1855 (2004).

51. Krisht, K.M., Palmer, C.A., Osborn, A.G. \& Couldwell, W.T. Giant ecchordosis physaliphora in an adolescent girl. Journal of Neurosurgery: Pediatrics 12, 328-333 (2013).

52. Ciarpaglini, R., et al. Intradural clival chordoma and ecchordosis physaliphora: a challenging differential diagnosis: case report. Neurosurgery 64, E387-388; discussion E388 (2009).

53. Macdonald, R.L. \& Deck, J.H. Immunohistochemistry of ecchordosis physaliphora and chordoma. The Canadian journal of neurological sciences. Le journal canadien des sciences neurologiques 17, 420-423 (1990).

54. Rosenberg, A.E., Brown, G.A., Bhan, A.K. \& Lee, J.M. Chondroid chordoma--a variant of chordoma. A morphologic and immunohistochemical study. American journal of clinical pathology 101, 3641 (1994).

55. Gibbs, C.P., et al. Stem-like cells in bone sarcomas: implications for tumorigenesis. Neoplasia 7, 967-976 (2005).

56. Schatton, T. \& Frank, M.H. The In Vitro Spheroid Melanoma Cell Culture Assay: Cues on Tumor Initiation[quest]. J Invest Dermatol 130, 1769-1771 (2010).

57. Hsu, W., et al. Identification of Cancer Stem Cells in Human Chordoma in 27th annual meeting of the AANS/CNS section on disorders of the spine and peripheral nerves. (2011).

58. Vujovic, S., et al. Brachyury, a crucial regulator of notochordal development, is a novel biomarker for chordomas. J Pathol 209, 157-165 (2006).

59. Sangoi, A.R., et al. Specificity of brachyury in the distinction of chordoma from clear cell renal cell carcinoma and germ cell tumors: a study of 305 cases. Mod Pathol 24, 425-429 (2011).

60. Oakley, G.J., Fuhrer, K. \& Seethala, R.R. Brachyury, SOX-9, and podoplanin, new markers in the skull base chordoma vs chondrosarcoma differential: a tissue microarray-based comparative analysis. Mod Pathol 21, 1461-1469 (2008).

61. Palena, C., et al. The human T-box mesodermal transcription factor Brachyury is a candidate target for T-cell-mediated cancer immunotherapy. Clin Cancer Res 13, 2471-2478 (2007).

62. Hayashi, T., et al. Cytopathologic features of orbital intraosseous chordoid meningioma: report of a case and distinction from other myxoid/mucoid tumors. Diagn Cytopathol 38, 818-821 (2010).

63. O'Donnell, P., et al. Diagnosing an extra-axial chordoma of the proximal tibia with the help of brachyury, a molecule required for notochordal differentiation. Skeletal Radiol 36, 59-65 (2007). 
64. Shen, J., et al. Classic chordoma coexisting with benign notochordal cell rest demonstrating different immunohistological expression patterns of brachyury and galectin-3. J Clin Neurosci (2010).

65. Tirabosco, R., et al. Brachyury expression in extra-axial skeletal and soft tissue chordomas: a marker that distinguishes chordoma from mixed tumor/myoepithelioma/parachordoma in soft tissue. Am J Surg Pathol 32, 572-580 (2008).

66. Presneau, N., et al. Role of the transcription factor $\mathrm{T}$ (brachyury) in the pathogenesis of sporadic chordoma: a genetic and functional-based study. The Journal of Pathology 223, 327-335 (2011).

67. Hsu, W., et al. Generation of Chordoma Cell Line, JHC7, and the Identification of Brachyury as a Novel Molecular Target. in 27th annual meeting of the AANS/CNS section on disorders of the spine and peripheral nerves. (2011).

68. Shalaby, A.A., et al. Analysis of the fibroblastic growth factor receptor-RAS/RAF/MEK/ERK-ETS2/ brachyury signalling pathway in chordomas. Mod Pathol 22, 996-1005 (2009).

69. Gotz, W., Kasper, M., Miosge, N. \& Hughes, R.C. Detection and distribution of the carbohydrate binding protein galectin-3 in human notochord, intervertebral disc and chordoma. Differentiation; research in biological diversity 62, 149-157 (1997).

70. ENDO, K., et al. Galectin-3 Expression is a Potent Prognostic Marker in Colorectal Cancer. Anticancer Research 25, 3117-3121 (2005).

71. Buljan, M., Šitum, M., Tomas, D., Milošević, M. \& Krušlin, B. Prognostic value of galectin-3 in primary cutaneous melanoma. Journal of the European Academy of Dermatology and Venereology 25, 1174-1181 (2011).

72. Ukita, K., et al. Wnt signaling maintains the notochord fate for progenitor cells and supports the posterior extension of the notochord. Mech Dev 126, 791-803 (2009).

73. Morin, P.J. $\beta$-catenin signaling and cancer. BioEssays 21, 1021-1030 (1999).

74. Nagayama, M., et al. Wnt/beta-catenin signaling regulates cranial base development and growth. J Dent Res 87, 244-249 (2008).

75. Yamaguchi, T.P., Takada, S., Yoshikawa, Y., Wu, N. \& McMahon, A.P. T (Brachyury) is a direct target of Wnt3a during paraxial mesoderm specification. Genes Dev 13, 3185-3190 (1999).

76. Vonica, A. \& Gumbiner, B.M. Zygotic Wnt activity is required for Brachyury expression in the early Xenopus laevis embryo. Dev Biol 250, 112-127 (2002).

77. Klaus, A. \& Birchmeier, W. Wht signalling and its impact on development and cancer. Nat Rev Cancer 8, 387-398 (2008).

78. Mosimann, C., Hausmann, G. \& Basler, K. [beta]-Catenin hits chromatin: regulation of Wnt target gene activation. Nat Rev Mol Cell Biol 10, 276-286 (2009).

79. Cho, H.Y., et al. Immunohistochemical comparison of chordoma with chondrosarcoma, myxopapillary ependymoma, and chordoid meningioma. Appl Immunohistochem Mol Morphol 17, 131-138 (2009).

80. Horiguchi, H., et al. Expression of cell adhesion molecules in chordomas: an immunohistochemical study of 16 cases. Acta Neuropathologica 107, 91-96 (2004).

81. Triana, A., Sen, C., Wolfe, D. \& Hazan, R. Cadherins and Catenins in Clival Chordomas: Correlation of Expression With Tumor Aggressiveness. The American Journal of Surgical Pathology 29, $1422-$ 1434 (2005).

82. Hendriksen, J., et al. Plasma membrane recruitment of dephosphorylated beta-catenin upon activation of the Wnt pathway. J Cell Sci 121, 1793-1802 (2008).

83. Wahl, J.K., 3rd, Kim, Y.J., Cullen, J.M., Johnson, K.R. \& Wheelock, M.J. N-cadherin-catenin complexes form prior to cleavage of the proregion and transport to the plasma membrane. J Biol Chem 278, 17269-17276 (2003). 
84. Riva, P., et al. Mapping of candidate region for chordoma development to $1 \mathrm{p} 36.13$ by LOH analysis. Int J Cancer 107, 493-497 (2003).

85. Weed, M., Mundlos, S. \& Olsen, B.R. The role of sonic hedgehog in vertebrate development. Matrix Biol 16, 53-58 (1997).

86. Katoh, Y. \& Katoh, M. Hedgehog target genes: mechanisms of carcinogenesis induced by aberrant hedgehog signaling activation. Curr Mol Med 9, 873-886 (2009).

87. Brandner, S. Nanog, Gli, and p53: a new network of stemness in development and cancer. EMBO J 29, 2475-2476 (2010).

88. Cates, J.M., Itani, D.M., Coffin, C.M. \& Harfe, B.D. The sonic hedgehog pathway in chordoid tumours. Histopathology 56, 978-979 (2010).

89. Miozzo, M., et al. A tumor suppressor locus in familial and sporadic chordoma maps to $1 \mathrm{p} 36$. Int J Cancer 87, 68-72 (2000).

90. Kelley, M.J., et al. Familial chordoma, a tumor of notochordal remnants, is linked to chromosome 7q33. Am J Hum Genet 69, 454-460 (2001).

91. Larizza, L., Mortini, P. \& Riva, P. Update on the cytogenetics and molecular genetics of chordoma. Hered Cancer Clin Pract 3, 29-41 (2005).

92. Yang, X.R., et al. T (brachyury) gene duplication confers major susceptibility to familial chordoma. Nat Genet 41, 1176-1178 (2009).

93. Almefty, K.K., Pravdenkova, S., Sawyer, J. \& Al-Mefty, O. Impact of cytogenetic abnormalities on the management of skull base chordomas. J Neurosurg 110, 715-724 (2009).

94. Gil, Z., et al. Cytogenetic analysis of three variants of clival chordoma. Cancer Genet Cytogenet $154,124-130$ (2004).

95. Hruban, R.H., Traganos, F., Reuter, V.E. \& Huvos, A.G. Chordomas with malignant spindle cell components. A DNA flow cytometric and immunohistochemical study with histogenetic implications. Am J Pathol 137, 435-447 (1990).

96. Kuzniacka, A., Mertens, F., Strombeck, B., Wiegant, J. \& Mandahl, N. Combined binary ratio labeling fluorescence in situ hybridization analysis of chordoma. Cancer Genet Cytogenet 151, 178-181 (2004).

97. Scheil, S., etal. Genome-wide analysis of sixteen chordomas by comparative genomic hybridization and cytogenetics of the first human chordoma cell line, U-CH1. Genes Chromosomes Cancer 32, 203-211 (2001).

98. Mitchell, A., et al. Chordoma and chondroid neoplasms of the spheno-occiput. An immunohistochemical study of 41 cases with prognostic and nosologic implications. Cancer 72 , 2943-2949 (1993).

99. Sawyer, J.R., Husain, M. \& Al-Mefty, O. Identification of isochromosome $1 q$ as a recurring chromosome aberration in skull base chordomas: a new marker for aggressive tumors? Neurosurg Focus 10, E6 (2001).

100. Colli, B.O. \& Al-Mefty, O. Chordomas of the skull base: follow-up review and prognostic factors. Neurosurg Focus 10, E1 (2001).

101. Bayrakli, F., Guney, I., Kilic, T., Ozek, M. \& Pamir, M.N. New candidate chromosomal regions for chordoma development. Surg Neurol 68, 425-430; discussion 430 (2007).

102. Brandal, P., Bjerkehagen, B., Danielsen, H. \& Heim, S. Chromosome 7 abnormalities are common in chordomas. Cancer Genet Cytogenet 160, 15-21 (2005).

103. Tallini, G., et al. Correlation between clinicopathological features and karyotype in 100 cartilaginous and chordoid tumours. A report from the Chromosomes and Morphology (CHAMP) Collaborative Study Group. J Pathol 196, 194-203 (2002). 
104. Schoedel, K.E., Martinez, A.J., Mahoney, T.M., Contis, L. \& Becich, M.J. Chordomas: pathological features; ploidy and silver nucleolar organizing region analysis. A study of 36 cases. Acta Neuropathol 89, 139-143 (1995).

105. Thompson, S.L., Bakhoum, S.F. \& Compton, D.A. Mechanisms of chromosomal instability. Curr Biol 20, R285-295 (2010).

106. Zhou, X.Z., et al. The telomerase inhibitor PinX1 is a major haploinsufficient tumor suppressor essential for chromosome stability in mice. J Clin Invest (2011).

107. Greenberg, R.A. Telomeres, crisis and cancer. Curr Mol Med 5, 213-218 (2005).

108. Gisselsson, D., et al. Telomere dysfunction triggers extensive DNA fragmentation and evolution of complex chromosome abnormalities in human malignant tumors. Proceedings of the National Academy of Sciences 98, 12683-12688 (2001).

109. Cui, W., et al. Stabilization of Telomere Length and Karyotypic Stability Are Directly Correlated with the Level of hTERT Gene Expression in Primary Fibroblasts. Journal of Biological Chemistry 277, 38531-38539 (2002).

110. Albanell, J., et al. High Telomerase Activity in Primary Lung Cancers: Association With Increased Cell Proliferation Rates and Advanced Pathologic Stage. Journal of the National Cancer Institute 89, 1609-1615 (1997).

111. Papadopoulou, A., et al. Telomerase activity and genetic alterations in primary breast carcinomas. Neoplasia 5, 170-178 (2003).

112. Izumi, H., et al. High telomerase activity correlates with the stabilities of genome and DNA ploidy in renal cell carcinoma. Neoplasia 4, 103-111 (2002).

113. Aue, G., Muralidhar, B., Schwartz, H.S. \& Butler, M.G. Telomerase activity in skeletal sarcomas. Ann Surg Oncol 5, 627-634 (1998).

114. Butler, M.G., et al. Cytogenetic, telomere, and telomerase studies in five surgically managed lumbosacral chordomas. Cancer Genet Cytogenet 85, 51-57 (1995).

115. Butler, M.G., Sciadini, M., Hedges, L.K. \& Schwartz, H.S. Chromosome telomere integrity of human solid neoplasms. Cancer Genet Cytogenet 86, 50-53 (1996).

116. Pallini, R., et al. Chordoma of the skull base: predictors of tumor recurrence. J Neurosurg 98 , 812-822 (2003).

117. Ricci-Vitiani, L., et al. Establishing tumor cell lines from aggressive telomerase-positive chordomas of the skull base. Technical note. J Neurosurg 105, 482-484 (2006).

118. Stephens, P.J., et al. Massive Genomic Rearrangement Acquired in a Single Catastrophic Event during Cancer Development. Cell 144, 27-40 (2011).

119. Lane, D.P. Cancer. p53, guardian of the genome. Nature 358, 15-16 (1992).

120. Vousden, K.H. \& Lu, X. Live or let die: the cell's response to p53. Nat Rev Cancer 2, 594-604 (2002).

121. Soussi, T. The p53 tumor suppressor gene: from molecular biology to clinical investigation. Ann N Y Acad Sci 910, 121-137; discussion 137-129 (2000).

122. Naka, T., et al. Alterations of G1-S checkpoint in chordoma: the prognostic impact of p53 overexpression. Cancer 104, 1255-1263 (2005).

123. Horbinski, C., et al. The prognostic value of Ki-67, p53, epidermal growth factor receptor, 1p36, 9p21, 10q23, and 17p13 in skull base chordomas. Arch Pathol Lab Med 134, 1170-1176 (2010).

124. Kilgore, S. \& Prayson, R.A. Apoptotic and proliferative markers in chordomas: a study of 26 tumors. Ann Diagn Pathol 6, 222-228 (2002).

125. Matsuno, A., et al. Immunohistochemical examination of proliferative potentials and the expression of cell cycle-related proteins of intracranial chordomas. Hum Pathol 28, 714-719 (1997). 
126. Naka, T., et al. Proliferative activities in conventional chordoma: a clinicopathologic, DNA flow cytometric, and immunohistochemical analysis of 17 specimens with special reference to anaplastic chordoma showing a diffuse proliferation and nuclear atypia. Hum Pathol 27, 381388 (1996).

127. Bergh, P., et al. Prognostic factors in chordoma of the sacrum and mobile spine: a study of 39 patients. Cancer 88, 2122-2134 (2000).

128. Wynford-Thomas, D. P53 in tumour pathology: can we trust immunocytochemistry? J Pathol 166, 329-330 (1992).

129. Manfredi, J.J. The Mdm2-p53 relationship evolves: Mdm2 swings both ways as an oncogene and a tumor suppressor. Genes Dev 24, 1580-1589 (2010).

130. Cordon-Cardo, C., et al. Molecular abnormalities of $\mathrm{mdm} 2$ and $\mathrm{p} 53$ genes in adult soft tissue sarcomas. Cancer Res 54, 794-799 (1994).

131. Sasaki, M., Nie, L. \& Maki, C.G. MDM2 binding induces a conformational change in $\mathrm{p} 53$ that is opposed by heat-shock protein 90 and precedes p53 proteasomal degradation. J Biol Chem 282, 14626-14634 (2007).

132. Qiu, W., et al. Retinoblastoma protein modulates gankyrin-MDM2 in regulation of p53 stability and chemosensitivity in cancer cells. Oncogene 27, 4034-4043 (2008).

133. Weinberg, R.A. The retinoblastoma protein and cell cycle control. Cell 81, 323-330 (1995).

134. Ragland, B.D., Bell, W.C., Lopez, R.R. \& Siegal, G.P. Cytogenetics and Molecular Biology of Osteosarcoma. Lab Invest 82, 365-373 (2002).

135. Liu, H., Dibling, B., Spike, B., Dirlam, A. \& Macleod, K. New roles for the RB tumor suppressor protein. Current Opinion in Genetics \& Development 14, 55-64 (2004).

136. Myong, N.H. Cyclin D1 overexpression, p16 loss, and pRb inactivation play a key role in pulmonary carcinogenesis and have a prognostic implication for the long-term survival in nonsmall cell lung carcinoma patients. Cancer Res Treat 40, 45-52 (2008).

137. Eisenberg MB, W.M., Sen C, Wolfe D. Loss of Heterozygosity in the Retinoblastoma Tumor Suppressor Gene in Skull Base Chordomas and Chondrosarcomas. Surgical Neurology 47, 156160 (1997).

138. Romagosa, C., et al. p16Ink4a overexpression in cancer: a tumor suppressor gene associated with senescence and high-grade tumors. Oncogene (2011).

139. Hallor, K.H., et al. Frequent deletion of the CDKN2A locus in chordoma: analysis of chromosomal imbalances using array comparative genomic hybridisation. Br J Cancer 98, 434-442 (2008).

140. Sommer, J., et al. Methylthioadenosine phosphorylase and activated insulin-like growth factor-1 receptor/insulin receptor: potential therapeutic targets in chordoma. J Pathol 220, 608-617 (2010).

141. Presneau, N., et al. Potential therapeutic targets for chordoma: PI3K/AKT/TSC1/TSC2/mTOR pathway. Br J Cancer 100, 1406-1414 (2009).

142. Thoms, H.C., Dunlop, M.G. \& Stark, L.A. CDK4 inhibitors and apoptosis: a novel mechanism requiring nucleolar targeting of RelA. Cell Cycle 6, 1293-1297 (2007).

143. Alberts, B. Mechanism of cell communication. in Molecular biology of the cell. p.879-964 (Garland Science, New York, 2008).

144. Bennasroune, A., Gardin, A., Aunis, D., Crémel, G. \& Hubert, P. Tyrosine kinase receptors as attractive targets of cancer therapy. Critical Reviews in Oncology/Hematology 50, 23-38 (2004).

145. Fasig, J.H., Dupont, W.D., LaFleur, B.J., Olson, S.J. \& Cates, J.M. Immunohistochemical analysis of receptor tyrosine kinase signal transduction activity in chordoma. Neuropathol Appl Neurobiol 34, 95-104 (2008). 
146. Orzan, F., et al. Expression study of the target receptor tyrosine kinase of Imatinib mesylate in skull base chordomas. Oncol Rep 18, 249-252 (2007).

147. Stacchiotti, S., et al. Imatinib mesylate in advanced chordoma: A multicenter phase II study. Journal of Clinical Oncology ASCO Annual Meeting Proceedings Part I. Vol 25(2007).

148. Tamborini, E., et al. Molecular and biochemical analyses of platelet-derived growth factor receptor (PDGFR) B, PDGFRA, and KIT receptors in chordomas. Clin Cancer Res 12, 6920-6928 (2006).

149. Tamborini, E., et al. Analysis of receptor tyrosine kinases (RTKs) and downstream pathways in chordomas. Neuro Oncol 12, 776-789 (2010).

150. Walter, B.A., et al. Gain of chromosome 7 by chromogenic in situ hybridization (CISH) in chordomas is correlated to c-MET expression. J Neurooncol (2010).

151. Weinberger, P.M., et al. Differential expression of epidermal growth factor receptor, c-Met, and HER2/neu in chordoma compared with 17 other malignancies. Arch Otolaryngol Head Neck Surg 131, 707-711 (2005).

152. Ostroumov, E. \& Hunter, C.J. Identifying mechanisms for therapeutic intervention in chordoma: c-Met oncoprotein. Spine (Phila Pa 1976) 33, 2774-2780 (2008).

153. Caron, E., et al. A comprehensive map of the mTOR signaling network. Mol Syst Biol 6(2010).

154. Shalaby, A., et al. The role of epidermal growth factor receptor in chordoma pathogenesis: a potential therapeutic target. J Pathol (2010).

155. Davies, H., et al. Mutations of the BRAF gene in human cancer. Nature 417, 949-954 (2002).

156. Wan, P.T.C., et al. Mechanism of Activation of the RAF-ERK Signaling Pathway by Oncogenic Mutations of B-RAF. Cell 116, 855-867 (2004).

157. Cully, M., You, H., Levine, A.J. \& Mak, T.W. Beyond PTEN mutations: the PI3K pathway as an integrator of multiple inputs during tumorigenesis. Nat Rev Cancer 6, 184-192 (2006).

158. SCHWAB, J., et al. Combination of $\mathrm{PI3K} / \mathrm{mTOR}$ Inhibition Demonstrates Efficacy in Human Chordoma. Anticancer Research 29, 1867-1871 (2009).

159. Kuemmerle, J.F. Endogenous IGF-I protects human intestinal smooth muscle cells from apoptosis by regulation of GSK-3 $\beta$ activity. American Journal of Physiology - Gastrointestinal and Liver Physiology 288, G101-G110 (2005).

160. Cheong, J.W., et al. Phosphatase and tensin homologue phosphorylation in the C-terminal regulatory domain is frequently observed in acute myeloid leukaemia and associated with poor clinical outcome. Br J Haematol 122, 454-456 (2003).

161. Bilanges, B. \& Vanhaesebroeck, B. A new tool to dissect the function of p70 56 kinase. Biochem J 431, e1-3 (2010).

162. Montagne, J., et al. Drosophila S6 Kinase: A Regulator of Cell Size. Science 285, 2126-2129 (1999).

163. Han, S., et al. Aberrant hyperactivation of akt and Mammalian target of rapamycin complex 1 signaling in sporadic chordomas. Clin Cancer Res 15, 1940-1946 (2009).

164. Zhou, J., et al. Activation of the PTEN/mTOR/STAT3 pathway in breast cancer stem-like cells is required for viability and maintenance. Proceedings of the National Academy of Sciences 104, 16158-16163 (2007).

165. Yang, C., et al. A novel target for treatment of chordoma: signal transducers and activators of transcription 3. Mol Cancer Ther 8, 2597-2605 (2009).

166. Yang, C., et al. Blockage of Stat3 With CDDO-Me Inhibits Tumor Cell Growth in Chordoma. Spine (Phila Pa 1976) 35, 1668-1675 (2010).

167. Hsieh, A.C. \& Ruggero, D. Targeting Eukaryotic Translation Initiation Factor 4E (elF4E) in Cancer. Clinical Cancer Research 16, 4914-4920 (2010). 
168. Lu, Y., et al. Src Family Protein-tyrosine Kinases Alter the Function of PTEN to Regulate Phosphatidylinositol 3-Kinase/AKT Cascades. Journal of Biological Chemistry 278, 40057-40066 (2003).

169. Li, A.G., et al. Mechanistic Insights into Maintenance of High p53 Acetylation by PTEN. Molecular Cell 23, 575-587 (2006).

170. Freeman, D.J., et al. PTEN tumor suppressor regulates p53 protein levels and activity through phosphatase-dependent and -independent mechanisms. Cancer Cell 3, 117-130 (2003).

171. Chan, J.A., et al. Pathogenesis of tuberous sclerosis subependymal giant cell astrocytomas: biallelic inactivation of TSC1 or TSC2 leads to mTOR activation. J Neuropathol Exp Neurol 63, 1236-1242 (2004).

172. Kimmell, K.T., Dayoub, H., Stolzenberg, E.D. \& Sincoff, E.H. Chordoma in the lateral medullary cistern in a patient with tuberous sclerosis: A case report and review of the literature. Surg Neurol Int 1, 13 (2010).

173. Borgel, J., Olschewski, H., Reuter, T., Miterski, B. \& Epplen, J.T. Does the tuberous sclerosis complex include clivus chordoma? A case report. Eur J Pediatr 160, 138 (2001).

174. Dutton, R.V. \& Singleton, E.B. Tuberous sclerosis: a case report with aortic aneurysm and unusual rib changes. Pediatr Radiol 3, 184-186 (1975).

175. Kombogiorgas, D., St George, E.J., Chapman, S., English, M. \& Solanki, G.A. Infantile clivus chordoma without clivus involvement: case report and review of the literature. Childs Nerv Syst 22, 1369-1374 (2006).

176. Lountzis, N.I., Hogarty, M.D., Kim, H.J. \& Junkins-Hopkins, J.M. Cutaneous metastatic chordoma with concomitant tuberous sclerosis. J Am Acad Dermatol 55, S6-10 (2006).

177. Schroeder, B.A., Wells, R.G., Starshak, R.J. \& Sty, J.R. Clivus chordoma in a child with tuberous sclerosis: CT and MR demonstration. J Comput Assist Tomogr 11, 195-196 (1987).

178. Storm, P.B., Magge, S.N., Kazahaya, K. \& Sutton, L.N. Cervical chordoma in a patient with tuberous sclerosis presenting with shoulder pain. Pediatr Neurosurg 43, 167-169 (2007).

179. Mirra, J.M. \& Brien, E.W. Giant notochordal hamartoma of intraosseous origin: a newly reported benign entity to be distinguished from chordoma. Report of two cases. Skeletal Radiol 30, 698709 (2001).

180. McMaster, M.L., Goldstein, A.M. \& Parry, D.M. Clinical features distinguish childhood chordoma associated with tuberous sclerosis complex (TSC) from chordoma in the general paediatric population. Journal of Medical Genetics (2011).

181. Barry, J.J., et al. The next step: innovative molecular targeted therapies for treatment of intracranial chordoma patients. Neurosurgery 68, 231-240; discussion 240-231 (2011).

182. Stacchiotti, S., et al. Phase II study of imatinib in advanced chordoma. J Clin Oncol 30, 914-920 (2012).

183. Stacchiotti, S., et al. Response to imatinib plus sirolimus in advanced chordoma. Ann Oncol 20, 1886-1894 (2009).

184. Singhal, N., Kotasek, D. \& Parnis, F.X. Response to erlotinib in a patient with treatment refractory chordoma. Anticancer Drugs 20, 953-955 (2009).

185. Aplin, A.E., Howe, A., Alahari, S.K. \& Juliano, R.L. Signal Transduction and Signal Modulation by Cell Adhesion Receptors: The Role of Integrins, Cadherins, Immunoglobulin-Cell Adhesion Molecules, and Selectins. Pharmacological Reviews 50, 197-264 (1998).

186. Lien, W.H., Klezovitch, O. \& Vasioukhin, V. Cadherin-catenin proteins in vertebrate development. Curr Opin Cell Biol 18, 499-506 (2006).

187. Shapiro, L. \& Weis, W.I. Structure and Biochemistry of Cadherins and Catenins. Cold Spring Harbor Perspectives in Biology 1(2009). 
188. Alberts, B. Cell junctions, Cell adhesion, and the Extracellular matric. in Molecular biology of the cell p.1131-1204 (Garland Science, New York, 2008).

189. Kemler, R. Classical cadherins. Semin Cell Biol 3, 149-155 (1992).

190. Berx, G. \& van Roy, F. Involvement of members of the cadherin superfamily in cancer. Cold Spring Harb Perspect Biol 1, a003129 (2009).

191. Wheelock, M.J., Shintani, Y., Maeda, M., Fukumoto, Y. \& Johnson, K.R. Cadherin switching. J Cell Sci 121, 727-735 (2008).

192. Hazan, R.B., Qiao, R., Keren, R., Badano, I. \& Suyama, K. Cadherin switch in tumor progression. Ann N Y Acad Sci 1014, 155-163 (2004).

193. Jiang, W.G. E-cadherin and its associated protein catenins, cancer invasion and metastasis. The British journal of surgery 83, 437-446 (1996).

194. Mori, K., Chano, T., Kushima, R., Hukuda, S. \& Okabe, H. Expression of E-cadherin in chordomas: diagnostic marker and possible role of tumor cell affinity. Virchows Arch 440, 123-127 (2002).

195. Naka, T., et al. Immunohistochemical analysis of E-cadherin, $\alpha$-catenin, $\beta$-catenin, $\gamma$-catenin, and neural cell adhesion molecule (NCAM) in chordoma. Journal of Clinical Pathology 54, 945-950 (2001).

196. Laskin, W.B. \& Miettinen, M. Epithelial-type and neural-type cadherin expression in malignant noncarcinomatous neoplasms with epithelioid features that involve the soft tissues. Arch Pathol Lab Med 126, 425-431 (2002).

197. Jeanes, A., Gottardi, C.J. \& Yap, A.S. Cadherins and cancer: how does cadherin dysfunction promote tumor progression[quest]. Oncogene 27, 6920-6929 (2008).

198. Qian, X., Karpova, T., Sheppard, A.M., McNally, J. \& Lowy, D.R. E-cadherin-mediated adhesion inhibits ligand-dependent activation of diverse receptor tyrosine kinases. EMBO J 23, 1739-1748 (2004).

199. Lee, K.H., et al. Association of extracellular cleavage of E-cadherin mediated by MMP-7 with HGF-induced in vitro invasion in human stomach cancer cells. Eur Surg Res 39, 208-215 (2007).

200. Aricescu, A.R. \& Jones, E.Y. Immunoglobulin superfamily cell adhesion molecules: zippers and signals. Current Opinion in Cell Biology 19, 543-550 (2007).

201. Christensen, C., Lauridsen, J.B., Berezin, V., Bock, E. \& Kiselyov, V.V. The neural cell adhesion molecule binds to fibroblast growth factor receptor 2. FEBS Letters 580, 3386-3390 (2006).

202. Kiselyov, V.V. NCAM and the FGF-Receptor. in Structure and Function of the Neural Cell Adhesion Molecule NCAM, Vol. 663 (ed. Berezin, V.) 67-79 (Springer New York, 2010).

203. Jacobsen, J., Kiselyov, V., Bock, E. \& Berezin, V. A Peptide Motif from the Second Fibronectin Module of the Neural Cell Adhesion Molecule, NCAM, NLIKQDDGGSPIRHY, is a Binding Site for the FGF Receptor. Neurochemical Research 33, 2532-2539 (2008).

204. Hübschmann, M. \& Skladchikova, G. The Role of ATP in the Regulation of NCAM Function. Neurochemical Research, 1-1 (2008).

205. Francavilla, C., et al. The binding of NCAM to FGFR1 induces a specific cellular response mediated by receptor trafficking. The Journal of Cell Biology 187, 1101-1116 (2009).

206. Povlsen, G.K. The Neural Cell Adhesion Molecule and Epidermal Growth Factor Receptor: Signaling Crosstalk. in Structure and Function of the Neural Cell Adhesion Molecule NCAM, Vol. 663 (ed. Berezin, V.) 199-209 (Springer New York, 2010).

207. Schwab, J.H., et al. Chordoma and chondrosarcoma gene profile: implications for immunotherapy. Cancer Immunol Immunother 58, 339-349 (2009).

208. Pamir, M.N. \& Ozduman, K. Tumor-biology and current treatment of skull-base chordomas. Adv Tech Stand Neurosurg 33, 35-129 (2008). 
209. Cho, N.H., et al. Increased expression of matrix metalloproteinase 9 correlates with poor prognostic variables in renal cell carcinoma. Eur Urol 44, 560-566 (2003).

210. Guo, C.B., et al. Relationship between matrix metalloproteinase 2 and lung cancer progression. Mol Diagn Ther 11, 183-192 (2007).

211. Li, H.C., et al. Prognostic value of matrix metalloproteinases (MMP-2 and MMP-9) in patients with lymph node-negative breast carcinoma. Breast Cancer Res Treat 88, 75-85 (2004).

212. Liu, Z., et al. Increased expression of MMP9 is correlated with poor prognosis of nasopharyngeal carcinoma. BMC Cancer 10, 270 (2010).

213. Mohammad, M.A., Ismael, N.R., Shaarawy, S.M. \& El-Merzabani, M.M. Prognostic value of membrane type 1 and 2 matrix metalloproteinase expression and gelatinase A activity in bladder cancer. Int J Biol Markers 25, 69-74 (2010).

214. Nart, D., et al. Expression of matrix metalloproteinase- 9 in predicting prognosis of hepatocellular carcinoma after liver transplantation. Liver Transpl 16, 621-630 (2010).

215. Yang, Q., et al. Expression of matrix metalloproteinase-9 mRNA and vascular endothelial growth factor protein in gastric carcinoma and its relationship to its pathological features and prognosis. Anat Rec (Hoboken) 293, 2012-2019 (2010).

216. Zhou, C.X., Gao, Y., Johnson, N.W. \& Gao, J. Immunoexpression of matrix metalloproteinase-2 and matrix metalloproteinase- 9 in the metastasis of squamous cell carcinoma of the human tongue. Aust Dent J 55, 385-389 (2010).

217. Naka, T., et al. Expression of matrix metalloproteinase (MMP)-1, MMP-2, MMP-9, cathepsin B, and urokinase plasminogen activator in non-skull base chordoma. Am J Clin Pathol 122, 926-930 (2004).

218. Naka, T., et al. Expression of matrix metalloproteinases-1, -2, and -9; tissue inhibitors of matrix metalloproteinases-1 and -2; cathepsin B; urokinase plasminogen activator; and plasminogen activator inhibitor, type I in skull base chordoma. Hum Pathol 39, 217-223 (2008).

219. Rahmah, N.N., Sakai, K., Nakayama, J. \& Hongo, K. Reversion-inducing cysteine-rich protein with kazal motifs and matrix metalloproteinase- 9 are prognostic markers in skull base chordomas. Neurosurg Rev 33, 167-173; discussion 173 (2010).

220. Chen, K.W., et al. Expression of vascular endothelial growth factor and matrix metalloproteinase-9 in sacral chordoma. J Neurooncol 101, 357-363 (2011).

221. Froehlich, E.V., et al. Expression of ezrin, MMP-9, and COX-2 in 50 chordoma specimens: a clinical and immunohistochemical analysis. Spine (Phila Pa 1976) 37, E757-767 (2012).

222. Haeckel, C., et al. Expression of cathepsin K in chordoma. Hum Pathol 31, 834-840 (2000).

223. Naka, T., etal. Expression ofc-MET, low-molecular-weight cytokeratin, matrixmetalloproteinases-1 and -2 in spinal chordoma. Histopathology 54, 607-613 (2009).

224. Jones, P.A. \& Baylin, S.B. The epigenomics of cancer. Cell 128, 683-692 (2007).

225. Longoni, M., et al. Evaluation of $1 \mathrm{p} 36$ markers and clinical outcome in a skull base chordoma study. Neuro Oncol 10, 52-60 (2008).

226. Le, L.P., et al. Recurrent chromosomal copy number alterations in sporadic chordomas. PloS one 6, e18846 (2011).

227. Duan, Z., et al. Differential expression of microRNA (miRNA) in chordoma reveals a role for miRNA-1 in Met expression. J Orthop Res 28, 746-752 (2010). 

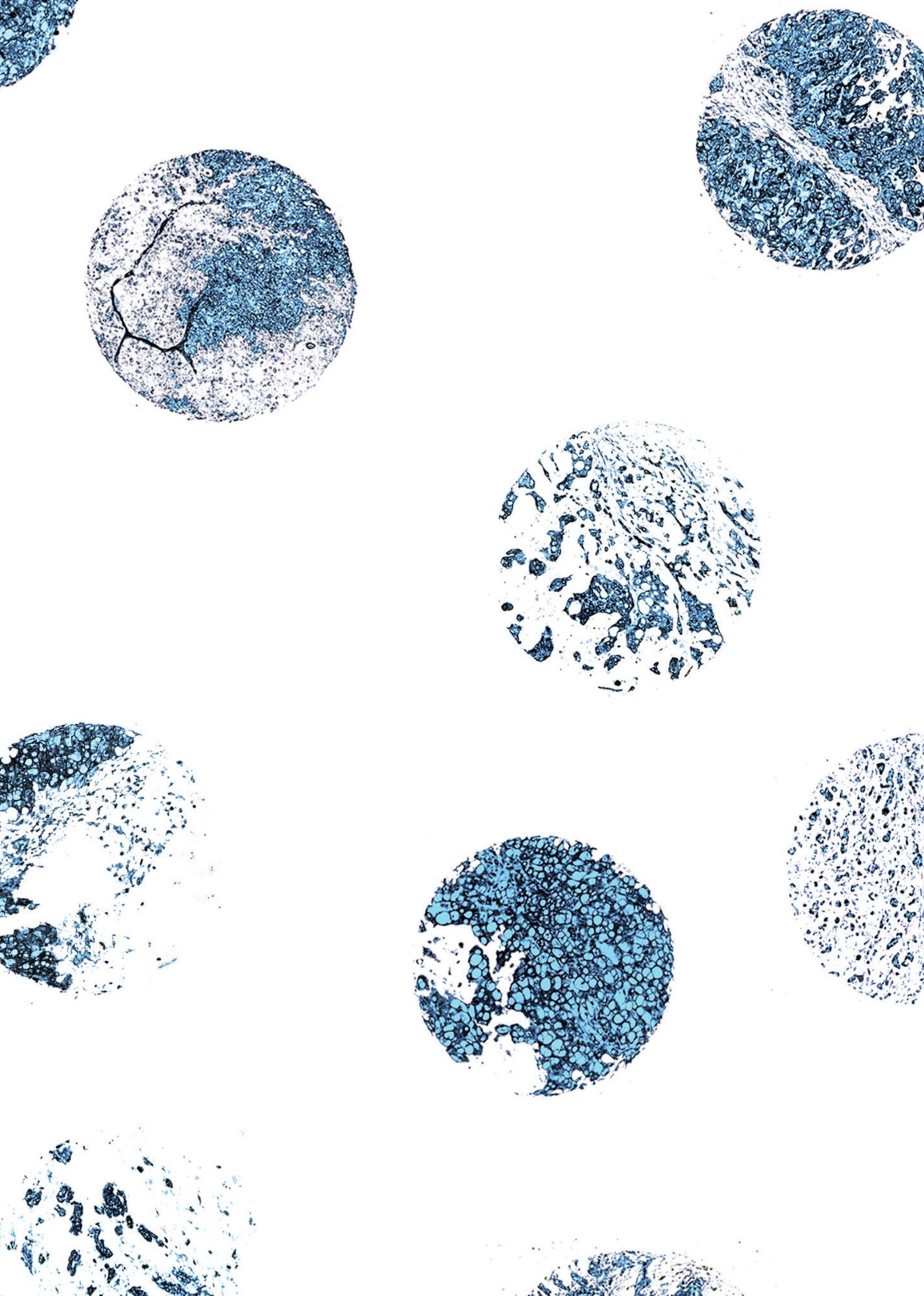


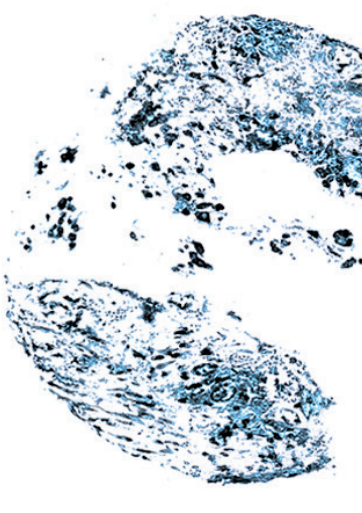

\section{Notochord isolation using laser capture microdissection}

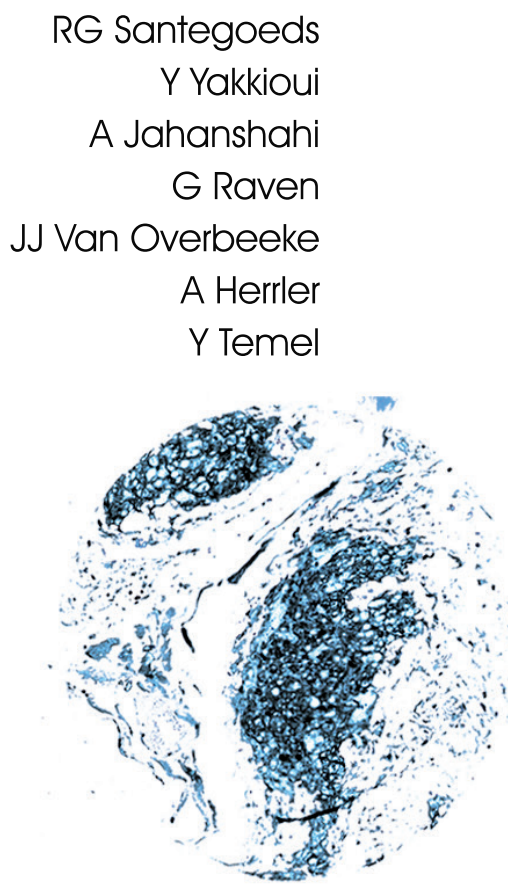

3ournal of Chemical Neuroanatomy 2017 March;80:37-43

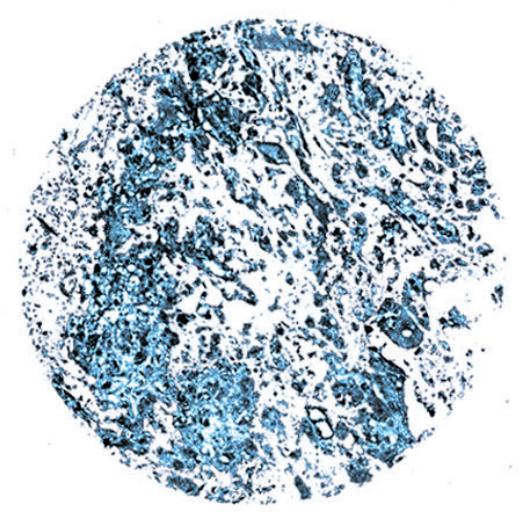

A Herrler
Y Temel 


\section{Abstract}

Background: Chordoma are malignant tumors of the axial skeleton, which arise from remnants of the notochord. The Notochord (chorda dorsalis) is an essential embryonic structure involved in the development of the nervous system and axial skeleton. Therefore, the notochord seems to be the most biologically relevant control tissue to study chordoma in molecular biology research.

Methods: Examination of human fetuses, with a gestation of 9,11 and 13 weeks, using (immuno) histochemical methods was performed. To isolate pure notochord cells for further molecular biology investigation five cryo-preserved fetuses between 9 and 10 weeks of gestation were dissected by microtome slicing. Thereafter pure notochord cells for further molecular biology investigation where harvested by using laser capture microdissection (LCM). RNA was extracted from these samples and used in quantitative PCR.

Results: This study illustrates notochord of embryonic spines in three different stages of gestation (9-11-13 weeks). Immunohistochemical staining with brachyury showed strong staining of the notochord, but also weak staining of the intervertebral disc and vertebral body. LCM of notochord slices and subsequent total RNA extraction resulted in a good yield of total RNA. qPCR analysis of two housekeeping genes confirmed the quality of the RNA.

Conclusion: LCM is a fast and precise method to isolate notochord and the quality and yield RNA extracted from this tissue is sufficient for qPCR analysis. Therefore early embryo notochord isolated by LCM is suggested to be the gold standard for future research in chordoma development, classification and diagnosis. 


\section{Introduction}

Chordoma are malignant tumors of the axial skeleton, which occur most frequently at the skull base and the sacrum. ${ }^{1}$ Complete removal of the tumor is often a challenging and not always possible mainly at the skull base. A 5 year recurrence is reported in up to $49.7 \%$ of all cases. ${ }^{2}$ Chordoma are thought to arise from remnants of the embryonic notochord. ${ }^{3,4}$ These remnants are destined to remain in the spine throughout life and can become malignant at any age, with a median between 53 and 58.5 years. ${ }^{1,5,6}$ Little is known about the underlying mechanisms that orchestrate the switch from benign notochord cell to malignant chordoma. To study these mechanisms in detail, molecular and cellular analysis of chordoma tissue is needed. Notochordal tissue seems to be a reliable control for this purpose. However, up to now most studies in chordoma do not use the notochord as a control tissue for various reasons. Either it was not available, or other types of tissue were used such as nucleus pulposus which might contain notochordal cells. ${ }^{7-11}$ If nucleus pulposus is used, it is important to use only the tissue of young patients as throughout age there is a transition from a notochordal cell rich tissue to that of more fibrotic and more populated by nucleus pulposus cells (also defined as chondrocyte-like cells, or nucleus pulpocytes). ${ }^{12}$ Throughout age, it is shown that the intervertebral disc cells do not show notochord-like cells after the age of 8 years, and notochordal cell markers disappear almost completely after 25 years. ${ }^{13}$

Other studies use muscle tissue, osteoblast cells, blood or other tumors like chondrosarcoma. ${ }^{3,8,14,15}$ Therefore it is essential to develop a feasible method how to isolate highly purified notochord cells for further basic investigations.

The human notochord, also called chorda dorsalis, is an embryologic structure that arises from the bilaminar disc in the third week of the gestation. The most important functions of the notochord are the patterning of the surrounding ectoderm, mesoderm and endoderm, as well as the induction of formation of different tissues (neuroectoderm, dermatotome, myotome, sclerotome). ${ }^{16,17}$ In the early stages, the notochord is a rod-shaped structure, positioned where the axial skeleton will form later on. During embryogenesis, most notochordal cells are replaced by bone in the vertebral body. ${ }^{18}$ Notochordal cells in the intervertebral discs are considered to be the precursor of nucleus pulposus cells. ${ }^{12}$ After 8 weeks of gestation, the notochord involutes into clusters in the intervertebral disc, which are connected by an acellular sheath. ${ }^{19}$ After 26 weeks of gestation, the notochord becomes less distinct from the intervertebral disc. ${ }^{19}$ Only few studies have been conducted to visualize the notochord in 8-13 weeks of gestation foetuses. ${ }^{19,20}$ To better understand the anatomy of the human notochord in the tissue that is provided to us, and to establish which age of gestation is best to be used for dissection, the first part of this study focuses on the notochord from human foetuses of 9-13 weeks of gestation.

Since the notochord clusters are microscopically small and completely surrounded by mesodermal tissue, it is impossible to dissect this macroscopically without significant contamina- 
tion with the surrounding tissue. So far, no study described an adequate way to dissect pure human notochordal tissue. The primary aim of this study was to establish an easy-to-use protocol to isolate notochord, which can be used as a gold standard for collecting control tissue in chordoma research. Our secondary aim was to investigate whether the quality of the extracted RNA from this tissue is sufficient for quantitative reverse transcriptase polymerase chain reaction ( $q R T-P C R$ ) analysis. QRT-PCR is a powerful tool to provide quantitative measurements of gene transcription, and is commonly used in tumor biology. Here, we used laser capture microdissection to isolate the notochord from five foetuses between 9 and 10 weeks of gestation. RNA was extracted from this tissue and used in a qRT-PCR.

\section{Materials and methods}

\subsection{Ethical considerations}

For this study, spines from aborted fetuses were used. Prior to the study, an approval from the Medical Ethics committee of Maastricht University Medical Center (MUMC, Maastricht, The Netherlands) was received (METC 13-4-043). Patients who underwent an abortion for known non-psychological medical reasons were excluded from this study, as this could affect the morphology and gene expression of the notochord. The procedure was performed in an abortion clinic in Maastricht (Centrum voor Anticonceptie, Seksualiteit en Abortus (CASA), Maastricht, The Netherlands). All patients were given enough time to consider signing a written informed consent and could withdraw their initial approval until just after the procedure. The abortion procedure, performed by the medical doctors in the abortion clinic, was exactly the same for patients that were included in the study as the patients that did not sign the informed consent, with the only difference being that the fetal spine was preserved from the aborted material of included patients. These patients were asked to fill in a questionnaire about lifestyle, medication use, and hereditary diseases, to minimize the possibility of an abnormal foetus to be included in this study. The data and tissue were stored and processed anonymously and could not be lead back to the patient by anyone.

\subsection{Notochord visualization and immunohistochemistry}

For determining the best age of embryo to be used, three aborted fetuses of 9, 11, and 13 weeks of gestation were collected at the abortion clinic. Immediately after the abortion procedure, the aborted material was washed in phosphate buffered saline (PBS) and transferred in a glass tray. From this material, the spine could usually be found in one or two pieces (Fig. 1). The spines were fixed in $3.7 \%$ formalin for 48 hours, paraffin embedded by standard procedure, and cut on a microtome (Leica RM 2245, Nussloch, Germany). Five-micrometer sections were cut from paraffin-embedded samples, dewaxed in xylene and rehydrated. Histological staining with haematoxylin and eosin was performed. Some adjacent sections were immunohistochemically stained with an anti-brachyury antibody, to 
confirm the notochord-identity of tissue. ${ }^{3}$ In these slides, antigen-retrieval was performed in $0.01 \mathrm{M}$ sodium citrate $(\mathrm{pH}=6.0)$ in a $99.9^{\circ} \mathrm{C}$ water bath for $15 \mathrm{~min}$. The endogenous peroxidase activity was inhibited with $0.3 \% \mathrm{H} 2 \mathrm{O} 2$ in Tris-buffered-Saline with Triton (TBS-T) and blocking of nonspecific binding with $3 \%$ normal donkey serum in TBS-T for 30 min at $37^{\circ} \mathrm{C}$.
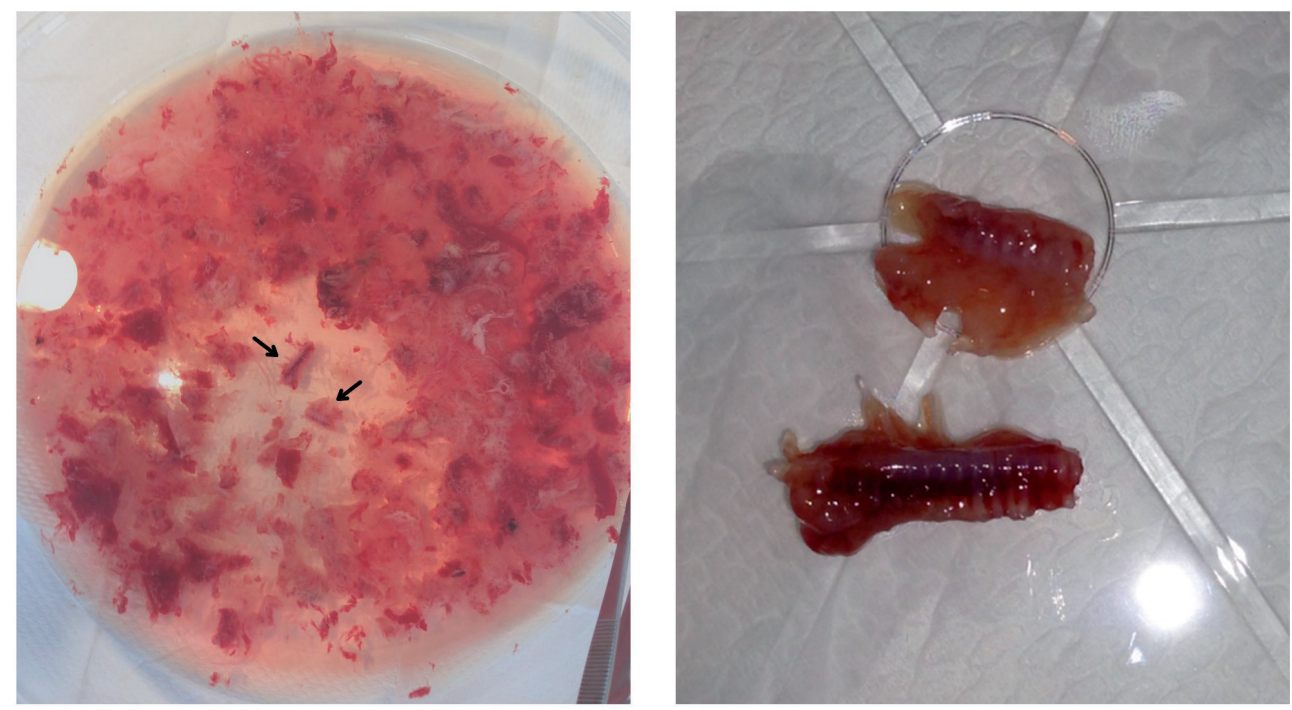

Fig. 1. A: Aborted material in a glass tray. This material was extracted with suction aspiration. Most organs and limbs can be identified in this tray aside to placental material. The spine is visible in two pieces in the middle of the tray (arrows). B: Picture of the two pieces of the spine that was found in the material after the abortion procedure. The scale bars represent $1 \mathrm{~cm}$.

The sections were incubated overnight at $5{ }^{\circ} \mathrm{C}$ with primary anti-brachyury antibody (Santa Cruz, CA, USA) diluted 1:100 in TBS-T. After washing three times in TBS-T an incubation of one hour with secondary antibody (Donkey-anti-rabbit; Jackson Immunoresearch Laboratories, West Grove, PA, USA), diluted 1:400 in TBS-T was performed. The signal was amplified with avidin-biotin complex. To visualize the horseradish peroxide reaction product, the sections were incubated with 3,3'-diaminobenzidine tetrahydrochloride with nickel chloride enhancement after further washing. The specificity of the primary antibody was tested with chordoma samples as positive control tissue, and chondrosarcoma and vestibular schwannoma samples as negative control tissue. Also, immunohistochemical reactions with chordoma samples without primary antibody were used as negative control.

\subsection{Notochord isolation}

Five spines of aborted fetuses with a gestation between 9 and 10 weeks were flash frozen in liquid nitrogen at the abortion clinic, immediately after the abortion procedure. The gestational age was estimated by measuring the fetal crown-rump length, because most 
patients did not know the first day of their last menstruation. Ultrasound alone has been proven to be even more accurate than a "certain" menstrual date for determining gestational age in the first and second trimesters ( $\leq 23$ weeks) in spontaneous conceptions. ${ }^{21}$ The gestational age was quantified as the duration of the pregnancy since the day of the fertilisation. The tissue was stored at $-80^{\circ} \mathrm{C}$. Pieces of the spine was fixed in Tissue Tek FSC22. (Leica biosystems, Maarn, the Netherlands; \#3801480) Sagittal, $14 \mu \mathrm{m}$ sections of the fetal spine were cut on a cryostat (Leica Microsystems; CM3050S), mounted on normal glass slides (Superfrost Plus microscope slides, WVR international, Leuven, Belgium; \#631-0108) and stained with toluidine blue (TB), to determine the position of the section and to check for notochord clusters. At first, ten sections were mounted and stained with TB. On these sections, vertebrae and intervertebral discs were visible. When approaching the centre of the spine, every time, two sections were made and stained with TB, until the notochord was visible. The next ten sections were mounted on a RNase free glass PEN membrane slide (Leica Microsystems, The Netherlands; \#11505189), which is suitable for laser capture microdissection (LCM). Subsequently, one section was mounted on a normal glass slide, and stained with TB. If there were still notochordal clusters visible, the next ten sections were mounted on one RNase free glass PEN membrane slide. Again, one section was cut and mounted on a normal glass slide, and stained with TB. This continued until there were no more notochordal clusters visible. The RNase free glass PEN membrane slides containing the notochord sections where kept at $-20^{\circ} \mathrm{C}$ all the time and stored for a maximum of 4 weeks at $-80^{\circ} \mathrm{C}$ till LCM.

The slides were transported on dry ice to the laser microdissection system (Leica LMD7000). This system is a contact- and contamination-free method for isolating small areas of tissue from glass slides. Prior to the dissection, the slides were stained with $0.5 \%$ toluidine blue, washed twice with DEPC-treated water and once with $70 \%$ alcohol in DEPC-treated water. A Leica LMD7000 laser microdissection system was used to dissect the notochord. The dissected tissue was collected in a $0.5 \mathrm{ml}$ Eppendorf tube with $40 \mu \mathrm{l}$ RLT buffer containing $1 \%$ beta-mercaptoethanol from an RNeasy micro plus kit (Qiagen $\mathrm{GmbH}$, Hilden, Germany, \#74034). RNA was extracted with the RNeasy micro plus kit according to the manufacturer's instruction. The quantity was tested with a nanodrop ND-1000 spectrophotometer (Isogen Life Science). cDNA conversion was performed with a commercially available cDNA synthesis kit (RevertAid first strand cDNA synthesis kit, Thermo Scientific, \#K1622), using oligo (dT)18 primers according to the manufacturer's instructions.

\section{4. qRT-PCR}

Reverse transcriptase quantitative PCR (RT-qPCR) was performed in 96-well plates with a lightcycler 480 Real-Time PCR system (Roche applied science, Rotkreuz, Switzerland, serial 20504). Two housekeeping genes were used (ACTB and YWHAZ). The primer sequence, primer efficiency, and amplicon length are listed in Table 1. One twentieth of the converted cDNA was used per reaction, with $250 \mathrm{nM}$ forward/reverse primer and $1 x$ sensimix (SYBR 
No-RCX; \#SMT-N-314304) in a $20 \mu$ reaction. The reaction conditions were set as: pre-incubation for $10 \mathrm{~min}$ at $95{ }^{\circ} \mathrm{C}$, followed by 40 cycles of $15 \mathrm{~s}$ at $95{ }^{\circ} \mathrm{C}, 15 \mathrm{~s}$ at $60{ }^{\circ} \mathrm{C}$, and $15 \mathrm{~s}$ at $72{ }^{\circ} \mathrm{C}$. Finally, a melting curve was analysed with a ramp rate of $0.29^{\circ} \mathrm{C} / \mathrm{s}$. Three chordoma sample were used as a positive controls. 'No template' and 'no reverse-transcriptase' negative controls were used for each primer.

Table 1. Genes and primers used for quantitative PCR

\begin{tabular}{|c|c|c|c|c|c|}
\hline Abbr. & Primer & $\begin{array}{l}\text { Primer sequences } \\
5^{\prime} \rightarrow 3^{\prime}\end{array}$ & $\begin{array}{l}\text { Amplicon } \\
\text { length } \\
\text { (Bp) }\end{array}$ & $\begin{array}{l}\text { Primer } \\
\text { efficiency } \\
(\%)\end{array}$ & $\begin{array}{l}\text { Annealing } \\
\text { temperature } \\
\left({ }^{\circ} \mathrm{C}\right)\end{array}$ \\
\hline АСТВ & Beta-Actin & $\begin{array}{l}\text { FW: GCACTCTTCCAGCCTTCCTT } \\
\text { RV: CGTACAGGTCTTTGCGGATG }\end{array}$ & 106 & 102 & 60 \\
\hline YWHAZ & $\begin{array}{l}\text { Tyrosine } \\
\text { 3-monooxygenase/ } \\
\text { tryptophan } \\
\text { 5-monooxygenase } \\
\text { activation protein }\end{array}$ & $\begin{array}{l}\text { FW: ACTTGACATTGTGGACATCGGA } \\
\text { RV: CAAAAGTTGGAAGGCCGGT }\end{array}$ & 86 & 103 & 60 \\
\hline
\end{tabular}

\section{Results}

Haematoxylin/Eosin staining was performed on three spines of 9, 11, and 13 weeks of gestation (Fig. 2). The dimensions of the spine are significantly increased in this period. The intervertebral disc almost doubles in diameter and the vertebral body shows central ossification from 11 weeks. However, the notochordal dimensions remained more or less the same. The notochordal clusters are connected by an acellular sheath, which is better visible in the earlier stages of the gestation. To further characterize the notochord, an immunohistochemical staining with brachyury was performed (Fig. 2D-F). There was a specific staining of the notochord. Unexpectedly, also the surrounding tissue was weakly stained with this marker. The immunohistochemical staining was validated by positive and negative control tissue.

Fig. 3 shows an example of a slide before and after the removal of the notochord with LCM. All extracted tissue per fetus was pooled and subsequently, total RNA extraction was performed. Nanodrop spectrophotometre analysis measured an average of 99.88 nanogram of total RNA (65.89 ng-171.6 ng; Table 2). qRT-PCR with beta-Actin primers resulted in an average cycle treshold (Ct) value of 27.72 (24.24-34.45), and qRT-PCR with YWHAZ primers resulted in an average $\mathrm{Ct}$ value of 28.83 (25.99-33.06). Three chordoma samples were used as a positive control for these genes, with $\mathrm{Ct}$ values of beta-actin between 25.03 and 28.50, and YWHAZ between 28.15 and 31.92. Results of individual samples are shown in Table 2.

With the exception of notochord sample \#3, all samples are considered good enough for qRT-PCR analysis of genes with lower gene expression. The amplification curve and gel electrophoresis of the notochord samples and 1 chordoma sample (Fig. 4) demonstrate that a single product is formed. 


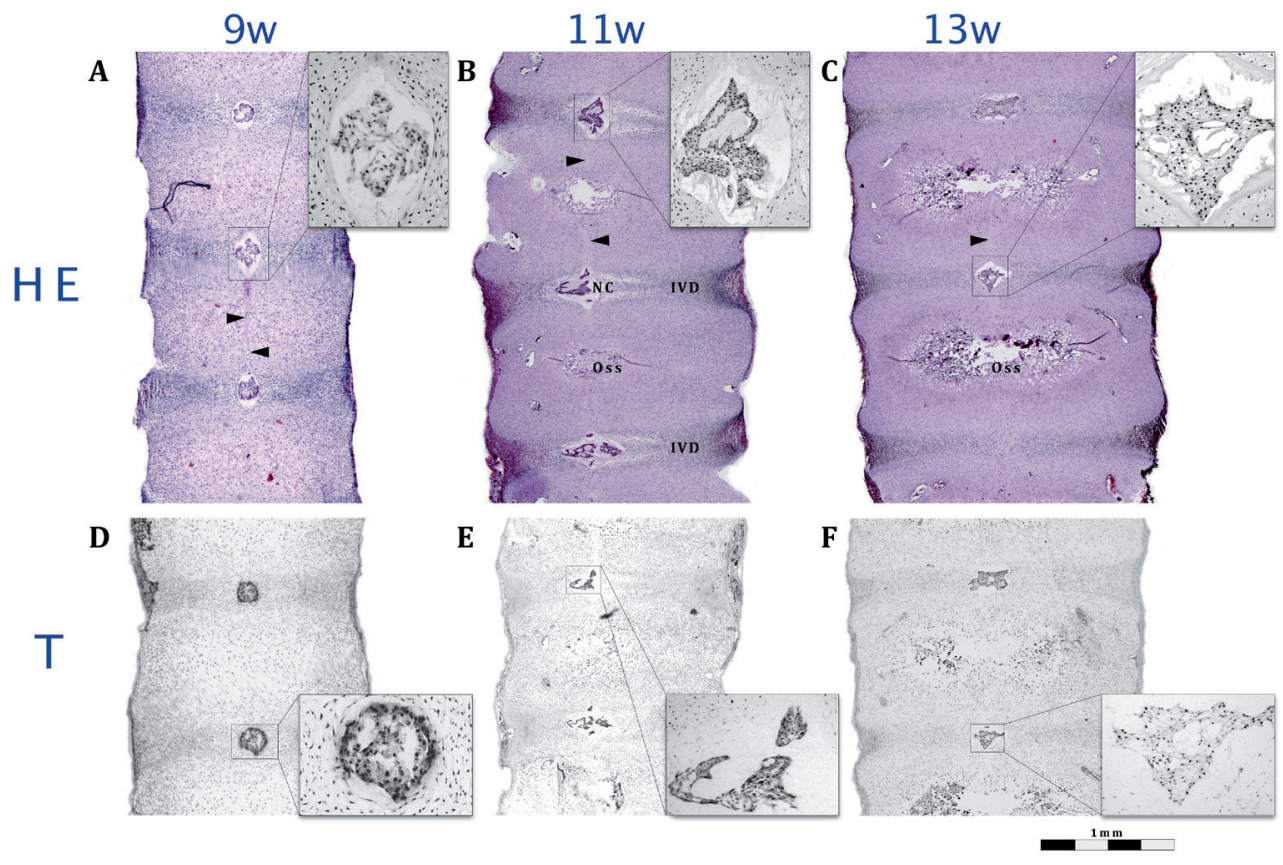

Fig. 2. A-C: Coronal sections of spines of respectively 9, 11 and 13 weeks of gestation. The notochord is located in the centre of the intervertebral disc. Even though the vertebral body and intervertebral disc grow significantly in this gestational period, the volume of the notochord stays more or less the same. The notochordal clusters are connected by an acellular sheath (arrowhead), which is best visible in figure A. In figure B and C, the start of the ossification of the vertebral body is visible. The scale bar represents $1 \mathrm{~mm}$ and is the same in all figures, the scale bar in the insets represents $60 \mu \mathrm{m}$. D-F: immunohistochemical staining with brachyury (T) of an adjacent section of respectively A, B and C. The nuclei of the notochordal clusters are stained with the highest intensity. However, there is also staining of the intervertebral disc and vertebral body. Abbr.: NC = notochord; IVD = Intervertebral disc; Oss = Ossification.

Table 2. Results of quantitative PCR

\begin{tabular}{llllllllll}
\hline & & \multicolumn{4}{c}{} & \multicolumn{3}{c}{ Nanodrop data } & \multicolumn{3}{c}{ qRT-PCR data } \\
\cline { 7 - 10 } Sample \# & $\begin{array}{l}\text { Gestational } \\
\text { age (days) }\end{array}$ & $\begin{array}{l}\text { Clusters } \\
\text { dissected }\end{array}$ & ng/ul & $260 / 280$ & $260 / 230$ & $\begin{array}{l}\text { Total RNA } \\
\text { (ng) }\end{array}$ & $\begin{array}{l}\text { Ct value } \\
\text { (beta-Actin) }\end{array}$ & $\begin{array}{l}\text { Ct value } \\
\text { (YWHAZ) }\end{array}$ \\
\hline 1 & 70 & 7 & 15.6 & 1.62 & 0.51 & 171.6 & 28.33 & 30.76 \\
\hline 2 & 60 & 11 & 5.99 & 1.59 & 0.64 & 65.89 & 26.79 & 28.25 \\
\hline 3 & 66 & 14 & 6.3 & 1.32 & 0.65 & 69.3 & 34.45 & 33.06 \\
\hline 4 & 66 & 18 & 8.44 & 1.49 & 0.76 & 92.84 & 24.24 & 25.99 \\
\hline 5 & 70 & 18 & 9.07 & 1.82 & 0.64 & 99.77 & 24.77 & 26.07 \\
\hline Average & & 13,6 & 9.08 & 1.57 & 0.64 & 99.88 & 27.72 & 28.83 \\
\hline
\end{tabular}




\section{Before LCM}

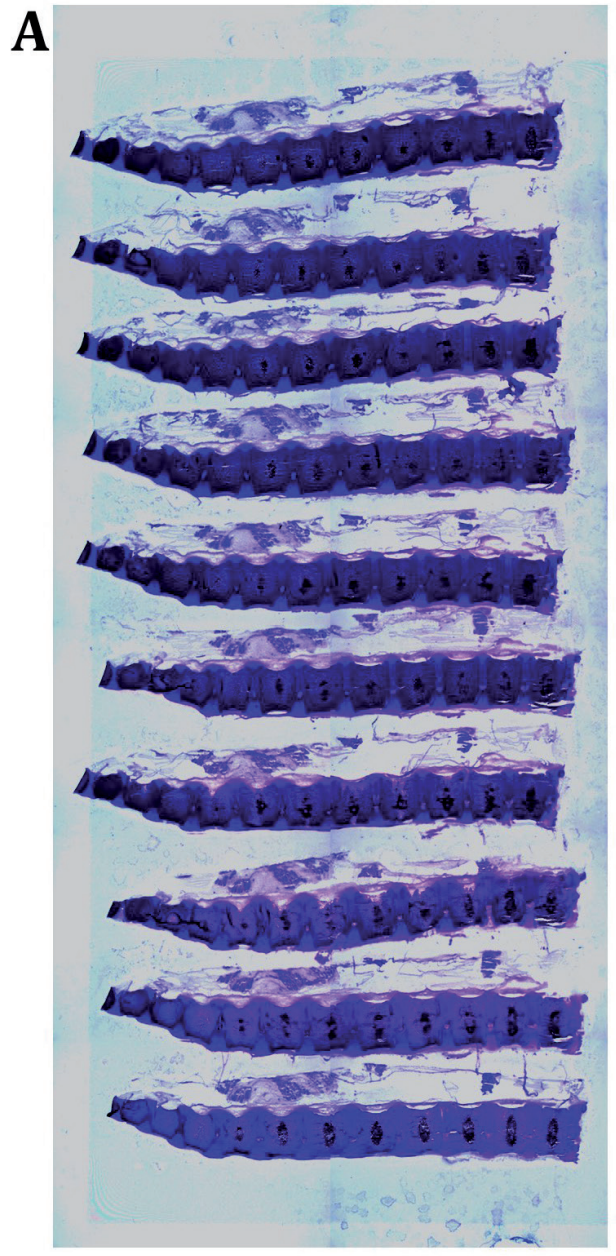

\section{After LCM}

B

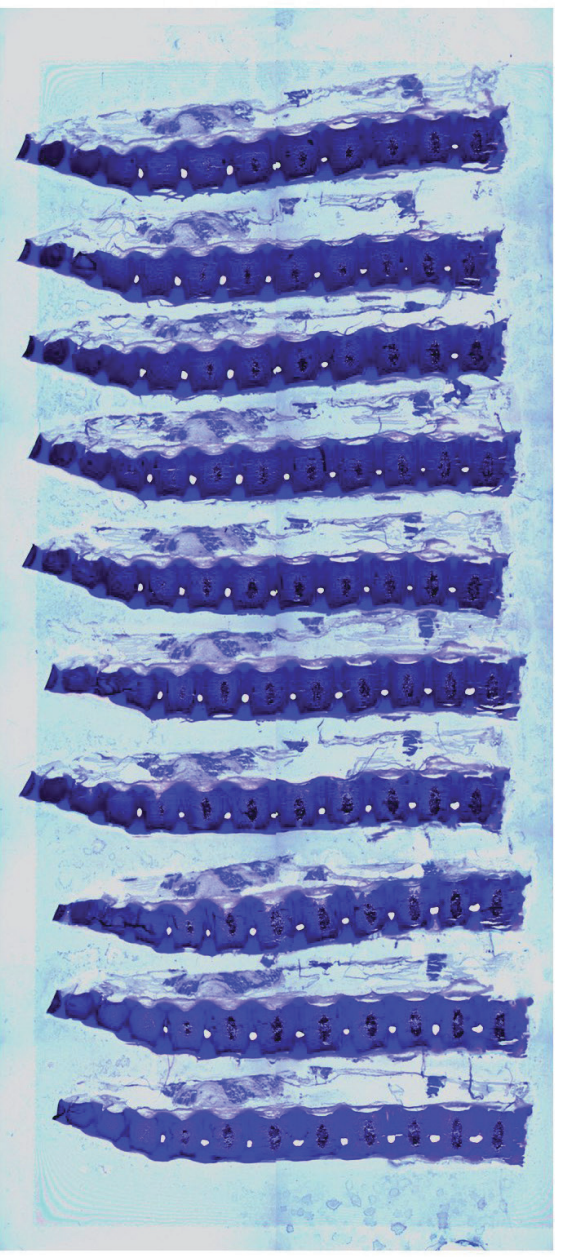

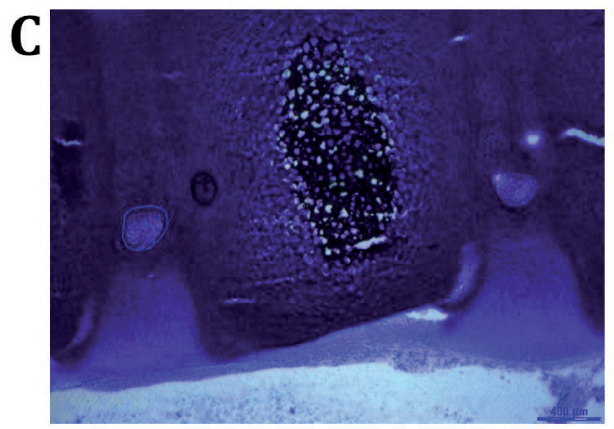

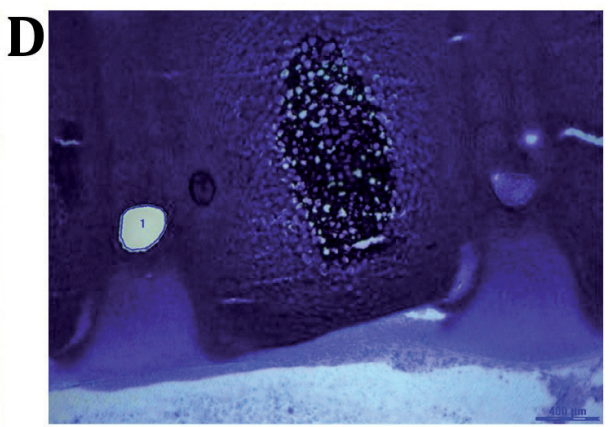

Fig. 3. Toluidine blue staining of a spine before (left) and after (right) LCM. It is clearly visible that nothing but the 8 notochord clusters has been cut out of the sections. The cut-out parts seem a little bit bigger than the notochordal clusters, which is caused by the intensity of the laser, which has a cutting thickness of a few micrometre (D). The scale bars represent $10 \mathrm{~mm}$ in the upper figures and $1 \mathrm{~mm}$ in the lower figures. Abbr.: IVD = Intervertebral disc; Oss = Ossification. Arrowhead: notochord. 

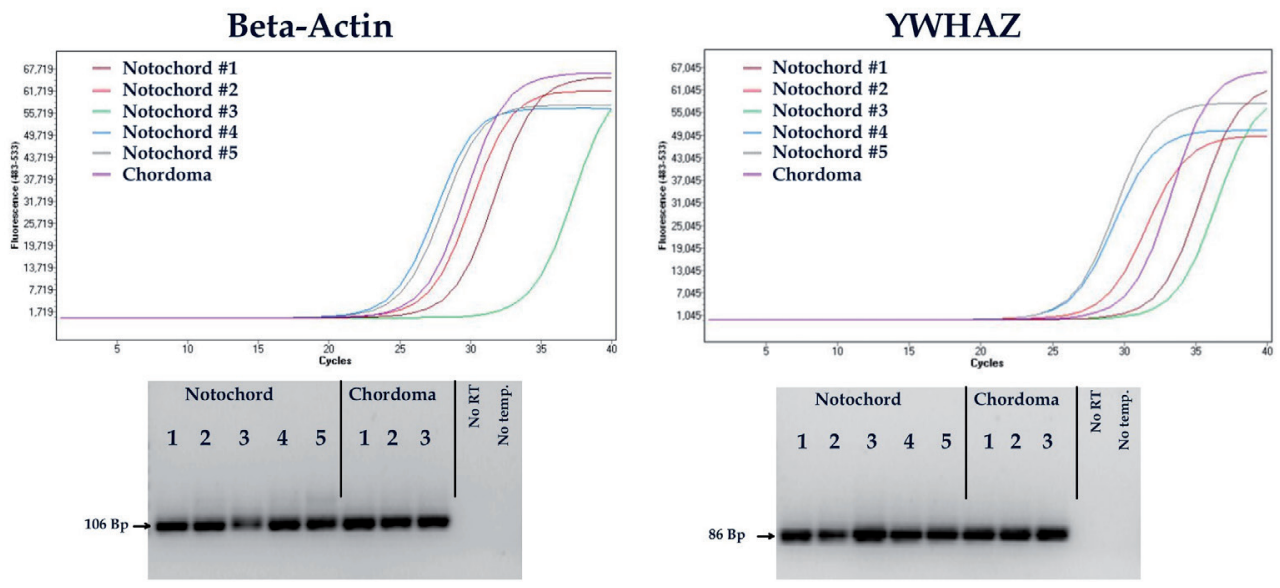

Fig. 4. Linear view of the amplification curve of notochord and chordoma samples in qRT-PCR for beta-actin (left) and YWHAZ (right). All samples show a good curve with a baseline, exponential and plateau phase. Gel electrophoresis of the PCR products of all five notochord samples and three chordoma samples show single bands at the correct height, implicating a single product has formed.

\section{Discussion}

The first part of this study focused on visualizing the notochord of human fetuses from 9 to 13 weeks of gestation to establish which age of gestation is best used for dissection. Sagittal sections of spines from aborted fetuses from 9, 11, and 13 weeks of gestation were made and stained with haematoxylin/eosin. In these stages, the notochord was clustered in the center of each intervertebral disc and connected to each other with an acellular sheath. These results are similar to previous studies. ${ }^{19,20,22}$ Immunohistochemical staining of these sections with anti-brachyury antibody, identified the clusters of densely stained notochordal cells. However, the surrounding tissue was also weakly stained with antibody. This is in contrast to an earlier study, in which only the notochord of embryos of 6-8 weeks of gestation stained positive for this marker, without the surrounding tissue. ${ }^{3}$ In the current study, we used the same methods and identical primary antibody as this study. One difference is that our specimens were $2-4$ weeks older than in the study by Vujovic et al. ${ }^{3}$ Another study immunohistochemically stained fetal spines of 12-40 weeks of gestation with brachyury, with no staining of notochord or surrounding tissue. ${ }^{23}$ Possibly, the notochord is only positive for this marker in the early and not in the later stages. Furthermore, this antibody may not be specific enough for brachyury, although there was no staining in all negative control tissue samples.

The other aim of the study was to isolate RNA from notochordal tissue, to use as control tissue for chordoma studies. In our experimental setup, notochord from fetuses of 9-10 weeks of gestation appears to be the best stage for dissection with this technique. Before the age of 9 weeks, the spine is too small to be distinguished within a sufficient time span 
adequately from other abortion material. This tissue could be obtained by using aborted fetuses that have been extracted by using an abortion pill. However, this tissue is deceased for at least a few hours, which leads to significant gene expression changes. Also, this tissue is usually not brought back to the abortion clinic. Notochord in a later stage ( $>13$ weeks of gestation) is also more difficult to find, due to legal restrictions to gestational age in abortion. Also, in this stage, it is more difficult to distinguish the notochord from nucleus pulposus tissue.

Spines of human fetuses between 9 and 10 weeks of gestation were collected and flash frozen within 20 min after the procedure, which preserved the RNA quality. The biggest strength of this technique is that almost every notochordal cell in the spine, with minimal contamination with surrounding tissue, can be dissected. This improves the quality of the control tissue significantly. The notochord in this stage is clearly distinguishable from the surrounding tissue, so there will be nearly no contamination with other cells. Nanodrop analysis resulted in an average yield of 99.88 nanogram of total RNA. However, the 260/280 and 260/230 ratio's are very poor, which makes these results less reliable. Nonetheless, qRT-PCR resulted in low Ct values in 4 out of 5 cases, which makes this RNA suitable for analysis, also for genes with low expression levels. Because only $10 \%$ of the cDNA was used for these reference genes, at least 10 genes can be tested with qRT-PCR per notochordal sample.

This is the first study that describes a method that can be routinely used for dissection of pure fetal notochordal tissue to use as a control for chordoma research. In an earlier study, notochord was used as control tissue for miRNA expression analysis, but it was not describe how and in what stage of gestation this tissue was collected. ${ }^{14}$ Furthermore the purity of tissue was vague. Another study, used LCM to isolate notochordal tissue from aborted fetuses of 24-27 weeks of gestation. ${ }^{24}$ This method cannot be routinely used, as this gestational material is not available in a regular manner. In addition, the time between abortion and freezing of the spine is significantly longer, since the intervertebral disc has to be cut out of an intact foetus. Moreover, every intervertebral disc has to be cut out separately and only few sections can be mounted on one glass, considering the volume of the intervertebral disc. In current study design, one section can contain multiple notochordal clusters and many sections can be mounted on one glass membrane. This does not only reduce costs, it's also easier and less time consuming. Furthermore, this gestational period correlates with a viable human being, which might impede ethical approval. Finally, the notochord disappears with increasing age, and becomes less distinctive from the intervertebral disc. ${ }^{19}$

The main purpose of the study was to establish a sound method to isolate control tissue for chordoma research. However, the question of the ideal stage of gestation that can be used as control tissue for chordoma remains unanswered. Even though 9-10 weeks of gestation may be the easiest to dissect with LCM, that this is the best control tissue for gene expression studies in chordoma was impossible to show. Furthermore, not only the stage, but also 
the location can influence the transcriptome. Possibly, notochordal tissue from the cervical vertebrae can serve as a better control tissue for skull base chordoma, and notochord in the lumbar region for sacral chordoma. Future research should investigate this hypothesis, as this technique could be used to collect all the clusters of the notochord separately. Finally, only one spine per age of gestation was investigated. There may be a variance in notochordal dimensions between fetuses, although we do not expect this to be a significant difference. In our opinion, the quantity and quality of total RNA can be improved in the LCM step. Immediately after the abortion procedure, the tissue is frozen. Also, cutting on the cryostat is in frozen condition. However, during staining with toluidine blue and LCM, the slides are at room temperature, facilitating RNA degradation by RNase. In current study, this period was around $30 \mathrm{~min}$. If this step can be shortened in a way, we believe that the quality and quantity would improve significantly.

Working with aborted material requires ethical consideration. We emphasize that the abortion procedure was not altered in any way when patients were included in the study. The patients were informed of the study, only after they made their final decision to proceed with the abortion, so this decision could not be influenced by the study. The only difference between inclusion/exclusion in the study was that of the aborted material of participants the spine was collected and analysed. The remaining tissue was disposed of by standard human tissue disposal procedures.

We suggest this procedure as a gold standard for collecting control tissue for chordoma studies. Because abortions of fetuses in this stage of gestation can be planned, and the tissue can be frozen immediately after the procedure, this is an excellent method to preserve tissue quality. Because the total size of the fetal spine is relatively small, sections of a foetal spine with at least 7 intervertebral discs (i.e. notochordal clusters) can be cut and mounted on the same glass. LCM is a fast, user friendly, and state-of-the-art technique, which is perfectly suitable for dissection of this kind of tissue. Without an amplification step, RNA isolated from these spines can be used in qRT-PCR. Using the here presented method, also DNA, proteins and miRNA can be extracted.

Since there is insufficient knowledge about the driving factors behind the formation of chordoma from notochord, this high quality control tissue may play a key role in understanding these molecular mechanisms. Understanding these mechanisms can facilitate the development of new targeted treatment and improve the treatment outcome of patients with chordoma. 


\section{References}

1. McMaster, M.L., Goldstein, A.M., Bromley, C.M., Ishibe, N. \& Parry, D.M. Chordoma: incidence and survival patterns in the United States, 1973-1995. Cancer Causes Control 12, 1-11 (2001).

2. Colli, B. \& Al-Mefty, O. Chordomas of the craniocervical junction: follow-up review and prognostic factors. J Neurosurg 95, 933-943 (2001).

3. Vujovic, S., et al. Brachyury, a crucial regulator of notochordal development, is a novel biomarker for chordomas. J Pathol 209, 157-165 (2006).

4. Yamaguchi, T., et al. Distinguishing benign notochordal cell tumors from vertebral chordoma. Skeletal Radiology 37, 291-299 (2008).

5. Noël, G., et al. Chordomas of the base of the skull and upper cervical spine. One hundred patients irradiated by a 3D conformal technique combining photon and proton beams. Acta Oncologica 44, 700-708 (2005).

6. Lee, J., Bhatia, N.N., Hoang, B.H., Ziogas, A. \& Zell, J.A. Analysis of prognostic factors for patients with chordoma with use of the California Cancer Registry. J Bone Joint Surg Am 94, 356-363 (2012).

7. Bayrak, O.F., et al. MicroRNA expression profiling reveals the potential function of microRNA-31 in chordomas. J Neurooncol 115, 143-151 (2013).

8. Rinner, B., et al. Chordoma characterization of significant changes of the DNA methylation pattern. PloS one 8, e56609 (2013).

9. Schwab, J.H., et al. Chordoma and chondrosarcoma gene profile: implications for immunotherapy. Cancer Immunol Immunother 58, 339-349 (2009).

10. Aydemir, E., et al. Characterization of cancer stem-like cells in chordoma. Journal of Neurosurgery $116,810-820$ (2012).

11. Zou, M.-X., et al. Identification of miR-140-3p as a marker associated with poor prognosis in spinal chordoma. International Journal of Clinical and Experimental Pathology 7, 4877-4885 (2014).

12. McCann, M.R. \& Seguin, C.A. Notochord Cells in Intervertebral Disc Development and Degeneration. Journal of developmental biology 4, 1-18 (2016).

13. Weiler, C., et al. Immunohistochemical identification of notochordal markers in cells in the aging human lumbar intervertebral disc. European Spine Journal 19, 1761-1770 (2010).

14. Duan, Z., et al. Differential expression of microRNA (miRNA) in chordoma reveals a role for miRNA-1 in Met expression. J Orthop Res 28, 746-752 (2010).

15. Duan, Z., et al. Prognostic significance of miRNA-1 (miR-1) expression in patients with chordoma. J Orthop Res 32, 695-701 (2014).

16. Cleaver, O. \& Krieg, P.A. Notochord patterning of the endoderm. Dev Biol 234, 1-12 (2001).

17. Stemple, D.L. Structure and function of the notochord: an essential organ for chordate development. Development 132, 2503-2512 (2005).

18. Hunter, C.J., Matyas, J.R. \& Duncan, N.A. Cytomorphology of notochordal and chondrocytic cells from the nucleus pulposus: a species comparison. J Anat 205, 357-362 (2004).

19. Pazzaglia, U.E., Salisbury, J.R. \& Byers, P.D. Development and involution of the notochord in the human spine. Journal of the Royal Society of Medicine 82, 413-415 (1989).

20. Babic, M.S. Development of the notochord in normal and malformed human embryos and fetuses. Int J Dev Biol 35, 345-352 (1991).

21. Butt, K. \& Lim, K. Determination of gestational age by ultrasound. Journal of obstetrics and gynaecology Canada : JOGC = Journal d'obstetrique et gynecologie du Canada : JOGC 36, 171-181 (2014). 
22. Cotten, A., Sakka, M., Drizenko, A., Clarisse, J. \& Francke, J.P. Antenatal differentiation of the human intervertebral disc. Surgical and Radiologic Anatomy 16, 53-56 (1994).

23. Shen, J., et al. Histological study of chordoma origin from fetal notochordal cell rests. Spine (Phila Pa 1976) 38, 2165-2170 (2013).

24. Long, C., et al. Integrated miRNA-mRNA Analysis Revealing the Potential Roles of miRNAs in Chordomas. PloS one 8, e66676 (2013). 

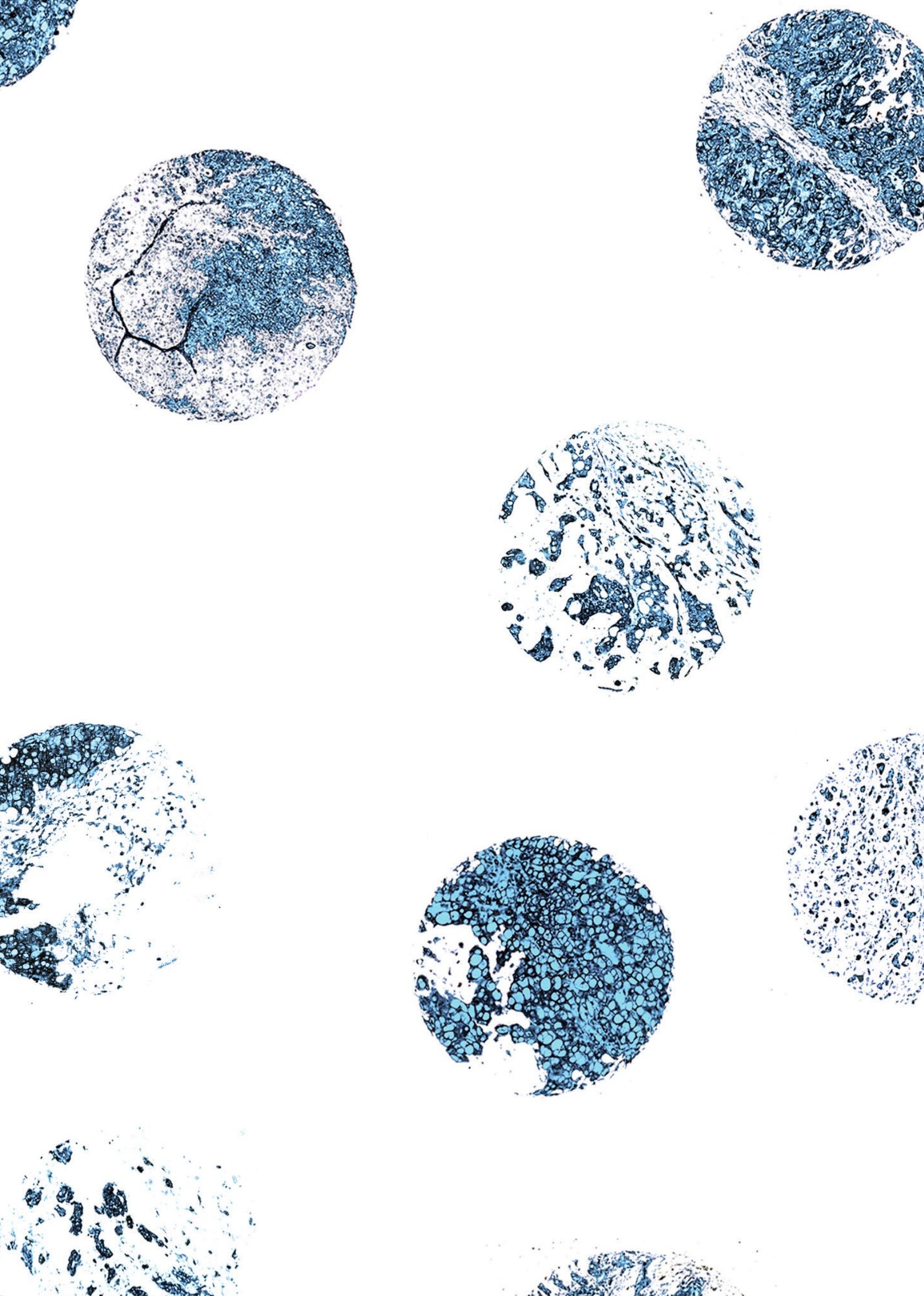


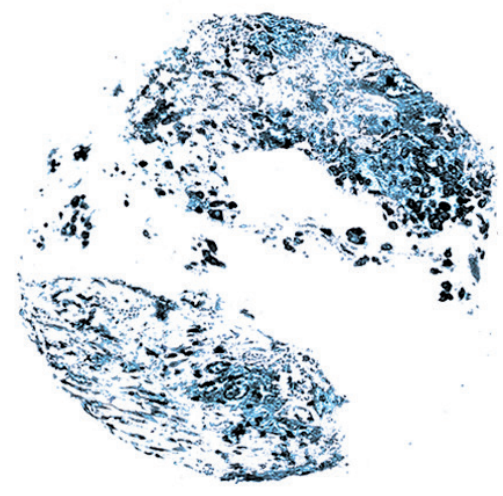

\title{
Integrated and quantitative proteomics of human tumors
}

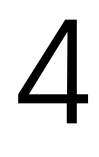

\author{
Y Yakkioui \\ Y Temel \\ E Cheve† \\ L Negroni
}
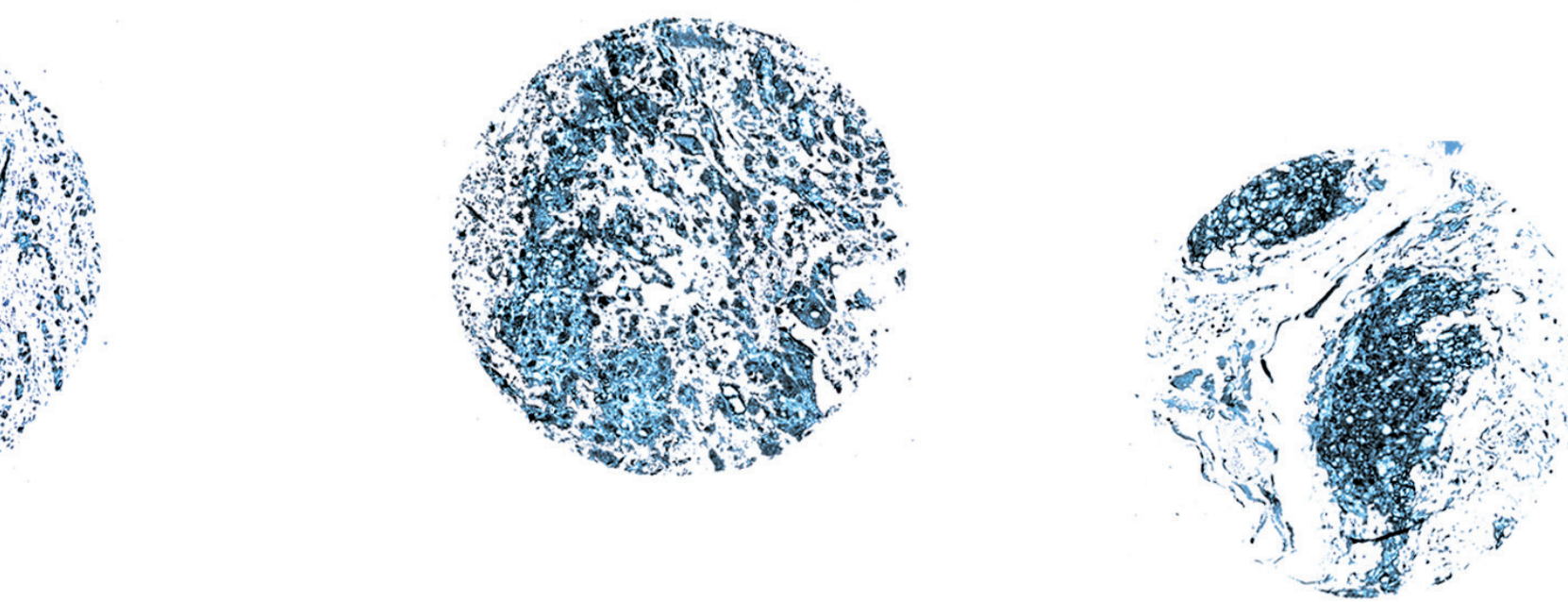

$-30$

Methods in Enzymology 201 7;586:229-246 


\section{Abstract}

Quantitative proteomics represents a powerful approach for the comprehensive analysis of proteins expressed under defined conditions. These properties have been used to investigate the proteome of disease states, including cancer. It has become a major subject of studies to apply proteomics for biomarker and therapeutic target identification. In the last decades, technical advances in mass spectrometry have increased the capacity of protein identification and quantification. Moreover, the analysis of posttranslational modification (PTM), especially phosphorylation, has allowed large-scale identification of biological mechanisms. Even so, increasing evidence indicates that global protein quantification is often insufficient for the explanation of biology and has shown to pose challenges in identifying new and robust biomarkers. As a consequence, to improve the accuracy of the discoveries made using proteomics in human tumors, it is necessary to combine (i) robust and reproducible methods for sample preparation allowing statistical comparison, (ii) PTM analyses in addition to global proteomics for additional levels of knowledge, and (iii) use of bioinformatics for decrypting protein list. Herein, we present technical specificities for samples preparation involving isobaric tag labeling, TiO2-based phosphopeptides enrichment and hydrazyde-based glycopeptides purification as well as the key points for the quantitative analysis and interpretation of the protein lists. The method is based on our experience with tumors analysis derived from hepatocellular carcinoma, chondrosarcoma, human embryonic intervertebral disk, and chordoma experiments. 


\section{Introduction}

Knowledge on mass spectrometry for proteomics significantly advanced in the 1990s with the development of two-dimensional (2D) gel electrophoresis and in-gel protein identification using MALDI-TOF mass fingerprinting. ${ }^{1} \mathrm{~A}$ decade later, gel-based proteomics was largely replaced by liquid chromatography coupled with nanoelectrospray because of higher reproducibility and sensitivity. Today single liquid chromatography-mass spectrometry (LC-MS/ MS) has allowed the near complete identification of the yeast proteome as well as up to 8400 proteins from Hela cells protein extracts. ${ }^{2,3}$ In parallel to this, increased performance mainly due to instrumentation improvement resulted in the development of two major domains in proteomics, namely (i) quantitative methods for proteomics and (ii) posttranslational modifications (PTMs) analysis.

(i) Quantitative proteomics-Quantitation is a major challenge for proteomics because of the instability of the nanospray and the limited peakcapacity of the chromatographic systems in regards to the sample complexity. The first approach, label-free quantification, does not need any isotopic labeling. ${ }^{4,5}$ It is based either on MS precursor signal intensity or on MS/MS spectral counting. ${ }^{6}$ The second approach uses isotopic labeling, either metabolic labeling with stable isotope labeling with amino acids in cell culture (SILAC) or isobaric labeling with isobaric tag for relative and absolute quantitation (iTRAQ) or tandem mass tag (TMT). ${ }^{7-9}$ In the present work, we illustrate this aspect of quantitative proteomics by using iTRAQ, which presents the unique advantage to pool eight labeled samples before LC-MS analysis, which consequently leads to an eightfold decrease in the analysis time.

(ii) Proteomics for PTMs - analysis of PTMs is the second challenging approach for proteomics because of the diversity of the PTM and their substoichiometry in complex mixtures. Herein, we have only presented methods for the analysis of protein phosphorylation and $\mathrm{N}$-glycosylation but other proteomic approaches for PTM are emerging to target modifications such as ubiquitination, acetylation, methylation, and O-glycosylation (see for review ${ }^{10-12}$ ). Phosphorylation in eukaryotes mainly occurs on serine, threonine, and tyrosine residues. Using mass spectrometry, large sets of phosphopeptides can be identified only after affinity enrichment and the relative abundance of $\mathrm{pS} / \mathrm{pT} / \mathrm{pY}$ containing peptides is approximately $100 / 10 / 1$. As a consequence, pY peptides are underrepresented in phosphoproteomics, with the exception of immunopurificated samples. ${ }^{13}$ For global phosphoproteomics, two major chromatography approaches are mainly used with either SCX-IMAC or TiO2 matrices. ${ }^{3,14-16}$ In the case of TiO2, metal is covalently linked to the solid phase, thereby allowing more stringent buffers for the washing steps. Therefore, the nonspecific binding of acidic peptides ( $D$ - and E-rich peptides) is generally decreased despite the absence of prefractionation. ${ }^{17}$ These methods have been used with success for cancer phosphoproteomics. ${ }^{18-20}$ Glycosylation has also been extensively studied, however, one major difficulty arises from the diversity of complex carbohydrates (glycan) chains. The main strategies for global glycoproteomics rely on chromatographic 
enrichment of glycopeptides using HILIC, lectins, graphite, or hydrazide $(\mathrm{Hz})$ columns (see for review ${ }^{21,22}$ ) which have all been implemented in cancer biomarker discovery. ${ }^{23-27}$ In this chapter, we describe an approach that combines quantitative and comparative proteome analysis and integrated PTM characterization in human tumors by integrating them in a single experimental workflow (Fig. 1). As such, we present a method for global-, phospho-, and glycoproteomics, which is performed using commercial reagents (iTRAQ, $\mathrm{TiO} 2$, and $\mathrm{Hz}$ gel), using a commercially available mass spectrometer. Briefly, each tumor sample is crunched and directly digested by trypsin. The resulting peptides are desalted and labeled with iTRAQ prior pooling (eight different specimens) for the following steps. An aliquot is reserved for global proteomics while the main part of the ITRAQ sample is purified with $\mathrm{TiO} 2$ and $\mathrm{Hz}$ gel. The complete method requires about a week's worth of work. Later, we present a step-by-step protocol to provide a convenient methodology.
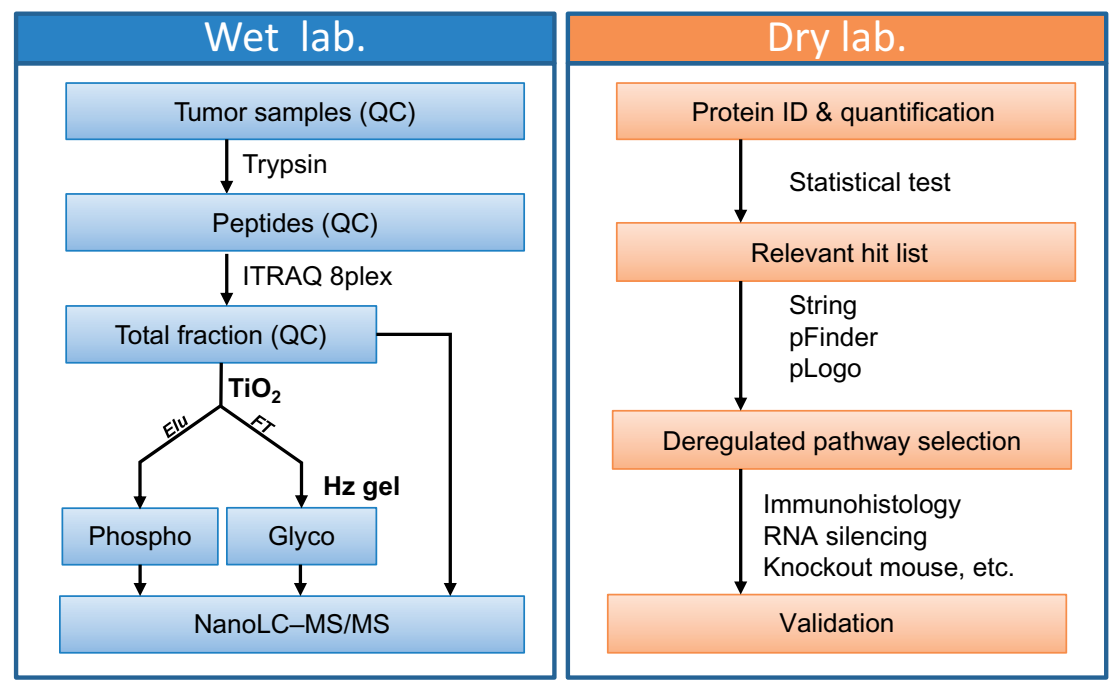

Fig. 1. Global experimental workflow. Tumoral and nontumoral (control) tissues are trypsin-digested then labeled using iTRAQ-8plex. Labeled peptides are analyzed using mass spectrometry either directly or following enrichment of specific classes of peptides (e.g., glycopeptides or phosphopeptides).

\section{Equipment, material and buffers}

\subsection{Trypsinolysis}

Sample disruption: $1.5 \mathrm{ml}$ polypropylene tube and plastic piston pellet (Eppendorf) or TissueLyser II (Qiagen) with stainless beads

- Reduction buffer: $0.1 \mathrm{M}$ ammonium bicarbonate, $0.15 \mathrm{M} \mathrm{NaCl}, 5 \mathrm{mM}$ TCEP, $2 \mathrm{mM}$ Na2VO3. Stock solutions: $\mathrm{NaCl}: 3 \mathrm{M}(175.3 \mathrm{mg} / \mathrm{ml})$; ammonium bicarbonate: $1 \mathrm{M}$ (79 $\mathrm{mg} / \mathrm{ml})$; TCEP: $1 \mathrm{M}$ in water $(287 \mathrm{mg} / \mathrm{ml})$. 
- Alkylation solution: $1 \mathrm{M}(185 \mathrm{mg} / \mathrm{ml})$ iodoacetamide in water, to be prepared extemporaneously.

- Trypsin: stock solution: $10 \mathrm{mg} / \mathrm{ml}$ TPCK-Treated trypsin in $2 \mathrm{mM} \mathrm{HCl}$.

- PNGase F (New England Biolabs Inc).

\subsection{SPE-C18}

Sep-Pak tC18 Plus cartridge (Waters) and $25 \mathrm{ml}$ plastic syringe.

- SPE-C18 buffer A: 0.1\% TFA.

- SPE-C18 buffer B: $60 \%$ acetonitrile.

\subsection{TiO2 chromatography}

TitansphereTiO2 particles (5 $\mu \mathrm{m}, \mathrm{GL}$ science) packed in a $1 \mathrm{~mm} \times 2.5 \mathrm{~cm}(19.6 \mu \mathrm{l})$ peek tubing plugged with an inox frit pulled in the $1 / 16$ hole of PEEK MicroTight ${ }^{\circledR}$ Adapters (IDEX).

- TiO2 buffer A1: Loading buffer: 1 M TFA, 1 M glycolic acid, 50\% ACN.

- TiO2 buffer A2: 50 mM TFA, 50\% ACN.

- TiO2 buffer B: $1 \mathrm{M} \mathrm{NH} 4 \mathrm{OH}$.

\subsection{Hydrazide $(\mathrm{Hz})$ gel chromatography}

Affi-Gel Hz Hydrazide Gel (Biorad) pulled in a spin columns (Thermo Scientific).

- Binding buffer: $0.1 \mathrm{M}$ sodium acetate, $0.15 \mathrm{M} \mathrm{NaCl}$ pH 5.5 (pH adjusted with $\mathrm{NaOH}$ ).

- NalO4 stock sol.: $100 \mathrm{mM}(21.4 \mathrm{mg} / \mathrm{ml})$ in water, to be prepared extemporaneously.

- NaS2O3 stock sol.: $200 \mathrm{mM}(31.6 \mathrm{mg} / \mathrm{ml})$ in water, to be prepared extemporaneously.

- PNGase F buffer: 100 mM sodium phosphate $\mathrm{pH}$ 7.5.

\subsection{LC-MS/MS}

- UltiMate 3000 RSLCnano System (Thermo Scientific); nanospray mass spectrometer Q-Exactive (Thermo Scientific), non-coated capillary probe (20 $\mu$ m i.d., New Objective). MS Columns. PEPMAP100 C18 cartridge (300 $\mathrm{m} \times 5$ mm); PEPMAP100 C18 Reverse phase $(75 \mu \mathrm{m} \times 15 \mathrm{~cm})$ from Thermo Scientific.

- HPLC pre-concentration buffer: $0.1 \%$ Formic acid.

- HPLC buffer A: 0.1\% formic acid.

- HPLC buffer B: $0.1 \%$ formic acid in $95 \%$ acetonitrile, $5 \% \mathrm{dH} 2 \mathrm{O}$.

- Gradient: after $3 \mathrm{~min}$ loading at $10 \mu \mathrm{l} / \mathrm{min}$, the valve is switched on in order to connect pre-concentration cartridge to the analytical column. Peptides are eluted with a linear gradient from 4 to $30 \%$ B for $110 \mathrm{~min}$. 


\section{Wet lab protocol}

\subsection{Sample collection and preparation}

Operative samples/biopsies must be snap-frozen in liquid nitrogen as soon as possible following resection and stored at $-80^{\circ} \mathrm{C}$. Transport should be performed if possible on dry ice. For proteomics, we use 50 to $100 \mathrm{mg}$ max of fresh sample is needed (i.e. a cube of $3 \mathrm{~mm}$ side). No more quantity in the Eppendorf tube. This is the maximum concentration possible in the Eppendorf tube before protein precipitation.

\subsection{Enzymatic digestion (18h)}

The tubes and reduction buffer must be kept on ice. Set thermomixer at $80^{\circ} \mathrm{C}$.

1. Add $0.1 \mathrm{ml}$ reduction buffer and crush with plastic piston pellet, wash the pellet with 0.9 $\mathrm{ml}$ buffer.

2. Heat $10 \mathrm{~min} 80^{\circ} \mathrm{C}$ with thermomixer at $1000 \mathrm{rpm}$ (Note 1 ).

3. Chill samples $5 \mathrm{~min}$ on ice prior alkylation.

4. Alkylate with $5 \%$ (vol/vol) alkylation solution ( $20 \mathrm{mM}$ IAA final) for $30 \mathrm{~min}$ at $25^{\circ} \mathrm{C}$.

5. Add $0.1 \%$ trypsin (\% $\mathrm{w} / \mathrm{w}$ fresh tissue) and incubate $1 \mathrm{~h}$ at $37^{\circ} \mathrm{C}$.

6. Add again $0.1 \%$ trypsin and incubate overnight at $37^{\circ} \mathrm{C}$.

7. Add $10 \%$ acetic acid, $1 \%$ TFA for stopping digestion. Mix until complete degassing.

8. Centrifuge at $16000 \mathrm{~g}$ for $10 \mathrm{~min}$, transfer supernatant in a clean tube for SPE and dry the pellet for weighting (Note 2 ).

\subsection{SPE for peptide desalting ( $15 \mathrm{~min}$ a sample)}

1. Solvate the SPE cartridge with $5 \mathrm{ml}$ pure ACN then $10 \mathrm{ml} \mathrm{SPE-C18}$ buffer $A$.

2. With a plastic syringe aspire the sample ( $1 \mathrm{ml})$ then $1 \mathrm{ml} \mathrm{SPE}-\mathrm{C} 18$ buffer $A$ and load the $2 \mathrm{ml}$ on the cartridge.

3. Wash with $10 \mathrm{ml} \mathrm{SPE-C18} \mathrm{buffer} \mathrm{A.}$

4. Elute with $2 \mathrm{ml} \mathrm{SPE}-\mathrm{C} 18$ buffer $\mathrm{B}$ in a tared $2 \mathrm{ml}$ tube (0.5 first $\mathrm{ml}$ are discarded) (Note 3 ).

5. Dry sample with speedVac.

6. Weight tube for an estimation of peptide amount.

\subsection{Peptide quantification ( $30 \mathrm{~min})$}

The method uses Biorad kit (DC protein assay) and BSA as standard protein. For verification, tryptic peptides of BSA may be prepared using digestion as described in 3.2 and 3.3. The dilution curves of intact BSA and its tryptic peptides should be similar.

1. Prepared standard at $1,0.5,0.1,0.05 \mathrm{mg} / \mathrm{ml}$ in water (stable 1 month at $4^{\circ} \mathrm{C}$ ).

2. Mix $50 \mu \mathrm{l}$ sample with $100 \mu \mathrm{l}$ reagent $A$ and $900 \mu \mathrm{l}$ reagent $B$, mix and read at $750 \mathrm{~nm}$ after 30 min RT incubation. 


\section{5. iTRAQ labelling}

The manufacturer ( $A B$ SCIEX) protocol is applied with minor modifications:

1. In $1.5 \mathrm{ml}$ tube, put $5 \mu \mathrm{l}$ peptides (50 $\mathrm{gg}$ of $10 \mathrm{mg} / \mathrm{ml}$ reconstituted solution).

2. Add $10 \mu$ TEAB $1 \mathrm{M}$, pH should be above 8.5 .

3. Add 1 unit iTRAQ previously diluted with $50 \mu$ of isopropanol.

4. Incubate $2 \mathrm{~h}$ under agitation at $25^{\circ} \mathrm{C}$ (Thermomixer).

5. Block possible active iTRAQ with $5 \mu \mathrm{l} 1 \mathrm{M}$ TRIS for $30 \mathrm{~min}$.

6. Add $10 \mu \mathrm{l}$ glacial acetic acid.

7. Pool the samples.

8. Concentrate to $25-50 \mu$ using SpeedVac.

\subsection{Phosphopeptides purification (1h)}

1. Dilute iTRAQ sample with TiO2 buffer A $(500 \mu \mathrm{L}$ final volume).

2. Use a $500 \mu \mathrm{l}$ syringe and a syringe driver to inject sample on column at $50 \mu \mathrm{l} / \mathrm{min}$, collect the flow through in an Eppendorf.

3. Wash TiO2 column with $1 \times 500 \mu \mathrm{TiO} 2$ buffer A1. Pool this flow through with the previous one.

4. Wash TiO2 column with $2 \times 500 \mu \mathrm{TiO} 2$ buffer $\mathrm{A} 2$.

5. Elute with $1 \times 500 \mu \mathrm{lTiO} 2$ buffer $B$ in a tube previously filled with $50 \mu$ l pure formic acid.

6. Concentrate to $50 \mu \mathrm{l}$ using speedVac.

7. Add $5 \mu \mathrm{l} 10 \%$ TFA prior LC-MS analysis.

\subsection{Glycopeptides purification ( 2 days)}

1. Desalt and dry the collected flow through from phosphopeptides purification with SPE-C18 as described in paragraph 3.3.

2. Reconstitute in $100 \mu \mathrm{l} 50 \%$ CAN.

3. Collect $50 \mu \mathrm{l}$ (about $200 \mu \mathrm{g}$ ) and adjust to $500 \mu \mathrm{l}$ with binding buffer.

4. Add $50 \mu \mathrm{l} \mathrm{NalO4} 100 \mathrm{mM}$ and incubate $1 \mathrm{~h} \mathrm{RT}$ in the dark.

5. Add $50 \mu \mathrm{l} \mathrm{NaS2O} 200 \mathrm{mM}$ and incubate $15 \mathrm{~min}$ RT in the dark.

6. Transfer $300 \mu$ l slurry hydrazide gel (corresponding to $150 \mu \mathrm{l}$ beads) in a spin columns.

7. Wash gel with $3 \times 700 \mu$ l binding buffer.

8. Add sample and mix overnight with a tube rotator at RT.

9. Wash column with $2 \times 0.7 \mathrm{ml} 60 \% \mathrm{ACN}, 2 \times 0.7 \mathrm{ml} 0.2 \mathrm{M}$ ammonium bicarbonate, $50 \%$ ACN, $3 \times 0.7 \mathrm{ml} 0.5 \mathrm{M}$ acetic acid, $50 \%$ ACN, $3 \times 0.7 \mathrm{ml} 50 \mathrm{mM}$ phosphate buffer $\mathrm{pH}$ 7.4.

10. Add $250 \mu$ l phosphate buffer and $1 \mu \mathrm{l}$ PGNase $F$, incubate overnight with agitation (Thermomixer) then add again $1 \mu \mathrm{l}$ PNGase $\mathrm{F}$ as for $24 \mathrm{~h}$.

11. Collect flow through and wash $(2 \times 250 \mu \mathrm{l} 0.5 \mathrm{M}$ acetic acid, $50 \% \mathrm{ACN})$, concentrated using SpeedVac and desalt with SPE-C18. 
Table 1. Bioinformatics webtools

\begin{tabular}{llll}
\hline Tool & Name & Website & Ref. \\
\hline Clustering & MeV & http://www.tm4.org & 28 \\
& Genesis & http://genome.tugraz.at/ & 29 \\
Sequence & & 30 \\
& peptidextender & http://schwartzlab.uconn.edu/pepextend & 30 \\
\hline ID conversion & pLogo & http://plogo.uconn.edu & 31 \\
Functional & Uniprot ID tool & http://www.uniprot.org/uploadlists & 32 \\
& DAVID & https://david.ncifcrf.gov & 33 \\
& gProfiler & http://biit.cs.ut.ee/gprofiler & http://string-db.org \\
& Networkin & http://networkin.info/ & 34 \\
\hline
\end{tabular}

\section{Dry lab protocol}

\subsection{Mass spectrometry}

Data processing is performed using Proteome Discoverer 1.4 or 2.1 (Thermo Scientific). Query parameters must be adjusted depending on the instrument. With Q-Exactive orbitrap, precursor and fragment tolerance are respectively 5 to $10 \mathrm{ppm}$, full tryptic peptides, 1 miss-cleavage, static modification on C (57.0215), N-terminal and lysine (304.2054), and dynamic modification on S, T, Y (+ 79.9663), N (+ 0.984), and M, P (+ 15.9949). The human sequences are extracted from the Swiss-Prot complete genome databases. Result filters are applied as: peptide confidence $=$ high (automatic adjustment of thresholds for a False Discovery Rate (FDR) <1\%).

\subsection{Quantitative analysis}

Quantitative values are extracted from MS/MS spectra using Proteome Discoverer and associated with their corresponding peptides. Because the same amount of sample (i.e. peptide) is used for each iTRAQ labelling, normalization is generally done with the sum of each iTRAQ column, then ratio is calculated using an iTRAQ channel as denominator. For PTM analysis, quantitative results are presented for peptide levels only. For total peptide analysis, the results are presented as protein ratios (ratios corresponding to the different peptides of a same protein are averaged). A log-2 transform is usually needed to obtain a Gaussian distribution that allows the use of parametric tests. An unsupervised hierarchical clustering is a first convenient test that can highlight the existence of sample groups (by example control 
vs. treatment). If associated with statistical tests (ANOVA, repeated t-test), clustering can also classify proteins into groups and subgroups (up- or down-regulated proteins, quantitative representation of a PTM).

\subsection{Sequence patterns}

Pattern analysis is associated with PTM. The graphic representation of specific motifs is straightforward and corresponds to a first rough step for the research of enzymes responsible of the studied PTM. A website software pLogo, is a convenient software which used sequences previously aligned with PeptidExtender. The use of both tools is straightforward and well documented.

\subsection{Gene function enrichment and pathway analysis}

Many informatics tools can be used for gene/protein analysis. Generally, these software need a list of genes/proteins of interest (i.e., deregulated) and a background gene/protein list (i.e., all the identified genes, this is optional). Functional analyses can point toward the deregulated pathways as an enrichment of controlled terms corresponding to specifically annotated pathway (KEGGS) or gene ontologies (GO). Several web applications can be used and are well illustrated with the following tools: one hand the gene enrichment with tabular results (DAVID, gProfiler, etc.) and on the other hand the gene enrichment with graphical presentation (String, Cytoscape, and its apps). The main outcome of those analyses results in the association of protein groups associated with comprehensive functions. But one has to keep in mind that many of the proteins found in the analysis remain unannotated due to the fact that either they correspond to groups with no enrichment or they are encoded by novel genes not yet characterized in term of function. As such this means that this analysis may spread pertinent genes for biomarker research.

\section{An example}

\subsection{Sample consideration}

Samples should be quality controlled at all the steps of the protocol to ensure that extraction yield of protein/peptide is equivalent for the different tissue samples. From a practical point of view, all the samples are processed in a same batch. Herein simple weighting of the peptide extract controls the yield of protein extraction / trypsin digestion and the amounts are confirmed using a Lowry protein concentration assay. Fig. 2 presents data from twelve samples extracted from three different tissues (notochord, chordoma, chondrosarcoma), illustrating the good correlation between the weight of dried peptides after Sep-Pack and protein concentration determination using Lowry assay (Fig. 2a). The same correlation is observed with the weight of the crude tissue and the amount of dried peptides (Fig. $2 b$ ). One can observe that two samples have higher peptide content. The following proteomic 
analysis has confirmed an original protein pattern of these two samples in comparison to the other tumors. Thus weighting of the tissue and of the resulting peptide extract provides relevant information for confirming the homogeneity of the samples prior to iTRAQ labelling.
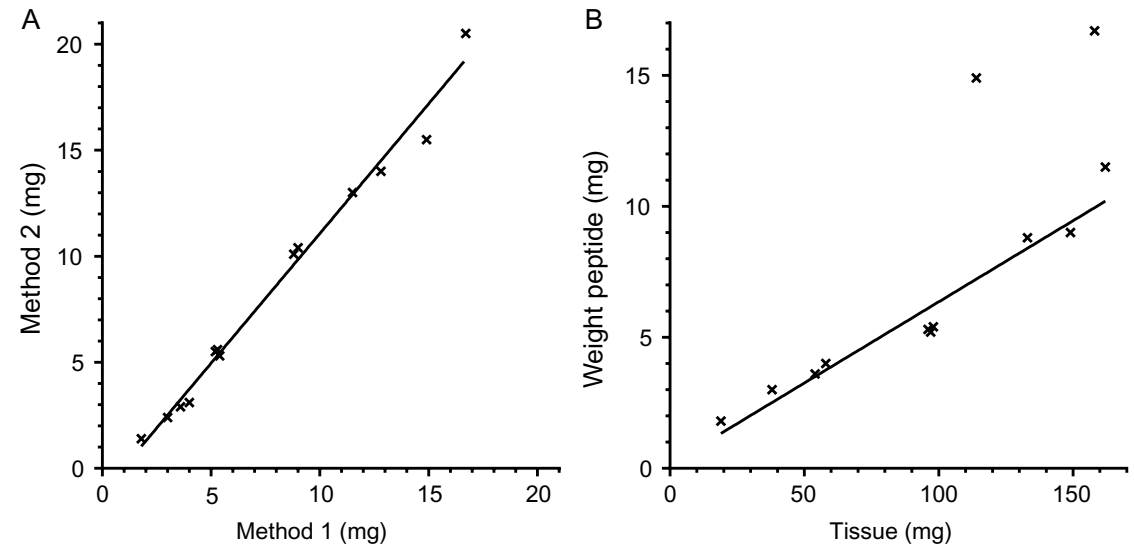

Fig. 2. Tryptic peptide Quality control. (a) Correlation between weight of purified peptides (method 1) and Lowry assay (method 2). (b) Correlation between tissue amount and purified tryptic peptide.

\section{2. iTRAQ Labeling}

The manufacturer recommends the labeling of up to $100 \mu \mathrm{g}$ with one unit of iTRAQ reagent. An excess of peptides results in a partial tagging of reactive amines. On the contrary, a nonspecific signal can be observed if free reagent remains active before mixing the samples. Fig. 3 shows iTRAQ signal for five samples and one control. ITRAQ 113 to 117 corresponds to five different tissues and ITRAQ 113 was used without sample; buffer only has reacted with reagent. Before mixing, we add two additional step in order to block residual reactive reagent by (i) adding an amine buffer as TRIS and (ii) adding acetic acid. However signal from ITRAQ 113 is still present and corresponds to $2.5 \%$ of the average signal of the samples. This test, which is performed without any protein/peptide, is extreme but demonstrates the risk to misinterpret fold change greater than an order of magnitude. Despite this limitation, Fig. 3 shows that the signal is notably correlated between the samples $(r 2>0.98$ ) and the small bias observed with ITRAQ 116 and 117 can be easily corrected with normalization as described in 3.5.

If a same reference sample is used in different iTRAQ series, it is also possible to compare more than eight samples. As such we successfully used this strategy in a study that presented a comparison between six non-tumoral samples and eighteen hepatocellular carcinoma tumor samples. 18 However, while the larger number of samples increases the statistical significance, an additional variable is introduced. Indeed, one part of the identified peptides/ proteins was different in the separate series analyzed and consequently common proteins were used for comparison, thus decreasing the number of proteins compared between series. 


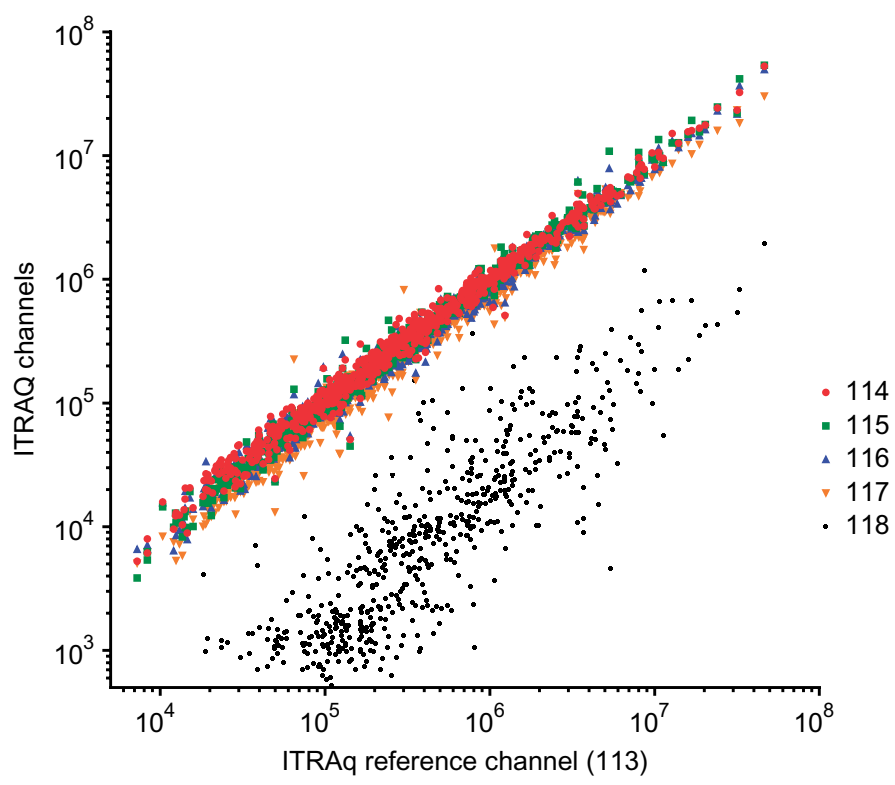

Fig. 3. Tryptic peptide Quality control. (a) Correlation between weight of purified peptides (method 1 ) and Lowry assay (method 2). (b) Correlation between tissue amount and purified tryptic peptide.

\subsection{Global quantitative and comparative proteomics}

Herein, we defined global proteomics as the proteomic analysis of samples without enrichment. A first convenient presentation of the data analysis is the non-supervised hierarchical clustering (HCL). The horizontal clustering highlights group that should correspond to samples groups while the vertical clustering groups proteins with the variation pattern. As an example, Fig. 4 shows the clustering of global proteomics from hepatocellular carcinoma. The HCL clearly separates two groups of proteins either up- or down-regulated (red and green box respectively). Regarding the horizontal clustering, the tumors group is well separated from non-tumor group. One can notice that two tumors have a different proteomics pattern than the other tumors and then are clustered with non-tumoral tissue. Thus, $\mathrm{HCL}$ may be used as a way to redefine groups before statistical analysis.

\subsection{Phosphoproteomics and N-Glycoproteomics}

Regarding the different proteomics approaches, phosphoproteomics data processing is performed on peptides level. Usually, different phosphopeptides belonging to the same protein are grouped in the same hierarchical cluster. This is a relevant validation criterion that can be carried out with global proteomics as well. Generally, the phosphopeptide fraction is contaminated with nonphosphorylated peptides that exhibit an increased proportion of aspartic acid and glutamic acid amino acid residues. Note that the quantitative variation of these background peptides should follow the variation of their corresponding protein in the global proteomic analysis. For the phosphopeptides as glycopeptides, two 


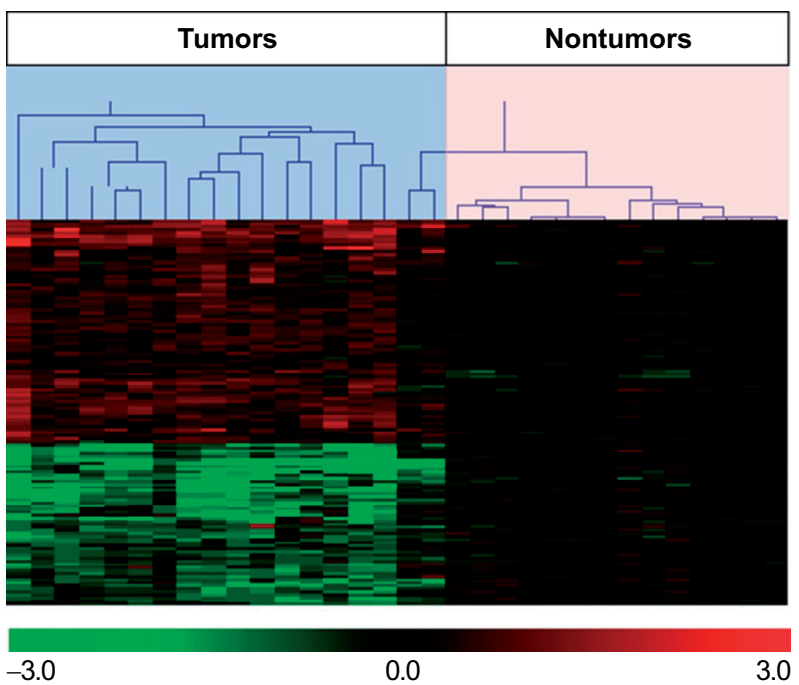

Fig. 4. Hierarchical Clustering ( $\mathrm{HCL}$ ) of Hepatocellular carcinoma and non-tumoral tissues. Each line corresponds to a protein, expressed as ratio (non-tumoral tissue as denominator).

complementary data processing approaches can be performed; sequence analysis pattern and the identification of the enzyme. Fig. 5 presents an example of motif analysis obtained with pLogo (see Table 1). If the upregulated and downregulated phosphopeptides have a different motif pattern, the signature of the upregulated phosphopeptides may correspond to the induction/activation of specific kinases. Here an SP motif is significantly overrepresented and some other motifs as RRxxS and SPxxP are present at a lower frequency (Fig. 5a). At the phosphoprotein level, each kinase can be identified using web-based programs (Fig. $5 b)$. In contrast to the identification of phosphopeptides, which are characterized by their phosphoryl group, $\mathrm{N}$-glycopeptides are identified after the hydrolysis of their sugar moiety with PNGase $\mathrm{F}$. PNGase $\mathrm{F}$ treatment converts the asparagine, within the $\mathrm{N}$-glycosylation consensus site ( $\mathrm{N}-\mathrm{XS} / \mathrm{T} / \mathrm{C}$, where $\mathrm{X}$ is any amino acid except proline) to an aspartic acid. This $\mathrm{N}$-glycosylation signature corresponds to a deamidation ( $\triangle \mathrm{M} 1 / 40.9840 \mathrm{Da})$. However, the deamidation is also a specific PTM and can occur under elevated $\mathrm{pH}$, indicating a common pitfall in large-scale $\mathrm{N}$-linked glycoproteomics. ${ }^{28}$ In this respect, we propose to remove the list of deamidated peptides identified in the eluted fraction, as previously identified in the flow through of $\mathrm{Hz}$ column (141 peptides in the case of Fig. 5c). Thus in our example only 383 of the 541 deamidated peptides identified in the PNGase F eluted fraction might indeed correspondto glycopeptides.

\subsection{Gene analysis and validation}

Following the identification of deregulated proteins, phosphopeptides, and glycopeptides, protein functional analysis can be performed for revealing deregulated functions in the diseased state. For instance, a straightforward process is to input the protein list in the 

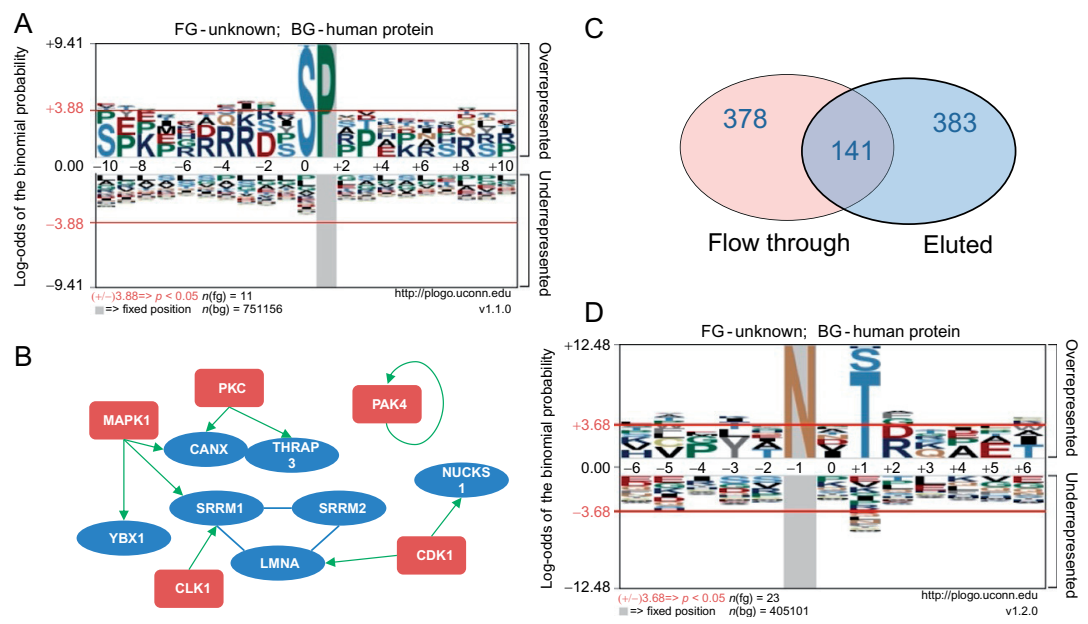

Fig. 5. Data analysis of phosphoproteomics and glycoproteomics. Phosphoproteomics: (a) Sequence motif analysis using pLogo of upregulated phosphopeptides in hepatocellular carcinoma. (b) Networkin-based analysis. Blue circles: gene name of the overrepresented phosphopeptides (substrat); red square: putative kinases. Glycoproteomics: (c) deamidated peptides identified in the flow through fraction of hydrazide column and in the eluted fraction after PNGase F reaction. (d) Sequence motif analysis of the glycopeptides as a control of the specificity of PNGase F.

web-based protein interaction software such as String. ${ }^{29}$ Presented is a layout from the String analysis obtained with the list of proteins whose expression is upregulated in HCC developed on normal liver. ${ }^{18}$ The 29 proteins of the list belong to a single highly connected network that displays 111 protein-protein interactions (38 expected) (Fig. 6). Moreover, the functional analysis of the network shown in Fig. 6 indicates the enrichment in proteins involved in endoplasmic reticulum homeostasis control and protein folding as also previously reported when integrating phosphoproteomics data. ${ }^{18}$

\section{Conclusion}

Proteomic approaches provide a global view of the (de)regulation occurring in given physiological or pathological situations. Outlined earlier is a presentation of an integrated protocol dedicated to the analysis of tumor tissues compared to their non tumoral counterparts and could be easily extended to other models. To complete such approaches, it is crucial that candidate proteins or pathways have to be validated using orthogonal approaches. The validation steps can include antibody-based strategies for Western blotting or immunohistochemistry that should be performed on both the initial sample set (samples that were analyzed by MS to be used as a mean for validating the proteomics approach) and on a validation sample set to prove the biological/pathological relevance of the information generated through proteomics. For validation purposes, targeted proteomics can represent an alternative to antibody-based methods. This is best illustrated by the use of multiple reaction moni- 


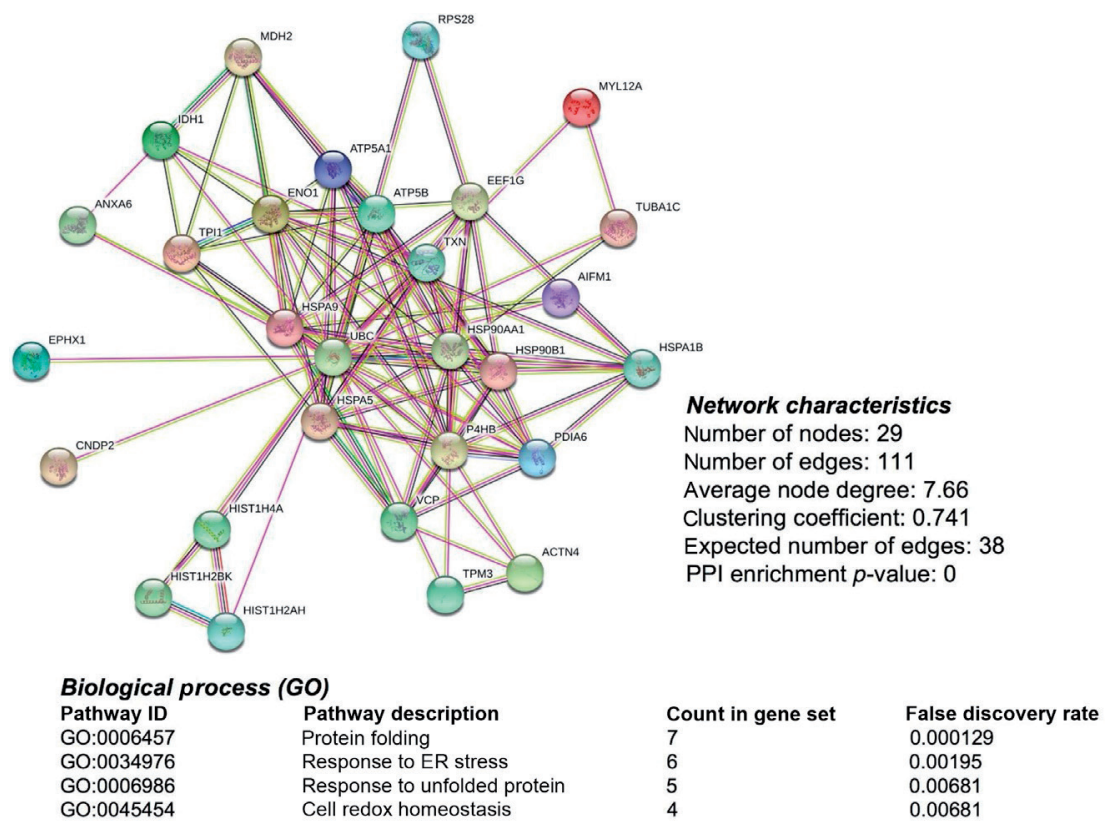

Fig. 6. Protein interaction network. Functional analysis of the proteins whose expressionis found systematically upregulated in HCC tumors developed on nonfibrous (normal) livers compared to their nontumoral counterparts. The 29 proteins with upregulated expression belong to a single network with 111 edges (expected 38). The protein-protein interaction enrichment p-value is null. A GO biological process analysis of this network reveals the enrichment in functions associated with endoplasmic reticulum homeostasis and protein-folding stress.

toring or parallel reaction monitoring that allows quantification of targeted proteins using peptides of reference..$^{30,31}$ The accuracy of quantification of a given peptide relies on the use of a synthetic-labeled internal standard (i.e., the heavy form of the proteotypic peptides). Once the observation has been confirmed and demonstrated as biologically/pathologically relevant, functional approaches using cell-based systems and animal models can be undertaken. In conclusion, in the current manuscript, we provide an experimental pipeline for integrated and quantitative proteomics of human tumors. This approach was successfully used in two types of tumors so far including hepatocellular carcinoma developed on nonfibrous livers and on chordoma. ${ }^{18}$ The flexibility and versatility of this experimental pipeline allows for easy and rapid application to other types of tissues of any origin for which quantitative approaches using metabolic labeling is impossible. 


\section{References}

1. Cordwell, S.J., et al. Cross-species identification of proteins separated by two-dimensional gel electrophoresis using matrix-assisted laser desorption ionisation/time-of-flight mass spectrometry and amino acid composition. Electrophoresis 16, 438-443 (1995).

2. Nagaraj, N., et al. System-wide perturbation analysis with nearly complete coverage of the yeast proteome by single-shot ultra HPLC runs on a bench top Orbitrap. Molecular \& cellular proteomics : MCP 11, M111 013722 (2012).

3. Kelstrup, C.D., et al. Rapid and deep proteomes by faster sequencing on a benchtop quadrupole ultra-high-field Orbitrap mass spectrometer. Journal of proteome research 13, 6187-6195 (2014).

4. Sandin, M., Chawade, A. \& Levander, F. Is label-free LC-MS/MS ready for biomarker discovery? Proteomics. Clinical applications 9, 289-294 (2015).

5. Latosinska, A., et al. Comparative Analysis of Label-Free and 8-Plex iTRAQ Approach for Quantitative Tissue Proteomic Analysis. PloS one 10, e0137048 (2015).

6. Mcllwain, S., et al. Estimating relative abundances of proteins from shotgun proteomics data. BMC bioinformatics 13, 308 (2012).

7. Mann, M. Fifteen years of Stable Isotope Labeling by Amino Acids in Cell Culture (SILAC). Methods in molecular biology (Clifton, N.J.) 1188, 1-7 (2014).

8. Tyanova, S., Mann, M. \& Cox, J. MaxQuant for in-depth analysis of large SILAC datasets. Methods in molecular biology (Clifton, N.J.) 1188, 351-364 (2014).

9. Rauniyar, N. \& Yates, J.R., 3rd. Isobaric labeling-based relative quantification in shotgun proteomics. Journal of proteome research 13, 5293-5309 (2014).

10. Huang, J., Wang, F., Ye, M. \& Zou, H. Enrichment and separation techniques for large-scale proteomics analysis of the protein post-translational modifications. Journal of chromatography. A 1372C, 1-17 (2014).

11. Kim, M.S., Zhong, J. \& Pandey, A. Common errors in mass spectrometry-based analysis of post-translational modifications. Proteomics 16, 700-714 (2016).

12. Olsen, J.V. \& Mann, M. Status of large-scale analysis of post-translational modifications by mass spectrometry. Molecular \& cellular proteomics : MCP 12, 3444-3452 (2013).

13. Boersema, P.J., et al. In-depth qualitative and quantitative profiling of tyrosine phosphorylation using a combination of phosphopeptide immunoaffinity purification and stable isotope dimethyl labeling. Molecular \& cellular proteomics : MCP 9, 84-99 (2009).

14. Huttlin, E.L., et al. A tissue-specific atlas of mouse protein phosphorylation and expression. Cell 143, 1174-1189 (2010).

15. Villen, J. \& Gygi, S.P. The SCX/IMAC enrichment approach for global phosphorylation analysis by mass spectrometry. Nature protocols 3, 1630-1638 (2008).

16. Lundby, A., et al. Quantitative maps of protein phosphorylation sites across 14 different rat organs and tissues. Nat Commun. 3:876., 10.1038/ncomms1871. (2012).

17. Negroni, L., et al. Comparison of IMAC and MOAC for phosphopeptide enrichment by column chromatography. Journal of chromatography. B, Analytical technologies in the biomedical and life sciences 891-892, 109-112 (2012).

18. Negroni, L., et al. Integrative quantitative proteomics unveils proteostasis imbalance in human hepatocellular carcinoma developed on nonfibrotic livers. Molecular \& cellular proteomics : MCP 13, 3473-3483 (2014). 
19. Britton, D., et al. Quantification of pancreatic cancer proteome and phosphorylome: indicates molecular events likely contributing to cancer and activity of drug targets. PloS one 9, e90948 (2014).

20. Jouy, F., et al. Integration of conventional quantitative and phospho-proteomics reveals new elements in activated Jurkat T-cell receptor pathway maintenance. Proteomics 15, 25-33 (2015).

21. Thaysen-Andersen, M., Packer, N.H. \& Schulz, B.L. Maturing Glycoproteomics Technologies Provide Unique Structural Insights into the N-glycoproteome and Its Regulation in Health and Disease. Molecular \& cellular proteomics : MCP 15, 1773-1790 (2016).

22. Zacchi, L.F. \& Schulz, B.L. N-glycoprotein macroheterogeneity: biological implications and proteomic characterization. Glycoconjugate journal 33, 359-376 (2016).

23. Zhang, Y., Jiao, J., Yang, P. \& Lu, H. Mass spectrometry-based N-glycoproteomics for cancer biomarker discovery. Clinical proteomics 11, 18 (2014).

24. Deeb, S.J., Cox, J., Schmidt-Supprian, M. \& Mann, M. N-linked glycosylation enrichment for in-depth cell surface proteomics of diffuse large B-cell lymphoma subtypes. Molecular \& cellular proteomics : MCP 13, 240-251 (2014).

25. Boersema, P.J., Geiger, T., Wisniewski, J.R. \& Mann, M. Quantification of the N-glycosylated secretome by super-SILAC during breast cancer progression and in human blood samples. Molecular \& cellular proteomics : MCP 12, 158-171 (2013).

26. Semaan, S.M., Wang, X., Marshall, A.G. \& Sang, Q.X. Identification of Potential Glycoprotein Biomarkers in Estrogen Receptor Positive (ER+) and Negative (ER-) Human Breast Cancer Tissues by LC-LTQ/FT-ICR Mass Spectrometry. Journal of Cancer 3, 269-284 (2012).

27. Yang, G., et al. Selective isolation and analysis of glycoprotein fractions and their glycomes from hepatocellular carcinoma sera. Proteomics 13, 1481-1498 (2013).

28. Palmisano, G., Melo-Braga, M.N., Engholm-Keller, K., Parker, B.L. \& Larsen, M.R. Chemical deamidation: a common pitfall in large-scale $\mathrm{N}$-linked glycoproteomic mass spectrometry-based analyses. Journal of proteome research 11, 1949-1957 (2012).

29. Jensen, L.J., et al. STRING 8-a global view on proteins and their functional interactions in 630 organisms. Nucleic Acids Research 37, D412-D416 (2009).

30. Ebhardt, H.A., Root, A., Sander, C. \& Aebersold, R. Applications of targeted proteomics in systems biology and translational medicine. Proteomics 15, 3193-3208 (2015).

31. Gallien, S. \& Domon, B. Detection and quantification of proteins in clinical samples using high resolution mass spectrometry. Methods (San Diego, Calif.) 81, 15-23 (2015). 

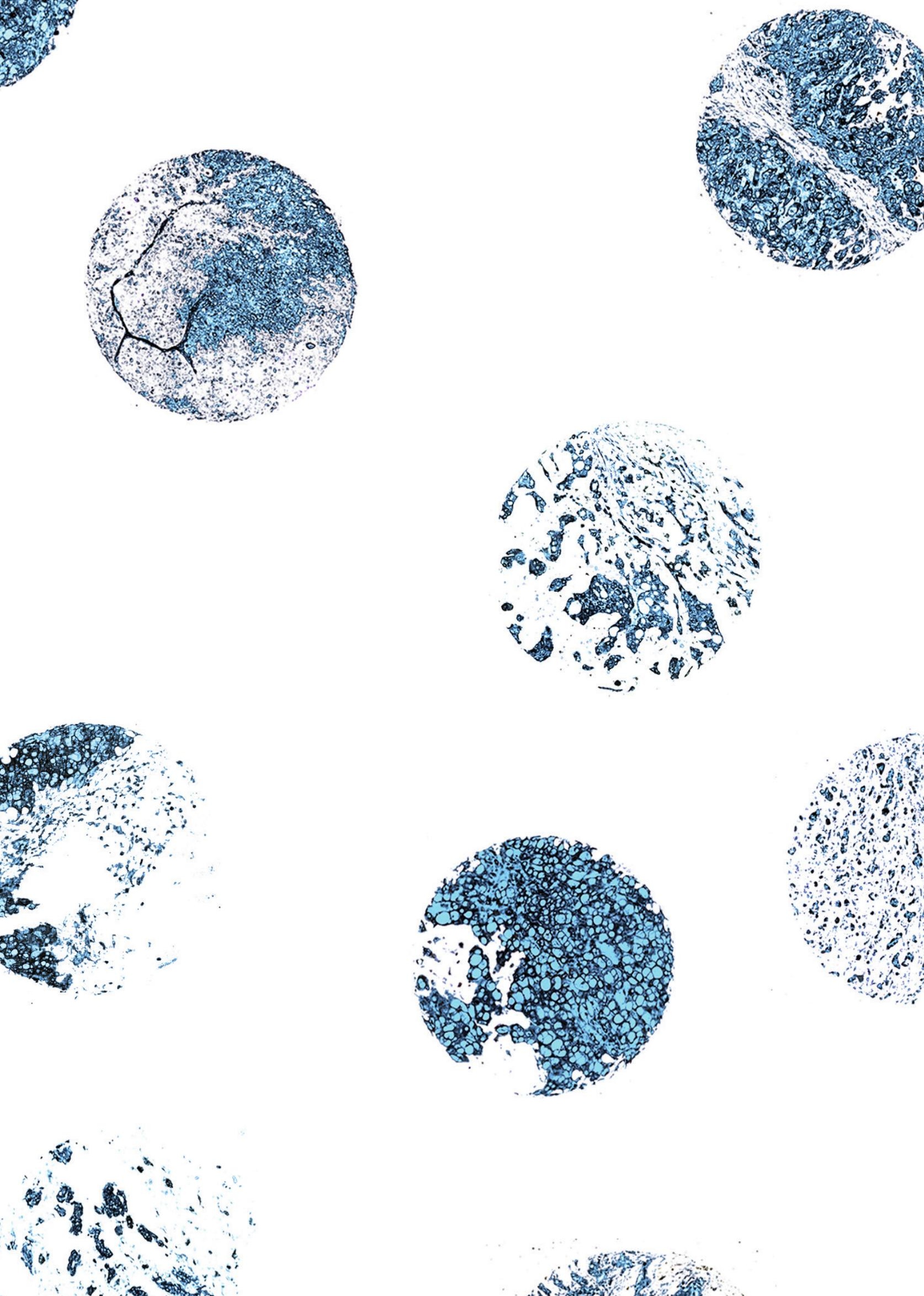

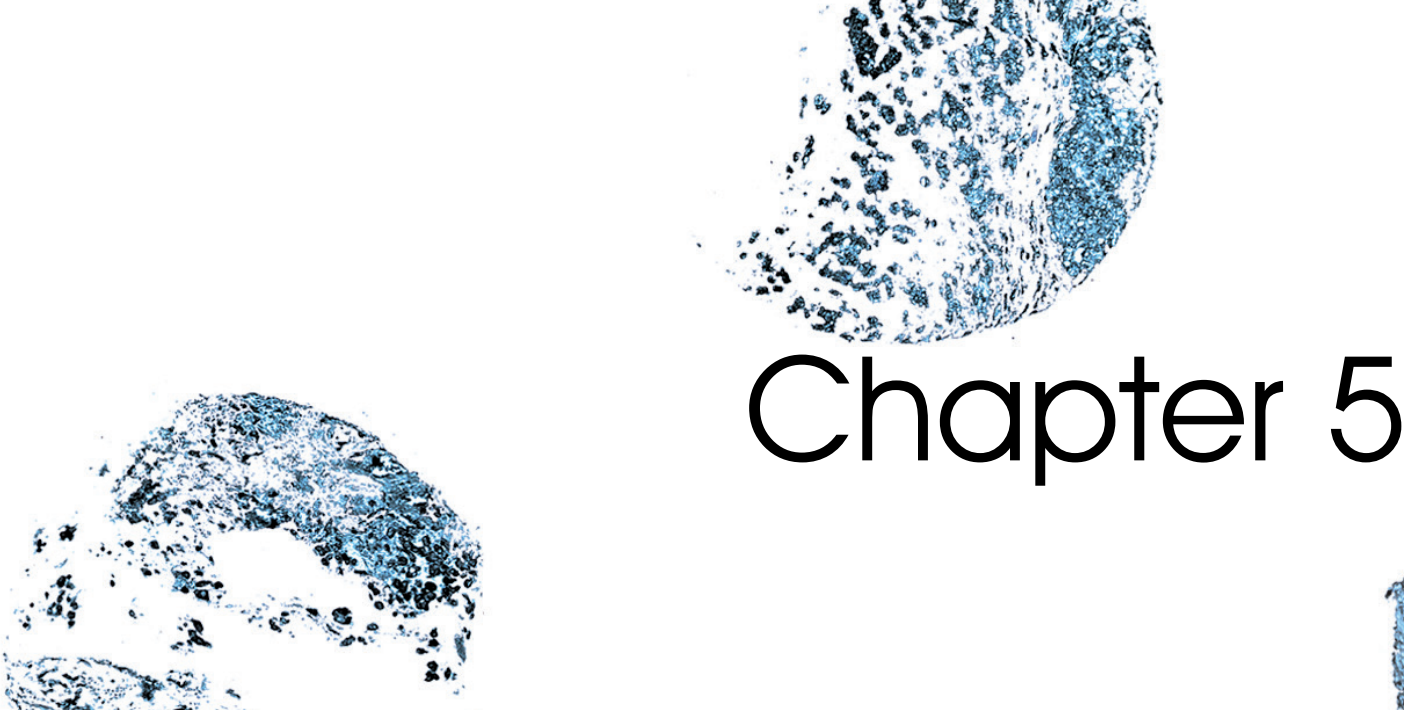

Kinase activity in recurring primary skull base chordomas and chondrosarcomas: identification of novel pathways of oncogenesis and potential drug targets

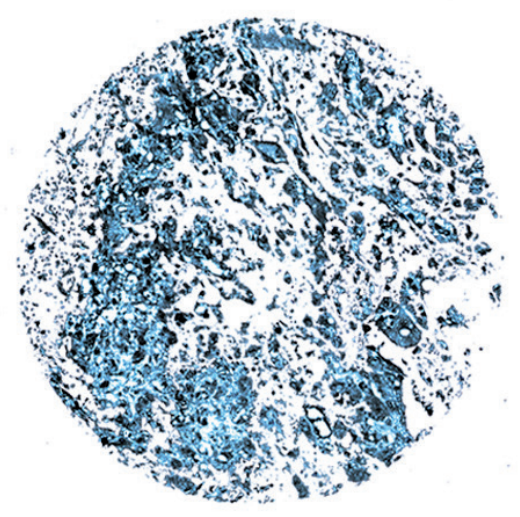

P Tatman
J Osbun
Y Yakkioui
S Kaur
C Parada
T Busald
D Born
O Ahmad
J Zhang
M Ferreira

World Neurosurg 2017 Nov; 107:75-81 


\section{Abstract}

Background: Chordomas and chondrosarcomas can occur in the skull base. Currently, $45 \%$ of chordomas and $56 \%$ of chondrosarcomas recur within 5 years of surgery. The role of adjuvant therapy is highly debated. No pharmacotherapies have been approved by the U.S. Food and Drug Administration for chordomas or chondrosarcomas. High propensity for recurrence and lack of definitive adjuvant therapy necessitate additional basic science research to identify molecular anomalies associated with recurrent disease.

Methods: We pooled tumor lysates from patients based on clinical criteria into 4 groups: primary chordomas, primary chordomas that recurred, primary chondrosarcomas, and primary chondrosarcomas that recurred. We used a peptide labeling method, isobaric tags for relative and absolute quantitation, to uniquely identify each tumor group. Phosphorylated peptides were identified and quantified via mass spectroscopy to determine and predict active kinases.

Results: Six groups of phosphorylated peptides were associated with primary tumors that later recurred. Specific kinases associated with primary chordomas that recurred were FES and FER. Specific kinases associated with primary chondrosarcomas that recurred were FES, FER, SRC family kinases, PKC, ROCK, and mitogen-activated protein kinase signaling (JNK, ERK1, p38).

Conclusions: These data provide clinicians with a means to screen skull base chordomas and chondrosarcomas to help identify tumors with a propensity to recur. Many of these kinases can be efficaciously inhibited by Food and Drug Administration-approved drugs that have not yet been used in clinical trials for treatment of skull base chordomas or chondrosarcomas. Validation of kinases identified in this study may advance treatment options for patients with these tumors. 


\section{Introduction}

Chordomas and chondrosarcomas are related neoplastic lesions that can occur in the skull base. The prognosis and clinical outcome for patients with these tumors is relatively poor. With surgery alone, the 5-year survival rate for chordomas of the skull base is $68 \%-83 \%^{1-4}$ and for chondrosarcomas of the skull base is $74 \% .{ }^{5}$ The 5 -year recurrence-free survival rates are $56 \%$ for chondrosarcomas ${ }^{5}$ and approximately $45 \%$ for chordomas. ${ }^{2,4}$ Surgery is currently the standard clinical treatment recommendation for both tumors and is the most significant predictor of improved patient outcome..$^{5-8}$

Adjuvant therapy for these neoplasms is heavily debated in the literature. ${ }^{6-11}$ Skull-based chordomas are considered to be resistant to radiotherapy, although high doses of radiotherapy may have some clinical efficacy. ${ }^{7}$ The use of radiotherapy in chondrosarcomas of the skull base has a relatively greater degree of efficacy with 5 -year survival rates $>90 \%$ in some clinical series. ${ }^{12}$ However, radiotherapy alone is not recommended for skull base chondrosarcomas because of poor survival compared with survival of patients who underwent surgery. ${ }^{7,8,13}$ At the present time, no U.S. Food and Drug Administration (FDA)approved drugs exist for the treatment of chordomas ${ }^{7,8,10}$ or chondrosarcomas. ${ }^{5-8,10,11}$

The lack of evidence for appropriate clinical management of chordomas and chondrosarcomas of the skull base may stem from the low prevalence of these tumors in the general population. Epidemiologic studies have shown these tumors are relatively rare, with chondrosarcomas accounting for $6 \%$ of tumors in the skullbase ${ }^{12}$ and chordomas accounting for $4 \%$ of tumors in the skull base. ${ }^{8}$ In general, most clinicians can expect a degree of uncertainty when treating patients with chordomas. ${ }^{7,8}$ Although patients with chondrosarcomas experience relatively greater benefit from adjuvant radiotherapy compared with patients with chordomas ${ }^{9}$, these tumors are often difficult to resect. ${ }^{14}$ This further complicates the management of these neoplasms given the lack of concrete clinical recommendations for patients who do not qualify for radiotherapy or fail radiotherapy. ${ }^{12,15}$

Histopathologic examination of chordomas and chondrosarcomas is inadequate in predicting rapidly progressive tumors. To develop evidence-based recommendations for the management of these tumors, basic science research is needed to determine molecular markers, which identify aggressive phenotypes that require additional medical interventions, and to identify drug targets, which can be targeted through new pharmacotherapy or repurposing of existing pharmacotherapy. Several recent studies have attempted to address this need. In chordomas, studies have implicated transforming growth factor- $\beta$ signaling, Akt signaling, mitogen-activated protein kinase signaling, and tyrosine kinase signaling as potential markers for aggression and thus potential targets for drugs. ${ }^{16-20}$ However, clinical trials and case studies that have attempted to use a targeted molecular approach to therapy have not resulted in significant improvement over current clinical guidelines for chordomas. ${ }^{10}$ In skull base chondrosarcomas, metalloproteinase activity, mito- 
gen-activated protein kinase signaling, and Akt signaling have been implicated as markers for aggression and therapy, ${ }^{21}$ although these targets have not resulted in clinically efficacious treatments. ${ }^{5,12}$ Despite this deficit, these studies do share a common theme in that intracellular phosphorylation is implicated as the primary mechanism for disease progression in both chordomas and chondrosarcomas. The complexity of the human kinome may account for the lack of translation of basic science research into clinical management of these cancers ${ }^{22-24}$; thus, global analysis and higher resolution studies of the phosphorylated proteome (phosphoproteome) may provide the necessary data to translate these basic science studies into appropriate clinical therapy.

In this study, we globally characterize the phosphoproteome of skull base primary chordomas, primary chordomas that recurred, primary chondrosarcomas, and primary chondrosarcomas that eventually recurred. Using an unbiased approach, we can understand the major changes in kinase signaling pathways that distinguish tumors that do not respond to surgery and tumors that do respond to surgery. This study reveals novel kinases not yet implicated in chondrosarcoma or chordoma pathophysiology and provides evidence to support further research into the use of specific kinase inhibitors in cases of recurrent disease.

\section{Materials and methods}

\subsection{Explanation of approach and overview of workflow}

To globally characterize the phosphoproteome across primary chordomas that did and did not recur and primary chondrosarcomas that did and did not recur, we first identified groups of patients who met our inclusion criteria for each group (Fig. 1). We then pooled the protein lysate from each tumor by tumor group and isolated the phosphorylated peptides. We used a peptide labeling method, isobaric tags for relative and absolute quantitation (iTRAQ), on our samples via mass spectroscopy (MS) (Fig. 1). The iTRAQ labels allowed us to determine the increase or decrease in phosphorylation of specific phosphorylation sites between recurrent and nonrecurrent tumors. These peptides and groups of peptides were analyzed using several open source bioinformatics programs to determine the kinasesresponsible for regulating the identified phosphosites and the resulting impact on cell signaling pathways.

\subsection{Patient selection}

All patients gave consent as part of an institutional review board-approved protocol. To be considered for inclusion in this study, patients had to have a primary tumor diagnosis of either a chordoma or a chondrosarcoma. Only patients with tumors of the skull base were included in this study. Patients with residual disease were excluded. Patients who were considered to have nonrecurrent disease must have undergone a gross total resection and had 10 years of follow-up while remaining disease-free. Patients with recurrent disease 


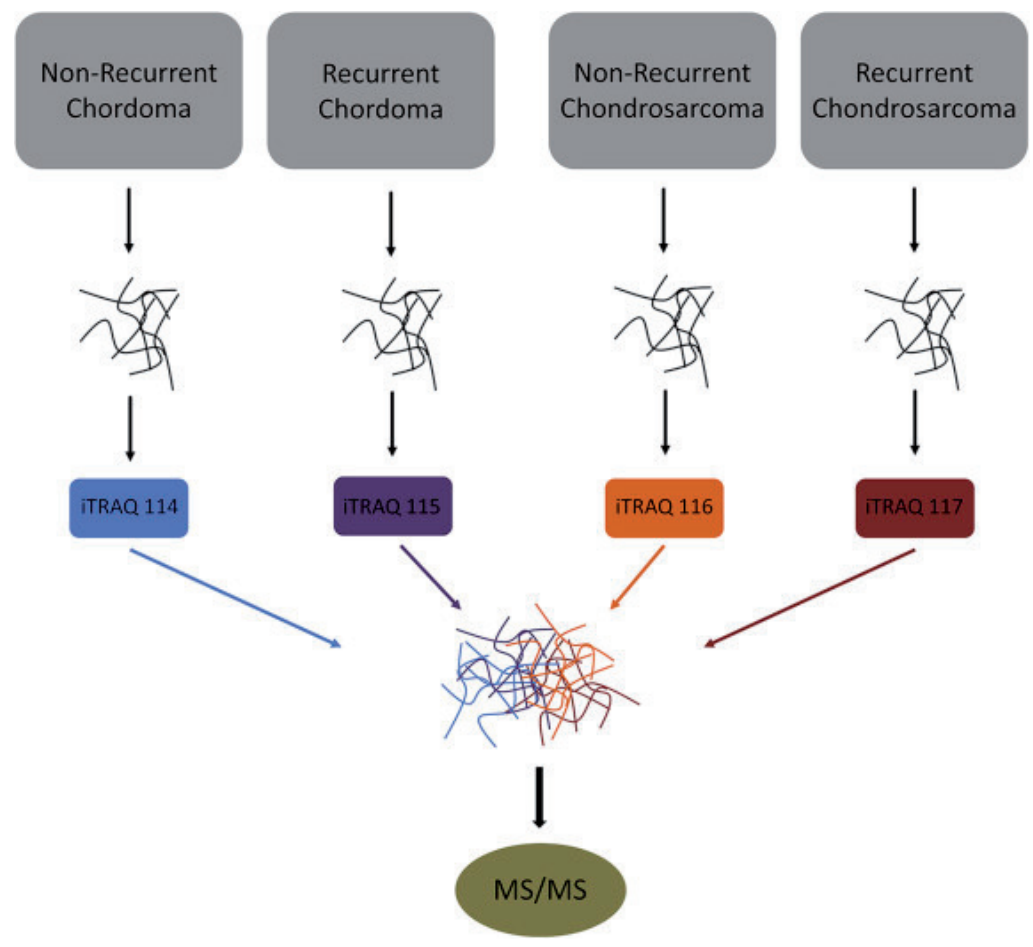

Fig. 1. Schematic depicts the workflow used to complete iTRAQ experiment. Protein lysate is pooled into groups based on clinical criteria. The pooled lysates are labeled with a unique iTRAQ tag, and then all samples are pooled into a single group and analyzed in a single liquid chromatography tandem mass spectrometry (MS/MS) run to eliminate run-to-run variation associated with label-free techniques.

must have undergone a gross total resection and had recurrent disease within 5 years of surgery. There was no history of clinically significant radiation exposure, other cancers, or tumors in our patient cohort. Two patients met our criteria for primary chondrosarcoma, 5 patients met criteria for primary chondrosarcoma with recurrence, 2 patients met criteria for primary chordoma, and 3 patients met criteria for a primary chordoma with recurrence.

\subsection{Tumor preparation}

Tumors were submerged in liquid nitrogen immediately after resection. All tumors were stored at $-80^{\circ} \mathrm{C}$ until initiation of experiments. From each tumor, $100 \mathrm{mg}$ of tissue was thawed in a 20-mmol/L HEPES buffer (Bio-Rad Laboratories, Inc., Hercules, California, USA) containing $0.1 \%$ NP-40, 0.1\% Triton X-100, 1× phosphate inhibitor (BioRad Laboratories, Inc.), $1 \mu \mathrm{mol} / \mathrm{L}$ okadaic acid, $1 \times$ protease inhibitor cocktail (BioRad Laboratories, Inc.), and 1 $\mathrm{mmol} / \mathrm{L}$ phenylmethylsulfonyl fluoride. The samples were homogenized via sonication and centrifuged at $15,000 \mathrm{~g}$ for 10 minutes. A bicinchoninic acid assay was performed on the supernatant, and $40 \mu \mathrm{g}$ of protein from each sample was pooled into the corresponding groups. From each of the pooled samples, $20 \mu \mathrm{g}$ of lysate was used for a silver stain (Fig. 2A). 
A

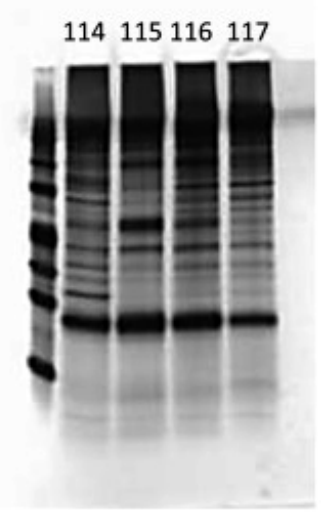

B

114115116117

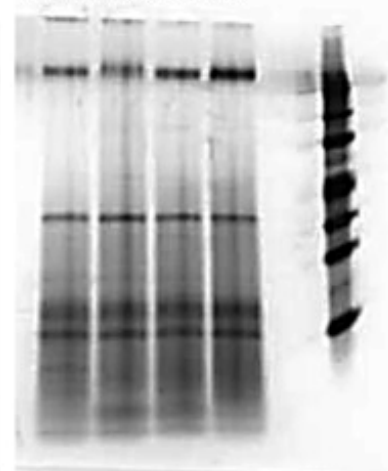

Fig. 2. Silver stains demonstrating successful isolation and digestion of protein into peptides. A bicinchoninic acid assay was performed on all pooled tumor lysate groups before digestion with trypsin to ensure equal amounts of protein were used across all samples. (A) Predigestion silver stain shows that an equal amount of protein was used in each tumor group, and (B) postdigestion sample shows that an equal amount of protein was recovered after digestion. These data show that an equal quantity of peptides were subjected to labeling with an iTRAQ reagent for each group, thus ensuring any differences in the data are inherent to the biology of the tumor.

The remainder of the lysate was incubated at $36^{\circ} \mathrm{C}$ and digested with trypsin for 16 hours. An additional $20 \mu \mathrm{g}$ of protein lysate was taken after digestion from each pooled sample to validate the digestion via silver stain (Fig. 2B).

\subsection{Phosphoproteome isolation, ITRAQ iabeling, and MS}

The samples were labeled with iTRAQ reagents (AB Sciex LLC, Framingham, Massachusetts, USA) per the manufacturer's protocol. The primary chordomas were labeled with isotope 114 , primary chordomas with recurrence were labeled with isotope 115 , primary chondrosarcomas were labeled with isotope 116, and primary chondrosarcomas with recurrence were labeled with isotope 117 . Once labeled, all 4 samples were pooled. Before isolating the phosphoproteome, excess reagents and ions were removed using a Waters Oasis Sep-Pak Vacuum column (Waters Corp., Milford, Massachusetts, USA). Phosphopeptides were isolated using a Pierce TiO2 Phosphopeptide Enrichment and Clean-up Kit (Thermo Fisher Scientific, Waltham, Massachusetts, USA) per the manufacturer's protocol. Each sample was then vacuum dried and suspended in $2 \mu \mathrm{L}$ of matrix solution. The sample was separated on a liquid chromatography column and analyzed via a MALDI TOF/TOF 4800 system (AB Sciex LLC). This protocol was performed in triplicate.

\subsection{Data analysis and peptide clusters}

Each MS output was combined into a single data set. Missed cleavage sites and unlabeled peptides were removed. To globally determine the increase or decrease of phosphorylation 
of phosphosites within the chordoma and chondrosarcoma groups, the isotope peak areas of each peptide for each group of tumors were transformed into a series of ratios (i.e., ratio of chordoma to recurrent chordoma for a given peptide). The ratios for each peptide were averaged across each run. All peptide ratios were imported into Cluster 3.0 (http://bonsai. hgc.jp/\%7Emdehoon/software/cluster/software.htm), each peptide was centered on its mean, and the peptides were grouped via a hierarchical uncensored method. The peptide groups were visualized as a heat map using Java Treeview (https://sourceforge.net/projects/ jtreeview/) (Fig. 3A). Groups of peptides were isolated form the heatmap based on their similarity across ratios and displayed graphically (Fig. 3B). Each peptide group was analyzed for kinase regulation in iGPS (http://igps.biocuckoo.org/).

A

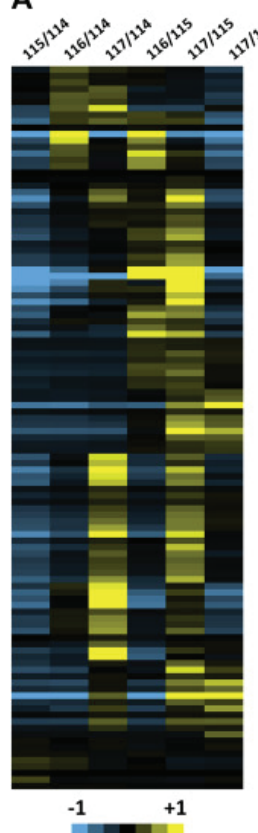

B
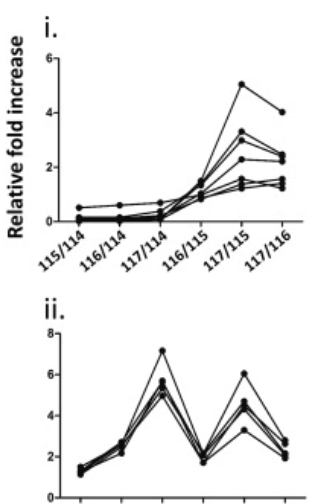

iii.

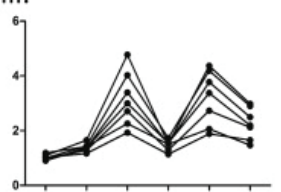

iv.
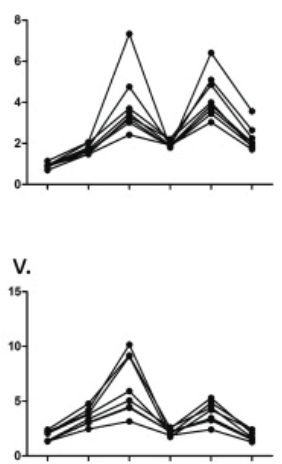

vi.

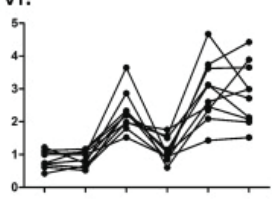

Fig. 3. Results of the phosphoproteome isolation and kinase predictions. (A) Heatmap displaying the ratios of phosphorylated peptides identified in our experiment. (B) Using a clustering algorithm, we identified 6 groups of peptides that exhibited similar patterns of phosphorylation ratios and had higher levels of phosphorylation in recurrent tumors. These peptides were then analyzed by a predictive kinase program, which identified the following kinases as having the potential to phosphorylate every peptide in a given group: i) MYCK; ii) PKC; iii) PKC, ROCK; iv) AKT1, FGR, FYN, LYN, YES; v) FER, FES; vi) ERK1 (MAPK3), JNK (MAPK8 and MAPK 9), p38 (MAPK11 and MAPK13).

\subsection{Network analysis using DAVID and STRING}

The list of peptides was uploaded to DAVID (https://david.ncifcrf.gov/) and subjected to GO (http://www.geneontology.org/) analysis to determine the cellular processes regulated by the phosphosites identified (Fig. 4A). Peptides found to have increased phosphorylation in tumors that recurred were isolated and also analyzed via $\mathrm{GO}$ to determine which processes may be responsible for disease progression (Fig. 4B). To identify additional levels of regu- 
lation, a protein motif enrichment was performed (Fig. 4C and D). The list of peptides and predicted kinases were loaded into the STRING (https://string-db.org/) database to see if experimental evidence from other studies existed that supported the protein-kinaserelationships identified in our study (Fig. S1).
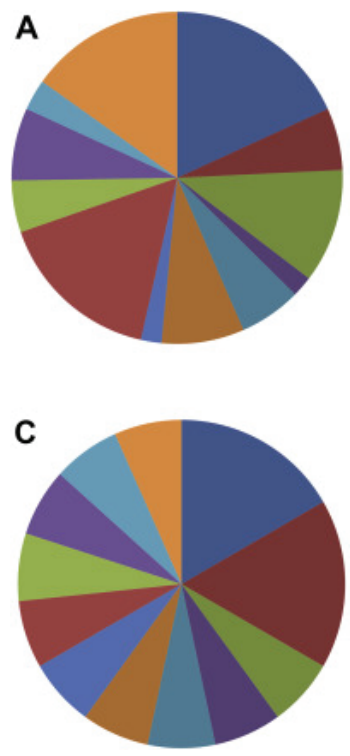

- Cytoskeletal protein binding - Calmodulin binding = Structural molecule activity - TPR domain binding m Carbohydrate binding = Identical protein binding = Nitric-oxide synthase regulator activity - Nucleotide binding $=$ Protein homodimerization activity n RNA binding = Unfolded protein binding $=$ Response to stress

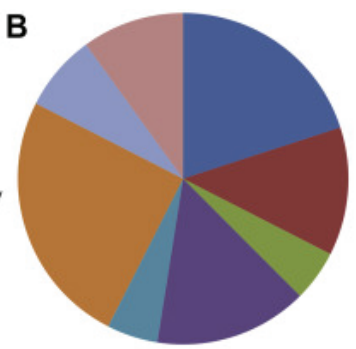

- Cytoskeletal protein binding - Calmodulin binding = TPR domain binding - RNA binding = Nitric-oxide synthase regulator activity - Nucleotide binding - Unfolded protein binding - Protein dimerization activity

Fig. 4. (A-D) Bioinformatics analysis comparing enrichment of cellular processes and protein function in primary benign and recurrent tumors. We performed a GO term and InterPro (https://www.ebi.ac.uk/interpro/) motif analysis to see which cellular processes and protein functions these phosphorylation sites could regulate. (A and C) Cellular processes identified in the GO term analysis for all peptides (A) and the phosphopeptides found in primary tumors that recurred (C). (B and D) Results from the InterPro motif analysis for all peptides (B) and the peptides found to have increased phosphorylation in primary tumors that recurred (D).

\section{Results}

The MS results returned a list of 91 phosphorylated peptide sites (Fig. 3A) from 75 proteins. Of this larger protein cohort, 35 had increased phosphorylated peptides in primary tumors, which recurred. A clustering algorithm grouped these peptides into 6 distinct groups (Fig. 3B). Kinase prediction software showed that each group of phosphopeptides is regulated by different kinases (Fig. 3Bi-vi). In total, the following kinases were predicted as having increased activity in primary tumors that recurred: MYCK, PKC, ROCK, AKT1, FGR, FYN, LYN, YES, FER, FES, ERK1, JNK, and p38.

Differences in kinase activity were also noted between primary chondrosarcoma that recurred and primary chordoma that recurred (Fig. 3B). The chordoma samples that recurred showed an increase of kinase activity only in FES and FER (Fig. 3Bi), whereas the chondrosarcoma samples that recurred showed a broad increase in kinase activity compared with 
benign chondrosarcoma (Fig. 3Bi-vi). Despite both tumors being part of the sarcoma family, primary chordomas and chondrosarcomas that recur do so through different signaling mechanisms.

Bioinformatics analysis to gain insight into both cellular and protein function regulated by these overactive kinases revealed enrichments unique to recurring primary tumors (Fig. 4). GO term analysis of the 35 proteins with increased phosphorylated peptides in primary tumors that recurred showed an enrichment of proteins responsible for cytoskeletonbinding, nucleotide binding, nitric oxide regulation, and protein folding (Fig. 4B). An InterPro analysis to look for enrichment of protein motifs in the same cohort of proteins showed an increase in protein motifs associated with nucleotide binding, heat shockdomains, adenosine triphosphate-binding domains, and Src homology-3 domains (Fig. 4D). This analysis suggests that these cellular processes and protein functions are subjected to a higher degree of kinase regulation in primary tumors that recur.

Through the use of the STRING database, we were able to show that the relationships identified in our study had empirical support from many other studies (Fig. S1). This analysis allowed us to validate our findings in the context of scientific literature. In accordance with our protein kinase predictions, nearly every interaction has been validated in other scientific articles (Fig. S1), thus providing validity for our bioinformatics analysis and kinase predictions.

\section{Discussion}

The main purpose of this study was to gain insight into the kinase signaling mechanisms in primary chordomas and chondrosarcomas that recur. Through the application of MS proteomics, we succeeded in identifying a group of kinases that appear to have higher activity in these neoplasms. From these data, we hope to inform the oncology community of novel driver mechanisms and potential drug targets to advance the treatment of these neoplasms and improve patient outcomes.

Both chordomas and chondrosarcomas are rare tumors of the skull base. Very few data exist to help distinguish primary tumors with a propensity to recur from tumors that do not recur. The identification of aggressive tumors is not possible with current histopathologic methods. Chordomas and chondrosarcomas could be screened using antibodies to any of the phosphopeptides, or predicted kinases, reported in this study as a means to identify tumors with a higher likelihood to recur.

Inhibition of specific kinases has had great success in other cancers. To determine the potential of our kinase cohort as targets for treatment, we reviewed the previous and current clinical trials listed on ClinicalTrials.gov to see if any of the kinases in this study have been targeted in clinical trials for skull base chordoma or chondrosarcoma. We found that 
none of the kinases described in this study have been directly targeted in a clinical trial specifically for chordomas or chondrosarcomas (Fig. 5 and 6). The interactions between currently targeted proteins and the kinases identified in our study may account for some of the efficacy observed in these clinical trials; however, patient outcome may be improved further with the additional use of inhibitors specific to our cohort of kinases.

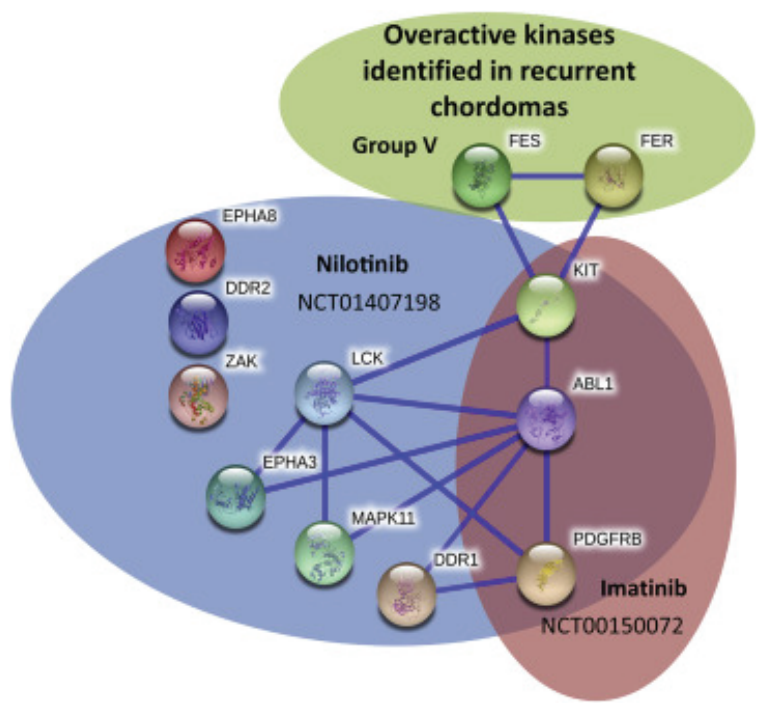

Fig. 5. By analyzing the targets for every clinical trial specific to chordomas, we found that none of these trials directly targeted the kinases found to be overactive in primary chordomas that recurred.

To date, many of the kinases from this study can be inhibited by FDA-approved drugs. Two studies, by Davis et al. ${ }^{25}$ and Wodicka et al., ${ }^{26}$ have comprehensively analyzed 456 known human kinases against FDA-approved drugs and small molecule inhibitors. By searching these databases, we were able to identify several potential drug-kinase matches. Based on our data, the treatment of both primary recurring chordomas and chondrosarcomas could be enhanced through the use of either FER or FES inhibitors. According to the previously mentioned studies, both FER and FES can be effectively inhibited by bosutinib ( $>400$ $\mathrm{nmol} / \mathrm{L}$ affinity, $>57 \%$ activity remaining at $0.5 \mu \mathrm{mol} / \mathrm{L}$ ). ${ }^{25,26}$ The treatment of chondrosarcomas could be improved by inhibiting additional kinases identified in our study. MLCK can be inhibited by sunitnib ( $>280 \mathrm{nmol} / \mathrm{L}$ affinity, $>26 \%$ activity remaining at $0.5 \mu \mathrm{mol} / \mathrm{L}$ ), any of the SRC family kinases (FGR, FYN, LYN, and YES) can be inhibited by dasatinib (>0.8 nmol/L affinity, $>2.0 \%$ activity remaining at $0.5 \mu \mathrm{mol} / \mathrm{L}$ ), and p38 can be inhibited by nilotinib (>36 $\mathrm{nmol} / \mathrm{L}$ affinity, $>16 \%$ activity remaining at $0.5 \% \mu \mathrm{mol} / \mathrm{L}){ }^{25,26}$ 


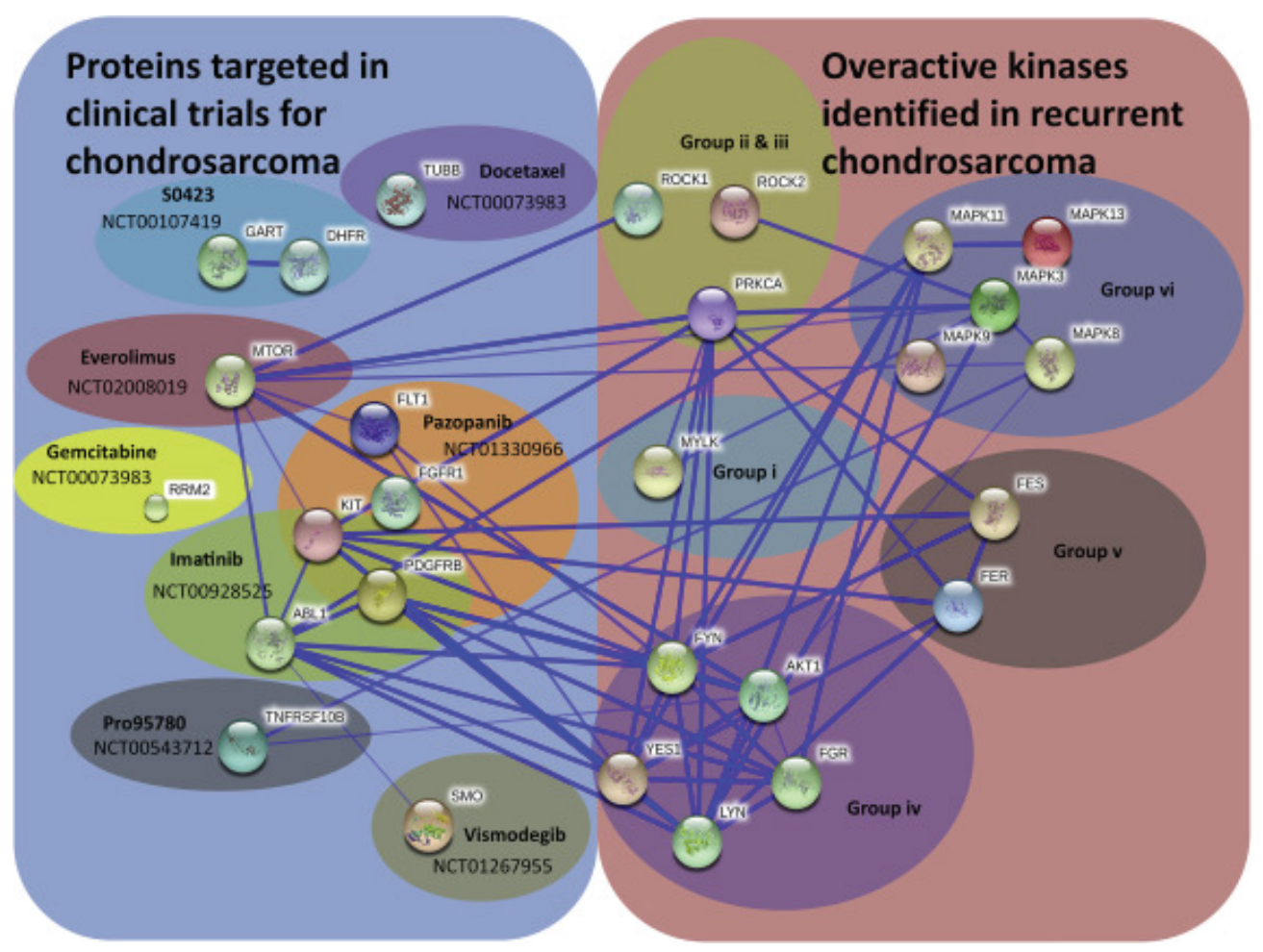

Fig. 6. The drug targets for each clinical trial specific to chondrosarcomas were compared with the kinases found to be overactive in primary chondrosarcomas that recurred. We found that none of the kinases we identified have been directly targeted in clinical trials specifically for chondrosarcomas.

\section{Conclusions}

This study has defined a group of biomarkers to identify skull base primary chordomas and chondrosarcomas with a propensity to recur. Furthermore, the kinases found to have increased activity have not been targeted in previous clinical trials for these neoplasms, but several FDA-approved drugs exist to inhibit these targets. If our results are validated in a larger cohort, application of our study in a clinical setting could allow physicians to identify chordomas and chondrosarcomas with a propensity to recur and subsequently make a treatment plan specific to the biology of the tumor. 


\section{References}

1. Di Maio, S., Rostomily, R. \& Sekhar, L.N. Current Surgical Outcomes for Cranial Base ChordomasCohort Study of 95 Patients. Neurosurgery 70, 1355-1360 (2012).

2. Ouyang, T., et al. Clinical Characteristics, Immunohistochemistry, and Outcomes of 77 Patients with Skull Base Chordomas. World Neurosurgery 81, 790-797 (2014).

3. Walter Rachinger, et al. Male sex as a risk factor for the clinical course of skull base chordomas. Journal of Neurosurgery 120, 1313-1320 (2014).

4. Wu, Z., et al. Prognostic factors for long-term outcome of patients with surgical resection of skull base chordomas-106 cases review in one institution. Neurosurgical Review 33, 451-456 (2010).

5. Bloch, O.G., et al. A systematic review of intracranial chondrosarcoma and survival. Journal of Clinical Neuroscience 16, 1547-1551 (2009).

6. Iyer, A., et al. Postsurgical management strategies in patients with skull base chondrosarcomas. CNS oncology 2, 203-208 (2013).

7. Stacchiotti, S. \& Sommer, J. Building a global consensus approach to chordoma: a position paper from the medical and patient community. The lancet oncology 16, e71-e83 (2015).

8. Walcott, B.P., et al. Chordoma: current concepts, management, and future directions. The lancet oncology 13, e69-e76 (2012).

9. Kano, H., lyer, A. \& Lunsford, L.D. Skull Base Chondrosarcoma Radiosurgery: A Literature Review. Neurosurgery 61, 155-158 (2014).

10. Lebellec, L., et al. Molecular targeted therapies in advanced or metastatic chordoma patients: Facts and hypotheses. Critical Reviews in Oncology/Hematology 95, 125-131 (2015).

11. Ossama Al-Mefty \& Luis A. B. Borba. Skull base chordomas: a management challenge. Journal of Neurosurgery 86, 182-189 (1997).

12. Bloch, O. \& Parsa, A.T. Skull Base Chondrosarcoma: Evidence-Based Treatment Paradigms. Neurosurgery Clinics of North America 24, 89-96 (2013).

13. Jones, P.S., et al. Outcomes and patterns of care in adult skull base chordomas from the Surveillance, Epidemiology, and End Results (SEER) database. Journal of Clinical Neuroscience 21, 1490-1496 (2014).

14. Rosenberg, A.E., et al. Chondrosarcoma of the base of the skull: a clinicopathologic study of 200 cases with emphasis on its distinction from chordoma. Am J Surg Pathol 23, 1370-1378 (1999).

15. Heif, M., Yen, R.D. \& Shah, R.J. ERCP with Probe-Based Confocal Laser Endomicroscopy for the Evaluation of Dominant Biliary Stenoses in Primary Sclerosing Cholangitis Patients. Digestive Diseases and Sciences 58, 2068-2074 (2013).

16. Fasig, J.H., Dupont, W.D., LaFleur, B.J., Olson, S.J. \& Cates, J.M. Immunohistochemical analysis of receptor tyrosine kinase signal transduction activity in chordoma. Neuropathol Appl Neurobiol 34, 95-104 (2008).

17. Shalaby, A., et al. The role of epidermal growth factor receptor in chordoma pathogenesis: a potential therapeutic target. The Journal of Pathology 223, 336-346 (2011).

18. Shalaby, A.A.E., et al. Analysis of the fibroblastic growth factor receptor-RAS/RAF/MEK/ ERK-ETS2/brachyury signalling pathway in chordomas. Modern Pathology 22, 996 (2009).

19. Tamborini, E., et al. Analysis of receptor tyrosine kinases (RTKs) and downstream pathways in chordomast. Neuro-Oncology 12, 776-789 (2010).

20. Wu, Z., et al. Experimental Study on Differences in Clivus Chordoma Bone Invasion: An iTRAQ-Based Quantitative Proteomic Analysis. PloS one 10, e0119523 (2015). 
21. Bloch, O., Sughrue, M.E., Mills, S.A. \& Parsa, A.T. Signaling pathways in cranial chondrosarcoma: potential molecular targets for directed chemotherapy. Journal of Clinical Neuroscience 18, 881-885 (2011).

22. Collins, M.O., Yu, L. \& Choudhary, J.S. Analysis of protein phosphorylation on a proteome-scale. Proteomics 7, 2751-2768 (2007).

23. Oppermann, F.S., et al. Large-scale Proteomics Analysis of the Human Kinome. Molecular \& Cellular Proteomics 8, 1751-1764 (2009).

24. Pierobon, M., Wulfkuhle, J., Liotta, L. \& Petricoin, E. Application of molecular technologies for phosphoproteomic analysis of clinical samples. Oncogene 34, 805 (2014).

25. Davis, M.I., et al. Comprehensive analysis of kinase inhibitor selectivity. Nature biotechnology 29, 1046 (2011).

26. Wodicka, L.M., et al. Activation State-Dependent Binding of Small Molecule Kinase Inhibitors: Structural Insights from Biochemistry. Chemistry \& Biology 17, 1241-1249 (2010).

\section{Supplemental material}

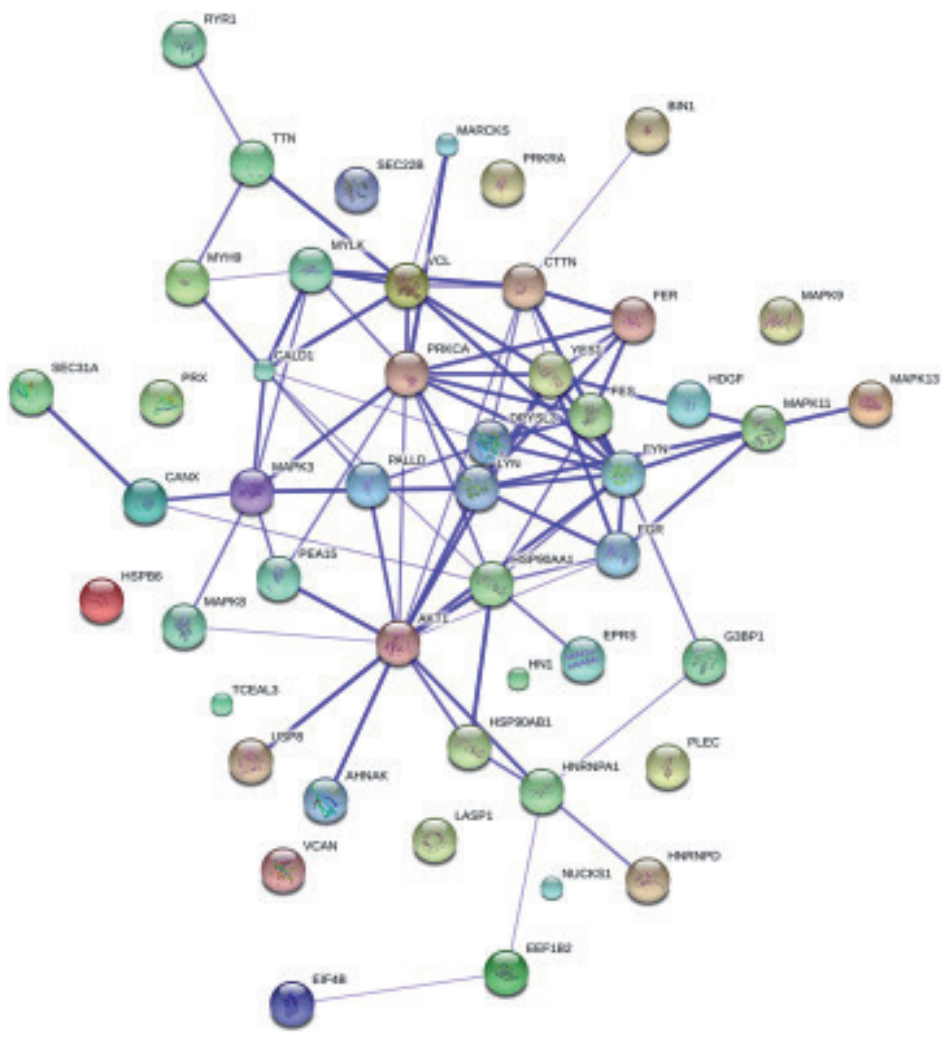

Fig. S1. String network of all peptides shown to have increased phosphorylation in recurrent tumors and the kinases predicted to phosphorylate them. 

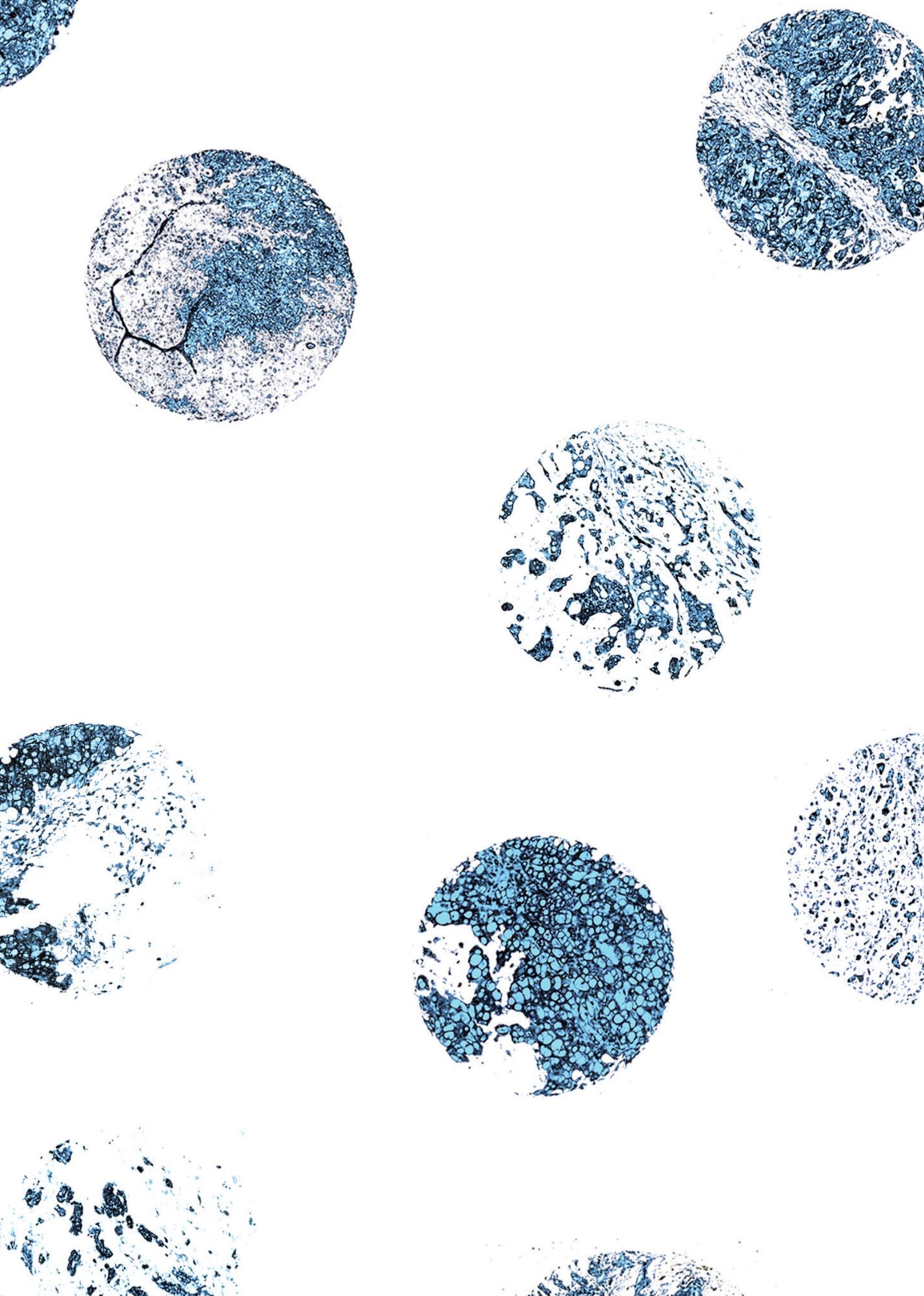

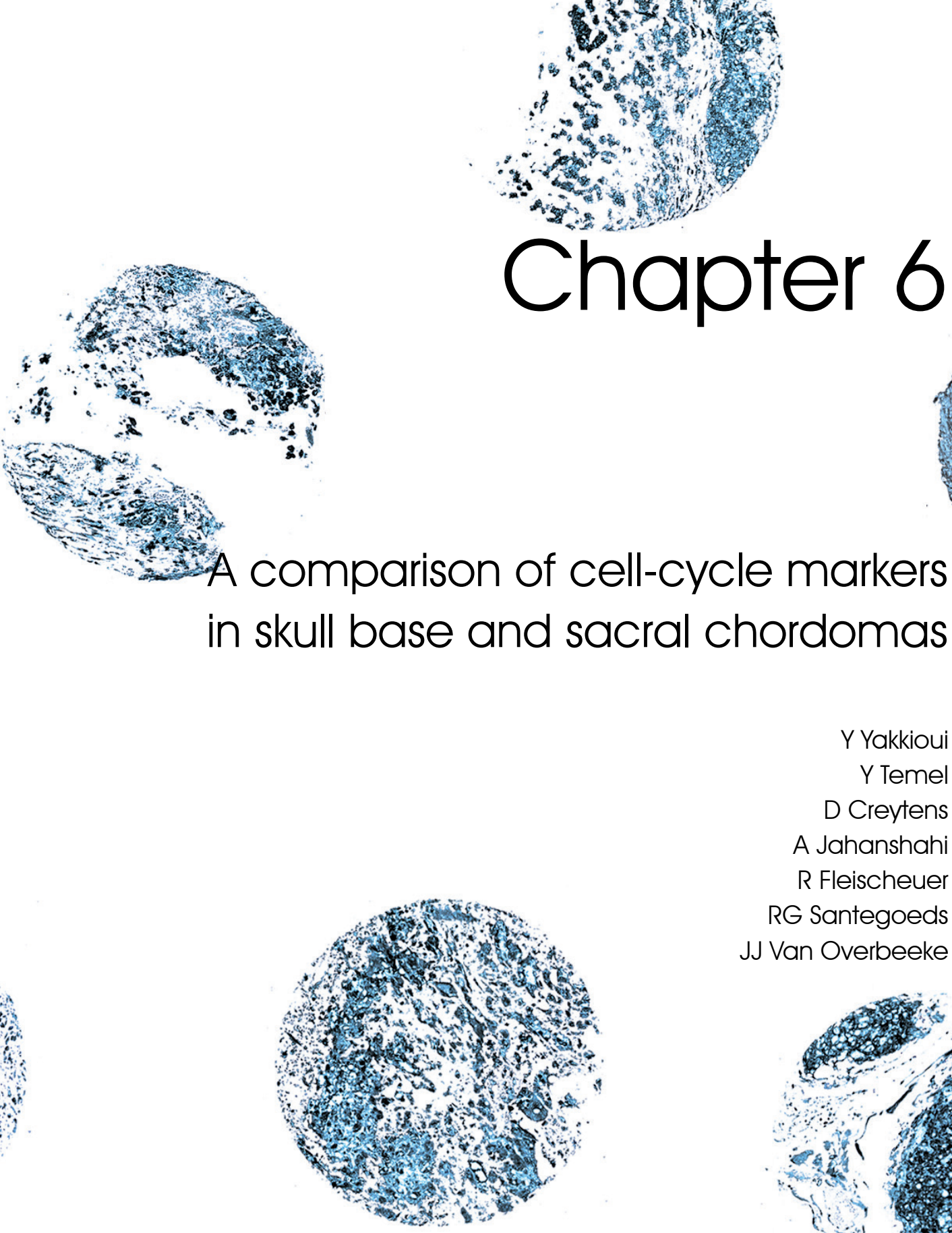

A Jahanshahi

R Fleischeuer RG Santegoeds JJ Van Overbeeke

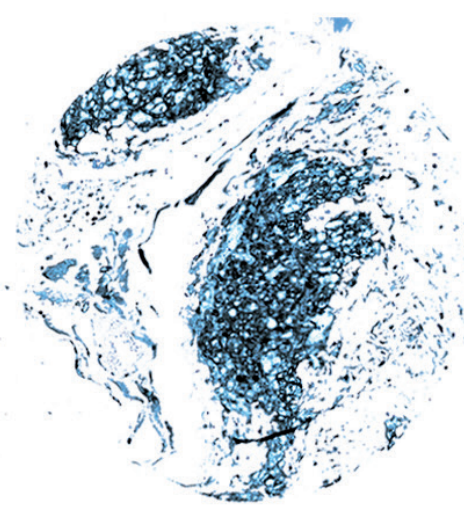




\section{Abstract}

Objective: Despite refinement of surgical techniques and adjuvant radiotherapy, the prognosis for patients suffering from a chordoma remains poor. Identification of prognostic factors related to tumor biology might improve this assessment and result in molecular markers for targeted therapy. Limited studies have been performed to unravel the impact of cell cycle markers in chordoma and those performed have shown inconclusive results. In the current study, we aimed at discovering the impact of cyclin dependent kinase 4 (CDK4) expression and its relation to prognosis and other cell cycle markers in chordoma.

Methods: Twenty-five human formalin fixed paraffin-embedded chordoma specimens were examined by immunohistochemistry for the expression of CDK4, protein 53 (p53) and murine double minute 2 (MDM2). The MIB-1 labeling index (MIB1-LI) and mitotic index (MI) were used for the examination of proliferation. We collected detailed demographic and clinical data.

Results: : Overexpression of CDK4, p53 and MDM2 were found in $5(20 \%), 7(28 \%)$ and 14 (56\%) of the cases, respectively. All three cell cycle markers showed a significant correlation with MIB1-LI. Expression of CDK4 ( $p=0.02)$ and P53 $(p<0.01)$ were both significantly correlated to poor overall survival (OS). Also, histologically observed necrosis $(p<0.05)$ and a dedifferentiated tumor subtype $(p<0.01)$ were related to adverse patient outcome.

Conclusion: Our results show that the expression of CDK4 and p53 are linked to cell proliferation capacity and worse outcome in patients with chordoma. 


\section{Introduction}

Chordomas, relatively uncommon neoplasms, usually cause a debilitating disease course due to their aggressive and invasive behaviour with destruction of the surrounding vital neurovascular structures. These neoplasms are almost exclusively formed in the axial skeleton, with a preference for the sacro-coccygeal and clival regions. Management of patients harboring a chordoma consists of initial gross surgical resection and additional radiotherapy, as both have been proven to be beneficial in prolonging patient survival. ${ }^{1,2}$ Even so, due to recurrent tumor growth, seen in up to $68 \%$ of the cases, the 5- and 10 -year survival rate for patients with chordoma are $67.6 \%$ and $39.9 \%$, respectively. ${ }^{3,4}$ To improve patient outcome, in the past decade, efforts are focused on the identification of molecular and clinicopathological factors to understand the mechanisms underlying chordomagenesis and its malignant behaviour. ${ }^{3-6}$ One of these molecular factors is the well-known regulatory protein p53, which is implicated in $40-45 \%$ of all cancers. ${ }^{7}$

Referred to as the "guardian" of the genome, p53 exhibits multiple functions in the regulation of cellular processes in response to various forms of stress. Following DNA damage, p53 exerts its tumor suppressive function by inducing a reversible cell cycle arrest or apoptosis. ${ }^{8}$ Loss of p53 function therefore is a key player in malignant progression, and may result from alteration in the gene encoding the protein or be due to protein-protein interaction. ${ }^{9}$ Concerning the latter, the mouse double murine 2(MDM2) negatively regulates p53's function by binding at the $\mathrm{N}$-terminal end and, by means of ubiqitination, modifies it for subsequent degradation. MDM2 expression is also controlled by p53 transcription, making it a negative feedback regulatory system. ${ }^{10}$ In chordoma, inconsistent p53 overexpression has been reported by several authors, ${ }^{11-17}$ but is shown to be well correlated with a high MIB-1 labeling index (LI), a proliferation index using the expression of the Ki-67 protein. ${ }^{13-17}$ Excess of $\mathrm{p} 53$ protein, in addition, is generally found to be associated with a worse clinical outcome, as patients exhibiting high expression levels show a decreased 5-year survival rate of $38.9 \%$ compared to the $\mathbf{7 9 . 4 \%}$ for patients harboring non-overexpressing tumors and are prone to have a regrowth of the tumor. ${ }^{11,13,14,17}$ MDM2 overexpression is also reported in $13 \%$ of chordoma patients, but was not found to be either associated with gene amplification or reduced overall survival. ${ }^{14}$

In addition to p53, cyclin dependent kinase 4 (CDK4) is well known for its important role in the regulation of the G1-S transition of the cell cycle. This protein forms molecular complexes with members of the cyclin D family, such as cyclin D1, to finally exert its negative effect on the tumor suppressor retinoblastoma (Rb). ${ }^{18-20}$ In similar fashion, CDK4 has also been shown to interact with other important mediators, including NFKB ${ }^{21}$ and Smad3. ${ }^{22}$ The regulation of CDK4 is by multiple factors (e.g. $\mathrm{p53},{ }^{23} \mathrm{Cdc} 37^{24-26}$ ), but has been largely attributed to inhibition by the p16INK4 protein. ${ }^{27,28}$ Reduced expression of this latter protein by aberrations in its gene transcript, CDKN2A, is frequently annotated in tumors and is likely to result in unrestrained CDK4 activity. ${ }^{29}$ In chordoma, the CDKN2A gene, which is located 
on 9p21, is shown by Hallor et al. to be homo- or heterozygously lost in $70 \%$ of chordoma tumors. ${ }^{30}$ Furthermore, aberrations on the 9 p21 region are also of prognostic value, as loss of heterogeneity of this specific area is correlated to a shorter overall survival. ${ }^{11}$ On the protein level, p16INK4expression was revealed to be absent in $74 \%$ to $100 \%$ of patients in several cohorts. ${ }^{14,31,32}$ These data together with the expression level and predictive value in chondrosarcomas, identifies CDK4 as a potential prognostic factor. ${ }^{33}$

In the present study, we evaluated the expression levels of cell cycle markers p53 and MDM2 in order to contribute to the scarce and precarious results so far. Additionally, we assessed the expression of a novel marker, CDK4, to examine its role in chordoma. Expression of all markers was compared to the presence and extent of cell-proliferation marker MIB-1(Ki67) and histopathological factors, including mitosis and tumor necrosis. Lastly, to evaluate a potential prognostic significance, the expression of the cell cycle markers was related to the clinical outcome of patients after (radio)surgical intervention.

\section{Materials and methods}

\subsection{Patients and tissue specimens}

All patients who underwent surgery at the Maastricht University Medical Center and Neurosurgical Science Center Tilburg between 1993 and 2009, were included. Clinical data was obtained by reviewing the medical charts and contacting the physicians-in-charge. Chordoma tissue specimens were obtained from the Maastricht Pathology Tissue Collection (MPTC) and the Tilburg Clinical Pathology Collection. Collection, storage and use of tissue and patient data were performed in agreement with the "Code for Proper Secondary Use of Human Tissue in the Netherlands" (http://www.fmwv.nl). All tumors were reclassified on hematoxylin- and eosin-stained slides, and histological subtype was reassessed by a pathologist (DC) using standard diagnostic criteria. Tumors were histologically classified according to the WHO classification (WHO Classification Tumours of Soft Tissue and Bone, 2002). In addition all sections were stained for detection of cytokeratin 8/18 (NCL-5D3, MP Biomedicals, Illkirch, France) and cytokeratin 5/6 (D5/16 B4, Dako, Glostrup, Denmark). The pathologic features of the tumors were evaluated by assessment of the mitotic index and histological necrosis. Concerning the former, mitotic figures were counted in 10 fields at high magnification ( $\mathrm{x} 400$ ) selected in the most proliferative areas and expressed as the number of mitoses in 10 high-power fields (HPFs).

\subsection{Immunohistochemistry}

Four micrometer thick sliced sections were deparaffinized and rehydrated using Xylene and graded ethanol steps. Endogenous peroxidase was inhibited using EnVision ${ }^{\text {TM }}$ FLEX Peroxidase-Blocking Reagent (Dako). Optimization of the staining was performed by the

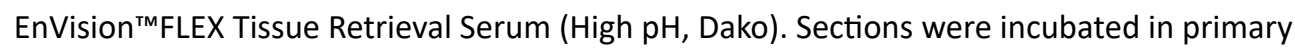


antibody at room temperature for either 20 min with CDK4 (DCS-31, Invitrogen, 1:200), P53 (DO-7, Dako, 1:500) and Ki67 (MIB-1, Dako, 1:400) or for 45 min with cytokeratin 8/18 (NCL5D3, MP Biomedicals, 1:100) and cytokeratin 5/6 (D5/16 B4, Dako, 1:100). Counterstaining was done using Gill II hematoxylin protocol.

Table 1. Primary antibodies and controls used

\begin{tabular}{llllll}
\hline Antibody & Clone & Supplier & Dilution & Incubation & Pos. control \\
\hline CDK4 & DCS-31 & Invitrogen & 0,180556 & 20 min at RT & Liposarcoma \\
P53 & DO-7 & Dako & 0,388889 & 20 min at RT & Vulva-carc. \\
MDM2 & IF2 & Invitrogen (Zymed) & 0,111111 & 20 min at RT & Liposarcoma \\
MIB-1 & MIB-1 & Dako & 0,319444 & 20 min at RT & Colon \\
Cytoker 8/18 & NCL5D3 & MP Biomedicals & 0,111111 & 45 min at RT & Colon \\
\hline Cytoker 5/6 & D5/16 B4 & Dako & 0,111111 & 45 min at RT & Lung \\
\hline
\end{tabular}

Primary cell-cycle antibodies were incubated for 20 minutes and cytokeratin markers for 45 minutes at RT. Negative controls were created by applying the same protocol without the use of the primary antibody. Positive controls were standardized controls used in the clinical setting. CDK4, cyclin-dependent kinase 4; RT, room temperature; MDM2, murine double minute 2 .

\subsection{Semiquantitaive assessments}

Extent of the staining was scored on number of positive cells (nuclear expression) by two experts (Y.Y and D.C.) as 0 (Negative), 1 (1-10\%), 2 (10-50\%) and $3(>50 \%)$ using the Nikon E400 microscope (Uvikon, Bunnik, The Netherlands) based on a method previously described by Kilgore and Prayson. ${ }^{12}$ Expression of the markers was considered positive if the score was either 2 or 3 (Fig. 1). Scoring was carried out in a double-blind manner and interobserver examinations between the two experts was substantial to almost in perfect agreement for CDK4 (weighted kappa>0.8 [0.78-0.96], linear kappa>0.7 [0.62-0.93]), p53 (weighted $>0.7$ [0.65-0.95], linear>0.66 [0.46-0.87]) and MDM2 (weighted kappa>0.8 [0.61-0.97], linear kappa $>0.67$ [0.45-0.88])..$^{34}$ Any disagreement was resolved by discussion in order to obtain the final score. MIB-1 labeling index (LI) was calculated by dividing the positive staining cells by the total number of cells. On average 2300 (range 1580-3122) cells were counted in

Table 2. Interobserver variability

\begin{tabular}{lllll}
\hline Markers & Weighted kappa & $95 \% \mathrm{Cl}$ & Linear kappa & $95 \% \mathrm{Cl}$ \\
\hline CDK4 & 0.871 & $0.779-0.962$ & 0.778 & $0.622-0.934$ \\
P53 & 0.798 & $0.652-0.945$ & 0.664 & $0.461-0.868$ \\
MDM2 & 0.789 & $0.609-0.969$ & 0.667 & $0.453-0.880$ \\
\hline
\end{tabular}

The presented table displays the interobserver variability, which was calculated with Cohen's kappa. Weighted kappas were chosen as categories are further apart and thus less weight should be put on agreements. The normal (linear) kappa values are also visualized, showing moderate-to-substantial agreement within the observers. CDK4, cyclin-dependent kinase 4; MDM2, murine double minute 2. 
well-labeled areas, as determined by scanning at low magnification with an Olympus BX50 microscope, using the Stereolnvestigator software (V 9.14, MicroBrightField, Williston, USA). For the selection of a highly proliferative group, a cut-off was set to be any number exceeding the MIB1-LI median value.

\subsection{Quantitative assessments}

Intensity of the immunohistochemical staining was quantitatively evaluated with optical density (OD) measurements. For this, the mean Grey values of p53- and CDK4-immunoreactive tumor cells of each patient, were assessed at 40x magnification using an Olympus AX70 bright field microscope (analySIS; Imaging System, Münster, Germany) connected to a digital camera (F-view; Olympus, Tokyo, Japan). Each cell was analyzed using the Image J software (NIH, http://rsbweb.nih.gov/ij/) and the light intensity and threshold conditions were similar for all sections. The density of pixels ranged from 0 (black) to 6553.50 (white) for a 16-bit digital signal. Every section was assessed for positive cells with nuclear staining and the density difference of the nucleus compared to the cytoplasm was taken as the outcome parameter. For the purpose of understanding grey values were converted resulting in higher values for the dark regions of interest and lower values for the less intensely stained areas. Statistical analysis was performed with log transformed optical density data.

\subsection{Demographic and clinical data}

Survival time was measured as the time from the date of the primary surgery until disease-related death or last follow up. Postoperative MRI scans were carried out for the first time approximately 3 months after surgery and then every six months and reviewed for the assessment of tumor regrowth by the attending neurosurgeon. Recurrence of chordoma was defined as secondary growth of the tumor observed on MRI. In case of metastatic disease, further analysis was carried out by PET and CT imaging. Survival analysis was performed for the following prognostic factors, age ( $<40$ vs. $>40)$, gender, tumor location, recurrent growth, interval to recurrent growth, metastasis, histological subtype, radiotherapy received, proton beam versus conventional photon-irradiation, histological (mitotic index and necrosis) and immunohistochemical properties (CDK4, P53, MIB-1 LI). Subgroup analysis was done for recurrent growth and metastasis and included the same factors.

\subsection{Statistical analyses}

Statistical analysis was performed using the Statistical Package of Social Sciences (SPSS, version 17.0, Chicago, IL, USA). Survival analysis was performed with the Kaplan-Meier model with log rank statistics. Correlation of non-parametric clinicopathological data was done using the Mann-Whitney U test and Spearman's correlation coefficient. Pearson's correlation coefficient was applied for the parametric data (MIB LI, mitosis index and optical density). Multivariate analysis using a logistic regression model was performed for the prognostic factors. 
To compare the mean difference in optical density between the three subgroups (IHC score 1,2 and 3) an independent t-test was used. A p-value of $<0.05$ was considered significant.

\section{Results}

\subsection{Demographic and clinical data}

Thirty-five chordoma specimens of 32 patients were archived, but only twenty-five met the criteria of being a primary chordoma of whom twenty-one had sufficient follow up data available. Only, these patients were included for the survival analysis. Primary reasons for exclusion from the study were due to primary surgical resection elsewhere or insufficient material for examination. Patient characteristics are summarized in Table 3 . The average age at operation was approximately 52-years (SD 16,2) and there was an almost equal distribution between the genders. Distributions of the tumors were 17 patients with skull base and 4 with sacral localization. All patients underwent gross surgical resection of the tumor, except for one patient with skull base chordoma who received biopsy only. All patients with a skull base chordoma except for one underwent additional irradiation and one patient received radiotherapy two months prior to surgery. For the sacral chordomas, no radiation therapy was applied. The mean duration of follow-up was 57 months (range, 21-142 months). In these periods, ten cases displayed regrowth of the tumor on MRI, with varying intervals. Distance metastasis occurred in $17 \%(n=5)$ of the patients and were located in the thoraco-lumbar vertebras, sacrum, lung, kidney and one cranial drop metastasis. In the study-period five patients died due to terminal disease state.

Table 3. Patient characteristics $(n=21)$

\begin{tabular}{|c|c|}
\hline \multicolumn{2}{|l|}{ Age at operation } \\
\hline Median & $52 Y$, range $(22-76)$ \\
\hline \multicolumn{2}{|l|}{ Gender } \\
\hline M & 9 \\
\hline $\mathrm{F}$ & 12 \\
\hline \multicolumn{2}{|l|}{ Location } \\
\hline Skull base & 17 \\
\hline Sacral & 4 \\
\hline \multicolumn{2}{|l|}{ Follow-up } \\
\hline Median & $57 \mathrm{M}$, range (21-142) \\
\hline Tumor regrowth & 10 \\
\hline Metastasis & 5 \\
\hline Deceased & 5 \\
\hline Subtype & 15 class, 5 chondr, 1 dedif \\
\hline
\end{tabular}

From the 25 patients who were included in this study, four did not meet the criteria of being a biopsy or primary resection. Therefore, the characteristics of the remaining 21 patients are shown here. All five patients died as the result of the disease. Class, classic chordoma; chondr, chondroid chordoma; dedif, dedifferentiated chordoma. 
The classic type of chordoma was most frequently observed. All chordomas were positive for S-100 and almost all chordomas stained positive with the cytokeratin 8/18 antibodies. Only one found to be negative, but demonstrated typical physaliphorous cells and was strongly positive for the pancytokeratin marker, epithelial membrane antigen and vimentin. The median mitotic index was 1 and no more than two specimens showed necrotic regions on histological analysis. The median MIB1 LI for all tissues was $2.8 \%$ and the cut off for the high proliferative group was set at 3.2\%. Based on the presence of positive nuclei, a median of 14.5 cells (range 5-32) and 19 (range 3-24) were used for the measurements of optical density for CDK4 and P53, respectively.

\subsection{Immunohistochemical findings}

\subsubsection{CDK4}

We found an overexpression of CDK4 in 20\% (5/25) of the tumors examined. The degree of cellular positivity was rated strong (3) in only one tumor. Optical density measurements correlated significantly $(r=0.7, p=0.02)$ with the amount of positive cells on the slide. Interestingly, the quantity of CDK4-expressing cells related well with the MIB1 LI $(r=0.7, p<0.01)$, which was particularly evident when the optical density values were plotted against the MIB1-LI ( $r=0.8, p=0.012)$. Positive CDK4 expression was also significantly correlated to positive $\mathrm{P} 53$ expression $(r=0.8, p<0.01$ ), however again the optical densities of both markers showed an even stronger connection $(r=0.9, p=0.01)$. In addition, the presence of mitotic figures was also related to the number of cells expressing CDK4 ( $r=0.5, p=0.02)$, but did not seem to be dependent on the number of mitotic figures. Both patients with histologic necrosis showed no immunoreactivity for the CDK4 antibody.

Mean optical densities for all three groups (IHC scores 1, 2 and 3) were computed and are shown in Table 4. A clear trend was observed between group 1 (0-10\% positive cells) and 2 (10-50\% positive cells). No statistical analysis was done for the single patient with an IHC score of 3.

\subsubsection{P53}

Concerning p53, overexpression seen on immunohistochemistry was present in $28 \%(7 / 25)$ of cases and also had a significant correlation with optical densities $(r=0.6, p=0.02)$. A positive relation was found for $p 53$ expression and MDM2 expression $(r=0.6, p<0.01)$ as well. Furthermore, MIB1-LI again was more related to optical density measurements of p53 $(r=0.7, p<0.01)$ compared to the number of $p 53$-positive cells $(r=0.6, p<0.01)$. In addition, an association with the presence of mitosis $(r=0.5, p=0.03)$ and an increased mitotic index ( $r=0.4, p=0.04$ ) was observed for $p 53$ overexpression. Histological necrosis, however, was not related to $\mathrm{p} 53$. The mean optical densities between the three IHC subgroups was significantly different $(\mathrm{p}=0.026 ; 95 \% \mathrm{Cl} 0.02-0.28)$ between group 1 and 2 . 
Table 4. General and histological findings in 25 chordoma specimens

\begin{tabular}{|c|c|c|c|c|c|}
\hline \multicolumn{3}{|c|}{ General findings } & \multicolumn{3}{|c|}{ IHC findings } \\
\hline \multirow[t]{2}{*}{ Age } & $<40$ & $32 \%(8)$ & CDK4 & 0 & $60 \%(15)$ \\
\hline & $>40$ & $68 \%(17)$ & & 1 & $20 \%(5)$ \\
\hline \multirow[t]{2}{*}{ Gender } & $M$ & $52 \%(13)$ & & 2 & $16 \%(4)$ \\
\hline & V & $48 \%(12)$ & & 3 & $4 \%(1)$ \\
\hline \multirow[t]{2}{*}{ Myx. BG } & $Y$ & $68 \%(17)$ & P53 & 0 & $40 \%(10)$ \\
\hline & $\mathrm{N}$ & $32 \%(8)$ & & 1 & $32 \%(8)$ \\
\hline \multirow[t]{3}{*}{ Subclas } & Class & $72 \%(18)$ & & 2 & $24 \%(6)$ \\
\hline & Chond & $24 \%(6)$ & & 3 & $4 \%(1)$ \\
\hline & Dedif & $4 \%(1)$ & MDM2 & 0 & $24 \%(6)$ \\
\hline \multirow[t]{2}{*}{ Mit_index } & 0 & $40 \%(10)$ & & 1 & $20 \%(5)$ \\
\hline & $\geq 1$ & $60 \%(15)$ & & 2 & $32 \%(8)$ \\
\hline \multirow[t]{2}{*}{ Necrosis } & $Y$ & $8 \%(2)$ & & 3 & $24 \%(6)$ \\
\hline & $N$ & $92 \%(23)$ & Cyt $8 / 18$ & $Y$ & $96 \%(24)$ \\
\hline \multirow[t]{3}{*}{ Ki67 } & $<5 \%$ & $80 \%(20)$ & & $\mathrm{N}$ & $4 \%(1)$ \\
\hline & $>5 \%$ & $20 \%(5)$ & Cyt 5/6 & $\mathrm{Y}$ & $8 \%(2)$ \\
\hline & & & & $\mathrm{N}$ & $92 \%(23)$ \\
\hline
\end{tabular}

Shown is an overview of the prognostic characteristics suggested by previous reports in our cohort on the left and immunological stainings performed in this study on the right. Class, classic chordoma; chond, chondroid chordoma; dedif, Dedifferentiated chordoma; Y, Yes/positive; N, no/negative; IHC, immunohistochemistry; CDK4, cyclin-dependent kinase 4; MDM2, murine double minute 2.

Table 5. Optical density measurements

\begin{tabular}{lllll}
\hline Antibody & IHC score & Sample size & Mean Log OD & p-value \\
\hline CDK4 & 1 & 5 & 5.95 & 0.08 \\
& 2 & 4 & 6.09 & \\
p53 & 3 & 1 & 6.22 & 0.03 \\
& 1 & 8 & 5.98 & \\
& 2 & 6 & 6.13 & \\
\hline
\end{tabular}

Depicted are log-transformed mean ODs corresponding to each subgroup with IHC scores of 1,2 , or 3 . The difference in mean value was evaluated using the independent t-test. In both stainings only one patient illustrated an IHC score of 3. Therefore, no statistical analysis was conducted to compare the third group. IHC, immunohistochemistry; OD, optical density; CDK4, cyclin-dependent kinase 4. *P-value IHC score 1 vs. 2.

\subsubsection{MDM2}

Overexpression of MDM2 was surprisingly found in 56\% (14/25) of the chordomas, with six specimens (24\%) showing a strong immunoreactivity graded as 3 . A relationship was found with the MIB1-LI $(r=0.7, p<0.01)$, however when selected for the high proliferative cut-off 
value, the correlation coefficient decreased considerably $(r=0.4, p=0.02)$. No other correlations were observed.

\subsection{Prognostic data}

Kaplan-Meier survival analysis, revealed CDK4 and p53 as prognostic factors, with log rank values of $5,321(p=0.021)$ and $13,336(p<0.01)$, respectively. Remarkably, all patients expressing CDK4 in more than $10 \%$ of the cells demonstrate a survival not exceeding five years (60 months) after surgery.

Furthermore, survival analysis related histological observed necrosis and a dedifferentiated tumor subtype, when compared to both the chondroid and conventional together, to an adverse patient outcome, with values of $8.500(p<0.01)$ and $18.000(p<0.01)$, respectively. For the recurrence of tumor growth $(3.273, p=0.07)$ and the mitotic index $(3.519, p=0.06)$ a clear trend was visible in relation to overall survival. Interestingly, this trend was also evident when the group was divided for treatment with proton beam therapy as displayed in Fig. 2 , but showed clearly no relation for the application of radiotherapy in general. Further, patient age, gender, tumor location and MIB-1 LI showed no relation with survival. When

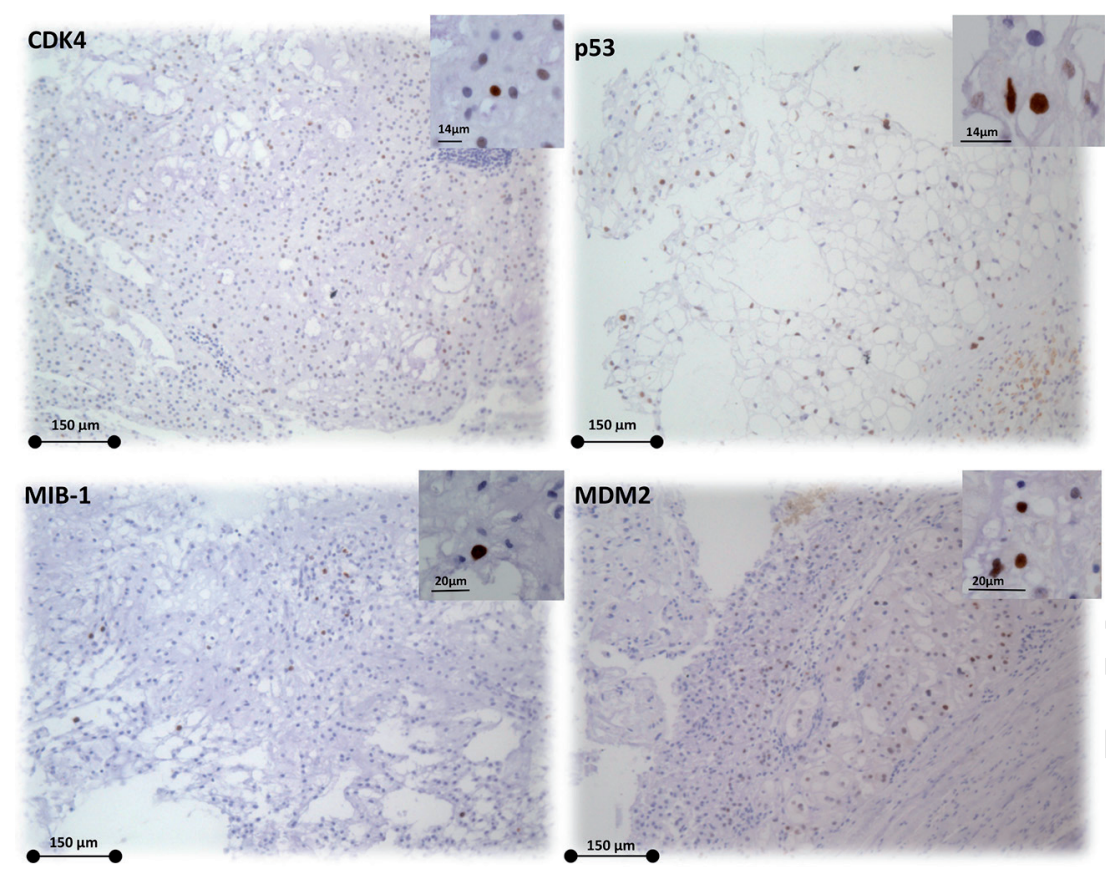

Fig. 1. Immunohistochemistry (IHC) staining of cell-cycle markers and MIB-1. Representative low-power photomicrographs (10x) are shown of 4- $\mu \mathrm{m}$-thick sections of chordoma specimens, IHC stained using cyclin-dependent kinase 4 (CDK4; top left), p53 (top right), murine double minute 2 (MDM2; bottom right), MIB-1 (bottom left, Ki-67) antibodies. Chordoma cell morphology can be witnessed as chordoma cells present as archetypal physaliphorous (vacuoles containing) cells. High-power photomicrograph (inset in top right corner) shows a magnification of cells considered positive. 
evaluated for the potential of independent prognostic markers, multivariate analysis unfortunately was not applicable for all factors due to collinear ties.

When Kaplan-Meier plots were used to investigate the prognostic effect of the clinicopathologic factors in contrast to survival after radiotherapy, an clear trend was visible for the time length to the initiation of radiotherapy $(3.082, p=0.08)$. Again charged protons as a radio-therapeutic medium showed a large difference in survival, which could not be proven to be statistically significant (Fig. 2b). All other factors did not show any specific prognostic value for the response to radiotherapy.

Effect of cell cycle factors on overall survival in chordoma.
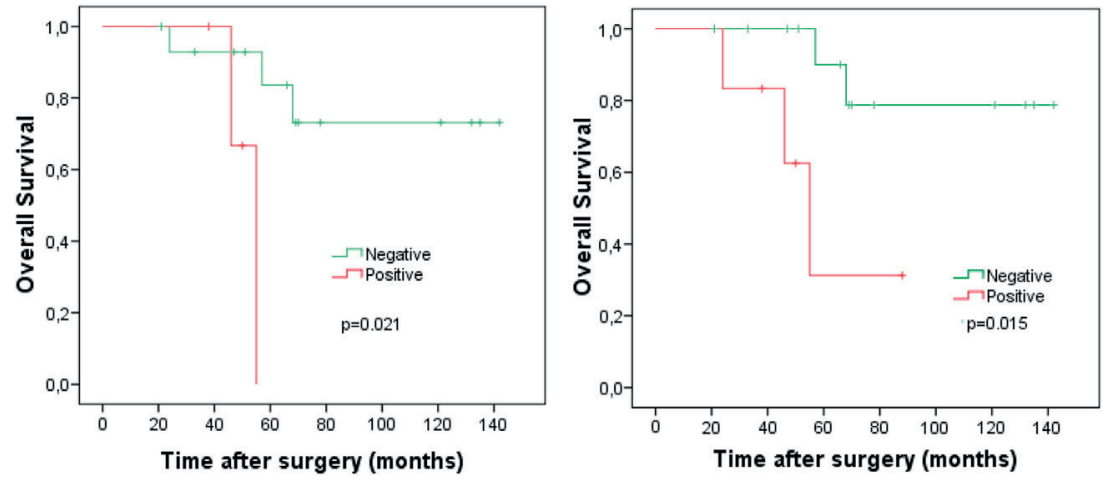

Fig. 2. Kaplan-Meier plots of cyclin-dependent kinase 4 (CDK4) and p53 expression. To evaluate the prognostic relevance, Kaplan-Meier curves were plotted and log rank statistics were applied to assess the significance of the observed difference. Note in the left panel that in the group that expresses the CDK4 protein, until now, none of the patients has lived beyond 5 years.

Effect of radiotherapy on overall survival in chordoma.
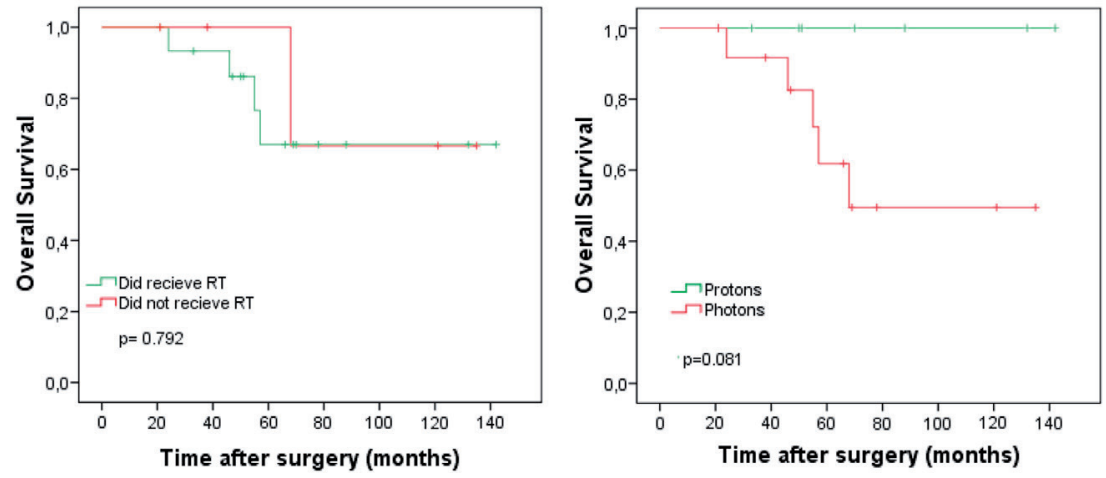

Fig. 3. Kaplan-Meier plot of proton beam therapy versus conventional photon therapy. Several factors, including photon radiation, a high mitotic index, and tumor regrowth, demonstrated a clear trend towards an unfavorable outcome. As an example the photon-irradiated patients are plotted against the patients who received proton beam irradiation. Similar graphs were seen for the other mentioned factors. 
Furthermore, although tumor regrowth was not a significant predictor for survival, when the total group was separated for the occurrence of regrowth, a relation was observed with the mitotic index $(p=0.014)$ and radiotherapy $(p=0.043)$, but was not seen for proton beam therapy specifically or for any of the cell cycle markers. Also, none of the factors seemed to be related to tumor metastasis.

\section{Discussion}

Chordomagenesis in our perspective is a multistep process and requires the cumulative effects of altered expression of gene transcripts and proteins. Identification of these biomarkers for chordoma will not only a have a great potential as a diagnostic tool or for the prediction of prognosis, but more importantly might serve as a target for medical therapy. This study was designed to assess the protein expressions of cell cycle markers in chordoma tissues and assess the potential correlation with histological features and patient outcome. Concerning the former, our results agree with the pro-oncogenic function that has been assigned to the CDK4 gene by many other studies, as CDK4 expression was highly correlated to MIB1-LI. Interestingly, in this respect, was the improvement for this relationship when the MIB-LI was plotted against the OD measurements, indicating a potential quantitative method for investigating immunohistochemistry in chordoma. Besides the MIB1 staining, we also encountered a strong correlation for CDK4 and p53. A possible explanation for this relation might be the overexpression of a known mutant form of p53 (H179Y), which is unable to regulate CDK4 expression and therefore not able to function as a known inhibitor. ${ }^{35}$ Also, aside from the inhibitory effect of the p16INK4 protein on the expression of CDK4, as previously mentioned, the other protein transcript of the CDKN2A gene, p14ARF is also reported to be to be strongly associated with stabilization of the p53 protein, via MDM2-mediated disinhibition. ${ }^{36-38}$ Here, loss of p14ARF function due to the loss of gene transcript results in increased MDM2 protein and might therefore explain the observed MDM2 overexpression in this study. The contra intuitively observed overexpression of p53 can be mediated via this same MDM2 overexpression, as it is reported that MDM2 overexpression results in a shift from transcription of full length p53 product to an alternatively translated p53/47K protein. ${ }^{39}$ This latter protein in turn does not function as a true p53 protein and thus the correlation of $\mathrm{p} 53$ to the MIB-LI should come as no surprise. So, genetic aberration on the CDKN2A gene can also account for p53's relation with CDK4 overexpression, but also clarify its strong positive correlation to MDM2 overexpression in our study and others reported. ${ }^{14}$

Also in conjunction with all three markers showing a positive correlation to the MIB1-LI, we found p53 and CDK4 to be predictive of a worse clinical as well. Particularly interesting in this regard, is the effect of a positive CDK4 expression with patients not surviving a longer period than five years so far. However, this biomarker could not be identified as an independent factor due to collinear ties resulting in a non-functioning model using multivariate 
regression analysis. This was also the case for all other factors and is presumably the result of the infrequent incidence of chordoma at our institute. Even so, the strong correlation of CDK4 with cell proliferation marker MIB1 and mitotic figures seen on histologic preparations together with its relationship to $\mathrm{p} 53$ and overall survival, indicates it to be a possible marker for the prediction of prognosis and highlights its potential as a target for medical therapy in a subset of patients. Further investigations examining the effect of CDK4 in larger samples and in vitro and in vivo models should verify these findings and could potentially establish the role of CDK4 as an interesting clinical predictor and therapeutic target.

In contrast to CDK4, a number of studies have analyzed p53 overexpression in chordoma. However, as previously stated, the clinical significance of p53 is not yet fully clear. Here we also a relation between patients expressing p53 and a worse survival. However, although we observed an obvious trend for tumor regrowth and a poor clinical outcome, unlike the results reported by Naka et al. and Matsuno et al., ${ }^{13}$ we did not find a relation between p53-expressing patients and the occurrence of regrowth in these patients. A possible reason for this discrepancy might be the effect of a different cut-off value for considering a tumor positive for $\mathrm{p} 53$ or the difference in using the terms recurrence and regrowth. Nevertheless, the discord on the scientific evidence of p53's significance is diminishing, as yet again it is shown to be a very important in the prognosis affecting patient outcome.

Regarding the histological predictors, our data illustrate an infrequent observation of mitotic figures in chordoma, with an exception of enhanced mitosis in the dedifferentiated tumor. These findings are in concordance to the results reported by others ${ }^{40-43}$ with a mean mitosis identical to the ones described by Kilgore et al. ${ }^{12}$ and Holton et al. ${ }^{44}$ The results from this study also demonstrate the mitotic index to be of significance, as not only a clear trend was visible with overall survival, but it also correlated well with tumor regrowth. Similar findings were published by Holton et al. ${ }^{44}$ who, besides patient age and MIB-1 LI >6\%, found the present of mitosis to be correlated with tumor doubling time. On the other hand, Kilgore and Prayson ${ }^{12}$ reported no relation for mitosis and recurrence, but have used different methods for comparing their groups (parametric vs. non-parametric).

In addition to the mitotic index, a clear statistically significant effect was evident for the foci of necrosis observed under the microscope and for the dediffentiated chordomas. O'Connell et $a l .{ }^{45}$ highlighted the significance microscopic tumor necrosis in pre-radiation biopsies by illustrating it to be adverse prognostic factors in patients with chordomas in sacrum and mobile spine. Later on, Suster and Moran ${ }^{41}$ in their case report of five mediastinal tumors and Holton et al. $^{44}$ found in their report of a cohort of nineteen skull base chordomas one dedifferentiated tumor and one unknown subtype of chordoma, respectively, to display foci of necrosis. In our cohort of the two patient exhibiting tumor necrosis, also one showed spindle cell sarcomatoid components, emphasizing its malignant potential. For the other tumor subtypes, the chondroid and conventional chordomas, Heffelfinger et al. as the initiator of the term chondroid chordoma, suggested an improved outcome in patients exhi- 
biting this tumor subtype. However, Mitchell et al. ${ }^{46}$ and Colli and Al-Mefty ${ }^{47}$ reported no difference in survival in their cohort and, recently, Jian et al. reviewed the published intracranial cases and found no difference between these two tumor subtypes. In this latter assessment of 560 non-duplicated patients, the authors also found no difference in survival when a cut-off for the age of 40 was applied or for additional radiotherapy. In keeping with this, no difference was observed in our cohort as well. Interestingly, however, additional proton beam therapy did show a trend toward a favorable outcome, which was even better visible when the post-radiation period was used as the survival parameter. These findings reflect the frequently worn proclamation of chordomas to be so-called radio-resistant to photon irradiation and confirm the beneficial effect of proton beam therapy. ${ }^{48-51}$

\section{Conclusion}

In toto, the study presented herein is the first to assess the expression of CDK4 in chordoma and its relation to other cell cycle markers, histological features and patient outcome. Our data support the initial hypothesis that CDK4 plays an important role in tumor growth in chordoma. 


\section{References}

1. Amichetti, M., Cianchetti, M., Amelio, D., Enrici, R.M. \& Minniti, G. Proton therapy in chordoma of the base of the skull: a systematic review. Neurosurg Rev 32, 403-416 (2009).

2. Soo, M.Y. Chordoma: review of clinicoradiological features and factors affecting survival. Australas Radiol 45, 427-434 (2001).

3. Jian, B.J., et al. Adjuvant radiation therapy and chondroid chordoma subtype are associated with a lower tumor recurrence rate of cranial chordoma. J Neurooncol 98, 101-108 (2010).

4. McMaster, M.L., Goldstein, A.M., Bromley, C.M., Ishibe, N. \& Parry, D.M. Chordoma: incidence and survival patterns in the United States, 1973-1995. Cancer Causes Control 12, 1-11 (2001).

5. Noël, G., et al. Chordomas of the base of the skull and upper cervical spine. One hundred patients irradiated by a 3D conformal technique combining photon and proton beams. Acta Oncologica 44, 700-708 (2005).

6. Bergh, P., et al. Prognostic factors in chordoma of the sacrum and mobile spine: a study of 39 patients. Cancer 88, 2122-2134 (2000).

7. Soussi, T. The p53 tumor suppressor gene: from molecular biology to clinical investigation. Ann N Y Acad Sci 910, 121-137; discussion 137-129 (2000).

8. Lane, D.P. Cancer. p53, guardian of the genome. Nature 358, 15-16 (1992).

9. Vousden, K.H. \& Lu, X. Live or let die: the cell's response to p53. Nat Rev Cancer 2, 594-604 (2002).

10. Manfredi, J.J. The Mdm2-p53 relationship evolves: Mdm2 swings both ways as an oncogene and a tumor suppressor. Genes Dev 24, 1580-1589 (2010).

11. Horbinski, C., et al. The prognostic value of Ki-67, p53, epidermal growth factor receptor, 1p36, 9p21, 10q23, and 17p13 in skull base chordomas. Arch Pathol Lab Med 134, 1170-1176 (2010).

12. Kilgore, S. \& Prayson, R.A. Apoptotic and proliferative markers in chordomas: a study of 26 tumors. Ann Diagn Pathol 6, 222-228 (2002).

13. Matsuno, A., et al. Immunohistochemical examination of proliferative potentials and the expression of cell cycle-related proteins of intracranial chordomas. Hum Pathol 28, 714-719 (1997).

14. Naka, T., et al. Alterations of G1-S checkpoint in chordoma: the prognostic impact of p53 overexpression. Cancer 104, 1255-1263 (2005).

15. Naka, T., et al. Proliferative activities in conventional chordoma: a clinicopathologic, DNA flow cytometric, and immunohistochemical analysis of 17 specimens with special reference to anaplastic chordoma showing a diffuse proliferation and nuclear atypia. Hum Pathol 27, 381-388 (1996).

16. Pallini, R., et al. Chordoma of the skull base: predictors of tumor recurrence. J Neurosurg 98, 812-822 (2003).

17. Sakai, K., Hongo, K., Tanaka, Y. \& Nakayama, J. Analysis of immunohistochemical expression of p53 and the proliferation marker Ki-67 antigen in skull base chordomas: relationships between their expression and prognosis. Brain Tumor Pathol 24, 57-62 (2007).

18. Ewen, M.E., et al. Functional interactions of the retinoblastoma protein with mammalian D-type cyclins. Cell 73, 487-497 (1993).

19. Wallace, M. \& Ball, K.L. Docking-Dependent Regulation of the Rb Tumor Suppressor Protein by Cdk4. Mol. Cell. Biol. 24, 5606-5619 (2004).

20. Day, P.J., et al. Crystal structure of human CDK4 in complex with a D-type cyclin. Proceedings of the National Academy of Sciences 106, 4166-4170 (2009).

21. Thoms, H.C., Dunlop, M.G. \& Stark, L.A. CDK4 Inhibitors and Apoptosis: A Novel Mechanism Requiring Nucleolar Targeting of RelA. Cell Cycle 6, 1293-1297 (2007). 
22. Matsuura, I., et al. Cyclin-dependent kinases regulate the antiproliferative function of Smads. Nature 430, 226-231 (2004).

23. Ewen, M.E., Oliver, C.J., Sluss, H.K., Miller, S.J. \& Peeper, D.S. p53-dependent repression of CDK4 translation in TGF-beta-induced G1 cell-cycle arrest. Genes Dev 9, 204-217 (1995).

24. Vaughan, C.K., et al. Structure of an Hsp90-Cdc37-Cdk4 complex. Mol Cell 23, 697-707 (2006).

25. Zhao, Q., Boschelli, F., Caplan, A.J. \& Arndt, K.T. Identification of a conserved sequence motif that promotes Cdc37 and cyclin D1 binding to Cdk4. J Biol Chem 279, 12560-12564 (2004).

26. Lamphere, L., et al. Interaction between Cdc37 and Cdk4 in human cells. Oncogene 14, 1999-2004 (1997).

27. Gump, J., Stokoe, D. \& McCormick, F. Phosphorylation of p16 INK4A Correlates with Cdk4 Association. Journal of Biological Chemistry 278, 6619-6622 (2003).

28. Mahajan, A., et al. Dissection of Protein-Protein Interaction and CDK4 Inhibition in the Oncogenic versus Tumor Suppressing Functions of Gankyrin and P16. Journal of Molecular Biology 373, 990-1005 (2007).

29. Ruas, M. \& Peters, G. The p16INK4a/CDKN2A tumor suppressor and its relatives. Biochimica et Biophysica Acta (BBA) - Reviews on Cancer 1378, 115-177 (1998).

30. Hallor, K.H., et al. Frequent deletion of the CDKN2A locus in chordoma: analysis of chromosomal imbalances using array comparative genomic hybridisation. Br J Cancer 98, 434-442 (2008).

31. Sommer, J., et al. Methylthioadenosine phosphorylase and activated insulin-like growth factor-1 receptor/insulin receptor: potential therapeutic targets in chordoma. J Pathol 220, 608-617 (2010).

32. Presneau, N., et al. Potential therapeutic targets for chordoma: PI3K/AKT/TSC1/TSC2/mTOR pathway. Br J Cancer 100, 1406-1414 (2009).

33. Schrage, Y.M., et al. Central chondrosarcoma progression is associated with pRb pathway alterations: CDK4 down-regulation and p16 overexpression inhibit cell growth in vitro. Journal of Cellular and Molecular Medicine 13, 2843-2852 (2009).

34. Viera, A.J. \& Garrett, J.M. Understanding interobserver agreement: the kappa statistic. Fam Med 37, 360-363 (2005).

35. Yang, D., et al. The over-expression of p53 H179Y residue mutation causes the increase of cyclin A1 and Cdk4 expression in HELF cells. Mol Cell Biochem 304, 219-226 (2007).

36. Watanabe, T., Nakamura, M., Yonekawa, Y., Kleihues, P. \& Ohgaki, H. Promoter hypermethylation and homozygous deletion of the p14ARF and p16INK4a genes in oligodendrogliomas. Acta Neuropathol 101, 185-189 (2001).

37. Anthony, J.S., Leonard, B.M., Anthony, J.A. \& Jason, D.W. Therapeutic Targets in the ARF Tumor Suppressor Pathway. Current Medicinal Chemistry 14, 1815-1827 (2007).

38. Kichina, J.V., Rauth, S., Das Gupta, T.K. \& Gudkov, A.V. Melanoma cells can tolerate high levels of transcriptionally active endogenous $\mathrm{p} 53$ but are sensitive to retrovirus-transduced $\mathrm{p} 53$. Oncogene 22, 4911-4917 (2003).

39. Yin, Y., Stephen, C.W., Luciani, M.G. \& Fahraeus, R. p53 stability and activity is regulated by Mdm2-mediated induction of alternative p53 translation products. Nat Cell Biol 4, 462-467 (2002).

40. Saito, A., et al. Dedifferentiated Chordoma: a Case Report. Japanese Journal of Clinical Oncology 28, 766-771 (1998).

41. Suster, S. \& Moran, C.A. Chordomas of the mediastinum: clinicopathologic, immunohistochemical, and ultrastructural study of six cases presenting as posterior mediastinal masses. Hum Pathol 26, 1354-1362 (1995). 
42. Mobley, B., et al. Loss of SMARCB1/INI1 expression in poorly differentiated chordomas. Acta Neuropathologica 120, 745-753 (2010).

43. Naka, T., et al. Skull base and nonskull base chordomas. Cancer 98, 1934-1941 (2003).

44. Holton, J.L., Steel, T., Luxsuwong, M., Crockard, H.A. \& Revesz, T. Skull base chordomas: correlation of tumour doubling time with age, mitosis and Ki67 proliferation index. Neuropathol Appl Neurobiol 26, 497-503 (2000).

45. O'Connell, J.X., et al. Base of skull chordoma. A correlative study of histologic and clinical features of 62 cases. Cancer 74, 2261-2267 (1994).

46. Mitchell, A., et al. Chordoma and chondroid neoplasms of the spheno-occiput. An immunohistochemical study of 41 cases with prognostic and nosologic implications. Cancer 72, 2943-2949 (1993).

47. Colli, B.O. \& Al-Mefty, O. Chordomas of the skull base: follow-up review and prognostic factors. Neurosurg Focus 10, E1 (2001).

48. Amendola, B.E., Amendola, M.A., Oliver, E. \& McClatchey, K.D. Chordoma: role of radiation therapy. Radiology 158, 839-843 (1986).

49. Catton, C., et al. Chordoma: long-term follow-up after radical photon irradiation. Radiother Oncol 41, 67-72 (1996).

50. Dahlin, D.C. \& Maccarty, C.S. Chordoma. Cancer 5, 1170-1178 (1952).

51. Forsyth, P.A., et al. Intracranial chordomas: a clinicopathological and prognostic study of 51 cases. J Neurosurg 78, 741-747 (1993). 

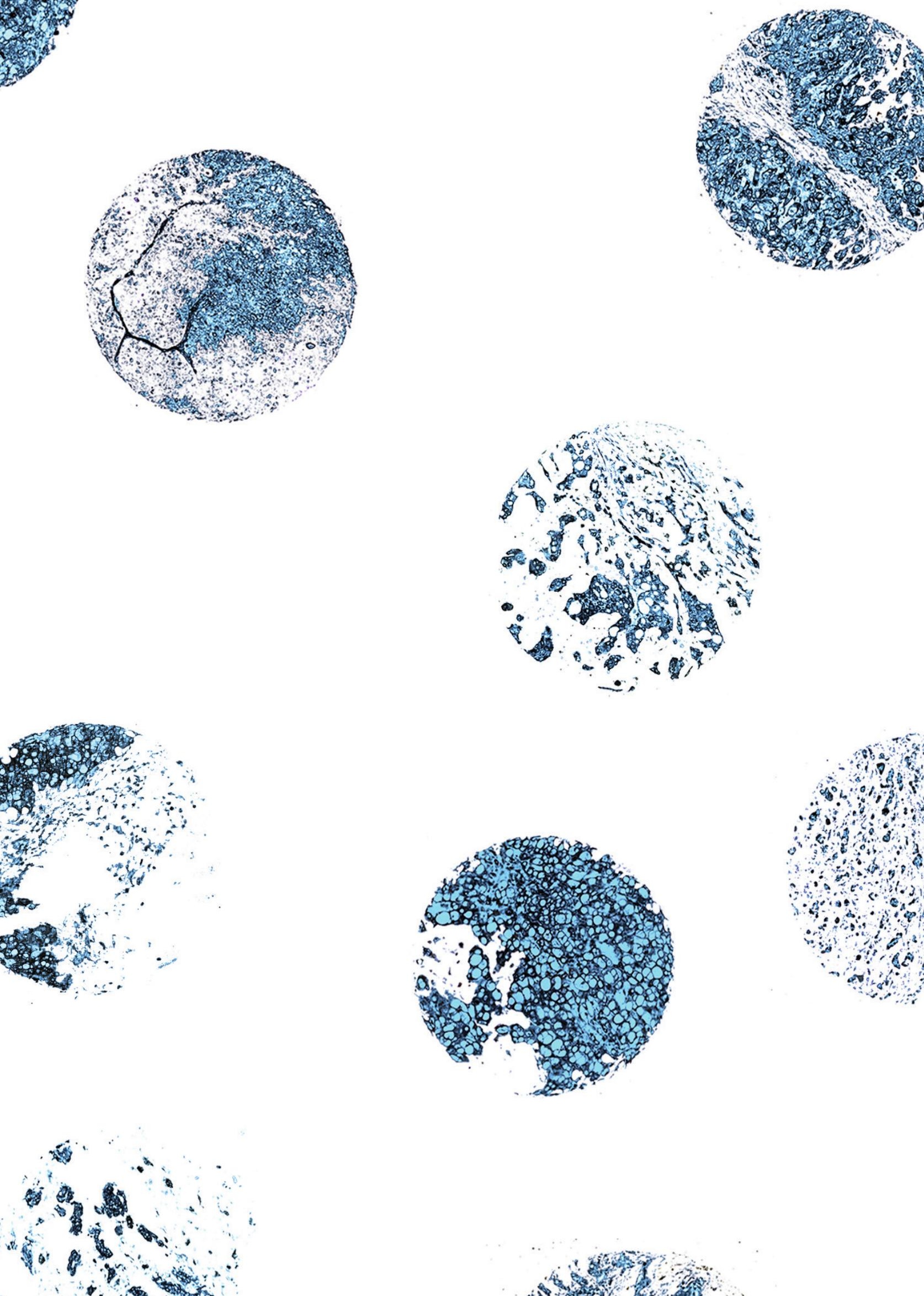


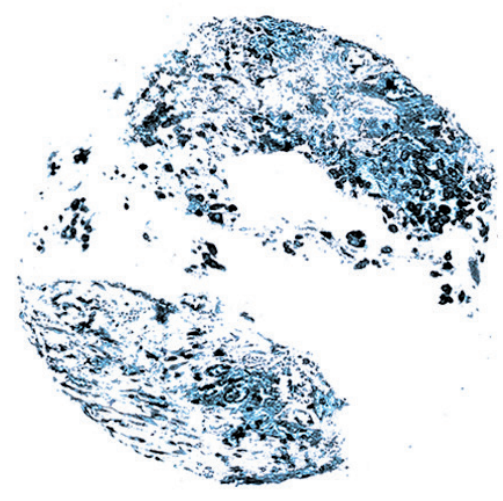

\title{
Oncogenic viruses in skull base chordomas
}

\author{
Y Yakkioui \\ E-JM Speel E \\ JJ Van Overbeeke \\ MGM Boderie \\ $S$ Pujari \\ A Zur Hausen \\ PFG Wolffs \\ Y Temel
}

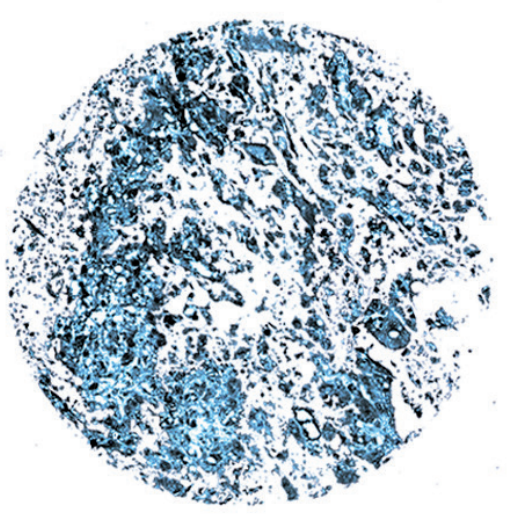

World Neurosurg. 2017 Nov 27. pili: S1878-8750(17)32049-1 


\section{Abstract}

Background: Chordomas are rare tumors assumed to derive from notochordal remnants. We believe that a molecular switch is responsible for their malignant behavior. The involvement of oncogenic viruses has not been studied, however. Thus, in the present study, we investigated the presence of oncogenic viruses in chordomas.

Methods: DNA and RNA from snap-frozen chordoma $(n=18)$ and chondrosarcoma $(n=15)$ specimens were isolated. Real-time PCR or RT-PCR was performed to assess the presence of multiple oncogenic viruses, including herpesviridea (herpes simplex virus [HSV]-1, HSV-2, Epstein-Barr virus [EBV], cytomegalovirus, human herpesvirus [HHV]- 6, HHV-7, and Kaposi's sarcoma-associated herpesvirus), polyomaviridea (parvovirus B19 [PVB19], BK virus, JC virus, Simian virus 40, Merkel cell polyomavirus, human polyomavirus [HPyV]-6, and HPyV-7), papillomaviridae, and respiratory viruses. Immunohistochemistry (IHC) and in situ hybridization (ISH) were used to validate the positive results.

Results: PVB19 DNA was detected in 4 of 18 chordomas (22\%) and in 1 of 15 chondrosarcomas $(7 \%)$. IHC recognizing the VP2 capsid protein of PVB19 showed a positive cytoplasmic staining in $44 \%$ of the cases (14 of 32). HHV7 DNA was present in 6 of the 18 chordomas (33\%). Genomic DNA of EBV was found in $22 \%$ of the samples; however, no positive results were found on ISH. None of the chordoma cases showed any presence of DNA from the remaining viruses.

Conclusion: Viral involvement in the etiology of chordomas is likely, with PVB19 being the most distinguishing. 


\section{Introduction}

Chordoma is a rare neoplasm that is believed to originate from remnants of notochordal cells, located almost exclusively in the axial skeleton. Long-term management of these tumors is limited, given that a high percentage of patients will experience regrowth of the tumor after multimodal therapy. Due to this predicament, research over the last decade has focused on the etiology of chordoma tumors in the hope of revealing biomarkers that can enhance our understanding of tumor growth and treatment management. A widely accepted view is that notochordal cells develop into chordomas subsequent to a benign notochordal tumor stage. ${ }^{1}$ The pathophysiological mechanism underlying this switch from indolent cells to malignant local invasive behavior is unknown. However, while consolidated knowledge is accumulating on the role of cellular and molecular mechanisms responsible for this malignant phenotype, no attempt has yet been made to investigate the involvement of cancer-related viruses in chordomas. Viral infections are an important etiological factor in the development of many tumors and are therefore a common target for investigation. A small group of oncogenic viruses (oncoviruses), including hepatitis viruses, human papillomaviruses (HPVs), human herpesviruses (HHVs), parvoviruses, and human polyomaviruses (HPyVs), are known to be responsible for a large proportion of virus-related cancers. ${ }^{2,3}$ Such infectious agents are estimated to be responsible for $12-15 \%$ of human tumors worldwide and to account for approximately $20 \%$ of cancer-related deaths. ${ }^{4-7}$

Although the exact mechanisms by which oncoviruses induce malignant biological behavior has yet to be unraveled, one proposal assumes cause by dysregulation of apoptosis due to genetic and epigenetic mechanisms. ${ }^{5,8-10} \mathrm{~A}$ viral etiology for chordomas might be interesting as merely a fraction of the patients with notochordal remnants develop a malignant chordoma phenotype. In addition, Stephens et al. (2011) illustrated the existence of chromosomal instability in chordomas and proposed a single crisis to be responsible for this phenomenon, otherwise known as chromotripsis. ${ }^{11}$ As viruses are implicated in the induction of chromosomal instability, a possible association was investigated. ${ }^{12,13}$

Here, we study the incidence of the most prevalent oncoviruses in skull base chordomas, their control tissue and in chondrosarcomas. The viruses under investigation include the Hepatitis B virus (HBV), Hepatitis C virus (HCV), Human papilloma viruses (HPV), Merkel cell polyomavirus (MCV) and Herpes viruses(HHV), including Herpes simplex virus-1/2( HSV-1/2, HHV 1/2) Epstein-Barr virus (EBV/HHV4), Cytomegalovirus (CMV, HHV5), Human herpes virus 7 (HHV-7) and Kaposi's sarcoma-associated herpes-virus (KSHV/ HHV8). In addition, we also determined the involvement of the Merkel cell polyomavirus, polyomavirus- 6 and 7, JC polyomavirus, BK polyomavirus, parvovirus B19 and the Simian virus 40 . 


\section{Materials and methods}

\subsection{Tumor tissues and DNA/RNA isolation}

Snap-frozen tissue specimens from 18 skull base chordomas and 15 chondrosarcomas were collected from surgeries performed at the Neurosurgery Department, Maastricht University Medical Center. Normal tissue, consisting of either bone or fat tissue removed for surgical exposure, was also collected from these surgeries. A tissue microarray (TMA) was generated from 32 formalin-fixed, paraffin-embedded blocks from 24 patients with chordomas, obtained from the Maastricht Pathology Tissue Collection. The storage and use of tissue and patient data were conducted in accordance with the Code for Proper Secondary Use of Human Tissue in The Netherlands (http://www.fmwv.nl). The use of tissue was approved by the local Ethical Committee (METC 16-4-267). DNA and RNA isolation was performed using TRIzol reagent (Thermo Fisher Scientific, Waltham, Massachusetts, USA), according to the manufacturer's protocol. To prevent contamination, the isolation of nucleic acids was performed in a specially designed, isolated environment for DNA and RNA extraction. For real-time PCR, all samples were spiked with murine CMV DNA or RNA, which served as an amplification control following extraction.

\subsection{PCR analysis for herpesviruses, $B K$ and JC viruses, and respiratory viruses}

Real-time PCR for all herpesviruses was performed using primers and probes as described previously, ${ }^{14-23}$ with the exception of primers targeting HHV-7, for which the primers and probe consisted of the following nucleotide sequences: forward primer: 5'-AACGTGATGCCTAACCAAC-3'; reverse primer: 5'-TAGTTCCAGCACTGCAATCG-3'; probe: FAM-5'-TGTATGCGTGCATTGGAAAGACCG-3'. For respiratory virus detection, a separate reverse-transcription step was performed using TaqMan reverse-transcriptase reagents, random hexamers (Applied Biosystems, Foster City, California, USA), and incubation for 10 minutes at $25^{\circ} \mathrm{C}$, for 30 minutes at $48^{\circ} \mathrm{C}$, and finally for 5 minutes at $95^{\circ} \mathrm{C}$. Consequently, for all targets, the PCR mix consisted of $20 \mu \mathrm{L}$ of isolated DNA (or produced CDNA), primers and probes, and $1 \times$ ABsolute QPCR Mix (ABgene, Epsom, UK).

The PCR protocol consisted of 15 minutes at $95^{\circ} \mathrm{C}$, followed by 42 cycles of 15 seconds at $95^{\circ} \mathrm{C}$ and 1 minute at $60^{\circ} \mathrm{C}$. All qualitative real-time PCR reactions were performed using an ABI Prism 7900 HT PCR machine (Applied Biosystems, Foster City, California, USA), and $\mathrm{Ct}$ values were determined using a threshold value of 0.05 and automatic baselining. The quality of the assays was ensured by positive and negative controls, as well as by a test on amplification inhibition in each sample by an external amplification control. DNA or RNA controls served as positive controls. Artificial DNA controls were constructed by cloning the PCR product into pGEM-3Z vectors, culturing of Escherichia coli containing the construct and subsequent plasmid isolation. The isolated plasmids were used as artificial DNA controls. For the generation of artificial RNA controls, RNA was initially constructed using pGEM-3Z vectors containing T7 RNA polymerase promoters flanking the multiple cloning region 
(Promega, Leiden, The Netherlands) into which the respective amplicons were cloned. Subsequently, RNA constructs containing the amplicons were generated and used as artificial RNA controls using T7 RNA polymerase.

\subsection{PCR analysis for HPVs}

Analysis for HPVs was performed as described previously using GP5+/6+-mediated PCR. ${ }^{24-27}$ In short, a step at $94^{\circ} \mathrm{C}$ for 4 minutes, 40 cycles of $94^{\circ} \mathrm{C}$ for 1 minute, $40^{\circ} \mathrm{C}$ for 2 minutes, and $72^{\circ} \mathrm{C}$ for 1.3 minutes, and then a final step at $72^{\circ} \mathrm{C}$ for 4 minutes were completed on the PTC-200 PCR apparatus (Bio-Rad, APP/ PCR-001). Acrylamide gels were analyzed using a microplate reader (Bio-Rad). For the assessment, both high-risk and low-risk HPV-positive controls were applied.

\subsection{PCR analysis for polyomaviruses}

Detection of Simian virus 40 was performed using previously published primers with the following PCR conditions: 10 minutes at $94^{\circ} \mathrm{C}, 40$ cycles of 30 seconds at $94^{\circ} \mathrm{C}, 30$ seconds at $55^{\circ} \mathrm{C}, 45$ seconds at $72^{\circ} \mathrm{C}$, and 7 minutes at $72^{\circ} \mathrm{C} .{ }^{28}$ The positive control was kindly provided by Dr. Verschoor from the Biomedical Primate Research Centre, Rijswijk, The Netherlands. RT-PCR for MCPyV (VP1 and M antigens), HPyV-6, and HPyV-7 were performed as described by Schowalter et $a .^{29}$ and Schrama et $a .^{30}$

\subsection{Immunohistochemistry and PCR analysis for PVB19}

Real-time PCR for PVB19 was performed with primers and a TaqMan probe as described by Dennert et al. ${ }^{31}$ The PCR mix consisted of $20 \mu \mathrm{L}$ of isolated DNA, a final concentration of $600 \mathrm{nM}$ of each primer, and $200 \mathrm{nM}$ of the probe and $1 \times$ ABsolute QPCR Mix. All real-time PCR reactions were performed in an ABI Prism 7900 PCR machine and quantified using a standard curve. The PCR assay used had a linear quantitative range from $10^{7}$ copies to $1 \times$ $10^{2}$ with a detection probability $>95 \%$. Below this range, semiquantitative detection was performed by extrapolation of the standard curve. The quality of the assays was ensured by positive and negative controls, as well as by a test on amplification inhibition in each sample with an additional external amplification control. For quantification of viral loads, standard curves were included for each run.

Immunohistochemistry (IHC) analyses were performed using the EnVision FLEX Mini Kit (Agilent Technologies, Santa Clara, California, USA) using an indirect method. ${ }^{32,33}$ Slides were cut to 4- $\mu$ thickness, adhered to Superfrost Plus Micro Slides (VWR, Radnor, Pennsylvania, USA), deparaffinized, and subjected to antigen retrieval using Tris/EDTA Target Retrieval solution buffer, pH 9 (Agilent Technologies) for 20 minutes at $97^{\circ} \mathrm{C}$. Endogenous peroxidase activity was quenched with $3 \% \mathrm{H}_{2} \mathrm{O}_{2}$ for 30 minutes. After overnight incubation at $4^{\circ} \mathrm{C}$ with primary anti-PVB19 antibody (1:100 MAB8293, VP2 capsid protein; MilliporeSigma, Darmstadt, Germany), the secondary antibody horseradish peroxidaseeconjugated goat 
anti-mouse/rabbit (EnVision FLEX, High pH, K801021-2, Agilent-Dako) was incubated for 2 hours at room temperature. Peroxidase activity was visualized by incubation of the slides in 3,3'-diaminobenzidine tetrahydrochloride plus chromogen/substrate buffer (EnVision). Counterstaining was performed by incubation in hematoxylin and eosin using the Mayer's staining protocol. A positive control sample was acquired from a cardiac biopsy specimen from a patient with chronic dilated cardiomyopathy with a high PVB19 viral load in the heart.

\subsection{In situ hybridization EBV}

Colorimetric in situ hybridization (ISH) was performed manually on $4-\mu \mathrm{m}$ sections of formalin-fixed, paraffin-embedded biopsy tissue on Superfrost Plus slides using the RNAscope 2.0 Brown Assay Kit (Advanced Cell Diagnostics, Hayward, California, USA). In brief, sections were treated with heat and protease, followed by hybridization with the probe cocktail, which includes 17 pairs of probes within a target region (25-968) of the virus. The development of hybridization was visualized with 3,3'-diaminobenzidine (Advanced Cell Diagnostics). Slides were counterstained with $50 \%$ hematoxylin for 2 minutes and then mounted with xylene-based SHUR/Mount (Triangle Biomedical Sciences, Durham, North Carolina, USA).

\section{Results}

PVB19 DNA was identified in 4 of 18 (22\%) chordoma specimens. In contrast, only 1 of 15 (7\%) chondrosarcoma specimens showed a positive signal after 39 PCR cycles. Viral load in the chordoma samples ranged from 104 copies $/ \mathrm{mL}$ to 2196 copies $/ \mathrm{mL}$. The single positive chondrosarcoma sample had 52 copies $/ \mathrm{mL}$. The samples were excised from a group of adult patients with a median age of 51 years (range, 35-75 years), with an exact 2:1 male to female ratio (12 males, 6 females).

In 4 patients, normal control tissue was also available. For these patients, we assessed whether PCR would detect the presence of PVB19 only in the tumor tissue, or in both the tumor tissue and normal tissue. We found viral involvement in 2 out of the 4 patients (50\%). In both of these patients, viral DNA was found in both normal tissue and tumor tissue.

Of the 32 chordoma tissue cores in the TMA stained for chordoma, positive cytoplasmic staining for parvovirus B19 VP2 capsid protein was seen in 14 (44\%) (Fig. 1). The four samples that were positive on PCR were from cases in which no formalin-fixed, paraffin-embedded material was available at the time of the TMA compilation, and thus a correlation could not be evaluated. None of the chordomas tested positive for other parvoviruses (BK virus, JC virus, Simian virus 40, MCPyV, HPyV-6, and HPyV-7) by PCR.

Chordomas were also tested for the presence of herpesviruses. Four of the 18 samples (22\%) were positive for EBV, with copy numbers ranging from 59 to $290 / \mathrm{mL}$. Normal control 

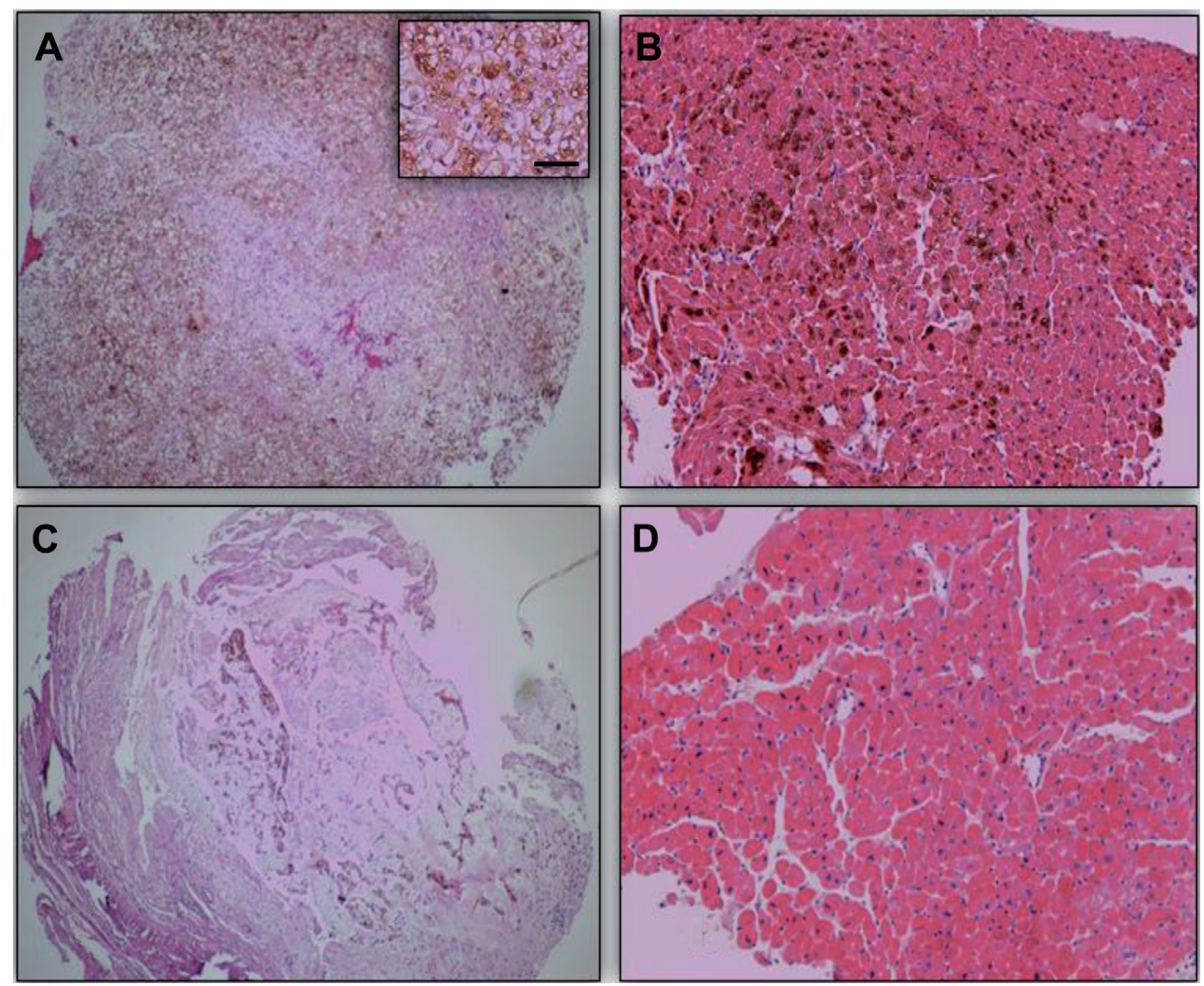

Fig. 1. A light microscopy microphotograph at 100x magnification of a chordoma tissue and cardiac muscle biopsy specimen stained for parvovirus B19 VP2 capsid protein (hematoxylin and eosin counterstain). (A and C) Positive and negative staining in chordoma samples. (B and D) Positive and negative control tissue. (Scale bar: $50 \mu \mathrm{m}$.)

tissue from the patients with chordomas was used to help determine the specificity of the signal. Our analysis revealed EBV RNA only in the control tissues, and not in the corresponding chordoma tissues of the same patient. ISH analysis for the location of EBV RNA in the tumor samples revealed no RNA (Fig. 2).

For HHV-7, in 6 out of 18 patients (33\%), PCR indicated amplified DNA, with copy numbers ranging from 112 to 4985 copies/mL. Similar to EBV, compared with normal tissue from the same patients, HHV-7 was positive in 2 of 4 chordoma samples. Tests of other herpesviruses, including CMV, HHV-1/2, HHV-6, and HHV-8, as well as the aforementioned respiratory viruses, did not show the presence of viral DNA in the chordoma samples. Tables 1 and 2 provide an overview of the positive results.

When considering all the expression data presented, it is to be noted that at least 1 of the 3 viruses - PVB19, EBV, or HHV-7 - was present in one-half of all the chordoma specimens analyzed. In 2 specimens, all 3 viruses were expressed. 

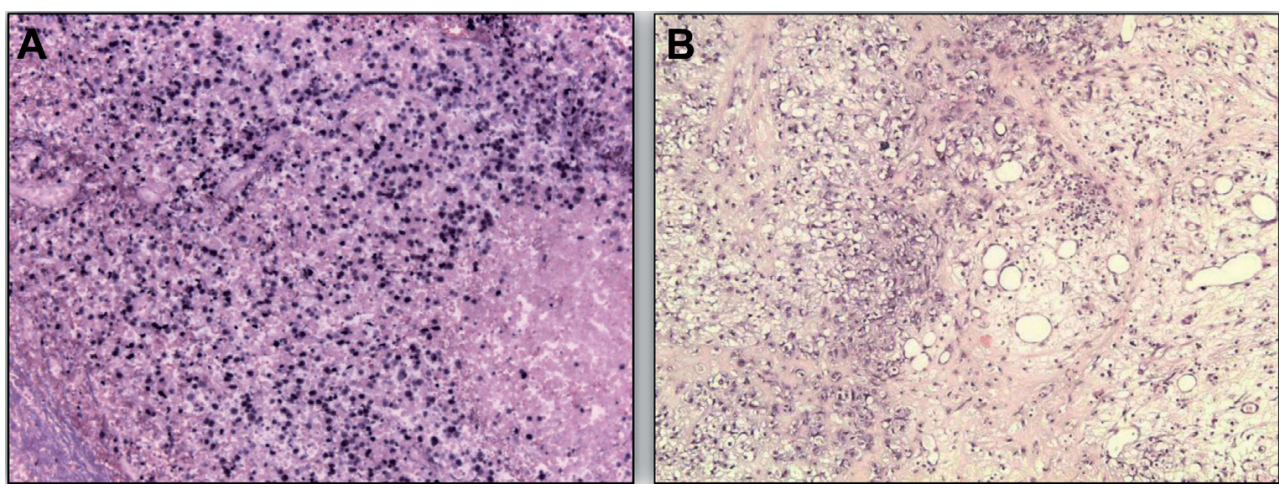

Fig. 2. In situ hybridization of Epstein-Barr virus in chordoma. (A) Positive control of nasopharyngeal carcinoma. (B) Negative staining in a chordoma sample. (Hematoxylin and eosin counterstain.)

Table 1. Results from PVB19, HHV-7, and EBV PCR analysis in 18 chordoma specimens and 15 chondrosarcoma specimens

\begin{tabular}{lcccccc}
\hline & \multicolumn{2}{c}{ PVB19 } & \multicolumn{2}{c}{ HHV-7 } & \multicolumn{2}{c}{ EBV } \\
\cline { 2 - 7 } Tumor type & Positive & Negative & Positive & Negative & Positive & Negative \\
\hline Chordoma, $\mathrm{n}$ & 4 & 14 & 6 & 12 & 4 & 14 \\
Chondrosarcoma, $\mathrm{n}$ & 1 & 14 & 0 & 2 & 0 & 2 \\
\hline
\end{tabular}

PVB19, parvovirus B19; HHV-7, human herpesvirus 7; EBV, Epstein-Barr virus; PCR, polymerase chain reaction.

Table 2. Results of PCR performed on normal and tumor tissue from the same patient

\begin{tabular}{llccc}
\hline Patient & Sample & PVB19 $(\mathrm{c} / \mathrm{mL})$ & HHV-7 $(\mathrm{C} / \mathrm{mL})$ & EBV $(\mathrm{c} / \mathrm{mL})$ \\
\hline Patient 1 & Normal & 1186 & 360 & 800 \\
Primary & Tumor & 91 & - & - \\
Patient 1 & Normal & 2621 & - & - \\
Recurrent & Tumor & 63 & - & - \\
Patient 2 & Normal & - & 1800 & - \\
& Tumor & - & - & - \\
Patient 3 & Normal & - & - & - \\
& Tumor & - & - & - \\
\hline
\end{tabular}

Two sample moments (primary resection and resection of a recurrent chordoma) were available for patient 1. PCR, polymerase chain reaction; PVB19, parvovirus B19; HHV-7, human herpesvirus 7; EBV, Epstein-Barr virus.

\section{Discussion}

Chordomas are believed to originate from notochordal remnants, which are present in $2 \%$ of adults. The scarce nature of this tumor and chromosomal distortion indicate a possible malignant switch in phenotype in these remnants, resulting in chordomagenesis. One of the 
potential mechanisms by which tumor formation can occur is through the involvement of oncogenic viruses. Approximately $15 \%$ of all human tumors are caused by viruses, involving intricate processes that remain incompletely understood. ${ }^{5}$

Here we describe, for the first time, the relationship of well-known oncogenic viruses and their occurrence in chordoma tissue samples. One of the most recently discovered oncogenic viruses, PVB19 was discovered in 1975 in healthy blood donors and was later related to the existence of erythema infectiosum as the causative agent. Later the virus was associated with other pathologies, including papillary thyroid carcinoma and germ cell tumors. ${ }^{34-37}$ In our cohort, the PVB19 genome was found in $22 \%$ of the chordoma specimens, compared with only $7 \%$ of the chondrosarcoma samples. In 4 of these patients, viral DNA was also detected in one-half of the normal surrounding tissues, indicating a larger area of previous infection. The prevalence of PVB19 infection, determined by the presence of IgG and IgM, is high in the general adult population, $70 \%-80 \%$, and highest in the elderly population. ${ }^{38-40}$ However, the presence of DNA in normal tissues and blood is very rare, with reported rates ranging from 0 to $10 \% .{ }^{40-44}$ Thus, an incidence of $22 \%$ for chordomas in contrast to chondrosarcomas and the general public is significantly higher. In addition, IHC staining showed a high percentage of positive samples, demonstrating that focal positivity of PVB19 in chordomas is not an uncommon finding. In chordomas, early PVB19 infection might explain the chromothripsis observed and thus could be responsible in part for the switch in notochordal remnants leading to chordomagenesis. ${ }^{1}$ Another potential mechanism could be an effect of PVB19 on the phenotype of the established tumor, either contributing to its progression rather than causing the carcinogenesis or causing impairment of the cancer cells, making them resistant to chemotherapeutic drugs. ${ }^{45}$ Finally, viral infection might be an opportunistic infection due to iatrogenic immunosuppression. However, considering that this phenomenon has not been observed in patients undergoing organ transplantation, such a concept is unconvincing. ${ }^{41,44,46}$ Thus, a more comprehensive investigation of the potential role of PVB19 in a larger cohort of chordoma samples with regard to its role in carcinogenesis, chemoresistance, and prognosis is needed.

Herpesviruses are implicated in the pathophysiology of many cancers. ${ }^{47,48}$ However, in contrast to HSV-1 and HSV-2, little is known about the contribution of HHV-7 to the etiology of cancer. HHV-7 was discovered in 1990, and an active infection has since been related to exanthema subitum in children. In addition to the skin, HHV-7 has an apparent predilection for the central nervous system, considered to be related to febrile seizures as well as viral DNA, being present in $14 \%$ of primary brain tumors. ${ }^{49}$ In line with this observation, our present cohort, $33 \%$ of the resected chordomas contained the HHV-7 genome. Given the location of skull base chordomas in the clival region, close to the sphenoid sinus, and the almost absent detection of HHV-7 in other internal organs, potential contamination of notochordal remnants by HHV-7 might be occurring..$^{50}$ Considering the ubiquitous nature of HHV-7 in human saliva and mandibular glands, this likely explains its existence in bony structures surrounding the tumor. 
In contrast to HHV-7, EBV has been extensively studied and has well-recognized associations with a multitude of tumors, including Burkitt's lymphoma, gastric cancer, breast cancer, and nasopharyngeal cancer. Variable positive fractions of these tumors contain EBV DNA, ranging from $10 \%-16 \%$ in conventional gastric adenocarcinomas to $10 \%-51 \%$ in breast tumors. ${ }^{51}$ The difference in persistent EBV infection reported could be explained by the heterogenetic presence of the virus in tissue when examined by ISH analysis and the potential of EBV to persist lifelong in the memory B-cell compartment. ${ }^{52}$ With this in mind, the presence of EBV in chordomas merits further investigation, with the contrast between positive results in EBV PCR and negative results in EBV ISH possibly explained by heterogeneity in the samples or the presence of EBV in neighboring non-neoplastic cells, termed bystander cells.

In conclusion, our present study indicates the prevalence of oncogenic viruses in chordomas, with variable presence of genomic DNA of BPV19, EBV, and HHV7 in our cohort. One-half of our patients demonstrated the presence of genomic DNA of at least 1 of these 3 viruses. These findings support the idea of the potential involvement of viruses in the etiology of chordomas. 


\section{References}

1. Yakkioui, Y., van Overbeeke, J.J., Santegoeds, R., van Engeland, M. \& Temel, Y. Chordoma: the entity. Biochim Biophys Acta 1846, 655-669 (2014).

2. Dalianis, T. \& Hirsch, H.H. Human polyomaviruses in disease and cancer. Virology 437, 63-72 (2013).

3. Parkin, D.M. The global health burden of infection-associated cancers in the year 2002. Int J Cancer 118, 3030-3044 (2006).

4. Globocan 2008, I. in WHO I Cancer fact sheet I updated january 2013.

5. Butel, J.S. Viral carcinogenesis: revelation of molecular mechanisms and etiology of human disease. Carcinogenesis 21, 405-426 (2000).

6. Schiller, J.T. \& Lowy, D.R. Vaccines to prevent infections by oncoviruses. Annu Rev Microbiol 64, 23-41 (2010).

7. Hausen, P.D.H.z. Infections Causing Human Cancer, (Wiley, Online, 2006).

8. Fuentes-Gonzalez, A.M., Contreras-Paredes, A., Manzo-Merino, J. \& Lizano, M. The modulation of apoptosis by oncogenic viruses. Virol J 10, 182 (2013).

9. Flanagan, J.M. Host epigenetic modifications by oncogenic viruses. Br J Cancer 96, 183-188 (2007).

10. Moore, P.S. \& Chang, Y. Why do viruses cause cancer? Highlights of the first century of human tumour virology. Nat Rev Cancer 10, 878-889 (2010).

11. Stephens, P.J., et al. Massive genomic rearrangement acquired in a single catastrophic event during cancer development. Cell 144, 27-40 (2011).

12. Gao, P. \& Zheng, J. Oncogenic virus-mediated cell fusion: new insights into initiation and progression of oncogenic viruses--related cancers. Cancer Lett 303, 1-8 (2011).

13. Duelli, D.M., et al. A virus causes cancer by inducing massive chromosomal instability through cell fusion. Curr Biol 17, 431-437 (2007).

14. Goossens, V.J., Wolffs, P.F., van Loo, I.H., Bruggeman, C.A. \& Verbon, A. CMV DNA levels and CMV gB subtypes in ART-naive HAART-treated patients: a 2-year follow-up study in The Netherlands. Aids 23, 1425-1429 (2009).

15. Gunson, R.N., Collins, T.C. \& Carman, W.F. Real-time RT-PCR detection of 12 respiratory viral infections in four triplex reactions. J Clin Virol 33, 341-344 (2005).

16. Leung, A.Y., Chan, M., Tang, S.C., Liang, R. \& Kwong, Y.L. Real-time quantitative analysis of polyoma BK viremia and viruria in renal allograft recipients. J Virol Methods 103, 51-56 (2002).

17. Niesters, H.G., et al. Development of a real-time quantitative assay for detection of Epstein-Barr virus. J Clin Microbiol 38, 712-715 (2000).

18. Ryschkewitsch, C., et al. Comparison of PCR-southern hybridization and quantitative real-time PCR for the detection of JC and BK viral nucleotide sequences in urine and cerebrospinal fluid. J Virol Methods 121, 217-221 (2004).

19. Templeton, K.E., Scheltinga, S.A., Beersma, M.F., Kroes, A.C. \& Claas, E.C. Rapid and sensitive method using multiplex real-time PCR for diagnosis of infections by influenza a and influenza $B$ viruses, respiratory syncytial virus, and parainfluenza viruses 1, 2, 3, and 4. J Clin Microbiol 42, 1564-1569 (2004).

20. van der Vries, E., et al. Evaluation of a rapid molecular algorithm for detection of pandemic influenza A (H1N1) 2009 virus and screening for a key oseltamivir resistance (H275Y) substitution in neuraminidase. J Clin Virol 47, 34-37 (2010).

21. van Doornum, G.J., Guldemeester, J., Osterhaus, A.D. \& Niesters, H.G. Diagnosing herpesvirus infections by real-time amplification and rapid culture. J Clin Microbiol 41, 576-580 (2003). 
22. van Elden, L.J., Nijhuis, M., Schipper, P., Schuurman, R. \& van Loon, A.M. Simultaneous detection of influenza viruses A and B using real-time quantitative PCR. J Clin Microbiol 39, 196-200 (2001).

23. Watzinger, F., et al. Real-time quantitative PCR assays for detection and monitoring of pathogenic human viruses in immunosuppressed pediatric patients. J Clin Microbiol 42, 5189-5198 (2004).

24. Brule, A.J.C.v.d., et al. GP5+/6+ PCR followed by Reverse Line Blot Analysis Enables Rapid and High-Throughput Identification of Human Papillomavirus Genotypes. Journal of Clinical Microbiology 40, 779-787 (2002).

25. Jacobs, M.V., et al. A general primer GP5+/GP6(+)-mediated PCR-enzyme immunoassay method for rapid detection of 14 high-risk and 6 low-risk human papillomavirus genotypes in cervical scrapings. Journal of Clinical Microbiology 35, 791-795 (1997).

26. Jacobs, M.V., et al. Reliable high risk HPV DNA testing by polymerase chain reaction: an intermethod and intramethod comparison. Journal of Clinical Pathology 52, 498-503 (1999).

27. Olthof, N.C., et al. Viral load, gene expression and mapping of viral integration sites in HPV16-associated HNSCC cell lines. International Journal of Cancer 136, E207-E218 (2015).

28. Campello, C., et al. Detection of SV40 in colon cancer: a molecular case-control study from northeast Italy. J Med Virol 82, 1197-1200 (2010).

29. Schowalter, R.M., Pastrana, D.V., Pumphrey, K.A., Moyer, A.L. \& Buck, C.B. Merkel cell polyomavirus and two previously unknown polyomaviruses are chronically shed from human skin. Cell Host Microbe 7, 509-515 (2010).

30. Schrama, D., Buck, C.B., Houben, R. \& Becker, J.C. No evidence for association of HPyV6 or HPyV7 with different skin cancers. J Invest Dermatol 132, 239-241 (2012).

31. Dennert, R., et al. Intravenous immunoglobulin therapy for patients with idiopathic cardiomyopathy and endomyocardial biopsy-proven high PVB19 viral load. Antivir Ther 15, 193-201 (2010).

32. Chen, X., Cho, D.-B. \& Yang, P.-C. Double staining immunohistochemistry. North American Journal of Medical Sciences 2, 241-245 (2010).

33. Ramos-Vara, J.A. Technical aspects of immunohistochemistry. Vet Pathol 42, 405-426 (2005).

34. Adamson, L.A., Fowler, L.J., Clare-Salzler, M.J. \& Hobbs, J.A. Parvovirus B19 infection in Hashimoto's thyroiditis, papillary thyroid carcinoma, and anaplastic thyroid carcinoma. Thyroid 21, 411-417 (2011).

35. Gray, A., et al. Persistence of parvovirus B19 DNA in testis of patients with testicular germ cell tumours. The Journal of general virology 79 ( Pt 3), 573-579 (1998).

36. Kerr, J.R., et al. Association of acute parvovirus B19 infection with new onset of acute lymphoblastic and myeloblastic leukaemia. J Clin Pathol 56, 873-875 (2003).

37. Wang, J.H., et al. Detection of human parvovirus B19 in papillary thyroid carcinoma. Br J Cancer 98, 611-618 (2008).

38. Tsujimura, M., et al. Human parvovirus B19 infection in blood donors. Vox Sang 69, 206-212 (1995).

39. Waldman, M. \& Kopp, J.B. Parvovirus B19 and the kidney. Clin J Am Soc Nephrol 2 Suppl 1, S47-56 (2007).

40. Woolf, A.D., et al. Clinical manifestations of human parvovirus B19 in adults. Arch Intern Med 149, 1153-1156 (1989).

41. Eid, A.J., Brown, R.A., Patel, R. \& Razonable, R.R. Parvovirus B19 infection after transplantation: a review of 98 cases. Clin Infect Dis 43, 40-48 (2006).

42. Heegaard, E.D. \& Brown, K.E. Human Parvovirus B19. Clinical Microbiology Reviews 15, 485-505 (2002). 
43. Plentz, A., Wurdinger, M., Kudlich, M. \& Modrow, S. Low-level DNAemia of parvovirus B19 (genotypes 1-3) in adult transplant recipients is not associated with anaemia. J Clin Virol 58, 443-448 (2013).

44. Porignaux, R., et al. Frequent occurrence of parvovirus B19 DNAemia in the first year after kidney transplantation. J Med Virol 85, 1115-1121 (2013).

45. Jacob, H.E. Chemotherapy for cranial base tumors. Journal of Neuro-Oncology 20, 327-335 (1994).

46. Carraturo, A., et al. Parvovirus B19 infection and severe anemia in renal transplant recipients. ScientificWorldJournal 2012, 102829 (2012).

47. Alibek, K., et al. Implication of human herpesviruses in oncogenesis through immune evasion and supression. Infect Agent Cancer 9, 3 (2014).

48. Rafferty, K.A., Jr. Herpes viruses and cancer. Sci Am 229, 26-33 (1973).

49. Chan, P.K., Ng, H.K. \& Cheng, A.F. Detection of human herpesviruses 6 and 7 genomic sequences in brain tumours. J Clin Pathol 52, 620-623 (1999).

50. Kempf, W., et al. Persistence of human herpesvirus 7 in normal tissues detected by expression of a structural antigen. J Infect Dis 178, 841-845 (1998).

51. Hippocrate, A., Oussaief, L. \& Joab, I. Possible role of EBV in breast cancer and other unusually EBV-associated cancers. Cancer Lett 305, 144-149 (2011).

52. Babcock, G.J., Decker, L.L., Volk, M. \& Thorley-Lawson, D.A. EBV persistence in memory B cells in vivo. Immunity 9, 395-404 (1998). 

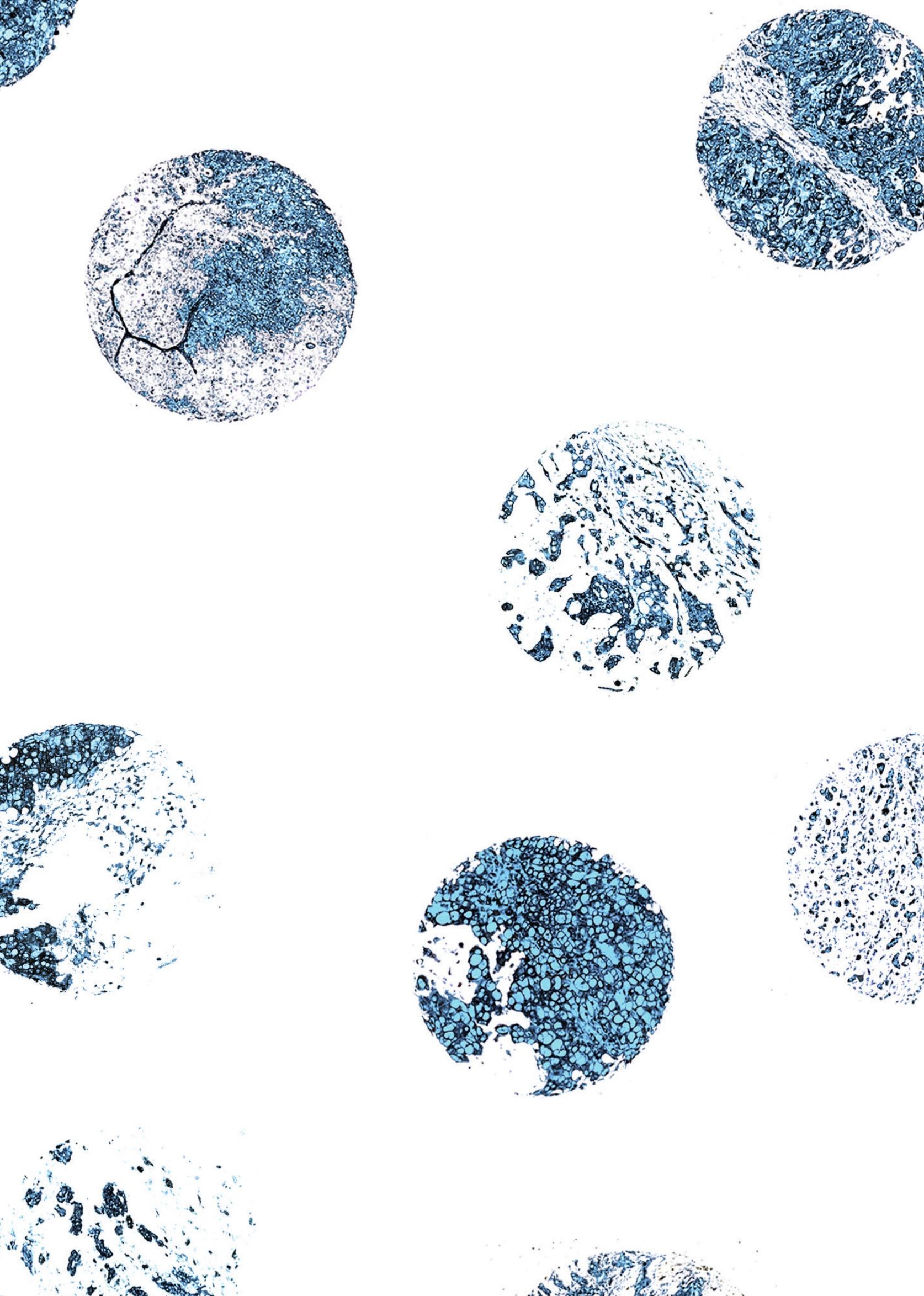

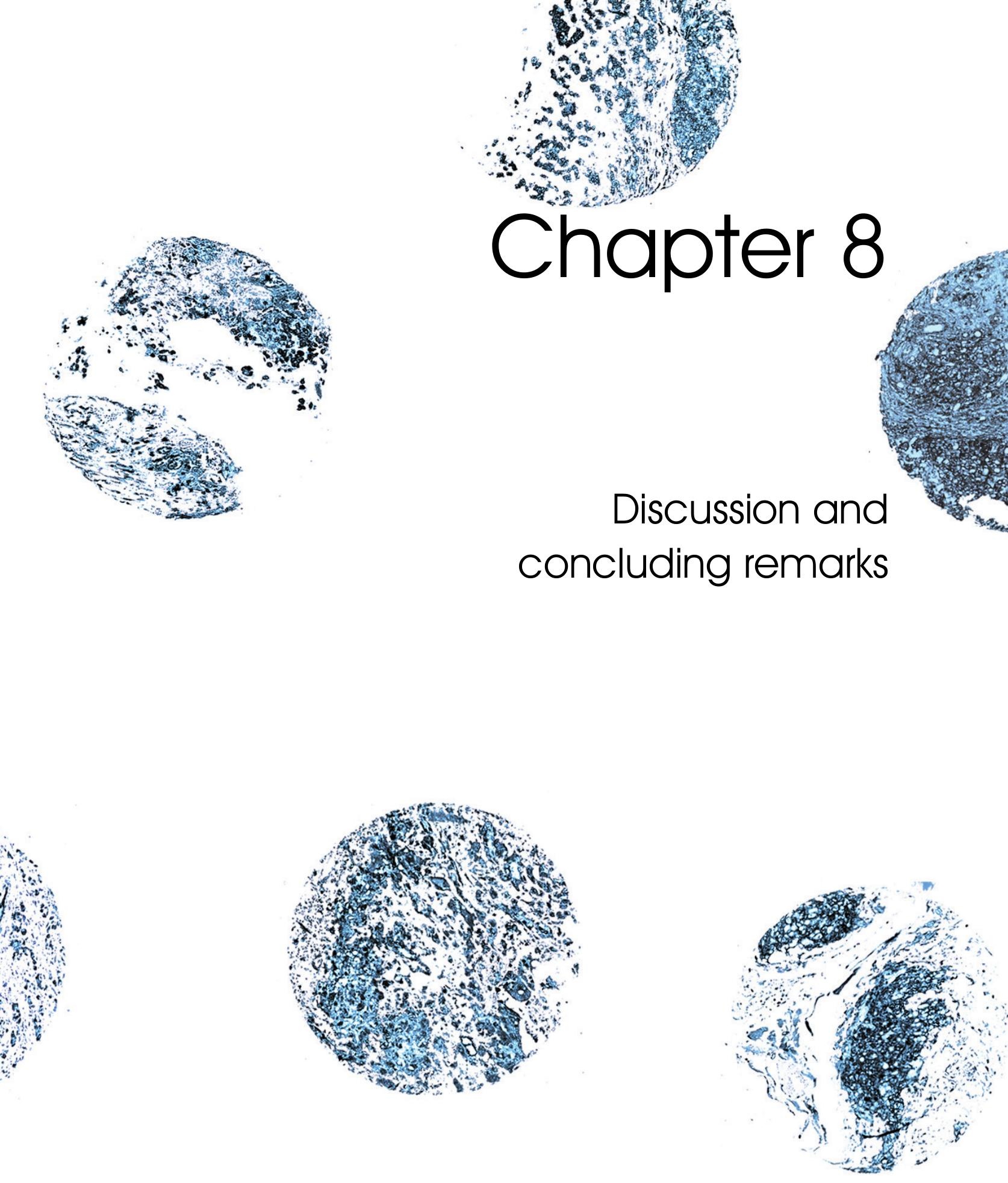

$4 y^{2}$

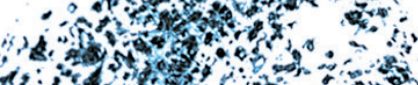

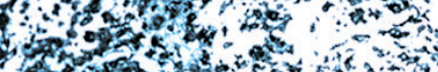

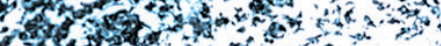





\section{General discussion}

\section{Clinical}

After two decades of vastly accumulating research in chordomas, these lesions still are a clinical challenge for medical professionals that treat these patients. Typically, chordomas present in adults with neurological deficits or pain as a result of their characteristic invasive tumor growth in and around critical neurovascular structures. Due to possible harm to these precarious tissues, management of these tumors remains difficult with total surgical resection achieved in only a minority of the cases. Although optimization of surgical techniques to achieve gross total resection have repeatedly been addressed as a primary focus in improving the management of these tumors, substantial gain in survival was achieved by the occurrence of a paradigm shift towards additional radiotherapy with proton beam radiation which now serves as the mainstay in postoperative care. ${ }^{1}$ Stereotactic radiosurgery or fractionated stereotactic radiotherapy can be considered as an alternative, even though no prospective studies have compared their effect with charged particle therapies. ${ }^{2-6}$ Additional conventional therapies on these tumors has no place in current treatment regimens as chordomas are resistant to conventional chemotherapeutic agents or conventional radiotherapy. ${ }^{7,8}$ Over time, this current treatment protocol has illustrated to improve the prognosis of cranial chordoma patients significantly. ${ }^{9}$ Even so, the fundamental concern with these cancers is the high recurrence/regrowth rate after multimodal therapy, with no standardized additional therapeutic option to offer patients. ${ }^{1,10}$ After recurrence or tumor growth, a treatment proposal can be offered for additional surgical resection or the possibility to enter a trial in the advanced stage of disease, even if another recurrence is imminent. ${ }^{11}$ Clinical variables that influence disease progression are suggested in a multitude of epidemiological studies. ${ }^{12}$ However, due to the infrequent occurrence of this tumor, prognostic data on these variables are presented in smaller cohort, with often conflicting reports. ${ }^{12,13}$ In line with this is the interesting occurrence of chondrosarcomas at the skull base. These tumors are radiologically and histologically difficult to differentiate from chondroid chordomas, but have shown to carry a significantly better prognosis. ${ }^{14}$ Variable treatment outcome in chordoma patients and the interesting nature of these tumors, therefore, have set in motion a quest for a requisite understanding of the tumor's fundamental molecular biology. Possible venues for incorporating the molecular knowledge gained are not merely scientific, but are crucial to accompany the increasing demand for promising molecular markers for purposes such as prognosis statement. However, even though prognosis statement might aid in the acceptance and management of disease for patients, it cannot provide the same immediate value when no predictive markers or proper therapy is exists. More crudely stated, the current literature increasingly acknowledges the importance of examining the molecular biology in order to improve medical management of these intricate tumors, even though it is merely the first of many steps. 


\section{Chordoma and the notochord}

As the name "chordoma" might imply, these tumors are believed to be derived from the chorda dorsalis, or more commonly known as the notochord. Arguments for attributing the tumor to its notochordal heritance is based on the location along the spinal axis and, even more so, on the histologically similar appearance of the tumor cells to notochordal cells. Additional characteristic features of these cells, is the molecular expression of proteins related to a potential notochordal origin, with one of the most prominent and promising being the notochordal transcription factor brachyury. After successfully resecting the human notochord from aborted fetuses, we confirmed that the human notochord expressed the brachyury protein. In addition, as shown in the graphs of chapter three, expression of brachyury is also present in the remaining axial skeleton. ${ }^{15}$ This observation leads to question the true origin of brachyury expression in chordoma. Is this expression the result of its notochordal origin or do chordoma tumors exhibit a phenotype that resembles the notochord and is the expression of brachyury a consequence of its location alongside the axial spine? In 2012, the group of Flanagan reported gene expression panels on knockdown of brachyury. Although many interesting finding are described, only minor relation has been observed with typical notochordal transcription factors. ${ }^{16}$ However, to our knowledge, no such markers or panels exists. In order to alleviate the doubt and to relate chordomas to the notochord, expression of a specific molecular marker or an expression profile in notochordal tissue is required. As the notochord, has several functions and concomitant molecular expression in the different stages of the developing fetus, obtaining a specific pivotal expression profile or tissue marker might reveal to be challenging. Thus, it therefore seems plausible to accept a paradigm in which a notochordal origin for these tumors is "most applicable" until we know more about the specific genetic expression of the notochord.

Another funding argument of the notochordal paradigm is based on the observations of Yamaguchi et al. ${ }^{17-20}$ in which benign notochordal lesions are detected neighboring a chordoma tumor. A potential malignant transformation was proposed by the authors, supporting a hypothesis were chordoma exist from notochordal remnant via a possible benign counterpart. However, as notochordal benign tumor or rarely observed and even less frequently adjoining a chordoma in the clinical setting, such correlation up to date has found little support. A possible venue to investigate the relation of the notochord with chordoma in this manner, would be substantial if patients harboring a skull base chordoma, would also be evaluate for the existence of a sacral (benign) tumor. This is not the current diagnostic protocol in the clinical setting. In addition, the claim of chordoma arising from a benign predecessor might also raise the question of histologic heterogeneity in these tumors. Chordomas diagnosed as such, might show traces of BNCT architecture. Kreshak et al. have evaluated 174 cases in their institution and report two mixed cases of BNCT and chordoma histology. ${ }^{21}$ Although this might substantiate the possible link between these tumors, it remains questionable why the other lesions did not show such a correlation. A possible explanation would be the slow growing nature of this tumor, so that most tumor have already developed a full 
chordoma phenotype over time. Investigating the molecular differential expression of these benign counterpart and chordoma with this infrequent occurrence would again highlight the necessity of collaborating chordoma institution on this front.

So, even though a notochordal origin is repeatedly proposed for chordomas with also a substantial amount of evidence potentiating a link between the two tissue types, there also remains doubt as no verification of this link has been made. The question as to whether this origin is important in understanding the biology of this disease is one where most scientists agree on largely.

The cell/tissue-of-origin question can now be addressed by analysis of DNA methylation profiles. Cancer methylomes are characterized by the epigenetic code of the cell of origin rather than the process of malignant transformation. ${ }^{22}$ Comprehensive profiling of DNA methylation, for example by Infinium $850 \mathrm{k}$ analysis, has been reported to facilitate identification of unknown primary tumors, ${ }^{23}$ molecular subtypes of brain tumors and skin cancers. ${ }^{24,25}$ Applying methylation profiling on tissue isolated using the protocol provided in chapter three, would be an interesting approach for identifying the cell of origin of chordomas.

To facilitate the implication of in vitro developed hypothesis to in vivo verified concepts, animal models are crucial. Here, it is worth the notion that no animal models exist that model the true chordoma tumors from remnants of the human notochord or from the human notochord itself. As no GEM models are available, the most viable in vivo options so far are the use of xenograft model or a recently discovered zebrafish model, reported by Burger et al., using a transgene-driven expression of HRASV12 in notochord cells ${ }^{26}$ Finding a true cell of origin with methods, such as methylation profiling, might not only lead to unraveling the (epi)genetic fingerprint that points to the hallmark that initiate the chordomagenesis but moreover could direct the development of optimal model systems to analyze the inquired pathophysiology.

\section{Biomarker research and targeted therapies}

One of the most trivial questions confronting clinicians is the uncertain period of time chordoma patients have before the tumor progresses after receiving the multimodal therapy containing surgery and radiotherapy. Anticipating this progression free survival time by discovering crucial biomarkers and potentially adapting clinical management to extent this time if proper treatment regimens are available, is a scientific challenge that occupies many researchers. In addition, it remains questionable whether all chordoma patients require this same primary multimodal therapy. Although case reports and case series have indicated a possible positive result of patient tailored therapy on the basis of the tumors' molecular profile, to date, no predictive markers are available for chordomas that steer the therapeutic regimen in these patients. ${ }^{27}$ Clinical benefit by using tumors' susceptibility to certain therapies based biomarker research is reported extensively and highlights the potential of patient-tailored treatment regimens. ${ }^{28}$ 
This patient-specific vulnerability has also been at the center of another detrimental question in chordoma. The underlying reason why chordoma tumors are believed to develop in only a minor portion of people harboring notochordal remnants is one that moves many scientists. Finding the key trigger for a potential molecular predilection for the chordomagenesis phenomenon is challenging as much of the scientific work has been performed before the rapid development of novel genome-wide technologies. Research two decades ago began with a more basic examination of the integrity of the chromosomes in this disease. These primary analysis illustrated frequent deletions occurring in chromosomes $1 p$ and $3 p$ and amplification of chromosome $7 .^{7}$ In 2008, homo- or heterozygous loss of the CDKN2A and CDKN2B gene loci in 9p21 were related to chordoma development. ${ }^{29}$ Even though these chromosomal aberrations are now known for a period of time and can be identified in a significant number of chordoma samples, the clinical significance is being debating only the past decade. As controversy exists on the role of deletion of 1 p36 on the clinical progression of disease, the effect of loss of heterozygosity on 9p21 seems to have a more reliant scientific base with a negative effect on survival. ${ }^{30-33}$ However, as most these findings are based on one-lab experiments with mixed treatment populations, the level of evidence is little requiring validation of these findings in larger cohorts prior to clinical implementation. In addition, can we pinpoint a more specific location and are there other contributors to this relation besides the impaired expression of CDKN2A and CDKN2B? Can these genes also aid in understanding the primary pathophysiology of chordomas? This is crucial, as using only cytogenetic abnormalities as a biomarker for predicting the primary pathology for chordomas appears to have minor scientific evidence as Al Mefty et al. ${ }^{34}$ reported in their article that in sporadic skull base chordomas $74 \%$ of the cases did not show any abnormalities in their chromosomal arrangement. Due to this predicament, the scientific venue hereafter changed to focus on deeper analysis using genome-wide screening methodologies.

Even so, using whole-exome and Sanger sequencing no significant driving mutation was found in chordomas by the group of Campbell et al..$^{35}$ The authors do, however, describe duplications of brachyury $(T)$ in $27 \%$ of the 104 sporadic cases. Expression of brachyury, was earlier found to be overexpressed in chordomas compared to other tumors, including chondrosarcomas, is implicated in the proliferation of chordoma cells, potentially related to the existence of single nucleotide polymorphism rs2305089 and was recently associated with the stemness of chordoma and more common aggressive cancers. ${ }^{36-39}$ As this evidence towards a significant impact of brachyury in chordoma's pathophysiology is growing, a yeast-based therapeutic vaccine targeting brachyury (GI-6301) is now being tested in a phase II clinical trial..$^{40}$ The prognostic relevance of brachyury, on the other side however, is less clear. Where in lung, colorectal and breast cancer brachyury expression in early stages seems to be predictive for impaired survival, in chordoma brachyury expression seems to show different prognostic outcomes. ${ }^{39,41-45}$ As brachyury evidently appears to be important in the biological markup of this tumor, association of its expression with other known over- 
expressed genes and proteins in chordoma were investigated. Where the expression of other tyrosine kinase receptors in chordoma have been extensively described, see chapter 2 , the group of Flanagan et al. and Quinones-Hinojosa et al. implicated the overexpression of brachyury with fibroblast growth factor. ${ }^{46}$ Quinones-Hinojosa et al. did illustrate a positive effect of brachyury on FGF2 expression and on cell growth in vitro, clinical relevance, however, of both is lacking as both studies did not address the prognostic effect in their population. As growing interest exist in inhibition of FGF-receptors by means of medical compounds, a possible venue is opened to inhibit this pathway in chordoma tumors ${ }^{47}$ Like FGFR, other receptor tyrosine kinases, are clinically tested in chordoma patients and have not found their application in the standard treatment regimen. Experimental treatment with imatinib in chordoma patients with advanced disease was suggested for patients with advanced disease. ${ }^{48}$ This inhibitor of the platelet-derived growth factor receptor (PDGFR) was shown to cause disease stabilization in $72 \%$ with a median progression free survival(PFS) of 9 months and an objective response rate of $2 \%(1 / 56) . .^{49}$ Selective compound testing in three chordoma cell lines and validation in vivo in two PDX-models has shown a potential for the use of epidermal growth factor receptor (EGFR) inhibitor Sapitinib. ${ }^{50}$ Other EGFR inhibitor, lapatinib, was tested earlier in a phase II trial and showed modest antitumor activity in chordoma, with $33 \%$ showing partial response and $38,9 \%$ stable disease and an PFS of $6-8$ months. ${ }^{51}$ However, as with all medical therapies, the quest of selecting the appropriate patient population for treatment in chordoma is challenging as most medical experimental therapies examined involve the RTK-pathway and showed very limited effect in only a small subset of patients. However, these targets are mainly studied in advanced disease, its effect in primary disease and the potential of these drug therapies in primary recurrent disease remains elusive. A large potential concerning this challenge lies in the application of patient derived organoids that can deliver a new dimension to our understanding of the heterogeneity within this rare patient population..$^{52}$ As outlined in chapter five, there might be a discrepancy in influence of a specific RTK spectrum in this timeline that might reflect the effect of these drug therapies as cross talk between the RTK family affects tumor cell sensitivity. ${ }^{53}$ Incorporating an assessment, for instance examining the expression of the 52 known RTKs in the tumor and testing of the compounds in patient derived xenograft (PDX) models or organoids prior to treatment, would likely benefit compound selection. ${ }^{54,55}$ In addition, with the emerging online platforms that allow for rapid collection of more frequently available next generation sequencing of patients with rare diseases, will result in greater advancement in understanding the biological basis of the disease. ${ }^{56}$

Unlike brachyury and RTKs, limited discussion exists around the clinical prognostic relevance of the cell cycle marker CDK4. As its biological role in cell proliferation would indicate in chordoma, the expected overexpression of CDK4, is clearly correlated to a worse prognosis. In chapter 6 we have illustrated this effect in our patient cohort, which has later been duplicated in a larger cohort. ${ }^{57,58}$ As in vitro experiments showed promising results with CDK4/6 inhibitor, palbociclib and abemaciclib, in consistently reducing chordoma cells growth, a 
potential application in chordoma patients seems worth exploring. A phase II trial with palbociclib is currently recruiting chordoma patients with advanced disease. ${ }^{59}$

With the growing interest for targeted immunotherapy in cancer research, new treatment paradigms were created for melanoma, non-small-cell lung cancer (NSCLC) and renal cell carcinoma (RCC) with the implementation of Nivolumab in their treatment regimen. Nivolumab, a human immunoglobulin targeted against programmed death-1 (PD-1) receptor, blocks the inhibitory activity of this receptor on activated $\mathrm{T}$ cells and thereby promotes antitumor immunity. In chordoma, PD-L1 expression is witnessed primarily in tumor-infiltrating lymphocytes, however, the correlation with prognosis still need to be established. ${ }^{60-63}$ Currently, clinical trials are examining the effect of Nivolumab in advanced or recurrent disease in chordoma patients.

Concluding, biomarker research in chordoma is of great interest for chordoma researchers, as clinicians are faced with a complex dilemma of tumor recurrence with limited therapeutic options. Now, multiple drug targets are being evaluated in clinical trial settings, were positive effect of targeted therapy against brachyury and other targets, is anticipated. However, many clinical phase II trials in chordoma have been undertaken in the past, with unfortunately little success. This highlights the lack of evidence that even substantial molecular studies in chordoma have, mostly due to the infrequent occurrence of the disease and lack of large validation of wet lab findings.

\section{Fundamental methodological challenges}

Conducting molecular research with special emphasis on biomarker research in chordomas presents numerous challenges and may explain the paucity of (interventional) clinical studies with patients harboring these tumors.

One of the major challenges for chordomas remains the relatively rare occurrence of the disease. For comprehensive molecular exploration, acquiring high number of cases required to validate experimentally developed concepts is essential. Therefore, as the majority of fundamental research in chordoma including the current thesis is performed on smaller number of tumor cases due to availability of tumor specimens, it needs to be noted that the minor level of evidence (LoE) established by these case-control studies (LoE III) still requires proper validation in larger cohorts, which is lacking in most cases. These cohorts can be accomplished by collaborating (inter)nationally and focusing clinical management in specialized care centers with clinical and scientific interest. An important aspect in this regard is the similarity in treatment regimen for all cases within the same treatment group. This latter poses a substantial challenge, as many centers apply different treatment protocols. Future chordoma patients are likely to have similar clinical management as a suggested guideline on the treatment is now available. ${ }^{11}$ Combining chordoma treatment centers with harmonized protocols and scientific interest in an international consortium would undoubtedly improve the quality and quantity in which research is performed on these tumors. 
Furthermore, for fundamental case-control design to be validated as such, a proper control should be established. Even if much of the studies regarding sub-classification of tumors can be achieved without a benign control tissue, experimental designs currently address notochordal remnant as the proper control for the fundamental studies. Although histological and minor experimental data might suggest such an origin, no decisive study has proven such a correlation. As previously mentioned, a proper study including novel methodological approaches, such as methylation profiling using the infinium $850 \mathrm{~K}$, might provide the core origin of the chordoma cell and would therefore reveal the proper non-malignant control. In addition, in order to evaluate a proper methodological set up, it is of high importance to differentiate primary and recurrent tumor, as these tumors show a differential molecular makeup. ${ }^{64}$ The same applies for the distinction between conventional chordomas versus more dedifferentiated type of chordomas. ${ }^{65}$

Furthermore, as many prognostic molecular biomarkers are suggested, none have found clinical implementation in chordoma management. The main reason for this shortcoming is the limited to no reproducibility of these factors, heterogeneity within chordoma tumors and treatment protocols and the varying outcome measurements applied. As recently a consensus on the management of chordoma patients exists, studies on the prognostic effect should in our opinion clearly define the population of interest. ${ }^{11}$ Here primary tumors, that haven't been treated with charged particle therapy, should be treated separately from recurrent cases. Patients that did not received their treatment according to the standardized care should not be included in studies considering primary prognosis. In addition, analysis of potential prognostic biomarkers should besides the frequently reported log rank test, reduce the probability of confounding by applying a multivariate analysis including the known prognostic factors (e.g. extent of resection, type of charged particle therapy and previously published markers). This way, internationally verified markers, after careful modeling of these predictive markers and validation in larger cohorts, could have a significant impact on the counseling of these patient and moreover might serve as important targets for medical therapy.

\section{Future perspectives}

While the literature on genomics, transcriptomics and recently proteomics in chordoma is increasing, paucity in research exists on the field of external factors as a predisposing feature or a causative agent in the oncogenic process of chordomas. In this light, chapter 7 was dedicated to investigating the presence of oncogenic viruses in chordoma. We establish the presence of parvovirus B19 (PVB19) DNA in 22\% (4/18) of chordoma and expression of the VP2 capsid protein of PVB19 in 44\% (14/32) of the cases. In addition, the occurrence of Human Herpes Virus 7 (HHV7) and Epstein-Barr Virus (EBV) were witnessed in 33\% and 22\%, respectively. Despite the fact that these viruses are also present in normal tissue, at least one of these three viruses was detected in $50 \%$ of the patients in this cohort. Future investigations might implement genome wide analysis studies or association experiments with clinical data 
for the purpose of investigating the complete presence and influence of viral involvement on the etiology and pathophysiology of chordomas. Other external factors that are interesting to consider investigating, could include environmental factors, but more significantly might be the tumor cell's extracellular matrix as this is an essential process in epithelial tumors. ${ }^{66}$

In addition, as in the molecular biology of chordomas evidence is pointing towards a single catastrophic event where genomic DNA is altered (chromothripsis) and no single driving mutation is found to be responsible for the malignant transformation, substantial advantage lies in amalgamating multiple fields of cell biology to gain insight in the comprehensive cancerous behavior in order to funnel the perspective to several crucial pathways responsible for chordomagenesis and pathophysiology. ${ }^{35,67}$ This quest should entail uncovering separate zones of cell biology within the same experiment, ${ }^{68}$ but moreover advance the knowledge to unexplored zones of tumor biology, such as the before mentioned influence of external pathogens and extracellular matrix. ${ }^{69,70}$ This holistic approach is desirable as it not only improves our understanding of the molecular foundation of chordoma, but would furthermore enable clinicians with medical targets and improved knowledge for application in a patient-tailored approach. Of vital importance in this perspective is to be critical on the methodology applied in the study with respect to the previously mentioned methodological challenges in chordoma research.

Finally, initial clinical management of chordoma tumors is largely dependent on the primary surgical resection. Gross total resection is by far the preferred initial treatment. However, as medical imaging often is insufficient to make the distinction, clinically, a chordoma is not well differentiated from the substantially less malignant chondrosarcoma and often confused with other tumors on the skull base or axial spine. Novel implicated diffusion weighted or PET imaging might prove to be of additional value in specifying the tumor, however, so far these have not found their implementation. Radiomics studies would therefore be a novel area within the chordoma research field with great immediate potential for improving patient management. For now, clinicians are exclusively dependent on tissue validation for the diagnosis. This results in some patients being operated in centers, where biopsies are being performed and subsequently are redirected to expert centers for gross total resection. This second surgery is challenging due to scaring and brings additional hazards to the surgery and sometimes makes gross total resection not possible due to tumor seeding. An unexplored area in chordoma research that will hopefully attract more scientific interest is the development of biomarker based molecular imaging agents. ${ }^{71} \mathrm{MRI}$ molecular targeted contrast agents might not only prove to be useful in visualizing the tumor and differential diagnosis, but moreover might illustrate a valuable vehicle to deliver targeted therapy. This latter is vital in the substantial portion of patient that show recurrent disease, where resection is often difficult. As no additional standardized medical therapies are implemented in patients with tumor recurrence, it remains an unforeseen misfortune that takes lives and therefore requires our devotion. ${ }^{11,49}$ 


\section{Concluding remarks}

Chordomas are tarnished tumors with an intricate clinical and molecular behavior. An improved and comprehensive understanding of chordomagenesis is accomplished by applying a holistic experimental approach, incorporating unexplored zones of tumor biology and amalgamating multiple fields of cell biology in the same experimental set-up. Before this can result in significant findings that would benefit the suffering patient, methological challenges in chordoma research should be taken into consideration when designing novel studies. Clinically, no established treatment options are available for the frequently encountered recurrent disease. Internationally validated molecular prognostic biomarkers and advancements in medical targeted therapy could improve the clinical management of these patients, provided that these therapies are examined and applied in a patient-tailored approach. 


\section{References}

1. Stacchiotti, S., et al. Best practices for the management of local-regional recurrent chordoma: a position paper by the Chordoma Global Consensus Group. Ann Oncol 28, 1230-1242 (2017).

2. Hasegawa, T., et al. Gamma Knife surgery for skull base chordomas and chondrosarcomas. J Neurosurg 107, 752-757 (2007).

3. Liu, A.L., et al. Gamma knife radiosurgery for residual skull base chordomas. Neurol Res 30, 557-561 (2008).

4. Kano, H., et al. Stereotactic radiosurgery for chordoma: a report from the North American Gamma Knife Consortium. Neurosurgery 68, 379-389 (2011).

5. Chang, S.D., Martin, D.P., Lee, E. \& Adler, J.R., Jr. Stereotactic radiosurgery and hypofractionated stereotactic radiotherapy for residual or recurrent cranial base and cervical chordomas. Neurosurg Focus 10, E5 (2001).

6. Bugoci, D.M., Girvigian, M.R., Chen, J.C., Miller, M.M. \& Rahimian, J. Photon-based fractionated stereotactic radiotherapy for postoperative treatment of skull base chordomas. Am J Clin Oncol 36, 404-410 (2013).

7. Yakkioui, Y., van Overbeeke, J.J., Santegoeds, R., van Engeland, M. \& Temel, Y. Chordoma: the entity. Biochim Biophys Acta 1846, 655-669 (2014).

8. De Amorim Bernstein, K. \& DeLaney, T. Chordomas and chondrosarcomas-The role of radiation therapy. J Surg Oncol 114, 564-569 (2016).

9. Chambers, K.J., et al. Incidence and survival patterns of cranial chordoma in the United States. Laryngoscope 124, 1097-1102 (2014).

10. Wu, Z., et al. Prognostic factors for long-term outcome of patients with surgical resection of skull base chordomas-106 cases review in one institution. Neurosurg Rev 33, 451-456 (2010).

11. Stacchiotti, S., et al. Best practices for the management of local-regional recurrent chordoma: a position paper by the Chordoma Global Consensus Group. Annals of Oncology 28, 1230-1242 (2017).

12. Lee, I.J., Lee, R.J. \& Fahim, D.K. Prognostic Factors and Survival Outcome in Patients with Chordoma in the United States: A Population-Based Analysis. World Neurosurg 104, 346-355 (2017).

13. Rachinger, W., et al. Male sex as a risk factor for the clinical course of skull base chordomas. J Neurosurg 120, 1313-1320 (2014).

14. Bohman, L.E., Koch, M., Bailey, R.L., Alonso-Basanta, M. \& Lee, J.Y. Skull base chordoma and chondrosarcoma: influence of clinical and demographic factors on prognosis: a SEER analysis. World Neurosurg 82, 806-814 (2014).

15. Santegoeds, R.G., et al. Notochord isolation using laser capture microdissection. J Chem Neuroanat 80, 37-43 (2017).

16. Nelson, A.C., et al. An integrated functional genomics approach identifies the regulatory network directed by brachyury (T) in chordoma. The Journal of Pathology 228, 274-285 (2012).

17. Yamaguchi, T., et al. Distinguishing benign notochordal cell tumors from vertebral chordoma. Skeletal Radiology 37, 291-299 (2008).

18. Yamaguchi, T., Suzuki, S., Ishiiwa, H., Shimizu, K. \& Ueda, Y. Benign Notochordal Cell Tumors: A Comparative Histological Study of Benign Notochordal Cell Tumors, Classic Chordomas, and Notochordal Vestiges of Fetal Intervertebral Discs. The American Journal of Surgical Pathology 28, 756-761 (2004). 
19. Yamaguchi, T., Watanabe-Ishiiwa, H., Suzuki, S., Igarashi, Y. \& Ueda, Y. Incipient chordoma: a report of two cases of early-stage chordoma arising from benign notochordal cell tumors. Mod Pathol 18, 1005-1010 (2005).

20. Yamaguchi, T., Yamato, M. \& Saotome, K. First histologically confirmed case of a classic chordoma arising in a precursor benign notochordal lesion: differential diagnosis of benign and malignant notochordal lesions. Skeletal Radiol 31, 413-418 (2002).

21. Kreshak, J., et al. Difficulty distinguishing benign notochordal cell tumor from chordoma further suggests a link between them. Cancer imaging : the official publication of the International Cancer Imaging Society 14, 4-4 (2014).

22. Bormann, F., et al. Cell-of-Origin DNA Methylation Signatures Are Maintained during Colorectal Carcinogenesis. Cell Reports 23, 3407-3418 (2018).

23. Moran, S., et al. Epigenetic profiling to classify cancer of unknown primary: a multicentre, retrospective analysis. The Lancet Oncology 17, 1386-1395 (2016).

24. Orozco, J.I.J., et al. Epigenetic profiling for the molecular classification of metastatic brain tumors. Nature communications 9, 4627 (2018).

25. Rodriguez-Paredes, M., et al. Methylation profiling identifies two subclasses of squamous cell carcinoma related to distinct cells of origin. Nature communications 9, 577 (2018).

26. Burger, A., et al. A zebrafish model of chordoma initiated by notochord-driven expression of HRASV12. Dis Model Mech 7, 907-913 (2014).

27. Di Maio, S., et al. Novel targeted therapies in chordoma: an update. Therapeutics and clinical risk management 11, 873-883 (2015).

28. Kamps, R., et al. Next-Generation Sequencing in Oncology: Genetic Diagnosis, Risk Prediction and Cancer Classification. International journal of molecular sciences 18, 308 (2017).

29. Hallor, K.H., et al. Frequent deletion of the CDKN2A locus in chordoma: analysis of chromosomal imbalances using array comparative genomic hybridisation. Br J Cancer 98, 434-442 (2008).

30. Longoni, M., et al. Evaluation of $1 \mathrm{p} 36$ markers and clinical outcome in a skull base chordoma study. Neuro Oncol 10, 52-60 (2008).

31. Zenonos, G.A., et al. Prospective validation of a molecular prognostication panel for clival chordoma. Journal of Neurosurgery 0, 1-10.

32. Horbinski, C., et al. The prognostic value of Ki-67, p53, epidermal growth factor receptor, 1p36, 9p21, 10q23, and 17p13 in skull base chordomas. Arch Pathol Lab Med 134, 1170-1176 (2010).

33. Kitamura, Y., et al. Molecular and Clinical Risk Factors for Recurrence of Skull Base Chordomas: Gain on Chromosome 2p, Expression of Brachyury, and Lack of Irradiation Negatively Correlate With Patient Prognosis. Journal of Neuropathology \& Experimental Neurology 72, 814-821 (2013).

34. Almefty, K.K., Pravdenkova, S., Sawyer, J. \& Al-Mefty, O. Impact of cytogenetic abnormalities on the management of skull base chordomas. J Neurosurg 110, 715-724 (2009).

35. Tarpey, P.S., et al. The driver landscape of sporadic chordoma. Nature communications 8,890 (2017).

36. Shah, S.R., et al. Brachyury-YAP Regulatory Axis Drives Stemness and Growth in Cancer. Cell Reports 21, 495-507.

37. Vujovic, S., et al. Brachyury, a crucial regulator of notochordal development, is a novel biomarker for chordomas. J Pathol 209, 157-165 (2006).

38. Wu, Z., et al. The Brachyury Gly177Asp SNP Is not Associated with a Risk of Skull Base Chordoma in the Chinese Population. International Journal of Molecular Sciences 14, 21258-21265 (2013). 
39. Bettegowda, C., et al. Spinal column chordoma: prognostic significance of clinical variables and T (brachyury) gene SNP rs2305089 for local recurrence and overall survival. Neuro-Oncology 19, 405-413 (2017).

40. Heery, C.R., et al. Phase I Trial of a Yeast-Based Therapeutic Cancer Vaccine (GI-6301) Targeting the Transcription Factor Brachyury. Cancer Immunol Res 3, 1248-1256 (2015).

41. Palena, C., et al. Overexpression of the EMT Driver Brachyury in Breast Carcinomas: Association With Poor Prognosis, (2014).

42. Kilic, N., et al. Brachyury expression predicts poor prognosis at early stages of colorectal cancer. European Journal of Cancer 47, 1080-1085 (2011).

43. Zhang, L., et al. Tissue Microarray Immunohistochemical Detection of Brachyury Is Not a Prognostic Indicator in Chordoma. PLOS ONE 8, e75851 (2013).

44. Haro, A., et al. Expression of Brachyury Gene Is a Significant Prognostic Factor for Primary Lung Carcinoma. Annals of Surgical Oncology 20, 509-516 (2013).

45. Otani, R., et al. Brachyury gene copy number gain and activation of the PI3K/Akt pathway: association with upregulation of oncogenic Brachyury expression in skull base chordoma. Journal of Neurosurgery 128, 1428-1437 (2018).

46. Shalaby, A.A.E., et al. Analysis of the fibroblastic growth factor receptor-RAS/RAF/MEK/ ERK-ETS2/brachyury signalling pathway in chordomas. Modern Pathology 22, 996 (2009).

47. Porta, R., et al. FGFR a promising druggable target in cancer: Molecular biology and new drugs. Critical Reviews in Oncology/Hematology 113, 256-267 (2017).

48. Stacchiotti, S. \& Sommer, J. Building a global consensus approach to chordoma: a position paper from the medical and patient community. The Lancet Oncology 16, e71-e83 (2015).

49. Stacchiotti, S., et al. Phase II study of imatinib in advanced chordoma. J Clin Oncol 30, 914-920 (2012).

50. Scheipl, S., et al. EGFR inhibitors identified as a potential treatment for chordoma in a focused compound screen. J Pathol 239, 320-334 (2016).

51. Stacchiotti, S., et al. Phase II study on lapatinib in advanced EGFR-positive chordoma. Ann Oncol 24, 1931-1936 (2013).

52. Puca, L., et al. Patient derived organoids to model rare prostate cancer phenotypes. Nature communications 9, 2404 (2018).

53. Zou, H., et al. Receptor tyrosine kinase cross talk affects tumor cell sensitivity to RTK inhibitors. Cancer Research 68, LB-198 (2008).

54. Colia, V. \& Stacchiotti, S. Medical treatment of advanced chordomas. European Journal of Cancer 83, 220-228 (2017).

55. Williams, J.A. Using PDX for Preclinical Cancer Drug Discovery: The Evolving Field. Journal of Clinical Medicine 7, 41 (2018).

56. Sharifnia, T., Hong, A.L., Painter, C.A. \& Boehm, J.S. Emerging Opportunities for Target Discovery in Rare Cancers. Cell Chemical Biology 24, 1075-1091 (2017).

57. Yakkioui, Y., et al. A comparison of cell-cycle markers in skull base and sacral chordomas. World Neurosurg 82, e311-318 (2014).

58. Liu, T., et al. CDK4 expression in chordoma: A potential therapeutic target. J Orthop Res (2017).

59. von Witzleben, A., et al. Preclinical Characterization of Novel Chordoma Cell Systems and Their Targeting by Pharmocological Inhibitors of the CDK4/6 Cell-Cycle Pathway. Cancer Research 75, 3823-3831 (2015).

60. Mathios, D., et al. PD-1, PD-L1, PD-L2 expression in the chordoma microenvironment. J Neurooncol 121, 251-259 (2015). 
61. Feng, Y., et al. Expression of programmed cell death ligand 1 (PD-L1) and prevalence of tumor-infiltrating lymphocytes (TILs) in chordoma. Oncotarget 6, 11139-11149 (2015).

62. Zou, M.X., et al. Expression of programmed death-1 ligand (PD-L1) in tumor-infiltrating lymphocytes is associated with favorable spinal chordoma prognosis. Am J Transl Res 8, 3274-3287 (2016).

63. Zou, M.X., et al. Clinicopathologic implications of CD8(+)/Foxp3(+) ratio and miR-574-3p/PD-L1 axis in spinal chordoma patients. Cancer Immunol Immunother 67, 209-224 (2018).

64. Chen, S., et al. Differential proteomic profiling of primary and recurrent chordomas. Oncol Rep 33, 2207-2218 (2015).

65. Mobley, B.C., et al. Loss of SMARCB1/INI1 expression in poorly differentiated chordomas. Acta Neuropathol 120, 745-753 (2010).

66. Buchheit, C.L., Weigel, K.J. \& Schafer, Z.T. Cancer cell survival during detachment from the ECM: multiple barriers to tumour progression. Nat Rev Cancer 14, 632-641 (2014).

67. Stephens, P.J., et al. Massive genomic rearrangement acquired in a single catastrophic event during cancer development. Cell 144, 27-40 (2011).

68. Long, C., et al. Integrated miRNA-mRNA analysis revealing the potential roles of miRNAs in chordomas. PLoS One 8, e66676 (2013).

69. Yakkioui, Y., et al. Oncogenic viruses in Skull Base Chordomas. World Neurosurg (2017).

70. Trapani, V., Bonaldo, P. \& Corallo, D. Role of the ECM in notochord formation, function and disease. Journal of Cell Science 130, 3203 (2017).

71. van Duijnhoven, S.M., Robillard, M.S., Langereis, S. \& Grull, H. Bioresponsive probes for molecular imaging: concepts and in vivo applications. Contrast Media Mol Imaging 10, 282-308 (2015). 

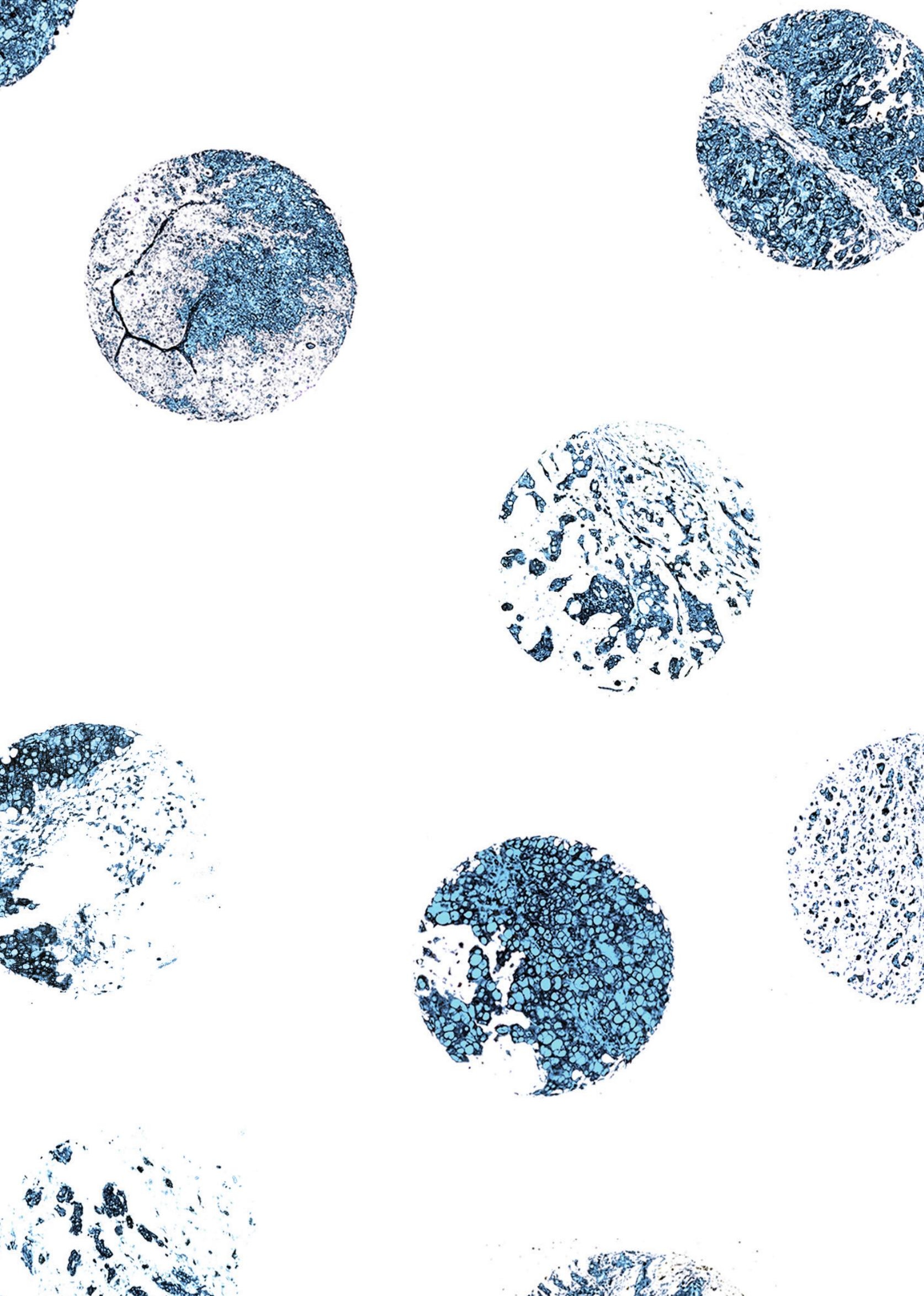

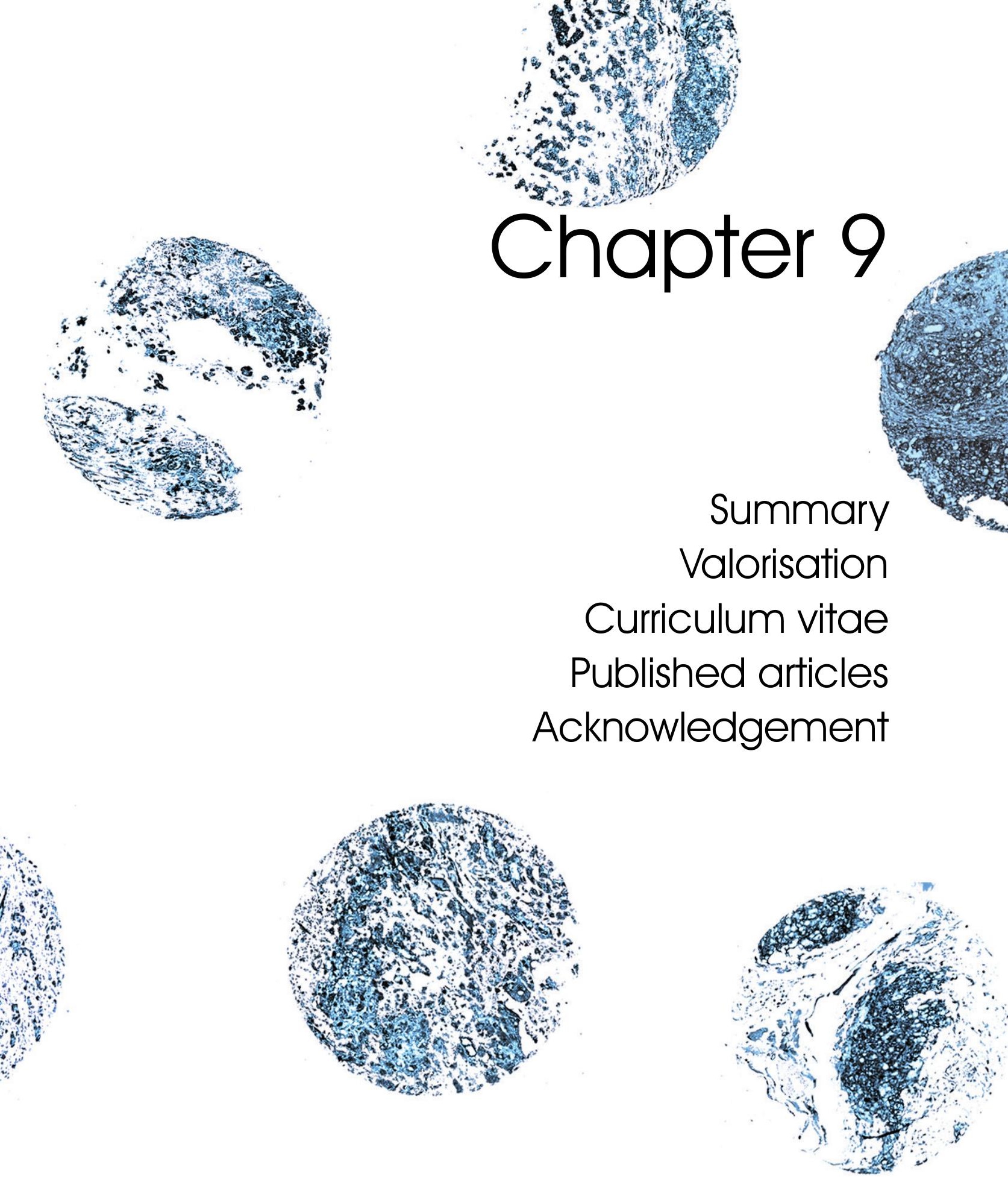

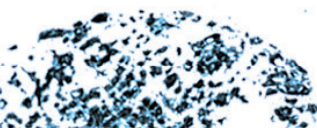
4No

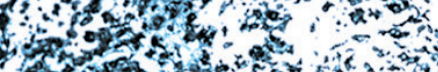

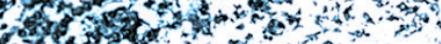





\section{Summary}

In this thesis, we present our focus of biomarker research in skull base chordomas. Biomarkers are defined as biological substances or characteristics, either qualitative or quantitative, that outlines a certain (patho)physiological state and is often used as a surrogate to guide clinicians to indicate disease severity, treatment response and prognosis. Here we summarize the most important findings of the chapters.

The first manuscript in chapter $\mathbf{2}$, presents a summary of the entity called chordoma. As many important historical and recent findings shaped our current thoughts and ideas of chordoma, we accentuate certain discoveries that are a mainstay in how we view the pathophysiological state in chordomas today. First, we admire the human embryology by describing the formation of the notochord, an embryonic elongated rod of cells that (amongst others) guides the formation of the vertebral axis and skull base by secretion of important signaling factors, the vertebral axis and the skull base. To illustrate the beliefs that form our current concept of chordomagenesis, the etiology of chordomas, we highlight the historical development of several paradigms and what we now consider the physiological foundation. By displaying a hypothesized model of these mechanisms, we inform the reader of the possible scenarios for chordomas to arise. The molecular groundwork responsible for tumor development and subsequent tumor behavior, has been very diverse over the past two decades, and primarily performed by single center studies. Here, we discuss (epi-)genetic findings, with the predominantly observation of chromosomal instability in chordoma cells and a proposed single crisis event that is advocated to precede it, called chromothripsis. This genetic backbone of the disease is very heterogeneous, possibly clarifying the array of aberrant molecular pathways in chordoma cells. Brachyury, as a relatively unique hallmark and more stable signaling factor in chordomas, is discovered in 2006 and is classified as a notochordal factor with associations to several pathological mechanisms of the disease. This transcriptionfactor, holds much promise as a biomarker and potential target for therapy. With the discovery of notochordal marker brachyury, the authors argue that there might be potential in further investigating of other notochordal transcriptionfactors. The paucity of studies performed on the level of epigenetics and other unexplored research fields is also touched on.

In chapter 3, the authors support the notion of the notochord being a crucial tissue for chordoma research. In detail, we describe a process by which we isolate notochordal tissue from the human embryonic intervertebral discs. Tissue collected from aborted fetuses with the gestational age of 9,11 , and 13 weeks were collected. After dissection, the spinal column was fixed in $3.7 \%$ formalin for 48 hours before being embedded in paraffin by standard procedure. Immunohistochemically stained tissue of the fetal vertebral spine for brachyury expression, resulted in strong staining of the notochord, but also weak staining of the intervertebral disc and vertebral body. Using laser capture microdissection, the notochordal section is isolated and good quality of RNA distracted from this section is confirmed. The 
authors discuss isolation of other gestational ages and suggest this protocol to be the new standard in isolation of notochordal tissue.

Using the collected intervertebral discs discussed in the previous chapter, in chapter 4, we report on technical specifications and requirements for isolating and comparing protein samples in proteomic analysis. Total protein extraction, as well as specific TiO2-based phosphopeptides enrichment and hydrazyde-based glycopeptides purification are described in detail. For quantitative differential protein expression, isobaric labeling with isobaric tag for relative and absolute quantitation (iTRAQ) is combined with liquid chromatography-mass spectrometry (LC-MS). The vast amount of data gathered from these analysis, represent a challenge for the investigator. The authors suggest the usage of several bioinformatics tools, depending on the preferred application. Software using gene enrichment with tabular results (DAVID, gProfiler, etc.) and gene enrichment with graphical presentation (String, Cytoscape) might prove to be helpful. However, as these results depict the association of genes, with protein-protein libraries not readily available, validation of such results remains a crucial aspect.

Chapter 5 sets out to use such a proteomic assessment to answer a pivotal question in chordoma, and to a lesser extent in chondrosarcomas; "Can we find biomarkers relating to tumor recurrence and do we have potential therapeutics to target them?". Here, we have pooled tumor lysates from patients in specific groups: primary chordomas, primary chordomas that recurred, primary chondrosarcomas, and primary chondrosarcomas that recurred. With the use of $\mathrm{TiO} 2$ phosphopeptide enrichment protocols, similar to ones described in chapter 4, the four groups of iTRAQ labeled phosphopeptides were compared after tandem mass spectrometry analysis. Differential expression of proteins between the tumors that have recurred plotted against tumors that haven't, demonstrates a set of biomarkers that are potentially associated with recurrence. In chordoma that recurred, increased phosphorylation of the discovered peptide could be tracked down to an increase of kinase activity in the tyrosine-protein kinases feline sarcoma oncogene (FES) and feline encephalitis virus-related kinase (FER). With regards to drug sensitivity, the set of phosphorylated chordoma proteins of recurrent patients were predicted to be targeted by Nilotinib and Imatinib. Future studies have to validate this proof of concept.

To summarize chapter $\mathbf{6}$, the authors examined cell cycle biomarkers in chordoma patients treated in our institution. Twenty-five formalin fixed paraffin-embedded chordoma specimens are immunohistochemically stained with antibodies for the cell-cycle markers protein 53 (p53), cyclin dependent kinase 4 (CDK4) and murine double minute 2 (MDM2). Extent of the staining was semi-quantitatively scored on number of positive cells (nuclear expression) categorized as 0 (Negative), 1 (1-10\%), 2 (10-50\%) and 3 (>50\%) and quantitatively scored using optical density measurements. Clinical variables, (e.g. age, gender and overall survival) and pathological outcomes scores (e.g. necrosis, mitotic index and Ki67 scores (MIB1-LI)) were also recorded. All three cell cycle markers showed a significant correlation with MIB1-LI, although the MIB1-LI along with patient age, gender, tumor location 
failed to show a relation with survival. Expression of CDK4 $(p=0.02)$ and P53 $(p<0.01)$, however, were both significantly correlated to poor overall survival. Also, histologically observed necrosis $(p<0.05)$ and a dedifferentiated tumor subtype $(p<0.01)$ were related to adverse patient outcome. These results advocate a direct or indirect link of these biomarkers with worse outcome in patients with chordoma tumors.

The final research chapter, chapter 7, concerns a novel hypothesis of viral involvement in the etiology of chordomas. As previously mentioned, a recent assumption in the etiology of chordomas, is chromothripsis. Viral involvement is frequently heralded as an event preceding this phenomenon. To examine the theory of viral involvement in chordoma, the authors report on a study in which the presence of multiple oncogenic viruses were assessed in chordoma and chondrosarcoma patients. As the most outstanding finding, the presence of parvovirus B19 (PVB19) DNA was detected in 4 of 18 chordomas (22\%) and in 1 of 15 chondrosarcomas (7\%). Immunohistochemical analysis recognized the VP2 capsid protein of PVB19 in 44\% of cases (14 of 32), suggesting an even higher percentage of tumors affected by the virus. DNA from other viruses such as human herpes virus 7 (HHV-7) and Epstein-Barr virus (EBV/HHV4) were present in 6 of the $18(33 \%)$ and 4 of the $18(22 \%)$ chordoma samples. Although a thorough genome-wide search of viral DNA would increase understanding of this hypothesis, this study potentiates a viral involvement in the etiology or pathophysiology of chordoma.

In the final chapter, the authors address the important findings and place them into a general scope of chordoma research. Firstly, a general description of the clinical challenges is briefly touched on to highlight the need for biomarker research. We challenge certain important etiologic and pathophysiological concepts, such as the notochordal origin and the significance of brachyury expression and chromothripsis. Due to lack of typical notochordal biomarkers, we finally accept a notochordal origin for these tumors as "most applicable" until a notochordal expression profile is recognized. Also, we advocate the established use of methylation profiling in unraveling the (epi)genetic fingerprint that points to the hallmark of chordomagenesis. We further highlight the amount of biomarker research performed and the paucity of these results being validated on larger data sets. This by itself addresses the great challenge most chordoma researchers stumble on; the unfortunate small number of patients and cases when compares to other more frequent occurring tumors, such as breast and colon cancer. Most of the biomarker study-result, including ours, therefore must be placed into a different perspective. However, it is still required of researchers, especially in a small research area like chordomas, to use a holistic understanding of the disease, including the paucity of high quality data, and to apply this knowledge for future studies. Amalgamating unexplored zones of tumor biology and multiple fields of cell biology, would help discover molecular (prognostic) biomarkers that might advance as molecular targets for medical therapy. This way, we hope to lift the burden that physicians and patient face in the clinical management of these tumors. 


\section{Valorisation}

Knowledge valorisation is decribed as 'the process of creating value from knowledge, by making knowledge suitable and/or available for social (and/

or economic) use and by making knowledge suitable for translation into competitive products, services, processes and new commercial activities'.

(definition taken from the report of the National Valorisation Committee, Leonie van Drooge, Rens Vandeberg et al., Waardevol: Indicatoren voor Valorisatie. Den Haag, Rathenau Instituut, 2011).

\section{Introduction}

The global burden of human cancer worldwide is rapidly growing and is predicted to become the single leading cause of death in every country of the world in the $21^{\text {st }}$ century. According to the latest release of the Global Cancer Observatory (GCO, GLOBOCAN 2018), it is estimated that there have been 18.1 million new cancer cases and 9.6 million cancer deaths in 2018. ${ }^{1}$ As we progress and improve our understanding of the epidemiology of cancers, the multitude of cancer-causing variables increases which captures the extraordinary diversity of this challenging disease. Due to research initiatives that are attempting to increase our understanding, preventative measures and novel processes and services are increasingly developed to tackle this conundrum. This section is dedicated to scientifically valorizing the research result of the current thesis and should be viewed through a biomedical scope.

\section{Fundamental research relevance}

The 'publish and/or perish' era we are currently participating in, results in minor appreciation for the fundamental understanding of diseased mechanisms and focusses excessively on clinical applicability. When viewed historically, great advances in medicine and biomedical science are the collective achievement of thousands by scientists for whom the primary goal was to understand fundamental mechanisms of biology. Funding institutions and project managers aiming primarily at swift results, preferring observing to understanding, often neglect this concept. As a result, we start to observe less and less and creativity is replaced by productivity. In chordoma, understanding the molecular processes responsible for tumor growth, cell and molecular heterogeneity and treatment resilience, are pivotal in the quest for finding a potential target for disease prediction and therapy. In order to provide insight into the majority of molecular data available we have published a comprehensive review of these molecules in our second chapter. One of the interesting mechanisms discussed is "chromothripsis". A phenomenon deemed responsible for the chromosomal instability often witnessed in chordoma cells. ${ }^{2}$ Investigating viral involvement in chordoma was a rational follow up as it is stated to relate to chromothripsis. ${ }^{3}$ In chapter 7 , we therefore studied 
the presence of oncogenic viruses in healthy and tumorous tissue derived from chordoma patients. The observation indicates a potential involvement of primarily parvovirus B19 in the disease, broadening the scope of potential biomarkers for potential clinical application.

\section{Clinical relevance}

The body of work in this dissertation has the primary focus to increase the scientific understanding of the tumor's biological behavior and to help unravel the complex heterogeneity that accompanies clinical research in chordoma. The essential foundation of clinical management of all patients, right after communicating the diagnosis, is guidance of patients during the disease course. For most physicians, a vigorous challenge lies within this aspect of care where patients, after processing the devastating diagnosis, generally inquire about the prognosis in order to assess their expected quality of life for the remainder of their life. For many experienced physicians the main dilemma lies within the vast heterogeneity of the prognosis. This complexity is, amongst others, primarily derived from the often-observed distinct treatment sequence and, more likely, biological predisposition. Identifying biological substances (biomarkers) that relate to a specific disease state, susceptibility to treatment or outcome often capture this biological tendency for a malignant or benign outcome. It should therefore come to no surprise that hunt on biomarkers in current biomedical research is one of the leading subjects. Discovered biomarkers in other cancers (e.g. glioma) are utilized to enhance the diagnosis and moreover to predict treatment outcome and prognosis. In the design of the study reported on in chapter 6 the authors set out to investigate clinical and molecular markers related to worse outcome. As displayed, were patient characteristics are not reliable markers for the prediction of disease course, molecular markers p53 and CDK4 are related to a more malignant disease course. As we were the first to report on the expression of CDK4 in chordoma and its relation to worse prognosis, it is interesting to note that recently, this negative association has been validated in a larger cohort of 75 patients further cementing this claim. ${ }^{4}$ Currently, a clinical trial using a CDK4 inhibitor, Palbociclib, is recruiting patients with advanced disease in chordoma. As this typical "from bench to bedside" exemplifies an increase of clinically relevant experiments performed today, one must note that often these single biomarker based research initiatives often fail to be reproduced in other datasets as important aspects, such as dose-response are often overlooked. Identifying a set of biomarkers often results in a more comprehensive understanding of the diseases state.

And so, the authors of this thesis in chapter have set out to investigate a more diverse set of proteins (proteome) with its relation to different chordoma like tissues. With the previously mentioned notochordal proposed origin and closely related chondrosarcoma's, a comparative study design was implemented. Data of such a design yielded significant findings, not included in this thesis, with a potential to serve clinical biomarkers.

However, computational analysis using algorithms to examine large sets of data with respect to certain clinical aspects bear the risk of overlooking the vulnerability of overfitting the 
data. This occurs when a multitude of potential predictive biomarkers are applied to differentiate a small number of outcome events. The apparent risk of failure to reproduce such findings with other clinical dataset remains a difficult problem.

\section{A socio-economic perspective}

As the incidence of cancer is increasing, a substantial socio-economic burden arises as, according to the World Health Organization (WHO) healthcare associated costs rising when plotted against per capita GDP. Latest indications (2018, CBS) indicate a weight of approximately 100 billion euro in the Netherlands, where most of the spending is made in the insured spectrum (Zorgverzekeringswet). ${ }^{5}$ Consideration on allocation of health care resources are based largely on cost-effectiveness analysis in which terms as quality-adjusted life-year (QALY) are the mainstay. Applying QALY's in decision support for allocation in cancer treatment are shown to contain important limitations. However, the high cost of (novel) cancer treatments on society is increasing and will become unaffordable, making further progression of the current standard impossible. Most of these costs in oncology are attributed to the high price of cancer drugs and the overuse of drugs in anticancer treatment regiments. Potent solutions to this problem have been proposed, with the most potent being a shift towards treatments tailored specifically to the genetic makeup of an individual's tumor. This way expenditure of (new) anticancer drugs that confer only a minor level of clinical benefit are eliminated.

In chordoma, standard primary treatment regimen for patients lacks any drug therapy, as chordomas are deemed unresponsive to conventional chemotherapy. Due to this limitation, a significant proportion of treated patients have a propensity to show tumor recurrence. Although recent treatment guidelines on this, frequently observed, recurrent growth of the tumor do reserve the possibility of implementing targeted therapy in the form of anticancer drugs in advanced disease, the scientific evidence favoring such a treatment remains limited. Reasons for this predicament are the relatively low incidence of chordoma and the heterogenic markup of the patient characteristics and cell pathophysiology. High costs, as a result of efforts of medical oncologists to treat patients with advanced disease and subsequent morbidity accompanying such a treatment, would be substantially diminished if tumor recurrence and implementation and accuracy of a patient tailored approach in advanced disease could be predicted.

In this thesis, chapter 5 is dedicated to discovering potential biomarkers in the tumor cells of chordoma and chondrosarcoma patients. By comparing tumor protein lysates of primary tumor of patients with no recurrence and primary tumor of patients with recurrent disease, we were able to identify a spectrum of phosphorylated kinases that are indicative of recurrent disease. Two of the more frequently proposed antidrug therapies in chordoma Imatinib and Nilotinib hold promise by targeting these biological factors. Although these findings require validation in a larger cohort, applying these biomarkers will benefit opti- 
mization of individual health care for chordoma patients and minimize disease burden for the general population by reducing unnecessary treatments and their related morbidities.

\section{From proprietary data to a collective effect and future perspective}

As quoted by Isaac Newton (1642-1727): "If I have seen further than others, it is by standing upon the shoulders of giants"', it is only with the help of previous research that we gain our insights in the underlying mechanism of the diseased process. For this to continue, it is imperative that scientist, as much as possible, confirm to the notion of shared knowledge to enable synergistic research. In this thesis, two research articles are dedicated to aiding future chordoma research endeavors by informing the reading on how to perform certain procedures. In chapter 3 , the authors illustrate how to isolate human notochordal tissue with the help of laser captured microdissection. Here, advice and procedural strategies on extraction of tissue from human fetuses, with a gestation of 9, 11 and 13 weeks, are discussed. This is relevant for chordoma research, as this tissue is proposed to be essential in the etiology of this tumor. A growing body of studies performed on the etiology of chordoma will therefore benefit from this detailed description.

Similarly, observation of trends toward increased investigation of the proteome in cancer research, has instigated our initiative to publish the methodology we have applied to research the chordoma proteome. Although the results of this final study are outside of the scope of this thesis, the promising outcome supports a more frequent use of this field of research.

As the title of the current manuscript already implies and recent standards in clinical care are progressively leaning towards the use of molecular biomarkers to guide our understanding and management of the disease. The author expects that single biomarker-based study designs will be replaced by a broader set of biomarkers derived from an integrated assessment of the disease state (e.g. genomics, transcriptomics, proteomics as well as metabolomics and nutriomics) plotted against a well-documented clinical databases. This large datasets, "Big Data", when balanced and validated accordingly, diminish concerns about

clinical and statistical validity that hinder their application and will provide the clinician and patients with increased knowledge on how to improve the quality of life. 


\section{References}

1. Bray, F., et al. Global cancer statistics 2018: GLOBOCAN estimates of incidence and mortality worldwide for 36 cancers in 185 countries. CA Cancer J Clin 68, 394-424 (2018).

2. Stephens, P.J., et al. Massive genomic rearrangement acquired in a single catastrophic event during cancer development. Cell 144, 27-40 (2011).

3. Koltsova, A.S., et al. On the Complexity of Mechanisms and Consequences of Chromothripsis: An Update. Frontiers in Genetics 10 (2019).

4. von Witzleben, A., et al. Preclinical Characterization of Novel Chordoma Cell Systems and Their Targeting by Pharmocological Inhibitors of the CDK4/6 Cell-Cycle Pathway. Cancer Res 75, 3823 3831 (2015).

5. Vonk, R.A.A., et al. Toekomstverkenning zorguitgaven 2015-2060 Kwantitatief vooronderzoek in opdracht van de Wetenschappelijke Raad voor het Regeringsbeleid. Deel 1: toekomstprojecties. in Rijksinstituut voor Volksgezondheid en Milieu. 


\section{Curriculum vitae}

Youssef Yakkioui werd geboren op 14 april 1985 in de Spaarndammerstraat in Amsterdam. Hij is de zoon van het Marokkaanse echtpaar Nadia Elhri en Mimoun Yakkioui en broer van Issam, Khalid, Sanae, Otman en Ismael. Na het behalen van het HAVO- en VWO-diploma aan de Christelijke Scholengemeenschap Buitenveldert, startte hij in 2003 met de studie Biomedische Wetenschappen aan de Vrije Universiteit in Amsterdam. Met zijn bachelorthesis genaamd "AAV-mediated knockdown of the DR1 receptor in mPFC" verricht aan het Center for Neurogenomics and Cognitive Research, behaalde hij zijn bachelordiploma. Hoewel deze studie zijn voorliefde voor onderzoek bevestigde, is de drang om meer te begrijpen van de geneeskunst de reden geweest om in 2007 te solliciteren voor de master Arts-Klinisch Onderzoeker in Maastricht. Tijdens deze studie heeft hij kennisgemaakt met de neurochirurgie en is direct verliefd geworden. Tijdens zijn masteropleiding, heeft hij samen met Professor Van Overbeeke en Professor Temel de eerste studie "The role of p53 in chordoma" opgezet. Na het behalen van zijn masterdiploma in 2011, is hij doorgegaan met het onderzoek wat geleid heeft tot het eerste artikel in 2014. In 2012 heeft hij een onderzoeksstage gedaan aan de Univeriteit van Washington om het proteoom van chordomen te onderzoeken. Na deze stage is hij begonnen aan de opleiding tot neurochirurg in december 2012. Dit leidde tot zijn registratie in 2018. Sinds 2019 is hij werkzaam als neurochirurg in het Noordwest Ziekenhuis te Alkmaar. Gedurende de opleiding is het onderzoek naar biomarkers in chordomen gecontinueerd, wat heeft geleid tot het proefschrift voor $u$. 


\section{List of publications}

\section{This thesis}

Yakkioui Y, van Overbeeke JJ, Santegoeds R, van Engeland M, Temel Y. Chordoma: the entity. Biochim Biophys Acta 2014 Dec;1846(2):655-669.

Santegoeds RG, Yakkioui Y, Jahanshahi A, Raven G, Van Overbeeke JJ, Herrler A, Temel Y. Notochord isolation using laser capture microdissection. Journal of Chemical Neuroanatomy 2017 March;80:37-43.

Yakkioui Y, Temel Y, Chevet E, Negroni L. Integrated and quantitative proteomics of human tumors. Methods in Enzymology 2017;586:229-246.

Tatman P, Osbun J, Yakkioui Y, Kaur S, Parada C, Busald T, Born D, Ahmad O, Zhang J, Ferreira $M$. Kinase activity in recurring primary Skull Base Chordomas and Chondrosarcomas: identification of novel pathways of oncogenesis and potential drug targets. World Neurosurg. 2017 Nov;107:75-81.

Yakkioui Y, Temel Y, Creytens D, Jahanshahi A, Fleischeuer R, Santegoeds RG, Van Overbeeke JJ. A Comparison of Cell-Cycle Markers in Skull Base and Sacral Chordomas. World Neurosurg. 2014 Jul-Aug;82:e311-e318.

Yakkioui Y, Speel E-JM, Van Overbeeke JJ, Boderie MGM, Pujari S, Zur Hausen A, Wolffs PFG, Temel Y. Oncogenic viruses in Skull Base Chordomas. World Neurosurg. 2017 Nov 27. pii: S1878-8750(17)32049-1.

\section{In preparation}

Negroni L; Chevet E; Vanderheijden C; Creytens D; Fleischeuer R; Temel Y; Overbeeke JJ; Yakkioui $Y$. Differential quantitative proteomic analysis of chordoma, notochord and chondrosarcoma: development

\section{Other publications}

Parada CA, Osbun J, Kaur S, Yakkioui Y, Shi M, Pan C, Busald T, Karasozen Y, Gonzalez-Cuyar LF, Rostomily R, Zhang J, Ferreira M Jr. Kinome and phosphoproteome of high-grade meningiomas reveal AKAP12 as a central regulator of aggressiveness and its possible role in progression. Sci Rep. 2018 Feb 1;8(1):2098.

Santegoeds RG, Yakkioui Y, Van Overbeeke JJ, Temel Y. Chordoma: current concepts and new developments. Tijdschr Neurol Neurochir. 2016;117(1):17-24)

Banaama S, Stokroos R, Yakkioui Y, van Overbeeke J, Temel Y. A novel drainage approach in patients with cholesterol granuloma: From petrous apex to mastoid air cell. Surg Neurol Int. 2017 Aug 22;8:196. doi: 10.4103/sni.sni_106_17. eCollection 2017. 
Hescham S, Temel Y, Casaca-Carreira J, Arslantas K, Yakkioui Y, Blokland A, Jahanshahi A. A neuroanatomical analysis of the effects of a memory impairing dose of scopolamine in the rat brain using cytochrome c oxidase as principle marker. J Chem Neuroanat. 2014 Sep;5960:1-7.

Jahanshahi A, Vlamings R, van Roon-Mom WM, Faull RL, Waldvogel HJ, Janssen ML, Yakkioui Y, Zeef DH, Kocabicak E, Steinbusch HW, Temel Y. Changes in brainstem serotonergic and dopaminergic cell populations in experimental and clinical Huntington's disease. Neuroscience. 2013 May 15;238:71-81. 


\section{Acknowledgement}

"Knowledge is in the end based on acknowledgement."

- L.J.J. Wittgenstein (1889-1951)

En dan is het toch nog goed gekomen! Het promotieonderzoek zit erop! Dit hele traject was natuurlijk onmogelijk zonder daarbij hulp te krijgen van collega's, familie en vrienden.

Om te beginnen wil ik graag de dappere patiënten bedanken die deelgenomen hebben aan de studie door wetenschap toe te staan op hun weefsels. Dit zonder eigen belang.

Daarnaast wil ik graag mijn promotoren bedanken.

Beste Professor Temel, beste Yasin. Zonder jou was er geen chordoma onderzoekslijn geweest. Jouw enorme werkdrive is motiverend voor iedereen die met jou samenwerkt. Ik wil jou dan ook enorm bedanken voor de steun tijdens het opzetten van het chordoomonderzoek. Hoewel ik weet dat het niet in jouw straatje lag als expert op het gebied van neuromodulatie, was je in 2010 zo verwelkomend om met mij en Koo deze lijn op te zetten. Dat vergde niet alleen financieel het een en ander, maar vooral ook tijd en aandacht. Dit was voor jou een schaarste, omdat jij, bijna neurochirurg op dat moment, als onderzoeker al bijna professor was. Met hiernaast ook nog eens een druk, maar warm gezin met twee kinderen, wist jij tijd vrij te maken om bij jou thuis de club jonge onderzoekers toe te spreken. Jouw brede blik op zaken en vernieuwde strategie, net als de vaak terugkomende uitspraak "onderzoek moet je zien als een hobby, het is geen 9 to 5 job" zal ik missen. Net als het gelach bij de reguliere cappuccino, zowel op de universiteit als op internationale congressen. Bir kahvenin kırk yıl hatırı vardır.

Beste Professor Van Engeland, Beste Manon. Na een studie biomedische wetenschappen heb ik, denk ik, het meeste van de moleculaire biologie geleerd door deel te nemen aan de persoonlijke gesprekken met jou en de altijd interessante labmeetings. Jouw kundigheid is dan ook af te zien aan het team wat jij om je heen gebouwd hebt. Ik ben blij dat ik van hen en jou heb mogen leren. Hoewel er de afgelopen jaren veel op jou is afgekomen en jouw tijd schaars was, heb ik mij altijd welkom gevoeld. Graag wil ik jou bedanken voor deze tijd, de adviezen en inzichten in een uitdagend onderzoeksveld van de oncologie.

Beste Professor van Overbeeke, Beste Koo. Waar te beginnen? Als jonge gedreven student klopte ik maar gewoon aan op uw deur, omdat ik er via andere paden niet tussenkwam. Mijn overtuiging was simpel, ik wilde graag neurochirurg worden en ook graag onderzoek doen. Gezien ik nog niet klaar was met mijn A-KO-opleiding, bood u mij de verschillende projecten aan die al liepen. Van epilepsieonderzoek tot spinaal onderzoek, u noemde alles op, tot u zei "ik heb ook nog een idee over chordomen die ik geopereerd heb". Beiden wisten 
we dat dat hetgeen was waar ik mijn aandacht op zou vestigen. Dit terwijl ik het woord chordoma opschreef als gordoma, en ik er alleen maar een oude Seat bij kon bedenken. De opeenvolgende jaren gingen snel voorbij, omdat uw enthousiasme voor het onderzoek een ware inspiratie was. Wat ik niet wist, is dat u de patiënten met deze nare tumor kende. En als ik bedoel kende, dan bedoel ik dat $u$ hen bij voornaam kon opsommen op elk gegeven moment en zij waarschijnlijk allemaal uw persoonlijke telefoonnummer hadden. We hebben veel tijd samen doorgebracht om het concept van chordomen goed te begrijpen. Al snel wisten wij dat we het lab in moesten omdat het prognostisch verschil niet op basis van patiëntkarakteristieken verklaard kon worden. Met uw connecties heb ik een hoop gezien, van het bezoeken van de Mount Rainier nabij Seattle en het zwemmen in de dode zee in Amman, tot aan samen in de nieuwe Tesla naar Strassbourg om samen iets te vertellen over ons onderzoek. $U$ stond achter mij, zowel in het onderzoek als in de kliniek. Graag wil ik u bedanken voor uw vertrouwen in mij en de onderwijskracht die u op meerdere vlakken voor mij was.

Ali Jahanshahi and Cas Vanderheijden. Dear Ali, from the start you have been at my side in the lab. Where people see impossibilities, you find solutions. I soon hope to witness your inauguration. Beste Cas, bedankt voor jouw inzet bij het onderzoek. Jouw gedrevenheid is een garantie op succes.

I would like to extend my gratitude to Luc Negroni and Eric Chevet. You guys have made proteomics fun for me to work on, which resulted in learning a lot from you. I am looking forward to submitting our masterpiece. Thank you for a nice collaboration. A tout à l'heure!

Dear Professor Sekhar and Jing-Zhang, dear Josh and Manny, thank you for the pleasant time in Seattle. Working with you was educational as it was motivating.

Zonder steun van collega's op het lab, was het niet mogelijk om het onderzoek te doen. Beste Anthony, Sonny, Rinske, Mark, Sarah, Pablo, Lisa, Dagmar, Paul, Fred en Melanie. Bedankt voor jullie inzichten en gezelschap, dit heeft mijn tijd op het lab tot een leuke ervaring gebracht.

Beste Karin, Joep en Muriel, wat heb ik veel van jullie mogen leren over methylering en PCR. Jullie open houding naar ideeën en behulpzaamheid was een groot geluk tijdens mijn onderzoek.

Peter, Edith en Kim, heel erg bedankt voor jullie hulp. Jullie ondersteuning op het lab was altijd zonder enige moeite. Dit toonde niet alleen jullie ervaring, maar ook een hele fijne en professionele houding. Ik denk dat er nog weinig mensen zijn zoals jullie, die helpen om het helpen. Mijn dank is groot.

Petra Wolfs, ondanks een ontzettend drukke job, kon je tijd vinden om het over virussen bij chordomen te hebben. Heel erg bedankt voor de prettige samenwerking. 
De beoordelingscommissie bestaande uit Prof. dr. H. van Santbrink, Dr. L. Ackermans, Prof. dr. Van Dijk, Dr. P. Kubben, en Prof. dr. W.P. Vandertop wil ik bedanken voor de beoordeling van dit proefschrift en voor het plaatsnemen in de corona. Daarnaast wil ik Prof. dr. W. Peul, Prof. dr. H.P.M. Kunst en Prof. dr. F. Ramaekers bedanken voor het plaatsnemen in de corona.

Daarnaast wil ik graag mijn oud-collega's van de neurochirurgie bedanken. Beste Toon, Vincent, Roel, Felix, Anouk, Suzanne, Lars, Tim, Jeroen, Karlijn en Rick. Bedankt voor de collegialiteit tijdens de opleiding.

Ook wil ik graag de neurochirurgen in het MUMC bedanken voor jullie enthousiasme voor onderzoek en opleiden.

Beste Luc, als spil in het web heb ik jouw aanwezig en mening altijd heel erg gewaardeerd. Bedankt voor de gezellige tijd die jij mij tijdens de opleiding hebt bezorgd.

Graag wil ik ook mijn collega's uit het Noordwest Ziekenhuis bedanken. Beste Bas, Christiaan, Lesley, Lisette en Martijn, bedankt voor jullie warme ontvangst in Alkmaar en jullie steun niet alleen bij deze promotie, maar ook bij de huidige projecten.

Uiteraard is promoveren een onderdeel van onderzoek doen, wat een groot deel heeft uitgemaakt en zal uitmaken van mijn leven. Hierin staan een aantal mensen centraal die ik wil bedanken.

Lieve Merel, een groot gedeelte van dit onderzoek heb jij meegekregen. Helaas zijn onze liefdeswegen gescheiden, maar zijn we nog wel goed bevriend. Graag wil ik jou heel erg bedanken voor jouw steun in de moeilijke tijden van dit onderzoek. Masha Danki.

Lieve Sonja, wie had gedacht dat op de laatste dag in het MUMC, ik de meest leuke persoon tegen zou komen. Jij bent een geweldige vrouw op verschillende vlakken. Jouw steun en liefde voor het onderzoek, de overstap naar het ziekenhuis in Alkmaar en iedere dag als wij samen opstaan, geven mij kracht. Ik hou van jou, schatje.

Tot slot en meest belangrijk op deze aardbol, mijn familie. Lieve mama, Ismael, Issam, Khalid \& Maartje, Otman \& Dale, Sanae \& Rashid, en mijn lieve neefjes \& nichtjes, woorden schieten altijd te kort om uit te drukken hoe dankbaar ik ben voor jullie warmte, steun en liefde. Niets is te gek om aan jullie te vragen, waardoor jullie centraal staan in mijn leven. Ik hou van jullie met heel mijn hart. 


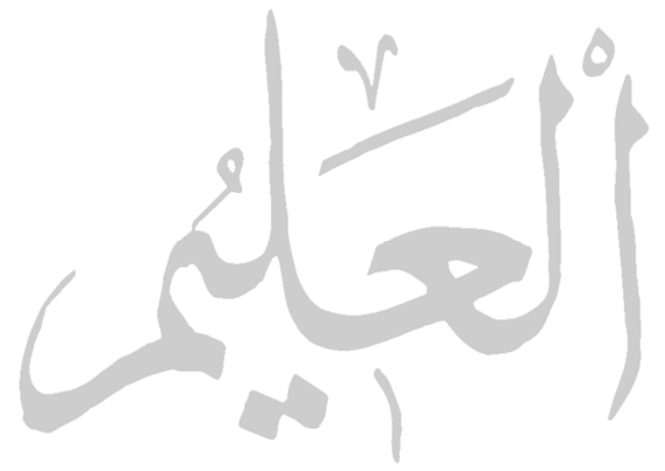


